\title{
Development of High-Efficiency Low-Lift Vapor Compression System - Final Report
}

S Katipamula

PR Armstrong

W Wang

N Fernandez

$\mathrm{H}$ Cho

W Goetzler

J Burgos

R Radhakrishnan

C Ahlfeldt

March 2010

\section{Pacific Northwest}

NATIONAL LABORATORY

Proudly Operated by Battelle Since 1965 



\title{
DISCLAIMER
}

This report was prepared as an account of work sponsored by an agency of the United States Government. Neither the United States Government nor any agency thereof, nor Battelle Memorial Institute, nor any of their employees, makes any warranty, express or implied, or assumes any legal liability or responsibility for the accuracy, completeness, or usefulness of any information, apparatus, product, or process disclosed, or represents that its use would not infringe privately owned rights. Reference herein to any specific commercial product, process, or service by trade name, trademark, manufacturer, or otherwise does not necessarily constitute or imply its endorsement, recommendation, or favoring by the United States Government or any agency thereof, or Battelle Memorial Institute. The views and opinions of authors expressed herein do not necessarily state or reflect those of the United States Government or any agency thereof.

\author{
PACIFIC NORTHWEST NATIONAL LABORATORY \\ operated by \\ BATTELLE \\ for the \\ UNITED STATES DEPARTMENT OF ENERGY \\ under Contract DE-AC05-76RL01830
}

Printed in the United States of America
Available to DOE and DOE contractors from the Office of Scientific and Technical Information,
P.O. Box 62, Oak Ridge, TN 37831-0062;
ph: (865) 576-8401
fax: (865) 576-5728
email: reports@adonis.osti.gov

\author{
Available to the public from the National Technical Information Service, \\ U.S. Department of Commerce, 5285 Port Royal Rd., Springfield, VA 22161 \\ ph: (800) 553-6847 \\ fax: (703) 605-6900 \\ email: orders@ntis.fedworld.gov \\ online ordering: http://www.ntis.gov/ordering.htm
}




\title{
Development of High-Efficiency Low-Lift Vapor Compression System - Final Report
}

\author{
S Katipamula \\ PR Armstrong* \\ W Wang \\ N Fernandez \\ $\mathrm{H}$ Cho \\ W Goetzler ${ }^{\dagger}$ \\ $\mathrm{J}^{\text {Burgos }}{ }^{\dagger}$ \\ R Radhakrishnan $^{\dagger}$ \\ C Ahlfeldt ${ }^{\dagger}$
}

March 2010

Prepared for Bonneville Power Administration

by Pacific Northwest National Laboratory

for the UNITED STATES DEPARTMENT OF ENERGY

under Contract DE-AC05-76RL01830

\footnotetext{
* Associate Professor Masdar Institute of Science and Technology

${ }^{\dagger}$ Navigant Consulting Inc. contributed to the Market Assessment and Incremental Cost Estimate sections of the report
} 


\section{Executive Summary}

Pacific Northwest National Laboratory (PNNL), with co-funding from the Bonneville Power Administration (BPA) and Building Technologies (DOE-BT) Program of the U.S. Department of Energy (DOE), conducted a research and development (R\&D) activity that is targeted at addressing the energy efficiency goals outlined in the Bonneville Power Administration (BPA) Roadmap. PNNL study investigated an integrated heating, ventilation and air conditioning (HVAC) system option referred to in this study as the low-lift cooling system (LLCS) that potentially offers an increase in HVAC energy performance relative to American Society of Heating, Refrigeration and Air Conditioning Engineers (ASHRAE) Standard 90.1-2004.

The LLCS PNNL evaluated consists of five interrelated elements:

1. Peak-load shifting by active or passive thermal energy storage (TES).

2. Dedicated outdoor air supply with enthalpy heat recovery from exhaust air (DOAS).

3. Radiant heating and cooling panels or floor system (RCP).

4. Low-lift vapor compression cooling equipment.

5. Advanced controls at the HVAC equipment and HVAC system (supervisory) levels.

The analysis shows that significant cooling system efficiency gains can be achieved by integrating a low-lift cooling system. The cooling energy savings for a standard-performance building range from $47 \%$ to $84 \%$ and, for a high-performance building, from $17 \%$ to $66 \%$.

\section{Building Prototypes and Climate Locations Used for Low-Lift Energy Savings Analysis} PNNL chose to use the modified DOE Benchmarks Prototype EnergyPlus input files (referred to as ASHRAE Benchmarks) for this analysis because the DOE prototypes were enhanced, largely as a result of the greater review provided by industry members. Also, note that these modifications will eventually be incorporated into the DOE Benchmarks. For standalone retail, supermarket and healthcare "outpatient" building types, the original DOE Benchmarks were used; for the rest of the building types, the ASHRAE Benchmarks are used. The 21 climate locations were selected by mapping each county in the Pacific Northwest to the TMY2 (typical meteorological year version 2) weather location that best approximated the climate in that county. To translate per-building savings into Pacific Northwest regional savings, PNNL employed the building weights that were developed by the Northwest Power Planning Council.

To estimate the energy consumption of a prototype building with baseline HVAC system (or some subset of it), a detailed simulation model is needed. The existing mainstream detailed simulation models (DOE-2 and EnergyPlus) currently lack the capability to simulate the full LLCS. Although EnergyPlus can model many of the elements, it currently lacks the requisite elements of a low-lift chiller, thermal storage and advanced controls that are needed to optimize the operation.

PNNL calculated the energy consumption estimates and savings in two steps: 1) estimated the building thermal loads for 12 different building types (two performance levels) and 21 climate locations using EnergyPlus simulations; and 2) simulated the systems - using the thermal loads 
as a basis, - with a set of component models that were developed as part of the DOE funded effort (Jiang et al. 2008, Katipamula et al. 2010) in the Matlab ${ }^{3}$ environment.

\section{Market Assessment}

PNNL contracted with Navigant Consulting Inc. (NCI) to conduct an assessment of the potential market for the LLCS. ${ }^{4}$ The NCI market assessment consisted of four steps: 1) review of the proposed technology and models, 2) identification of potential benefits and barriers to market penetration, 3) validation of those benefits and barriers through surveys and discussions with stakeholders and 4) recommended initiatives that might be taken to accelerate market adoption of the proposed low-lift solutions.

Based on stakeholder feedback about the individual technologies comprising the LLCS, NCI made the following recommendations and actions for PNNL to take to accelerate market adoption (Figure E-1)

\section{Major Regional Barrier}

Inexpensive and clean energy

- Low energy costs lengthen payback period of efficiency improvements

- Time-of-use pricing is not currently common

- Low carbon emission rates

\section{Regional Climate}

- Low cooling demand

- Micro-climates and variable humidity levels depending on region

Lack of Experience with Technology

- Building owners and contractors are risk adverse to being an early adopter

- Lack of awareness with performance, installation, and O\&M requirements

\section{Potential Strategy}

\section{Targeted Incentives}

- Offer additional state and utility incentives for this technology that target institutional facilities and regions with higher energy rates (e.g. government facilities in larger cities like Portland)

\section{Customized System Configurations}

- Offer customized applications (e.g. optional enthalpy wheel for humidity control)

- Combine cooling technology with heating applications to improve equipment payback

- Make enthalpy wheel and radiant cooling optional

\section{Informational Program and Resources}

- Publish results of regional case studies tracking long-term performance

- Develop public database of local installations with performance data

- Offer complimentary feasibility studies

Figure E-1 Major Regional Barriers Identified and Potential Strategy to Overcome Barrier

NCI concluded that the LLCS is an attractive option worthy of further research, development and deployment (RD\&D). They noted that the stakeholders were generally very receptive, and that there did not seem to be any "deal-breakers." Stakeholders seem to be most interested in packaged solutions, rather than individual technologies. It also appears that the timing is good, because more and more stakeholders are realizing the importance of energy efficiency, and are

\footnotetext{
${ }^{3}$ Matlab is a high-level programming language and interactive environment used to develop and perform computational applications faster than with traditional programming languages such as $\mathrm{C}, \mathrm{C}++$, and Fortran.

${ }^{4}$ Navigant also provides technical support and analysis to DOE's HVAC/R program.
} 
becoming interested in green buildings. One of the most important steps moving forward will be case studies and demonstrations of benefits, including cost and energy savings. Many of the findings are consistent with PNNL's own experience. NCI's recommendation provides useful insight to BPA because these recommendations generally apply to most integrated technology options that are going to be used in high performance and net-zero energy buildings.

PNNL concurs with the limitation and barriers noted by NCI for the use of active TES. Although PNNL has investigated the active TES option, PNNL does not think that active TES is essential to realize the savings potential. A significant fraction of the savings that can be attributed to TES can be achieved by passive TES (using thermal mass). PNNL has not yet evaluated passive TES as an option because of simulation limitations.

Another issue identified by NCI (although noted as minor), is the need for advanced controls that are user-friendly and tailored to the needs of building operator and maintenance personnel. To achieve high efficiencies, the high performance and net-zero energy buildings will use highly integrated systems, which will need advanced controls and diagnostic tools that can help even an unsophisticated operator to manage the buildings efficiently.

\section{Incremental Cost Estimates for Low-Lift System}

One of the objectives of this study was to conduct an economic analysis of the LLCS. In line with the zero energy buildings goal of five-year paybacks by 2025, PNNL decided to estimate simple payback, rather than conducting a detailed life-cycle cost analysis. For simple payback, both incremental cost and energy savings estimates are needed.

Estimating incremental cost of emerging technology is difficult because of limited availability of information that is available in the open literature. To estimate the incremental cost for the components that make up the LLCS, PNNL retained the services of NCI.

NCI's core findings are as follows:

- Office buildings may be the most ideal first application for low-lift cooling technologies/systems, particularly those using multi-zone rooftop systems.

- The large cost of the multi-zone rooftop systems (with respect to a similar-sized chiller) allows for a favorable cost comparison for low-lift chiller systems in medium office buildings.

- Large office buildings show a low incremental cost per square foot, as a result of small increases in chiller costs, and large savings from the smaller ductwork required by the DOAS system.

- Radiant cooling drives the cost incremental for all of the building types. A large portion of these costs is associated with the labor required for installation.

- The cost advantage resulting from reduction of the ductwork for large buildings is a large factor and needs to be validated further.

In addition, there are additional items to consider: 
- Some components of the low-lift system, particularly the radiant cooling system, can be considered emerging technologies. There is often a 10-20\% premium associated with emerging technologies that may gradually decline as the technology is commoditized.

- Potential additional benefits of the low-lift system include reducing the amount of materials used in construction, particularly the ductwork material.

These are the best estimates given the scope of the work and time frame. PNNL believes that these costs are conservative for a number of reasons:

1. Limited availability of cost information for the emerging technologies.

2. Emerging technologies generally have a premium when introduced but generally the cost goes down significantly as the market is transformed (e.g., compact fluorescent lamps).

3. Low-lift chiller size has not been optimized to reflect the lower size needed when used with the passive thermal storage option.

4. Redundant heating systems have been added for the building with a low-lift system, which may not be needed.

Widespread use of these technologies and when the building is designed and optimized for the LLCS could lower the cost between 20 and 30\% from the NCI estimates.

\section{Energy Savings}

Estimating the potential technical energy savings for this technology in the Pacific Northwest (PNW) is fairly involved, because of the number of variables involved:

- 21 climate zones

- 12 building types

- 8 different cases of the LLCS, in addition to the baseline reference case (described below)

- 2 different levels of overall building performance - standard and high performance, with lower thermal loads.

- 2 different chiller performance curves (ideal chiller and prototype chiller).

Details of this analysis, including by specific building type, are included in the main report, but the key overall findings are provided in Tables E-1 and E-2. This analysis shows that significant cooling system efficiency gains can be achieved by integrating low-lift cooling technologies: variable-speed compressor and transport motor controls, radiant cooling with dedicated ventilation air transport and dehumidification, and cool storage. The cooling energy savings for a standard-performance building range from $47 \%$ to $84 \%$ and, for a high-performance building, from $17 \%$ to $66 \%$. These estimates, which include cooling, fans and pumps, are scaled up from the savings from the prototype buildings used in the analysis. Table E-1 summarizes the annual technical energy savings potential in the Pacific Northwest for the full LLCS, compared to the building using a conventional HVAC system. Note that these estimates are for new construction and building-types and climate locations for which the full LLCS is applicable. The aggregate percent savings across all climate locations and building types (weighted by new construction volume) is about $74 \%$ for standard-performance buildings and $64 \%$ for the high-performance buildings. Table E-2 summarizes the annual technical energy savings potential in the Pacific 
Northwest for the full LLCS, compared to a building with a better system - one that uses a conventional air distribution system with a two-speed chiller.

Table E-1 Summary of Annual Technical Site Electricity and Peak ${ }^{5}$ Savings Potential in Pacific Northwest for the Low-Lift Cooling System Compared to Conventional HVAC system (assuming $100 \%$ Penetration)

\begin{tabular}{|l|r|r|r|}
\hline $\begin{array}{c}\text { Building Performance } \\
\text { Level }\end{array}$ & \multicolumn{3}{|c|}{ Cooling and Fan and Pump Electricity Savings } \\
\cline { 2 - 4 } & million kWh/year & $\begin{array}{c}\text { Peak Reduction } \\
\text { aMW }\end{array}$ & $\begin{array}{c}\text { Percentage Electricity } \\
\text { Savings }\end{array}$ \\
\hline Standard & $\mathbf{5 4 . 0}$ & 6.2 & $\mathbf{7 4 . 1 \%}$ \\
\hline High Performance & $\mathbf{1 5 . 5}$ & 1.8 & $63.5 \%$ \\
\hline
\end{tabular}

aMW = average Mega Watts

Table E-2 Summary of Annual Technical Site Electricity and Peak Savings Potential in Pacific Northwest for the Low-Lift Cooling System Compared to two-Speed Chiller as the Baseline (assuming 100\% Penetration)

\begin{tabular}{|l|r|r|r|}
\hline $\begin{array}{c}\text { Building Performance } \\
\text { Level }\end{array}$ & \multicolumn{3}{|c|}{ Cooling and Fan and Pump Electricity Savings } \\
\cline { 2 - 4 } & million kWh/year & $\begin{array}{c}\text { Peak Reduction } \\
\text { aMW }\end{array}$ & $\begin{array}{c}\text { Percentage Electricity } \\
\text { Savings }\end{array}$ \\
\hline Standard & $\mathbf{4 2 . 1}$ & 4.8 & $\mathbf{7 1 . 1 \%}$ \\
\hline High Performance & $\mathbf{1 1 . 3}$ & 1.3 & $61.0 \%$ \\
\hline
\end{tabular}

Although parts of the LLCS are applicable for a large portion of the existing commercial building stock and the full LLCS may be applicable to a fraction of the existing building stock, the savings for existing buildings are not considered in this study because the primary market as with most advanced HVAC systems involving systems engineering in building design - is new construction. In this sense, the technical potential presented here is conservative.

For baseline buildings that are compliant with ASHRAE 90.1-2004, the full LLCS saves about 54 million $\mathrm{kWh}$ of site electricity use in 1 year with the full LLCS being applied to total new construction in 2010 new commercial building stock. The peak savings associated with it is roughly 6.2 average MW. The annual site electricity savings are about 15.5 million $\mathrm{kWh}$ for high-performance buildings. Assuming the new construction growth rates remain the same for the next 10 years (through the year 2020), the total technical site energy savings potential (again assuming 100\% penetration) for the baseline building would be 625 million kWh in 2020 (Figure E-2). To reiterate, all of these savings are in site energy terms; to calculate the "busbar" savings, the previous estimates should be multiplied by factor of 1.0725 (using the average transmission loss of $7.625 \%)^{6}$ The total savings potential - relative to the baseline building - is therefore 670 million $\mathrm{kWh}$ in 2020.

\footnotetext{
${ }^{5}$ Average megawatt (aMW) of electricity is an average measure of the total energy delivered in one year -- 8,760,000 kilowatt-hours per year.

${ }^{6}$ http://www.bpa.gov/Energy/N/pdf/October 2009 Implementation Manual FINAL.pdf page 2.
} 


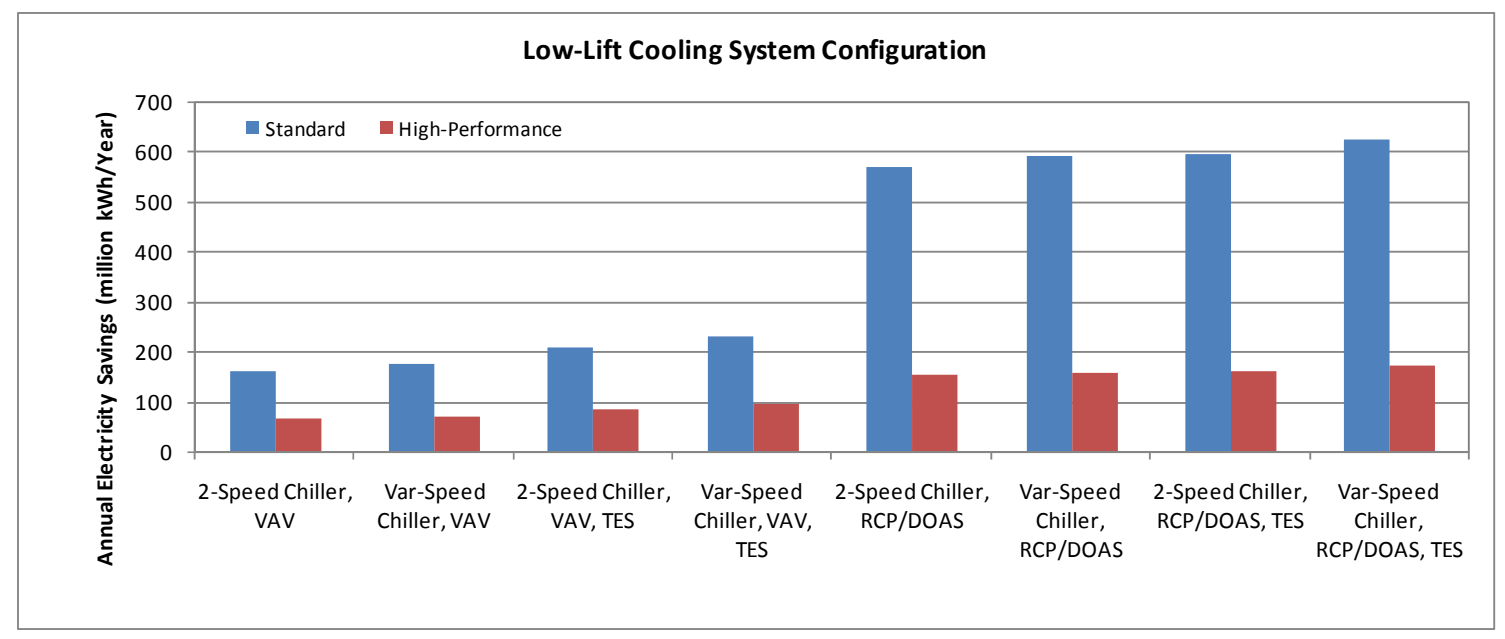

Figure E-2 Pacific Northwest Region Technical Site Electricity Savings in 2020 over the Standard HVAC System for Different System Configurations for 2020 Assuming 100\% Penetration over 10 Years of New Construction

As noted above, the analysis of LLCS cases includes eight different combinations, with Case 8 being the full application of the LLCS and Case 0 being the baseline. These EnergyPlus simulations are:

1. Case 0: the EnergyPlus base HVAC configuration case (different of each building)

2. Case 1: two-speed chiller with variable air volume (VAV) or constant air volume (CAV) air handling unit (AHU), depending on building type - the low-lift base case HVAC configuration

3. Case 2: low-lift variable-speed chiller and VAV AHU - this configuration uses the lowlift base case (Case 1), but with variable-speed low-lift chiller, pump and fan equipment

4. Case 3: two-speed chiller with RCP/DOAS - this configuration assumes the low-lift base case (Case 1) without VAV or CAV AHU, with a hydronic distribution system serving radiant cooling/heating panels and a DOAS for ventilation

5. Case 4: low-lift variable-speed chiller, VAV AHU and TES - this is the Case 2 system modified to use an idealized discrete TES

6. Case 5: two-speed chiller with VAV AHU and TES - this is the low-lift base case (Case 1) system modified to use an idealized discrete TES

7. Case 6: low-lift variable-speed chiller with $\mathrm{RCP} / \mathrm{DOAS}$ - combines the alternatives provided separately in Case 2 and Case 3 (low-lift variable-speed chiller and $\mathrm{RCP} / \mathrm{DOAS}$ )

8. Case 7: two-speed chiller with RCP/DOAS and TES - this is the Case 3 system modified to use an idealized discrete TES 
9. Case 8: low-lift variable-speed chiller with RCP/DOAS and TES - this is the complete envisioned low-lift option incorporating low-lift variable-speed chiller, RCP/DOAS and idealized discrete TES

To provide some flavor for the level of analytical resolution contained in this report, please consider the following illustration for application of these cases for standard-performance medium office building. Depicted in Figure E-3 is simulated electricity consumption per year, for the eight cases, for 21 Pacific Northwest locations. Similar analysis was conducted for the other building types, and then aggregated to provide the regional savings presented earlier.

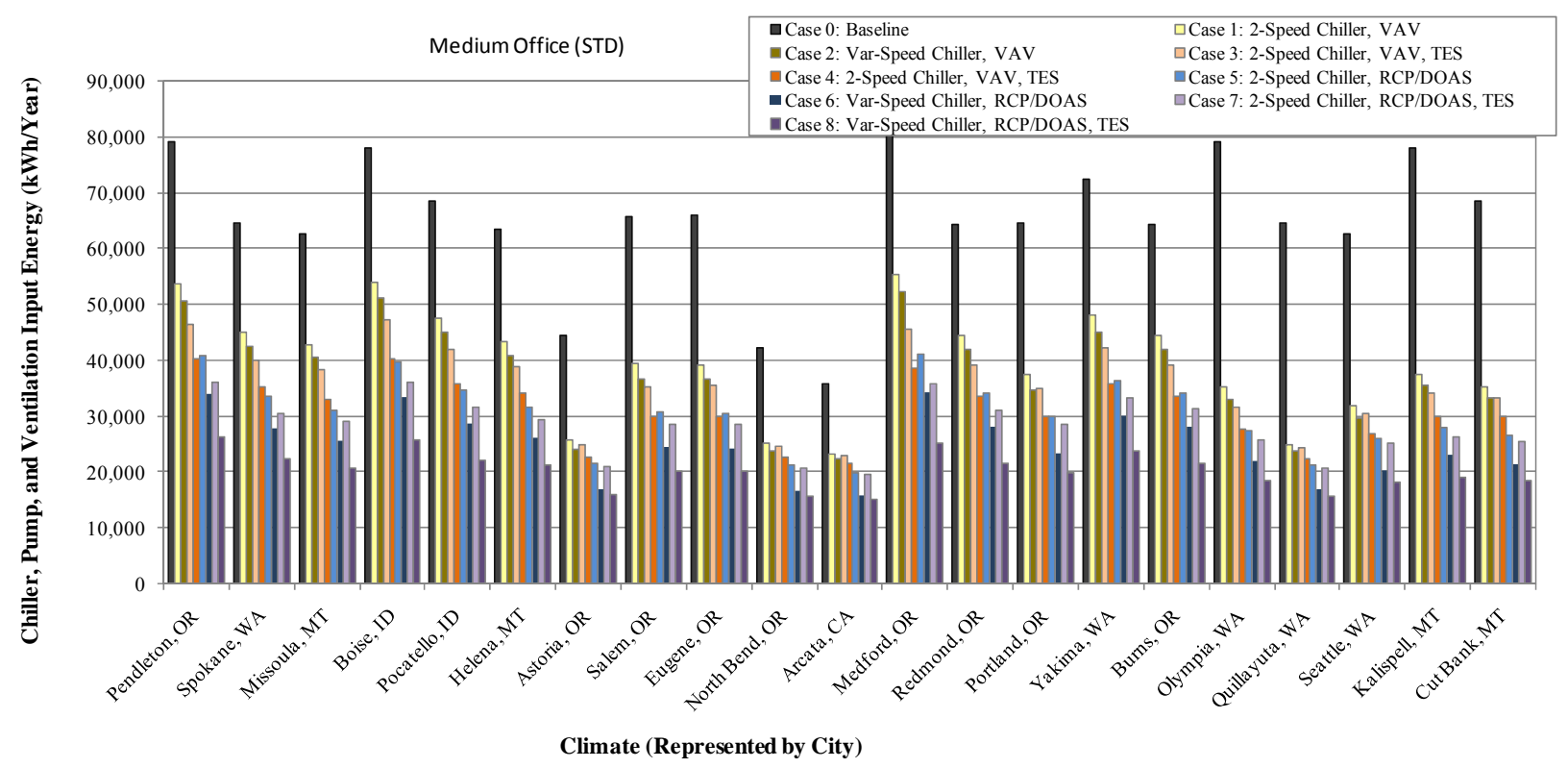

Figure E-3 Comparison of Annual Chiller and Distribution Energy Consumption for Standard Performance Medium Office Building for Various System Configurations in 21 Locations

\section{Economic Analysis}

Unless the benefits (energy cost savings) are significant compared to the incremental cost of the LLCS, it is unlikely that these technologies will find widespread acceptance. NCI's incremental cost estimates are for Case 7 - variable-speed low-lift chiller, radiant cooling, and dedicated outdoor-air system. The national average incremental costs for four building types (medium office, large office, supermarket and secondary schools) were estimated to be $\$ 0, \$ 383,000$, $\$ 276,000, \$ 624,000$, respectively (cost estimates shown previously in Table E-1 are for Houston). The medium size office buildings typicalyl use a multi-zone packaged system, which is relative more expensive than single-zone packaged units, so cost of these systems is much closer to the variable speed chiller cost. After adjusting the national costs to the various climate regions and using energy savings estimates, simple payback was estimated, as shown in Table E5. Because the incremental cost of the medium office is negative, the LLCS has a zero payback. The range of paybacks for the large office and secondary school buildings are between 8 and 30 years, which is probably a little bit high even for an emerging technology. Although the technology is applicable to supermarkets, it is difficult to complete with the relatively 
inexpensive single-zone packaged units. It appears that in the Pacific Northwest, this LLCS may not be favorable, in the absent of innovation breakthroughs in technology or provision of other incentives.

The aggregate payback (weighted by the new construction volume) for large office and secondary schools is reasonable, 17 and 23 years, respectively.

Table E-4 Simple Payback by Building Type for each Climate Location

\begin{tabular}{|l|r|r|r|r|}
\multicolumn{1}{c|}{} & Office Medium & Office Large & Supermarket & Secondary School \\
\hline Spokane, WA & 0 & 10.0 & 28.8 & 20.6 \\
\hline Pendleton, OR & 0 & 13.5 & 27.9 & 16.7 \\
\hline Missoula, MT & 0 & 12.2 & 17.1 & 14.9 \\
\hline Boise, ID & 0 & 14.0 & 32.9 & 21.7 \\
\hline Pocatello, ID & 0 & 8.3 & 24.4 & 23.8 \\
\hline Helena, MT & 0 & 7.8 & 14.7 & 14.8 \\
\hline Astoria, OR & 0 & 22.3 & 39.3 & 26.7 \\
\hline Salem, OR & 0 & 17.1 & 33.3 & 20.4 \\
\hline Eugene, OR & 0 & 16.9 & 33.5 & 20.2 \\
\hline North Bend, OR & 0 & 24.9 & 40.3 & 28.7 \\
\hline Arcata, CA & 0 & 25.5 & 24.1 & 19.0 \\
\hline Medford, OR & 0 & 17.2 & 29.7 & 16.7 \\
\hline Redmond, OR & 0 & 15.6 & 27.0 & 19.6 \\
\hline Portland, OR & 0 & 17.6 & 34.5 & 20.9 \\
\hline Yakima, WA & 0 & 15.6 & 30.6 & 20.3 \\
\hline Burns, OR & 0 & 13.2 & 26.9 & 19.0 \\
\hline Olympia, WA & 0 & 19.4 & 37.0 & 24.3 \\
\hline Quillayuta, WA & 0 & 24.3 & 42.2 & 29.1 \\
\hline Seattle, WA & 0 & 18.5 & 41.5 & 25.6 \\
\hline Kalispell, MT & 0 & 14.2 & 17.2 & 16.5 \\
\hline Cut Bank, MT & 0 & 10.4 & 14.9 & 17.0 \\
\hline
\end{tabular}




\section{Acknowledgement}

The authors would like to acknowledge the Bonneville Power Administration and the Buildings Technologies Program of the U.S. Department of Energy Office of Energy Efficiency and Renewable Energy for supporting the research and development effort. The authors would also like to thank Erik Boyer (BPA Project Manager), Jack Callahan (BPA), and Andrew Nicholls (PNNL) for their thoughtful comments and insights and Sue Arey for the editorial support. Support of the Masdar author by the Masdar Initiative is gratefully acknowledged. Thanks to Tom Watson of McQuay and numerous PNNL colleagues for thoughtful discussions on the lowlift systems approach. 


\section{Content}

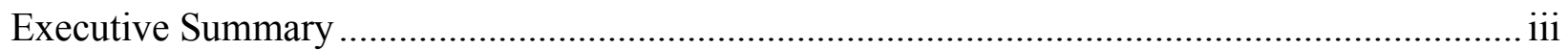

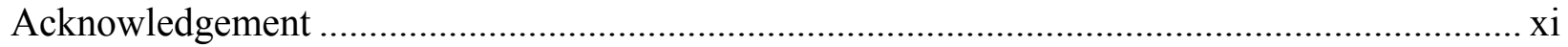

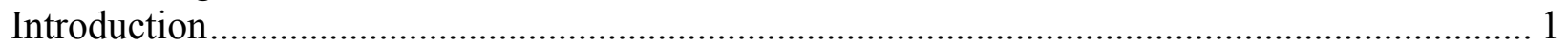

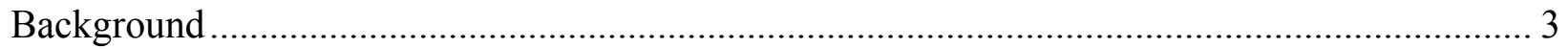

Prototype Chiller Development and Performance Characterization............................................... 5

Specification of Prototype Low-Lift Chiller...……………................................................ 5

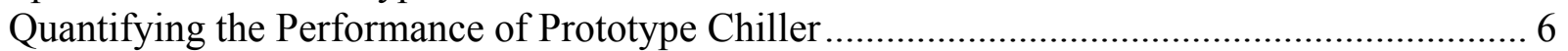

Ideal Low-Lift RCP-Chiller Performance Map .................................................................. 9

Ideal Low-Lift VAV-Chiller Performance Map ……………………………………….......... 11

Prototype Low-Lift RCP-Chiller Chiller Performance Map ……………………………........ 12

Prototype Low-Lift VAV-Chiller Performance Map …………………………...................... 14

Conventional Chiller Performance Map .............................................................................. 14

Comparison of Prototype Chiller Performance to Ideal Low-Lift Chiller................................ 15

Comparison of Prototype Chiller Performance to Conventional Chiller................................... 15

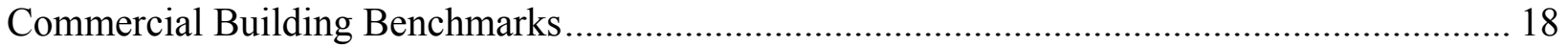

Commercial Building Benchmarks............................................................................ 18

Building Prototypes and Climate Locations Used for Low-Lift Energy Savings Analysis ..... 19

Market Assessment of Low-Lift Cooling System ………............................................................ 24

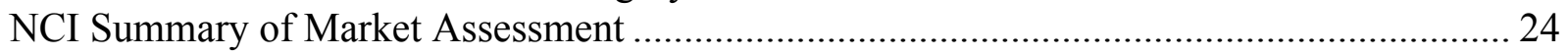

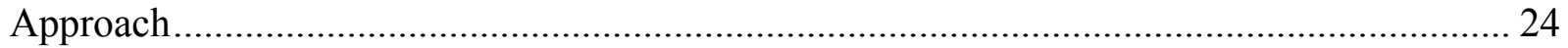

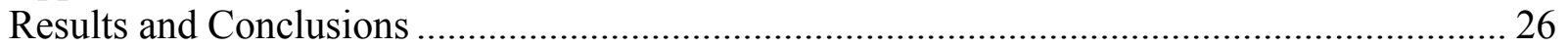

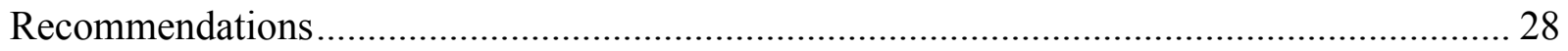

PNNL Conclusion of Market Assessment …………….................................................... 28

Incremental Cost Estimates for the Low-Lift Cooling System.................................................. 29

NCI Summary of Incremental Cost Estimates..................................................................... 29

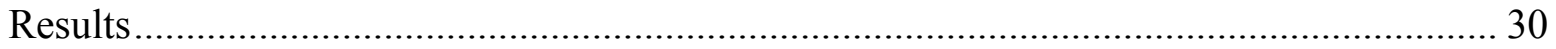

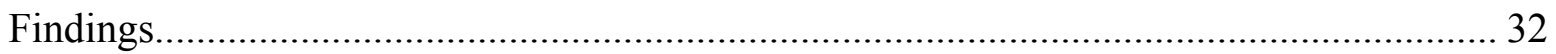

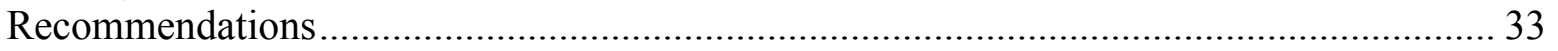

PNNL Conclusions on Incremental Cost Estimates ………................................................ 33

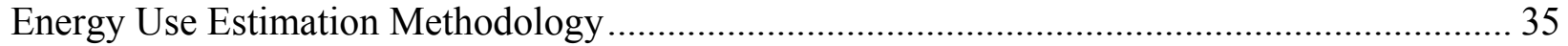

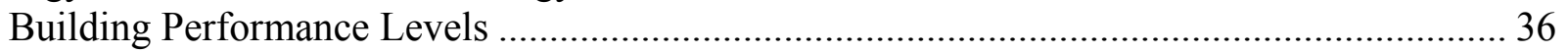

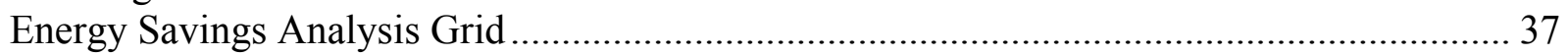

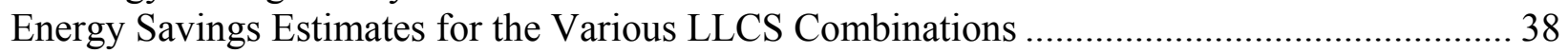

Energy Use Estimates for the Various LLCS and Building Configurations ............................ 39

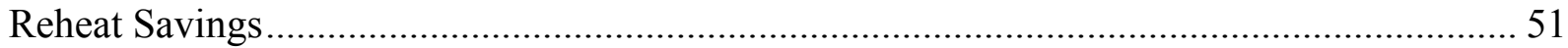

Pacific Northwest Regional Energy Savings Estimation Methodology ……………..................... 54

Pacific Northwest Regional Technical Energy Savings Potential ............................................... 57

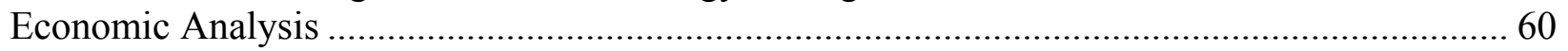

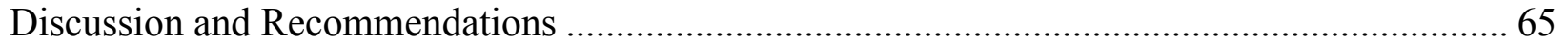

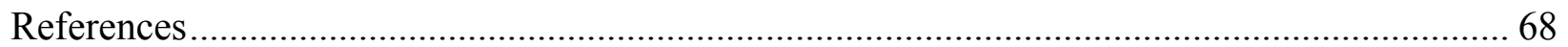

A Appendix: Market Assessment Supporting Material ................................................... A-1

B Appendix: Incremental Cost Supporting Material .......................................................... B-1

C Appendix: Energy Use Estimate Tables and Figures ........................................................ C-1 


\section{Figures}

Figure 1 Ideal Low-Lift Chiller-RCP System Performance Map at $\mathrm{Tz}=72^{\circ} \mathrm{F}$ with Tx ranging from $110^{\circ} \mathrm{F}$ (topmost curve) to $50^{\circ} \mathrm{F}$ in $10 \mathrm{R}$ increments

Figure 2 Chilled Water Reset Schedule (Appendix G, ASHRAE 90.1-2000) ............................. 11

Figure 3 Ideal Low-Lift VAV-Chiller Performance Map with the Chilled Water Reset Schedule

Shown in Figure 2 .................................................................................................. 12

Figure 4 Prototype Low-Lift RCP-Chiller System Performance Map at $\mathrm{T}_{\mathrm{z}}=72^{\circ} \mathrm{F}$ with $\mathrm{T}_{\mathrm{x}}$ ranging from $110^{\circ} \mathrm{F}$ (topmost curve) to $50^{\circ} \mathrm{F}$ in $10 \mathrm{R}$ increments 13

Figure 5 Prototype Low-Lift VAV-Chiller Performance Map with the Chilled Water Reset

Schedule Shown in Figure 2 ............................................................................................ 14

Figure 6 Performance Map of a Typical Conventional Air-Cooled Chiller ................................. 15

Figure 7 Comparison of Prototype Low-Lift VAV-Chiller System Performance Map (left) at Tz

$=72^{\circ} \mathrm{F}$ with $\mathrm{Tx}$ ranging from $110^{\circ} \mathrm{F}$ (topmost curve) to $50^{\circ} \mathrm{F}$ in $10 \mathrm{R}$ increments with Ideal Low-

Lift VAV-Chiller Performance (right)................................................................................ 16

Figure 8 Comparison of Prototype Low-Lift RCP-Chiller System Performance Map (left) at Tz=

$72^{\circ} \mathrm{F}$ with $\mathrm{Tx}$ ranging from $110^{\circ} \mathrm{F}$ (topmost curve) to $50^{\circ} \mathrm{F}$ in $10 \mathrm{R}$ increments with Ideal Low-

Lift RCP-Chiller Performance (right)................................................................................ 17

Figure 9 Major Regional Barriers Identified and Potential Strategy to Overcome Barrier .......... 27

Figure 10 Incremental Cost (National Average) for Medium Office Building Using Low-Lift

Cooling .......................................................................................................................... 30

Figure 11 Incremental Cost (National Average) for Large Office Building Using Low-Lift

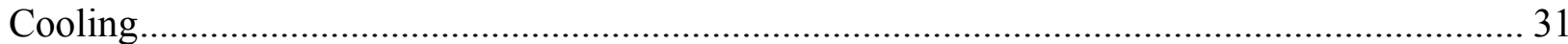

Figure 12 Incremental Cost (National Average) for Supermarket Building Using Low-Lift

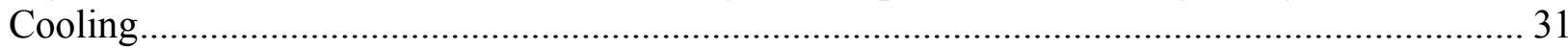

Figure 13 Incremental Cost (National Average) for Secondary School Building Using Low-Lift

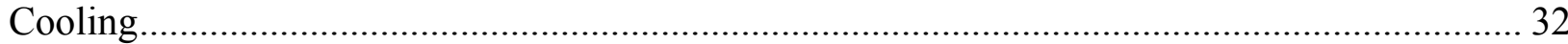

Figure 14 Comparison of Annual Chiller and Distribution Energy Consumption for Standard-

Performance Medium Office Building for Various System Configurations in 21 Locations ...... 45

Figure 15 Comparison of Annual Chiller and Distribution Energy Consumption for High-

Performance Medium Office Building for Various System Configurations in 16 Locations ...... 45

Figure 16 Comparison of Annual Chiller and Distribution Energy Consumption for Standard-

Performance Large Office Building for Various System Configurations in 21 Locations........... 46

Figure 17 Comparison of Annual Chiller and Distribution Energy Consumption for High-

Performance Large Office Building for Various System Configurations in 21 Locations........... 47

Figure 18 Comparison of Annual Chiller and Distribution Energy Consumption for Standard-

Perforamance Supermarket Building for Various System Configurations in 21 Locations. 47

Figure 19 Comparison of Annual Chiller and Distribution Energy Consumption for HighPerformance Supermarket Building for Various System Configurations in 21 Locations........... 48 Figure 20 Comparison of Annual Chiller and Distribution Energy Consumption for StandardPerformance Secondary School Building for Various System Configurations in 21 Locations .. 49 Figure 21 Comparison of Annual Chiller and Distribution Energy Consumption for HighPerformance Secondary School Building for Various System Configurations in 21 Locations .. 49 Figure 22 Variable Air Volume System with Terminal Reheat ................................................ 52 
Figure 23 Comparison of Regional Technical Site Electricity Savings Potential for the Year 2010 for Various Low-Lift Cooling Design Option Sets (assuming 100\% Penetration) in Comparison

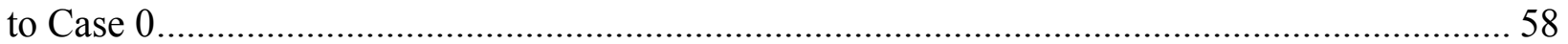
Figure 24 Comparison of Regional Technical Site Electricity Savings Potential for the Year 2010 for Various Low-Lift Cooling Design Option Sets (assuming 100\% Penetration) in Comparison

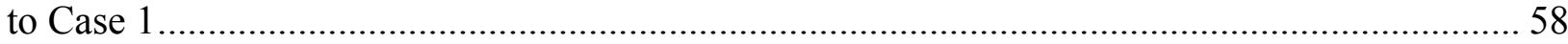

Figure 25 Pacific Northwest Regional Technical Site Electricity Savings in 2020 over the Standard HVAC System (Case 0) for Different System Configurations for 2020 Assuming 100\%

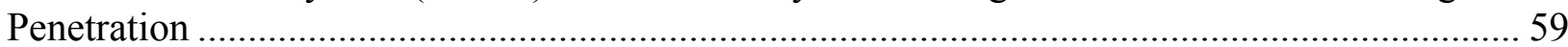

Figure 26 Pacific Northwest Regional Savings Technical Site Electricity Savings in 2020 over Case 1 for Different System Configurations for 2020 Assuming 100\% Penetration ................. 59

Figure: C-1 Comparison of Annual Chiller and Distribution Energy Consumption for StandardPerformance Small Office Building for Various System Configurations in 21 Locations with Ideal Low-Lift Chiller for the LLCS Configurations ...................................................... C-13 Figure: C-2 Comparison of Annual Chiller and Distribution Energy Consumption for HighPerformance Small Office Building for Various System Configurations in 21 Locations with Ideal Low-Lift Chiller for the LLCS Configurations C-14 Figure: C-3 Comparison of Annual Chiller and Distribution Energy Consumption for StandardPerformance Medium Office Building for Various System Configurations in 21 Locations with Ideal Low-Lift Chiller for the LLCS Configurations C-14 Figure: C-4 Comparison of Annual Chiller and Distribution Energy Consumption for HighPerformance Medium Office Building for Various System Configurations in 16 Locations with Ideal Low-Lift Chiller for the LLCS Configurations .................................................... C-15 Figure: C-5 Comparison of Annual Chiller and Distribution Energy Consumption for StandardPerformance Large Office Building for Various System Configurations in 21 Locations with Ideal Low-Lift Chiller for the LLCS Configurations C-15 Figure: C-6 Comparison of Annual Chiller and Distribution Energy Consumption for HighPerformance Large Office Building for Various System Configurations in 21 Locations with Ideal Low-Lift Chiller for the LLCS Configurations .................................................... C-16 Figure: C-7 Comparison of Annual Chiller and Distribution Energy Consumption for StandardPerformance Stand-Alone Retail Building for Various System Configurations in 21 Locations with Ideal Low-Lift Chiller for the LLCS Configurations C-16 Figure: C-8 Comparison of Annual Chiller and Distribution Energy Consumption for HighPerformance Stand-Alone Retail Building for Various System Configurations in 21 Locations with Ideal Low-Lift Chiller for the LLCS Configurations C-17 Figure: C-9 Comparison of Annual Chiller and Distribution Energy Consumption for StandardPerformance Strip Mall Retail Building for Various System Configurations in 21 Locations with Ideal Low-Lift Chiller for the LLCS Configurations C-17 Figure: C-10 Comparison of Annual Chiller and Distribution Energy Consumption for HighPerformance Strip Mall Retail Building for Various System Configurations in 21 Locations with Ideal Low-Lift Chiller for the LLCS Configurations C-18 Figure: C-11 Comparison of Annual Chiller and Distribution Energy Consumption for StandardPerformance Primary School Building for Various System Configurations in 21 Locations with Ideal Low-Lift Chiller for the LLCS Configurations C-18 
Figure: C-12 Comparison of Annual Chiller and Distribution Energy Consumption for HighPerformance Primary School Building for Various System Configurations in 21 Locations with Ideal Low-Lift Chiller for the LLCS Configurations C-19 Figure: C-13 Comparison of Annual Chiller and Distribution Energy Consumption for StandardPerformance Secondary School Building for Various System Configurations in 21 Locations with Ideal Low-Lift Chiller for the LLCS Configurations C-19

Figure: C-14 Comparison of Annual Chiller and Distribution Energy Consumption for HighPerformance Secondary School Building for Various System Configurations in 21 Locations with Ideal Low-Lift Chiller for the LLCS Configurations C-20 Figure: C-15 Comparison of Annual Chiller and Distribution Energy Consumption for StandardPerformance Hospital Building for Various System Configurations in 21 Locations with Ideal

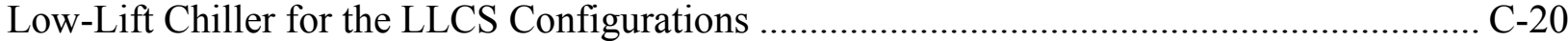
Figure: C-16 Comparison of Annual Chiller and Distribution Energy Consumption for HighPerformance Hospital Building for Various System Configurations in 21 Locations with Ideal Low-Lift Chiller for the LLCS Configurations .............................................................. Figure: C-17 Comparison of Annual Chiller and Distribution Energy Consumption for StandardPerformance Outpatient Health Care Building for Various System Configurations in 21 Locations with Ideal Low-Lift Chiller for the LLCS Configurations. C-21

Figure: C-18 Comparison of Annual Chiller and Distribution Energy Consumption for HighPerformance Outpatient Health Care Building for Various System Configurations in 21 Locations with Ideal Low-Lift Chiller for the LLCS Configurations. C-22 Figure: C-19 Comparison of Annual Chiller and Distribution Energy Consumption for StandardPerformance Supermarket Building for Various System Configurations in 21 Locations with Ideal Low-Lift Chiller for the LLCS Configurations C-22 Figure: C-20 Comparison of Annual Chiller and Distribution Energy Consumption for HighPerformance Supermarket Building for Various System Configurations in 21 Locations with Ideal Low-Lift Chiller for the LLCS Configurations C-23 Figure: C-21 Comparison of Annual Chiller and Distribution Energy Consumption for StandardPerformance Warehouse Building for Various System Configurations in 21 Locations with Ideal Low-Lift Chiller for the LLCS Configurations C-23

Figure: C-22 Comparison of Annual Chiller and Distribution Energy Consumption for HighPerformance Warehouse Building for Various System Configurations in 21 Locations with Ideal Low-Lift Chiller for the LLCS Configurations C-24 Figure: C-23 Comparison of Annual Chiller and Distribution Energy Consumption for StandardPerformance Large Hotel Building for Various System Configurations in 21 Locations with Ideal Low-Lift Chiller for the LLCS Configurations .............................................................. C-24 Figure: C-24 Comparison of Annual Chiller and Distribution Energy Consumption for HighPerformance Large Hotel Building for Various System Configurations in 21 Locations with Ideal Low-Lift Chiller for the LLCS Configurations .............................................................. C-25 Figure: C-25 Comparison of Annual Chiller and Distribution Energy Consumption for StandardPerformance Small Office Building for Various System Configurations in 21 Locations with Prototype Low-Lift Chiller for the LLCS Configurations C-40 Figure: C-26 Comparison of Annual Chiller and Distribution Energy Consumption for HighPerformance Small Office Building for Various System Configurations in 21 Locations with Prototype Low-Lift Chiller for the LLCS Configurations C-40 
Figure: C-27 Comparison of Annual Chiller and Distribution Energy Consumption for StandardPerformance Standalone Retail Building for Various System Configurations in 21 Locations with Prototype Low-Lift Chiller for the LLCS Configurations C-41

Figure: C-28 Comparison of Annual Chiller and Distribution Energy Consumption for HighPerformance Standalone Retail Building for Various System Configurations in 21 Locations with Prototype Low-Lift Chiller for the LLCS Configurations C-41

Figure: C-29 Comparison of Annual Chiller and Distribution Energy Consumption for StandardPerformance Strip Mall Retail Building for Various System Configurations in 21 Locations with Prototype Low-Lift Chiller for the LLCS Configurations C-42 Figure: C-30 Comparison of Annual Chiller and Distribution Energy Consumption for HighPerformance Strip Mall Retail Building for Various System Configurations in 21 Locations with Prototype Low-Lift Chiller for the LLCS Configurations ............................................... C-42 Figure: C-31 Comparison of Annual Chiller and Distribution Energy Consumption for StandardPerformance Primary School Building for Various System Configurations in 21 Locations with Prototype Low-Lift Chiller for the LLCS Configurations... C-43 Figure: C-32 Comparison of Annual Chiller and Distribution Energy Consumption for HighPerformance Primary School Building for Various System Configurations in 21 Locations with Prototype Low-Lift Chiller for the LLCS Configurations... C-43 Figure: C-33 Comparison of Annual Chiller and Distribution Energy Consumption for StandardPerformance Hospital Building for Various System Configurations in 21 Locations with Prototype Low-Lift Chiller for the LLCS Configurations C-44 Figure: C-34 Comparison of Annual Chiller and Distribution Energy Consumption for HighPerformance Hospital Building for Various System Configurations in 21 Locations with Prototype Low-Lift Chiller for the LLCS Configurations .............................................. C-44 Figure: C-35 Comparison of Annual Chiller and Distribution Energy Consumption for StandardPerformance Outpatient Health Care Building for Various System Configurations in 21 Locations with Prototype Low-Lift Chiller for the LLCS Configurations..... C-45

Figure: C-36 Comparison of Annual Chiller and Distribution Energy Consumption for HighPerformance Outpatient Health Care Building for Various System Configurations in 21 Locations with Prototype Low-Lift Chiller for the LLCS Configurations C-45 Figure: C-37 Comparison of Annual Chiller and Distribution Energy Consumption for StandardPerformance Warehouse Building for Various System Configurations in 21 Locations with Prototype Low-Lift Chiller for the LLCS Configurations C-46 Figure: C-38 Comparison of Annual Chiller and Distribution Energy Consumption for HighPerformance Warehouse Building for Various System Configurations in 21 Locations with Prototype Low-Lift Chiller for the LLCS Configurations C-46 Figure: C-39 Comparison of Annual Chiller and Distribution Energy Consumption for StandardPerformance Large Hotel Building for Various System Configurations in 21 Locations with Prototype Low-Lift Chiller for the LLCS Configurations.... C-47 Figure: C-40 Comparison of Annual Chiller and Distribution Energy Consumption for HighPerformance Large Hotel Building for Various System Configurations in 21 Locations with Prototype Low-Lift Chiller for the LLCS Configurations...... 


\section{Tables}

Table 1 ARI Performance Test ........................................................................................... 7

Table 2 Additional Test to Characterize the Chiller Performance................................................ 7

Table 3 Coefficients for the Ideal Chiller Performance Map, $\mathrm{x}=$ Outdoor Dry-Bulb Temperature

in Fahrenheit, $y=$ part load fraction .................................................................................... 10

Table 4 Prototype Chiller Performance Map Coefficient, $x=$ Outdoor Dry-Bulb Temperature in

Fahrenheit, $\mathrm{y}=$ part load fraction, $\mathrm{z}=$ Chilled Water Temperature in Fahrenheit ........................ 13

Table 4 Categorization of 2003 CBECS Data for Benchmark Buildings................................... 19

Table 5 Modifications to the DOE and ASHRAE-Modified Benchmarks Made by PNNL for

Analysis of Low-Lift Cooling......................................................................................... 21

Table 6 Selected Commercial Building Benchmark Locations for the Pacific Northwest........... 22

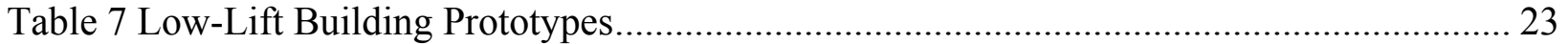

Table 8 State Rankings for Key Market Attributes Associated with Low Lift Cooling

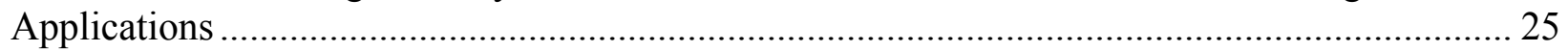

Table 9 Stakeholder Interview List............................................................................... 25

Table 10 Regional Customer Acceptance Level of Each Technology ..................................... 26

Table 11 HVAC System Components and Cost Sources ........................................................ 29

Table 12 Comparison of Key Parameters for the Baseline and High-Performance Buildings.... 37

Table 13 Annual Energy Consumption (Chiller, Fan, and Pump) for the Standard-Performance

Medium Office Building Design for Various HVAC Combinations across 21 Climate Locations

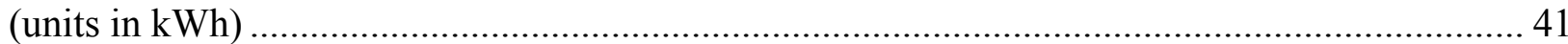

Table 14 Annual Energy Consumption (Chiller, Fan, and Pump) for the High-Performance

Medium Office Building Design for Various HVAC Combinations across 21 Climate Locations

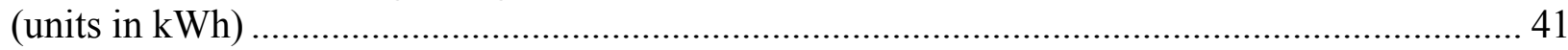

Table 15 Annual Energy Consumption (Chiller, Fan, and Pump) for the Standard-Performance

Large Office Building Design for Various HVAC Combinations across 21 Climate Locations (units in $\mathrm{kWh}$ )

Table 16 Annual Energy Consumption (Chiller, Fan, and Pump) for the High-Performance Large Office Building Design for Various HVAC Combinations across 21 Climate Locations (units in

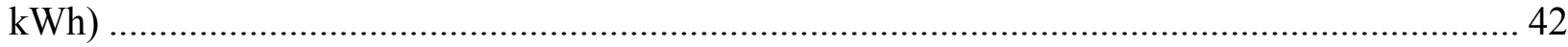

Table 17 Annual Energy Consumption (Chiller, Fan, and Pump) for the Standard-Performance Supermarket Building Design for Various HVAC Combinations across 21 Climate Locations (units in $\mathrm{kWh}$ )

Table 18 Annual Energy Consumption (Chiller, Fan, and Pump) for the High-Performance Supermarket Building Design for Various HVAC Combinations across 21 Climate Locations

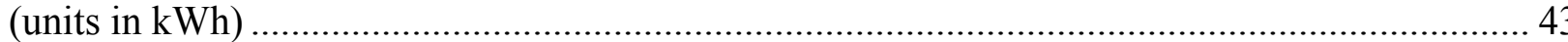

Table 19 Annual Energy Consumption (Chiller, Fan, and Pump) for the Standard Performance Secondary School Building Design for Various HVAC Combinations across 21 Climate Locations (units in $\mathrm{kWh}$ ).....

Table 20 Annual Energy Consumption (Chiller, Fan, and Pump) for the High Performance Secondary School Building Design for Various HVAC Combinations across 21 Climate Locations (units in $\mathrm{kWh}$ ).....

Table 21 Range of Energy Reduction (between Case 0 and Case 8) in Annual Chiller and Distribution Energy Consumption for both Standard and High-Performance Buildings in Various Climate Locations . 
Table 22 Range of Energy Reduction (between Case 1 and Case 8) in Annual Chiller and Distribution Energy Consumption for both Standard- and High-Performance Buildings in Various Climate Locations 51

Table 23 Reheat Savings for Selected Building Types in Different Climate Locations (million

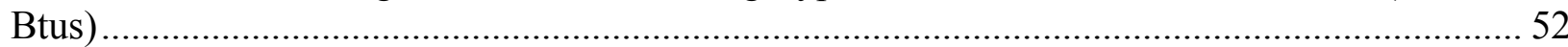

Table 24 Reheating Savings as a Fraction of the Total Heating............................................ 53

Table 25 Benchmark Building Prototype Areas .................................................................. 55 Table 26 Annual New Construction Weights (number of buildings per year) by Building Type and Climate Location 56 Table 27 Summary of Regional Technical Site Electricity Savings Potential for the Year 2010 for the Low-Lift Cooling Design Option Set - Case 8 (assuming 100\% Penetration) in Comparison to Case 0 .......

Table 28 - Summary of Regional Technical Site Electricity Savings Potential for the Year 2010 for the Low-Lift Cooling Design Option Set - Case 8 (assuming 100\% Penetration) Compared to

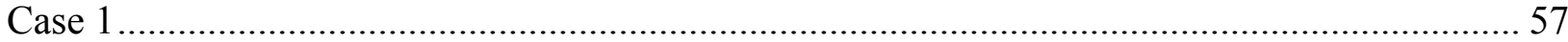

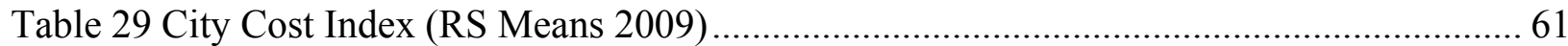

Table 30 Incremental Cost of the LLCS by Building Type in each Climate Location ............... 62

Table 31 Energy Cost Savings by Building Type in each Climate Location ............................ 63

Table 32 Simple Payback by Building Type for each Climate Location .................................. 64

Table: C-1 Annual Energy Consumption (Chiller, Fan, and Pump) for the Standard-Performance Small Office Building Design for Various HVAC Combinations across 21 Climate Locations (units in $\mathrm{kWh}$ ) with Ideal Low-Lift Chiller for LLCS Configurations.

Table: C-2 Annual Energy Consumption (Chiller, Fan, and Pump) for the High-Performance Small Office Building Design for Various HVAC Combinations across 21 Climate Locations (units in $\mathrm{kWh}$ ) with Ideal Low-Lift Chiller for LLCS Configurations .................................. C-1 Table: C-3 Annual Energy Consumption (Chiller, Fan, and Pump) for the Standard-Performance Medium Office Building Design for Various HVAC Combinations across 21 Climate Locations (units in $\mathrm{kWh}$ ) with Ideal Low-Lift Chiller for LLCS Configurations. $\mathrm{C}-2$ Table: C-4 Annual Energy Consumption (Chiller, Fan, and Pump) for the High-Performance Medium Office Building Design for Various HVAC Combinations across 21 Climate Locations (units in $\mathrm{kWh}$ ) with Ideal Low-Lift Chiller for LLCS Configurations. Table: C-5 Annual Energy Consumption (Chiller, Fan, and Pump) for the Standard-Performance Large Office Building Design for Various HVAC Combinations across 21 Climate Locations (units in $\mathrm{kWh}$ ) with Ideal Low-Lift Chiller for LLCS Configurations................................... C-3 Table: C-6 Annual Energy Consumption (Chiller, Fan, and Pump) for the High-Performance Large Office Building Design for Various HVAC Combinations across 21 Climate Locations (units in $\mathrm{kWh}$ ) with Ideal Low-Lift Chiller for LLCS Configurations ................................. C-3 Table: C-7 Annual Energy Consumption (Chiller, Fan, and Pump) for the Standard-Performance Retail Strip Mall Building Design for Various HVAC Combinations across 21 Climate Locations (units in $\mathrm{kWh}$ ) with Ideal Low-Lift Chiller for LLCS Configurations................................... C-4 Table: C-8 Annual Energy Consumption (Chiller, Fan, and Pump) for the High-Performance Retail Strip Mall Building Design for Various HVAC Combinations across 21 Climate Locations (units in $\mathrm{kWh}$ ) with Ideal Low-Lift Chiller for LLCS Configurations C-4 
Table: C-9 Annual Energy Consumption (Chiller, Fan, and Pump) for the Standard-Performance Retail Stand-Alone Building Design for Various HVAC Combinations across 21 Climate Locations (units in $\mathrm{kWh}$ ) with Ideal Low-Lift Chiller for LLCS Configurations .... C-5 Table: C-10 Annual Energy Consumption (Chiller, Fan, and Pump) for the High-Performance Retail Stand-Alone Building Design for Various HVAC Combinations across 21 Climate Locations (units in kWh) with Ideal Low-Lift Chiller for LLCS Configurations ..... C-5 Table: C-11 Annual Energy Consumption (Chiller, Fan, and Pump) for the StandardPerformance Primary School Building Design for Various HVAC Combinations across 21 Climate Locations (units in $\mathrm{kWh}$ ) with Ideal Low-Lift Chiller for LLCS Configurations C-6 Table: C-12 Annual Energy Consumption (Chiller, Fan, and Pump) for the High-Performance Primary School Building Design for Various HVAC Combinations across 21 Climate Locations (units in $\mathrm{kWh}$ ) with Ideal Low-Lift Chiller for LLCS Configurations .................................. C-6 Table: C-13 Annual Energy Consumption (Chiller, Fan, and Pump) for the StandardPerformance Secondary School Building Design for Various HVAC Combinations across 21 Climate Locations (units in $\mathrm{kWh}$ ) with Ideal Low-Lift Chiller for LLCS Configurations ........ C-7 Table: C-14 Annual Energy Consumption (Chiller, Fan, and Pump) for the High-Performance Secondary School Building Design for Various HVAC Combinations across 21 Climate Locations (units in $\mathrm{kWh}$ ) with Ideal Low-Lift Chiller for LLCS Configurations ..... C-7

Table: C-15 Annual Energy Consumption (Chiller, Fan, and Pump) for the StandardPerformance Hotel Large Building Design for Various HVAC Combinations across 21 Climate Locations (units in $\mathrm{kWh}$ ) with Ideal Low-Lift Chiller for LLCS Configurations .................... C-8 Table: C-16 Annual Energy Consumption (Chiller, Fan, and Pump) for the High-Performance Hotel Large Building Design for Various HVAC Combinations across 21 Climate Locations (units in $\mathrm{kWh}$ ) with Ideal Low-Lift Chiller for LLCS Configurations ................................... C-8 Table: C-17 Annual Energy Consumption (Chiller, Fan, and Pump) for the StandardPerformance Supermarket Building Design for Various HVAC Combinations across 21 Climate Locations (units in $\mathrm{kWh}$ ) with Ideal Low-Lift Chiller for LLCS Configurations .... C-9 Table: C-18 Annual Energy Consumption (Chiller, Fan, and Pump) for the High-Performance Supermarket Building Design for Various HVAC Combinations across 21 Climate Locations (units in $\mathrm{kWh}$ ) with Ideal Low-Lift Chiller for LLCS Configurations C-9 Table: C-19 Annual Energy Consumption (Chiller, Fan, and Pump) for the StandardPerformance Warehouse Building Design for Various HVAC Combinations across 21 Climate Locations (units in kWh) with Ideal Low-Lift Chiller for LLCS Configurations ..... C-10 Table: C-20 Annual Energy Consumption (Chiller, Fan, and Pump) for the High-Performance Warehouse Building Design for Various HVAC Combinations across 21 Climate Locations (units in $\mathrm{kWh}$ ) with Ideal Low-Lift Chiller for LLCS Configurations C-10 Table: C-21 Annual Energy Consumption (Chiller, Fan, and Pump) for the StandardPerformance Outpatient Health Care Building Design for Various HVAC Combinations across 21 Climate Locations (units in $\mathrm{kWh}$ ) with Ideal Low-Lift Chiller for LLCS Configurations . C-11 Table: C-22 Annual Energy Consumption (Chiller, Fan, and Pump) for the High-Performance Outpatient Health Care Building Design for Various HVAC Combinations across 21 Climate Locations (units in kWh) with Ideal Low-Lift Chiller for LLCS Configurations .... C-12 Table: C-23 Annual Energy Consumption (Chiller, Fan, and Pump) for the StandardPerformance Hospital Building Design for Various HVAC Combinations across 21 Climate Locations (units in $\mathrm{kWh}$ ) with Ideal Low-Lift Chiller for LLCS Configurations C-12 
Table: C-24 Annual Energy Consumption (Chiller, Fan, and Pump) for the High-Performance Hospital Building Design for Various HVAC Combinations across 21 Climate Locations (units in $\mathrm{kWh}$ ) with Ideal Low-Lift Chiller for LLCS Configurations . C-13 Table: C-25 Annual Energy Consumption (Chiller, Fan, and Pump) for the StandardPerformance Small Office Building Design for Various HVAC Combinations across 21 Climate Locations (units in kWh) with Prototype Low-Lift Chiller for the LLCS Configurations....... C-25 Table: C-26 Annual Energy Consumption (Chiller, Fan, and Pump) for the High-Performance Small Office Building Design for Various HVAC Combinations across 21 Climate Locations (units in $\mathrm{kWh}$ ) with Prototype Low-Lift Chiller for the LLCS Configurations C-26 Table: C-27 Annual Energy Consumption (Chiller, Fan, and Pump) for the StandardPerformance Retail Standalone Building Design for Various HVAC Combinations across 21 Climate Locations (units in $\mathrm{kWh}$ ) with Prototype Low-Lift Chiller for the LLCS Configurations

Table: C-28 Annual Energy Consumption (Chiller, Fan, and Pump) for the High-Performance Retail Standalone Building Design for Various HVAC Combinations across 21 Climate Locations (units in kWh) with Prototype Low-Lift Chiller for the LLCS Configurations....... C-28 Table: C-29 Annual Energy Consumption (Chiller, Fan, and Pump) for the StandardPerformance Retail Strip Mall Building Design for Various HVAC Combinations across 21 Climate Locations (units in kWh) with Prototype Low-Lift Chiller for the LLCS Configurations

Table: C-30 Annual Energy Consumption (Chiller, Fan, and Pump) for the High-Performance Retail Strip Mall Building Design for Various HVAC Combinations across 21 Climate Locations (units in $\mathrm{kWh}$ ) with Prototype Low-Lift Chiller for the LLCS Configurations .... C-30 Table: C-31 Annual Energy Consumption (Chiller, Fan, and Pump) for the StandardPerformance Primary School Building Design for Various HVAC Combinations across 21 Climate Locations (units in kWh) with Prototype Low-Lift Chiller for the LLCS Configurations

Table: C-32 Annual Energy Consumption (Chiller, Fan, and Pump) for the High-Performance Primary School Building Design for Various HVAC Combinations across 21 Climate Locations (units in $\mathrm{kWh}$ ) with Prototype Low-Lift Chiller for the LLCS Configurations C-32 Table: C-33 Annual Energy Consumption (Chiller, Fan, and Pump) for the StandardPerformance Large Hotel Building Design for Various HVAC Combinations across 21 Climate Locations (units in kWh) with Prototype Low-Lift Chiller for the LLCS Configurations....... C-33 Table: C-34 Annual Energy Consumption (Chiller, Fan, and Pump) for the High-Performance Large Hotel Building Design for Various HVAC Combinations across 21 Climate Locations (units in $\mathrm{kWh}$ ) with Prototype Low-Lift Chiller for the LLCS Configurations ..................... C-34 Table: C-35 Annual Energy Consumption (Chiller, Fan, and Pump) for the Standard Performance Warehouse Building Design for Various HVAC Combinations across 21 Climate Locations (units in $\mathrm{kWh}$ ) with Prototype Low-Lift Chiller for the LLCS Configurations....... C-35 Table: C-36 Annual Energy Consumption (Chiller, Fan, and Pump) for the High Performance Warehouse Building Design for Various HVAC Combinations across 21 Climate Locations (units in $\mathrm{kWh}$ ) with Prototype Low-Lift Chiller for the LLCS Configurations .... C-36 Table: C-37 Annual Energy Consumption (Chiller, Fan, and Pump) for the StandardPerformance Outpatient Healthcare Building Design for Various HVAC Combinations across 21 Climate Locations (units in $\mathrm{kWh}$ ) with Prototype Low-Lift Chiller for the LLCS Configurations 
Table: C-38 Annual Energy Consumption (Chiller, Fan, and Pump) for the High-Performance Outpatient Health Care Building Design for Various HVAC Combinations across 21 Climate Locations (units in kWh) with Prototype Low-Lift Chiller for the LLCS Configurations....... C-38 Table: C-39 Annual Energy Consumption (Chiller, Fan, and Pump) for the StandardPerformance Hospital Building Design for Various HVAC Combinations across 21 Climate Locations (units in $\mathrm{kWh}$ ) with Prototype Low-Lift Chiller for the LLCS Configurations....... C-39 Table: C-40 Annual Energy Consumption (Chiller, Fan, and Pump) for the High-Performance Hospital Building Design for Various HVAC Combinations across 21 Climate Locations (units in $\mathrm{kWh}$ ) with Prototype Low-Lift Chiller for the LLCS Configurations................................... C-39 


\title{
Acronyms and Abbreviations
}

\author{
A/C air conditioning \\ AEDG Advanced Energy Design Guide \\ AHU air handler unit \\ ANSI American National Standards Institute \\ ARI American Refrigeration Institute \\ ARTI Air-Conditioning and Refrigeration Technology Institute \\ ASHRAE American Society of Heating, Refrigeration and Air-Conditioning Engineers \\ BPA Bonneville Power Adminstration \\ BT Building Technologies Program \\ CBECS Commercial Building Energy Consumption Survey \\ $\mathrm{C} / \mathrm{C} \quad$ cooling coil \\ CFC chlorofluorocarbons \\ cfm cubic feet per minute \\ COP coefficient of performance \\ $\mathrm{CV} \quad$ constant volume air distribution system \\ CRTF comprehensive room transfer function \\ CTF conduction transfer function \\ DCV demand-controlled ventilation \\ DDC direct digital control \\ DOAS dedicated outdoor air conditioning system \\ DOE U.S. Department of Energy \\ DV displacement ventilation \\ DX direct expansion \\ ECM electrically commutated motors \\ EER energy efficiency ratio \\ EIA Energy Information Administration \\ ELWT Evaporator Leaving Water Temperature \\ EWFR Evaporator Water Flow Rate \\ ERV energy recovery ventilation \\ EUI energy use intensity \\ FLEOH full-load-equivalent operating hours \\ FDD fault detection and diagnostics \\ GIS geographical information systems \\ gpm gallons per minute \\ GSA General Services Administration \\ $\mathrm{H} / \mathrm{C} \quad$ heating coil \\ HP heat pump \\ HPB high-performance building \\ HX heat exchanger \\ HSTF heat source transfer function \\ HVAC heating, ventilation and air conditioning \\ IAQ indoor air quality \\ IESNA Illuminating Engineering Society of North America \\ $\mathrm{kBh}$ thousand Btu per hour
}




$\begin{array}{ll}\text { kWh } & \text { kilowatt hours } \\ \text { LBNL } & \text { Lawrence Berkeley National Laboratory } \\ \text { LEED } & \text { Leadership in Energy and Environmental Design } \\ \text { LLC } & \text { low-lift cooling } \\ \text { LLCS } & \text { low-lift cooling system } \\ \text { MCH } & \text { McGraw-Hill Construction } \\ \text { NCI } & \text { Navigant Consulting Inc. } \\ \text { NWPC } & \text { Northwest Power Planning Council } \\ \text { NZEB } & \text { Net-Zero Energy Building } \\ \text { NREL } & \text { National Renewable Energy Laboratory } \\ \text { ODB } & \text { outdoor dry-bulb temperature } \\ \text { OEM } & \text { original equipment manufacturer } \\ \text { PBA } & \text { principal building activity } \\ \text { PCM } & \text { phase change materials } \\ \text { PNNL } & \text { Pacific Northwest National Laboratory } \\ \text { PLR } & \text { part load ratio } \\ \text { PSZ } & \text { package single zone } \\ \text { QUAD } & \text { quadrillion (10 }{ }^{15} \text { ) British Thermal Units (Btus) } \\ \text { R\&D } & \text { research and development } \\ \text { RCP } & \text { radiant cooling panel } \\ \text { RTP } & \text { real-time pricing (electric utility rate) } \\ \text { SEER } & \text { seasonal energy efficiency ratio } \\ \text { SHGC } & \text { solar heat gain coefficient } \\ \text { SHR } & \text { sensible heat ratio } \\ \text { SP } & \text { special projects (working groups within ASHRAE) } \\ \text { TES } & \text { thermal energy storage } \\ \text { TOU } & \text { time of use (utility rate) } \\ \text { UA } & \text { conductance coefficient } \\ \text { UFAD } & \text { under-floor air distribution } \\ \text { VAV } & \text { variable air volume } \\ \text { VFD } & \text { variable frequency drive } \\ \text { VRV } & \text { variable refrigerant volume } \\ \text { VS } & \text { variable-speed } \\ \text { VSD } & \text { variable-speed drive } \\ \text { W/cfm } & \text { Watts per cubic feet per minute (measure of fan power efficiency) } \\ \text { W/sf } & \text { Watts per square foot } \\ \text { WWR } & \text { window-to-wall Ratio } \\ \text { ZEB } & \text { zero energy building } \\ & \end{array}$




\section{Introduction}

Design of cost-effective high-performance buildings has focused mainly on lighting, window and other envelope measures. Efforts directed at improving the heating, ventilating and air conditioning (HVAC) performance have tended to pursue, and in many cases achieved, incremental efficiency improvements. There are a number of potential integrated solutions that can provide significant HVAC efficiency improvements. Pacific Northwest National Laboratory (PNNL), with co-funding from Bonneville Power Administration (BPA) and the Building Technologies (DOE-BT) Program of the U.S. Department of Energy (DOE), conducted this research and development $(R \& D)$ activity to address the energy efficiency goals outlined in the BPA Roadmap. ${ }^{7}$ The R\&D effort evaluated one integrated HVAC design option.

The objective of this R\&D project is to show that integrated HVAC design options have the potential to reduce the HVAC energy consumption significantly in the Pacific Northwest region through utilization of synergies between emerging HVAC technologies and advanced controls. The integrated technology, referred to as low-lift cooling system (LLCS) in the report, evaluated as part of this project leverages increased part-load efficiencies of equipment and the operational efficiency of the building as an integrated system. The LLCS consists of:

1. Peak-load shifting by means of active or passive (pre-cooling of building mass) thermal energy storage (TES). ${ }^{8}$

2. Dedicated outdoor air system (DOAS) and enthalpy heat recovery from exhaust air.

3. Radiant heating and cooling (RCP) panels or floor system.

4. Low-lift ${ }^{9}$ vapor compression cooling equipment.

5. Advanced controls at the HVAC equipment and HVAC system (supervisory) levels.

This report describes the work performed for the BPA portion of the work. For the DOE portion of the work refer to Katipamula el al. (2010), Jiang et al. (2008), Armstrong et al. (2009a, b). The objectives of the work are:

1. selecting a manufacturing partner to build the low-lift chiller prototype

2. developing a specification for a "low-lift" electrically driven vapor compression chiller system

3. building a prototype to meet the specification

4. conducting a market assessment in the Pacific Northwest region to understand the barriers and perceived benefits of the LLCS

5. developing incremental cost estimates for the low-lift system compared to conventional chiller

\footnotetext{
${ }^{7}$ http://www.bpa.gov/corporate/business/innovation/docs/2006/RM-06 EnergyEfficiencyFinal.pdf

${ }^{8}$ In this report active denotes peak-shifting by means of a discrete TES such as a stratified water tank; passive refers to pre-cooling of the intrinsic mass (building fabric and contents) by forced air or hydronic radiant cooling using a chiller and/or air-, water-, or refrigerant-side free cooling.

${ }^{9}$ The American Refrigeration Institute defines chiller part-load rating conditions as $50^{\circ} \mathrm{F}$ chilled water supply and $80^{\circ} \mathrm{F}$ outdoor dry-bulb temperature; we consider low-lift conditions to be $60-65^{\circ} \mathrm{F}$ chilled water supply, $\sim 80^{\circ} \mathrm{F}$ outdoor dry-bulb temperature (day) and $\sim 70^{\circ} \mathrm{F}$ outdoor dry-bulb temperature (night).
} 
6. developing performance maps for the prototype and comparing them to the conventional vapor compression system

7. quantifying the energy, emissions and peak load reduction benefits from widespread use of the proposed technology options in the BPA's service territory

The savings estimates reported are based on thermal loads from the EnergyPlus simulations and the energy consumption estimates from the component models developed as part of the DOE funded effort. In addition, the savings are based on the use of a larger set of building types (12) and climate locations (21).

The report provides a brief background about the technology option (Background); followed by a section that describes the prototype chiller specification and its performance (Prototype Chiller Development and Performance Characterization). The EnergyPlus prototype templates that were used to generate the thermal loads are described in the Commercial Building Benchmarks section. The market assessment to identify potential barriers and perceived benefits from the use the LLCS was conducted by Navigant Consulting Inc. (NCI) under subcontract to PNNL. The summary of the market assessment is described in Market Assessment of Low-Lift Cooling System section. In addition to market assessment, PNNL also had NCI develop incremental cost estimates for the low-lift option; summary of that work is described in the section Incremental Cost Estimates for the Low-Lift Cooling System. The methodology used to estimate the energy use for the various low-lift combinations is described in Energy Use Estimation Methodology section. The energy savings for various combinations of low-lift technologies compared to the base case and simple backpack estimates for selected building types are presented in Energy Savings Estimates for the Various LLCS Combinations section. The methodology used to estimate the technical potential energy savings in the Pacific Northwest is described in Pacific Northwest Regional Energy Savings Estimation Methodology section. The technical potential savings for the Pacific Northwest and estimates for energy savings estimates for year 2020 are presented in Pacific Northwest Regional Technical Energy Savings Potential section. The economic analysis, including the simple payback calculation is described in Economic Analysis section. The discussion and recommendations are provided in the Discussion and Recommendations section. 


\section{Background}

All the component technologies that comprise the LLCS have been in use, to some extent, for a number of years but not in the U.S. These efforts, even those that combined radiant panel distribution and/or night pre-cooling concepts however, have continued to assume a more or less conventional cooling plant. Conversely, efforts to optimize chiller and TES operations have generally assumed a conventional air-distribution system. Although these technologies can and have been used independently to provide incremental savings, when used together, they achieve significant energy savings by integrating HVAC equipment, distribution and control in a highly synergistic manner. Peak shifting and active and passive thermal energy storage are proven technologies that improve chiller load factor and can increase chiller efficiency. DOAS with enthalpy recovery ${ }^{10}$ provide more efficient latent cooling so that radiant cooling can be used to satisfy sensible cooling loads. Radiant cooling further increases chiller efficiency by allowing the higher temperature of the radiant panel/ceiling, and hence of the chilled water supplied, to be only a few degrees below room temperature. Compared to all-air systems, the fan energy use of a RCP/DOAS is dramatically reduced. When advanced controls are integrated with the above technologies, additional energy and peak demand savings can be achieved by coordinating variable-speed compressors, fans and pumps for maximum efficiency, by anticipating and shifting daytime cooling loads, and by eliminating simultaneous heating and cooling.

It is recognized that substantial efficiency improvements in office, retail and other building types can be achieved with advanced envelopes (e.g., reduced conduction and infiltration, improved windows), lighting technologies/controls, and plug load power density reductions. These technologies are basic to continued advances in overall energy efficiency. As the envelope reaches a very high level of performance and ventilation load is taken up by a DOAS, the remaining cooling load will be dominated by internal gains: lights, plugs, and people. Most building types will have — and all building core zones have always had - cooling load patterns that do not vary much from week to week and even from summer to winter seasons. This is the ideal situation for a baseload cooling system with modest storage — analogous to a light, streamlined hybrid vehicle with a small and very efficient engine.

With the assumed low design load (high performance envelope and low lighting and equipment power densities) for cooling loads that can be satisfied with higher chilled water and supply air temperatures $\left(60\right.$ to $\left.65^{\circ} \mathrm{F}\right)$ and, with roughly half of the cooling delivered at night, the lowest lifecycle-cost plant will be one that is optimized for low condensing temperature $\left(75^{\circ} \mathrm{F}\right.$ or less) as well. Hydronic radiant cooling distribution can only be used in conjunction with DOAS equipment to address latent load. One can thus consider a LLCS to address the cooling and ventilation piece of the zero energy building (ZEB) puzzle as an integration of three key elements:

1. Efficient low-lift $\left(75^{\circ} \mathrm{F}\right.$ condenser, $60^{\circ} \mathrm{F}$ evaporator) variable-speed cooling plant.

2. Intrinsic building mass and controls to halve the typical cooling plant load factor.

3. RCP/DOAS with enthalpy recovery and efficient distribution.

\footnotetext{
${ }^{10}$ Uses outdoor-exhaust air enthalpy difference to pre-heat and humidify or pre-cool and pre-dry outdoor air.
} 
Efficient pre-cooling of building mass, enabled by advanced controls and efficient distribution, has two potential effects on chiller cost and performance: 1) the plant operates at much lower average discharge pressure, and 2) shifting load away from the peak can reduce the required cooling plant capacity. Other high performance building characteristics involving the envelope, windows and shading, lighting and controls, and office equipment can be expected to reduce peak cooling loads by at least $50 \%$. With the reduction in plant capacity, further improvements in chiller plant efficiency can be justified (refer to Jiang et al. 2008 for details).

The theoretical potential for high efficiency, low-lift vapor-compression cooling is well understood. The source and sink temperatures between which a thermodynamic cycle operates are determined by conditions and by approach temperatures in the load-side and rejection-side heat exchangers. The Carnot and Lorentz ideal cycle efficiencies represent fundamental upper bounds on performance to which current products and standards do not come anywhere near. Industry has argued that further improvements are not cost effective. However, the value engineering analyses that reach these conclusions typically assume current design practices such as not using thermal storage, using the same heat exchanger for sensible and latent cooling, using fixed-speed motors and sizing for peak load. Most cool storage installations to date have been justified by time-of-use electric rates; none have, to our knowledge, used chillers optimized for low-lift operation or for very efficient operation at less than half rated capacity. The main reasons for this are: 1) the double approach temperature penalty inherent in most discrete cool storage configurations, 2) a dearth of low-lift, high part-load efficiency chillers in the marketplace, and 3) low probability of finding an owner willing to try two or three new, mutually dependent cooling technologies in the same building.

As the results show, the proposed LLCS is applicable to many commercial building types and climates where mechanical cooling equipment is considered necessary (cooling applications that cannot be $100 \%$ satisfied by natural ventilation or air- or water-side economizer operation). This market represents well over half of the entire U.S. commercial building sector even if we count only applications that benefit from all elements of the LLCS. 


\section{Prototype Chiller Development and Performance Characterization}

One of the objectives of the project was to work with a manufacturing partner and develop a prototype low-lift optimized air-cooled chiller. After talking to a number of manufacturers, PNNL chose to work with McQuay International to develop the prototype chiller. The specifications for the prototype chiller were prepared by PNNL staff and consultants. PNNL then worked with the manufacturing partner to negotiate the final prototype chiller specification. The following section provides the details of the prototype chiller.

\section{Specification of Prototype Low-Lift Chiller}

The chiller specifications are as follows:

1. Chiller type: Air cooled.

2. Power supply: three-phase $208(+5 \%$ to $-10 \%)$ volts $60 \mathrm{~Hz}$.

3. Cooling capacity: A minimum desired nominal rated cooling capacity of 15 tons $(90,000$ $\mathrm{Btu} / \mathrm{h}$ or $26 \mathrm{~kW})$; the rated capacity should not exceed 15 tons $(180,000 \mathrm{Btu} / \mathrm{h}$ or $52 \mathrm{~kW})$.

4. Heating capacity: Optional, but if provided, a minimum desired nominal rated heating capacity of $90,000 \mathrm{Btu} / \mathrm{h}(26 \mathrm{~kW})$.

5. Number of compressors: Two or more compressors, with one compressor fitted with variable-speed drive.

6. Type of compressors: Preferably at least one scroll compressor with variable-frequency drive (VFD) the other fixed-speed compressor(s) can also be scrolls. The intent is that the modulating compressor should have very high efficiency at low load and a low pressure ratio. With the combination of compressor sequencing and speed modulation of one compressor, the chiller will operate efficiently and reliably at as low as $20 \%$ of rated capacity. Motor-VFD efficiency of the variable-speed compressor shall be at least $90 \%$ above $20 \%$ rated speed.

7. Water side heat exchanger: Brazed plate type.

8. Air side heat exchanged: Cross fin coil type.

9. Condenser fan: Very efficient condenser fan, motor and adjustable-speed drive with 7:1 turn down $(100 \%, 90 \%, 65 \%, 50 \%, 40 \%, 37 \%, 34 \%, 30 \%)$. Motor-VFD efficiency shall be at least $85 \%$ above $30 \%$ rated speed.

10. Refrigerant type: R410A. 
11. Refrigeration Control: Electrical expansion valve.

12. Subcooling: A liquid receiver that provides sub-cooling to ensure the liquid entering the expansion valve is also subcooled.

13. Defrost type: Reverse cycle defrost.

14. Temperature control: Control with outlet water temperature.

15. Chiller system (excluding chilled water pump): The chiller shall achieve a coefficient of performance (COP) of 3.0 or higher at rated conditions (i.e., $95^{\circ} \mathrm{F}$ outdoor dry-bulb and $44^{\circ} \mathrm{F}$ chilled water temperature). A COP of at least 4.0 or higher at $95^{\circ} \mathrm{F}$ outdoor drybulb and $68^{\circ} \mathrm{F}$ chilled water leaving temperature is also required.

16. Internal controls will provide independent optimal control of motor speeds and an electronic expansion valve such that:

a. Suction superheat is always controlled to a reasonable value.

b. At any given outdoor and chilled water return temperature, chilled water pump, and compressor specific power ( $\mathrm{kW} /$ ton) are nearly monotonic with capacity from $100 \%$ to $30 \%$ of rated capacity (e.g., $\mathrm{kW} /$ ton at $50 \%$ cap should be greater than or equal to energy efficiency ratio [EER] at $60 \%$ capacity).

c. At any given capacity and chilled water return temperature, condenser fan, and compressor specific power (kW/ton) must all fall monotonically with outdoor air dry-bulb from $100^{\circ} \mathrm{F}$ to $50^{\circ} \mathrm{F}$ (e.g., $1.0 \mathrm{~kW} /$ ton at $100^{\circ} \mathrm{F}$ should be $0.5 \mathrm{~kW} /$ ton at $\left.50^{\circ} \mathrm{F}\right)$.

d. At any given capacity and outdoor air dry-bulb temperature, condenser fan, and compressor specific power ( $\mathrm{kW} /$ ton) must all fall monotonically as chilled water return temperature rises from $55^{\circ} \mathrm{F}$ to $75^{\circ} \mathrm{F}$ (e.g., at $80^{\circ} \mathrm{F}$ outdoor air dry-bulb temperature, $1.0 \mathrm{~kW} /$ ton at $55^{\circ} \mathrm{F}$ should fall to $0.6 \mathrm{~kW} /$ ton at $75^{\circ} \mathrm{F}$ ).

e. The control will allow user-defined chilled water pump speed vs. delta-T schedule (e.g., 2 gpm per ${ }^{\circ} \mathrm{F}$ temperature difference would be a typical simple linear relationship but a non-linear relationship should also be allowed for PNNL's testing purposes).

17. Protective devices: All standard protective devices including high-pressure switch, fan driver overload protector, over current relay, inverter overload protector, etc.

\section{Quantifying the Performance of Prototype Chiller}

The performance of the chiller was quantified in a controlled environment at the Intertek Laboratory in Cortland, NY. The details of the test conditions and measurement made to quantify the chiller performance are described below.

The chiller performance was first characterized at the American Refrigeration and Institute (ARI) test conditions, as shown in Table 1. 
Table 1 ARI Performance Test

\begin{tabular}{|r|r|r|r|}
\hline $\begin{array}{c}\text { Chiller } \\
\text { Step } \\
\text { Number }\end{array}$ & $\begin{array}{c}\text { Load ARI Standard IPLV } \\
(\%)\end{array}$ & $\begin{array}{c}\text { ODB } \\
\left({ }^{\circ} \mathrm{F}\right)\end{array}$ & $\begin{array}{c}\text { ELWT } \\
\left({ }^{\circ} \mathrm{F}\right)\end{array}$ \\
\hline 24 & 100 & 95 & 44 \\
\hline 18 & 75 & 80 & 44 \\
\hline 12 & 50 & 65 & 44 \\
\hline 6 & 25 & 55 & 44 \\
\hline 0 & 0 & 55 & 44 \\
\hline
\end{tabular}

ODB: Outdoor dry-bulb temperature

ELWT: Evaporator leaving water temperature

In addition to the standard ARI test, the performance of the chiller was also characterized at the following test conditions.

Table 2 Additional Test to Characterize the Chiller Performance

\begin{tabular}{|c|c|c|c|c|c|}
\hline Test No & $\begin{array}{l}\text { Chiller } \\
\text { Step }\end{array}$ & $\begin{array}{l}\text { Load } \\
(\%)\end{array}$ & $\begin{array}{l}\text { ODB } \\
(\mathrm{OF})\end{array}$ & $\begin{array}{l}\text { ELWT } \\
(\mathrm{oF})\end{array}$ & $\begin{array}{c}\text { EWFR } \\
\text { (gal/min) }\end{array}$ \\
\hline 1 & 24 & 100 & 110 & 55 & 29.3 \\
\hline 2 & 24 & 100 & 90 & 55 & 29.3 \\
\hline 3 & 24 & 100 & 70 & 55 & 39.8 \\
\hline 4 & 24 & 100 & 50 & 55 & 41.7 \\
\hline 5 & 16 & 66 & 110 & 55 & 22.8 \\
\hline 6 & 16 & 66 & 90 & 55 & 22.8 \\
\hline 7 & 16 & 66 & 70 & 55 & 27.8 \\
\hline 8 & 16 & 66 & 50 & 55 & 29.6 \\
\hline 9 & 8 & 33 & 110 & 55 & 13.6 \\
\hline 10 & 8 & 33 & 90 & 55 & 15.0 \\
\hline 11 & 8 & 33 & 70 & 55 & 16.7 \\
\hline 12 & 8 & 33 & 50 & 55 & 18.6 \\
\hline 13 & 3 & 15 & 110 & 55 & 6.4 \\
\hline 14 & 3 & 15 & 90 & 55 & 7.4 \\
\hline 15 & 3 & 15 & 70 & 55 & 7.8 \\
\hline 16 & 3 & 15 & 50 & 55 & 8.7 \\
\hline 17 & 24 & 100 & 110 & 65 & 26.4 \\
\hline 18 & 24 & 100 & 90 & 65 & 29.2 \\
\hline 19 & 24 & 100 & 70 & 65 & 45.5 \\
\hline 20 & 24 & 100 & 50 & 65 & 47.9 \\
\hline 21 & 16 & 66 & 110 & 65 & 26.4 \\
\hline 22 & 16 & 66 & 90 & 65 & 26.4 \\
\hline 23 & 16 & 66 & 70 & 65 & 31.7 \\
\hline 24 & 16 & 66 & 50 & 65 & 33.8 \\
\hline 25 & 8 & 33 & 110 & 65 & 15.8 \\
\hline 26 & 8 & 33 & 90 & 65 & 17.5 \\
\hline 27 & 8 & 33 & 70 & 65 & 19.1 \\
\hline 28 & 8 & 33 & 50 & 65 & 21.4 \\
\hline 29 & 3 & 15 & 110 & 65 & 7.4 \\
\hline 30 & 3 & 15 & 90 & 65 & 8.3 \\
\hline 31 & 3 & 15 & 70 & 65 & 9.0 \\
\hline
\end{tabular}




\begin{tabular}{|r|r|r|r|r|r|}
\hline Test No & \multicolumn{1}{|c|}{$\begin{array}{c}\text { Chiller } \\
\text { Step }\end{array}$} & \multicolumn{1}{c|}{$\begin{array}{c}\text { Eoad } \\
(\%)\end{array}$} & \multicolumn{1}{c|}{$\begin{array}{c}\text { ODB } \\
\text { (oF) }\end{array}$} & $\begin{array}{c}\text { ELW } \\
\text { (oF) }\end{array}$ & $\begin{array}{c}\text { EWFR } \\
\text { (gal/min) }\end{array}$ \\
\hline 32 & 3 & 15 & 50 & 65 & 10.0 \\
\hline 33 & 8 & 33 & 75 & 70 & 19.6 \\
\hline 34 & 8 & 33 & 70 & 65 & 38.2 \\
\hline 35 & 18 & 75 & 70 & 55 & 25.0 \\
\hline 36 & 12 & 50 & 70 & 55 & 23.7 \\
\hline 37 & 6 & 25 & 55 & 55 & 15.1 \\
\hline 38 & 16 & 66 & 75 & 44 & 23.4 \\
\hline 39 & 8 & 33 & 55 & 44 & 15.6 \\
\hline 40 & 3 & 15 & 55 & 44 & 7.4 \\
\hline 41 & 3 & 15 & 110 & 55 & 6.4 \\
\hline 42 & 3 & 15 & 90 & 58 & 7.4 \\
\hline 43 & 3 & 15 & 70 & 62 & 7.8 \\
\hline 44 & 3 & 15 & 50 & 65 & 8.7 \\
\hline 45 & 6 & 25 & 110 & 55 & 11.4 \\
\hline 46 & 6 & 25 & 90 & 58 & 13.4 \\
\hline 47 & 6 & 25 & 70 & 62 & 14.7 \\
\hline 48 & 6 & 25 & 50 & 65 & 16.4 \\
\hline 49 & 13 & 55 & 90 & 65 & 25.5 \\
\hline 50 & 8 & 33 & 50 & 65 & 15.6 \\
\hline 51 & 12 & 50 & 70 & 65 & 23.7 \\
\hline 52 & 9 & 38 & 90 & 65 & 23.7 \\
\hline
\end{tabular}

EWFR: Entering water flow rate

For all tests the following data was collected at 1-minute intervals.

- Compressor discharge temperature

- Compressor discharge pressure

- Compressor suction temperature

- Compressor suction pressure

- Outdoor coil liquid temperature

- Outdoor coil liquid pressure

- Outdoor condenser fan temperature for each system

- Temperature difference across the condenser should be measured using a thermopile

- Total voltage per leg

- Total amps per leg

- Total kW

- Total kW for the two constant-speed compressors

- Total kW for the one variable-speed compressor

- Total kW for the condenser fans

- Condenser fan speed

- Variable-speed compressor speed

- Total water flow in gallon per minute (gpm) across evaporator

- Entering water temperature

- Leaving water temperature

- Condenser air inlet - approximately four locations

- Water pressure drop across evaporator for each system 
- Refrigeration mass flow rate

Calculated data:

- Calculated superheat

- Calculated subcooling

- Calculated capacity

- Calculated EER.

There are two objectives to characterize the performance of the prototype chiller: 1) generate a chiller performance map that can be used in the simulations to estimate the chiller energy consumption at various part-load conditions and 2) compare the prototype chiller performance to the ideal low-lift optimized and a conventional chiller performance.

Three versions of the chiller model were developed to produce two ideal low-lift chiller performance maps. The first performance map is for the RCP system, which includes both compressor and refrigerant-side economizer operation. The chiller model for economizer operation uses the same components as the chiller for compressor operation except that the compressor is replaced by a flow-pressure characteristic of the compressor bypass branch used during economizer operation. At each performance evaluation, the two maps are evaluated and the mode of operation (compressor or economizer) is determined by which map evaluation returns the lower $\mathrm{kW} /$ ton number.

The variable air volume (VAV) system uses an air-side economizer so only one chiller model is needed to produce a chiller performance map. However, the map has three regions corresponding to a chilled water supply temperature reset schedule, which is a function of outdoor temperature. Two-speed operation of the compressor, condenser fan and chilled water pump is simulated by performance curves derived from the variable-speed performance map. The low- and high-speed specific power curves - functions of outdoor temperature only - are obtained by evaluating the variable-speed performance map at part-load fractions of 0.5 and 1.0.

\section{Ideal Low-Lift RCP-Chiller Performance Map}

A map of chiller system input power was produced for an indoor temperature, $T_{z}$, of $72^{\circ} \mathrm{F}$ on a grid of cooling load, $Q$, and outdoor temperature, $T_{x}$. A set of input power versus cooling load curves was generated for each outdoor temperature. A bi-cubic was fit to the surface because the bi-cubic accurately represents the chiller performance surface and is compatible with most simulation programs. The bi-cubic also satisfies the need of the 24-hour look-ahead controller for computational efficiency and for a power versus load function that is smooth to at least its first derivative.

Figure 1 shows the optimal chiller system performance map for indoor temperature $T_{z}=72^{\circ} \mathrm{F}$ with outdoor temperature, $T_{x}$, ranging from $110^{\circ} \mathrm{F}$ to $50^{\circ} \mathrm{F}$ in $10^{\circ} \mathrm{F}$ increments. Note the inflections at low capacity fraction on the $50^{\circ} \mathrm{F}$ and $60^{\circ} \mathrm{F}$ outdoor temperature lines; the compressor is bypassed below these inflection points to make use of the refrigerant-side economizer. Table 3 documents the coefficients for the performance maps curves. 


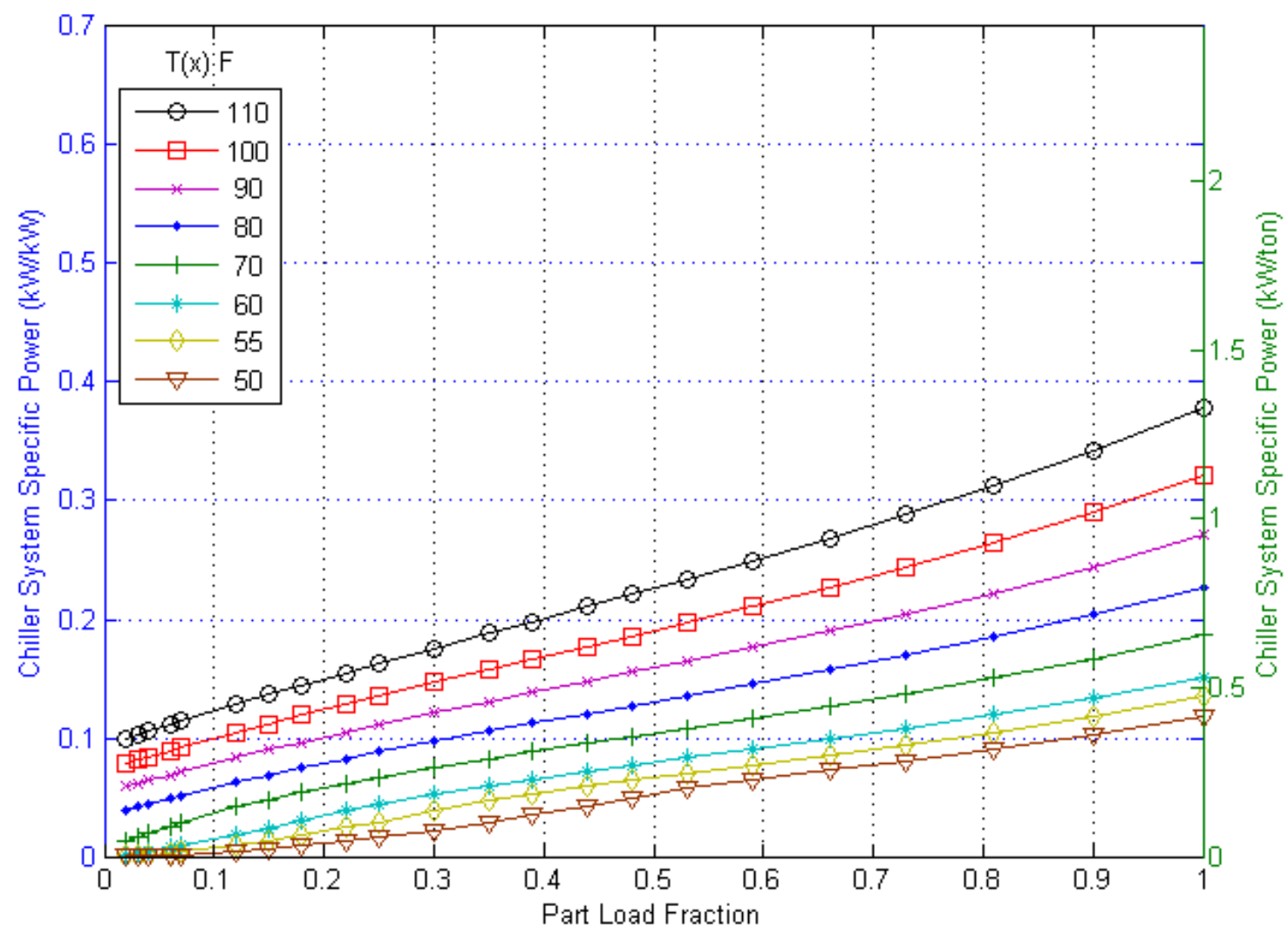

Figure 1 Ideal Low-Lift Chiller-RCP System Performance Map at $\mathrm{Tz}=72^{\circ} \mathrm{F}$ with $\mathrm{Tx}$ ranging from $110^{\circ} \mathrm{F}$ (topmost curve) to $50^{\circ} \mathrm{F}$ in $10 \mathrm{R}$ increments

Table 3 Coefficients for the Ideal Chiller Performance Map, $x=$ Outdoor Dry-Bulb Temperature in Fahrenheit, $y=$ part load fraction

\begin{tabular}{|l|r|r|r|r|}
\hline & \multicolumn{1}{|c|}{ Ideal VAV } & \multicolumn{3}{|c|}{ Ideal RCP } \\
\hline & & \multicolumn{1}{c|}{$\mathrm{x}<50^{\circ} \mathrm{F}$} & $50^{\circ} \mathrm{F}<\mathrm{x}<80^{\circ} \mathrm{F}$ & \multicolumn{1}{c|}{$\mathrm{x}>80^{\circ} \mathrm{F}$} \\
\hline constant & $-1.990 \mathrm{E}-01$ & $-2.502 \mathrm{E}-01$ & $-2.640 \mathrm{E}-01$ & $-4.326 \mathrm{E}-01$ \\
\hline $\mathrm{X}$ & $4.905 \mathrm{E}-03$ & $1.037 \mathrm{E}-02$ & $7.730 \mathrm{E}-03$ & $1.273 \mathrm{E}-02$ \\
\hline $\mathrm{y}$ & $3.190 \mathrm{E}-01$ & $1.056 \mathrm{E}-01$ & $3.961 \mathrm{E}-01$ & 0.801471605 \\
\hline $\mathrm{x} 2$ & $-3.637 \mathrm{E}-05$ & $-1.487 \mathrm{E}-04$ & $-6.947 \mathrm{E}-05$ & -0.000109547 \\
\hline $\mathrm{xy}$ & $-2.845 \mathrm{E}-03$ & $-1.003 \mathrm{E}-03$ & $-9.881 \mathrm{E}-03$ & -0.014008642 \\
\hline $\mathrm{y} 2$ & $-2.729 \mathrm{E}-01$ & $-8.095 \mathrm{E}-02$ & $-1.478 \mathrm{E}-01$ & -0.432111111 \\
\hline $\mathrm{x} 3$ & $1.452 \mathrm{E}-07$ & $8.642 \mathrm{E}-07$ & $3.378 \mathrm{E}-07$ & $3.82373 \mathrm{E}-07$ \\
\hline $\mathrm{x} 2 \mathrm{y}$ & $2.461 \mathrm{E}-05$ & $1.843 \mathrm{E}-05$ & $8.704 \mathrm{E}-05$ & $8.08642 \mathrm{E}-05$ \\
\hline $\mathrm{xy} 2$ & $1.225 \mathrm{E}-03$ & $3.983 \mathrm{E}-04$ & $1.400 \mathrm{E}-03$ & 0.003972222 \\
\hline $\mathrm{y} 3$ & $1.183 \mathrm{E}-01$ & $4.980 \mathrm{E}-02$ & $5.180 \mathrm{E}-02$ & 0.1 \\
\hline
\end{tabular}




\section{Ideal Low-Lift VAV-Chiller Performance Map}

The chiller performance model for all-air (Constant Volume and VAV) applications differs from an RCS-plus-DOAS application with respect to chilled water supply temperature. The chilled water supply temperature reset schedule for all-air systems provided in Appendix G of ASHRAE 90.1-2000 was adopted, as shown in Figure 2. Because the chilled water supply temperature is a function of outdoor dry-bulb temperature, the chiller performance map may still be represented as a black-box function of specific power, $Q$, and $T_{X}$, as shown in Figure 3. Two points should be noted: 1) the capacity of the cooling coil is assumed to be adequate, i.e., with the reset schedule of Figure 2, capacity is constrained by chilled water flow rate rather than coil proportionality constant, UA, and 2) for the all-air system, supply fan power is not included in the chiller coefficient of performance (COP) numbers represented in Figure 3. A separate model that relates fan power to hourly cooling and ventilation loads is used to compute annual fan energy.

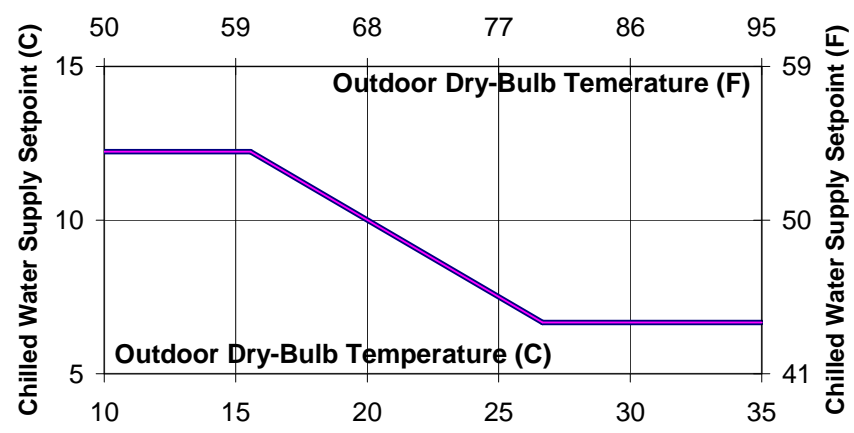

Figure 2 Chilled Water Reset Schedule (Appendix G, ASHRAE 90.1-2000) 


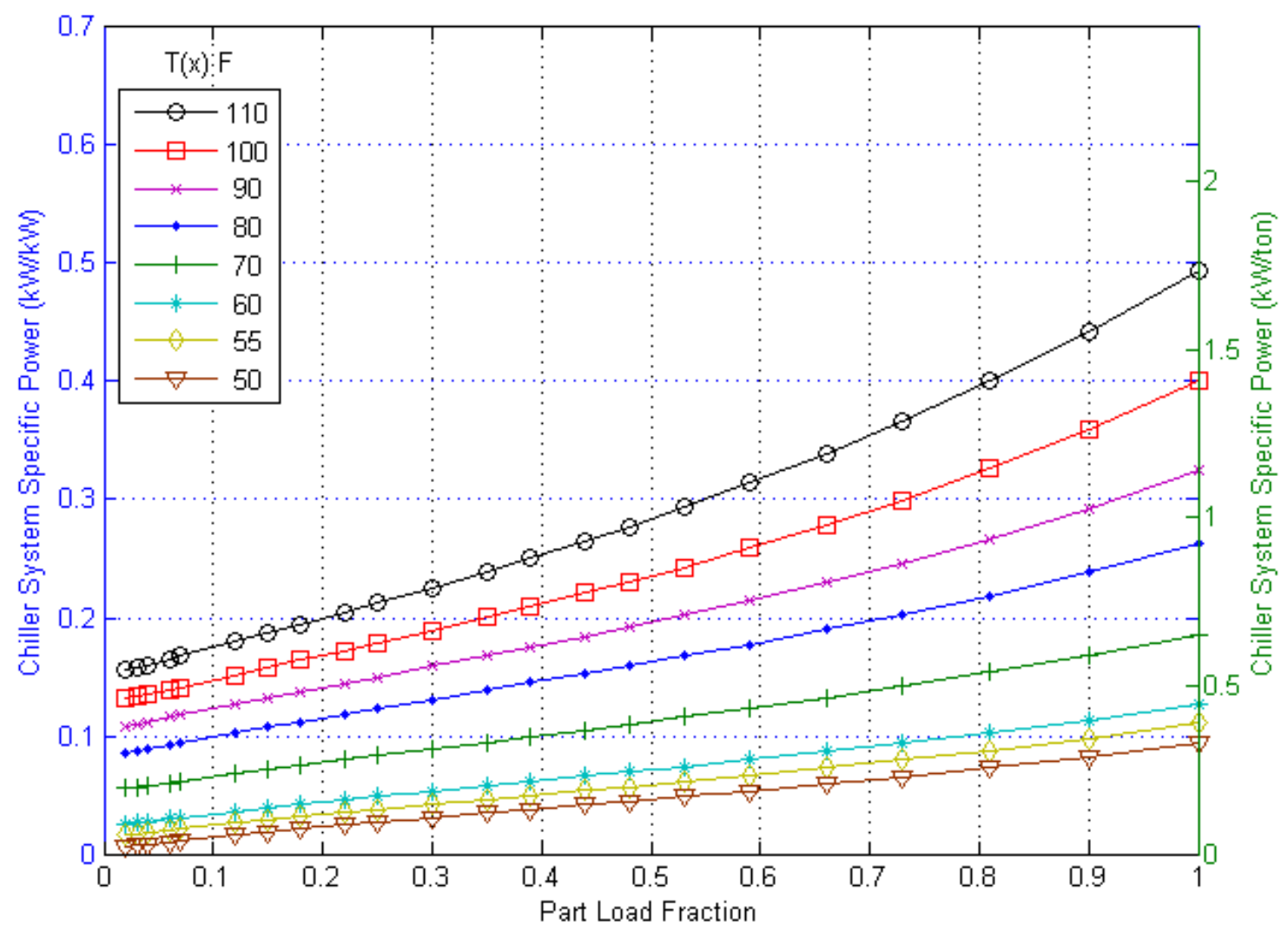

Figure 3 Ideal Low-Lift VAV-Chiller Performance Map with the Chilled Water Reset Schedule Shown in Figure 2

\section{Prototype Low-Lift RCP-Chiller Chiller Performance Map}

Figure 4 shows the prototype low-lift chiller system performance map for indoor temperature $T_{z}$ $=72^{\circ} \mathrm{F}$ with outdoor temperature, $T_{x}$, ranging from $110^{\circ} \mathrm{F}$ to $50^{\circ} \mathrm{F}$ in $10^{\circ} \mathrm{F}$ increments. Note the inflections at low capacity fraction on the $50^{\circ} \mathrm{F}$ and $60^{\circ} \mathrm{F}$ outdoor temperature lines; the compressor is bypassed below these inflection points to make use of the refrigerant-side economizer. Table 4 documents the coefficients for the performance maps curves. 


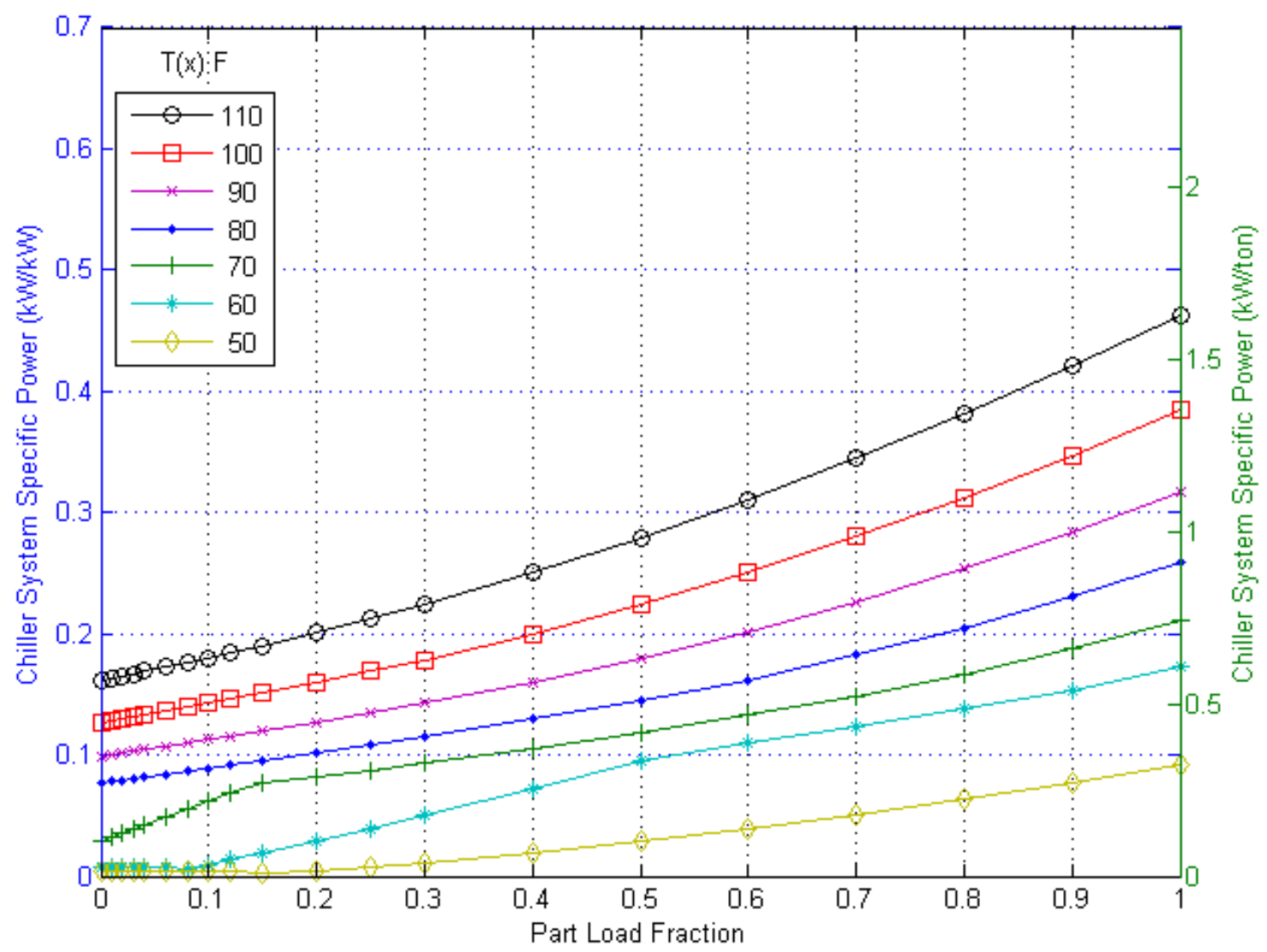

Figure 4 Prototype Low-Lift RCP-Chiller System Performance Map at $T_{z}=72^{\circ} F$ with $T_{x}$ ranging from $110^{\circ} \mathrm{F}$ (topmost curve) to $50^{\circ} \mathrm{F}$ in $10 \mathrm{R}$ increments

Table 4 Prototype Chiller Performance Map Coefficient, $x=$ Outdoor Dry-Bulb Temperature in Fahrenheit, $y=$ part load fraction, $z=C h i l l e d$ Water Temperature in Fahrenheit

\begin{tabular}{|l|r|r|r|}
\hline & \multicolumn{2}{|l|}{ Prototype RCP } & Prototype VAV \\
\hline & \multicolumn{1}{|c|}{$\mathrm{x}>=\mathrm{z}^{*}$} & $\mathrm{x}<\mathrm{z}$ & \\
\hline constant & $4.156 \mathrm{E}-01$ & $6.485 \mathrm{E}-01$ & $4.156 \mathrm{E}-01$ \\
\hline $\mathrm{x}$ & $1.229 \mathrm{E}-03$ & $-2.356 \mathrm{E}-02$ & $1.229 \mathrm{E}-03$ \\
\hline $\mathrm{z}$ & $-1.437 \mathrm{E}-02$ & & $-1.437 \mathrm{E}-02$ \\
\hline $\mathrm{y}$ & $3.282 \mathrm{E}-02$ & $-6.879 \mathrm{E}-01$ & $3.282 \mathrm{E}-02$ \\
\hline $\mathrm{x} 2$ & $5.015 \mathrm{E}-05$ & $2.101 \mathrm{E}-04$ & $5.015 \mathrm{E}-05$ \\
\hline $\mathrm{z} 2$ & $1.832 \mathrm{E}-04$ & & $1.832 \mathrm{E}-04$ \\
\hline $\mathrm{y} 2$ & $5.603 \mathrm{E}-02$ & $6.370 \mathrm{E}-02$ & $5.603 \mathrm{E}-02$ \\
\hline $\mathrm{xz}$ & $-1.150 \mathrm{E}-04$ & & $-1.150 \mathrm{E}-04$ \\
\hline $\mathrm{xy}$ & $2.946 \mathrm{E}-03$ & $1.442 \mathrm{E}-02$ & $2.946 \mathrm{E}-03$ \\
\hline $\mathrm{yz}$ & $-2.441 \mathrm{E}-03$ & & $-2.441 \mathrm{E}-03$ \\
\hline
\end{tabular}

*for RCP $\mathrm{z}=75-\mathrm{y} x 15$; for $\operatorname{VAV~} \mathrm{z}=44$ if $\mathrm{x}>=80^{\circ} \mathrm{F}, \mathrm{z}=44+0.5 \mathrm{x}(80-\mathrm{x})$ if $60^{\circ} \mathrm{F}>\mathrm{x}<80^{\circ} \mathrm{F}, \mathrm{z}=$ 54 if $\mathrm{x}<=60^{\circ} \mathrm{F}$; 


\section{Prototype Low-Lift VAV-Chiller Performance Map}

The prototype low-lift chiller performance model for all-air (CV and VAV) applications differs from an RCS-plus-DOAS application with respect to chilled water supply temperature. Because the chilled water supply temperature is a function of outdoor dry-bulb temperature, the chiller performance map may still be represented as a black-box function of specific power, $Q$, and $T_{X}$ as shown in Figure 5.

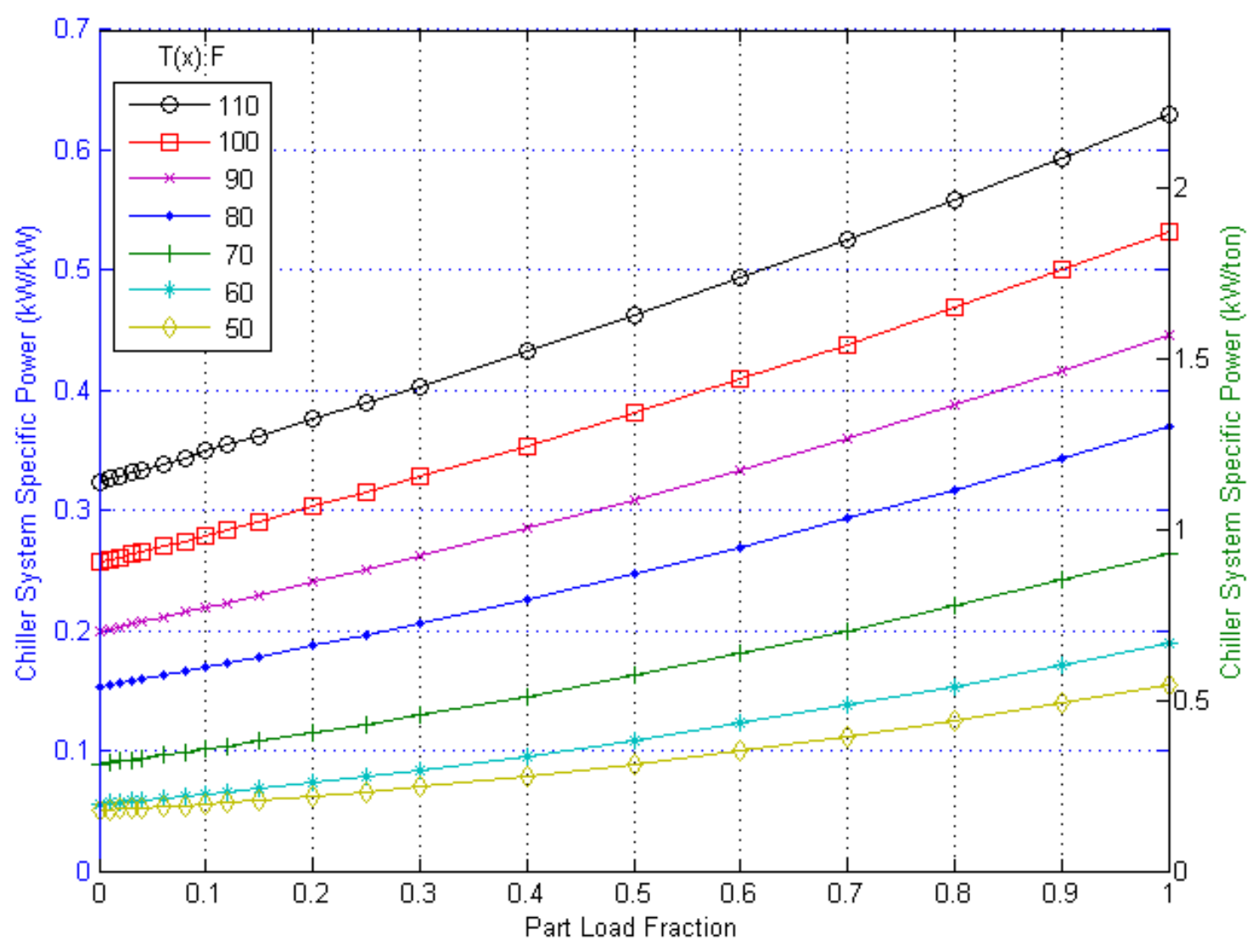

Figure 5 Prototype Low-Lift VAV-Chiller Performance Map with the Chilled Water Reset Schedule Shown in Figure 2

\section{Conventional Chiller Performance Map}

Figure 6 shows the performance of a typical conventional single-speed air-cooled chiller.

Although at full-load the conventional chiller performance is comparable to prototype low-lift or the ideal low-lift chiller, its performance below 50\% part-load is significantly higher that the variable-speed low-lift chiller options. 


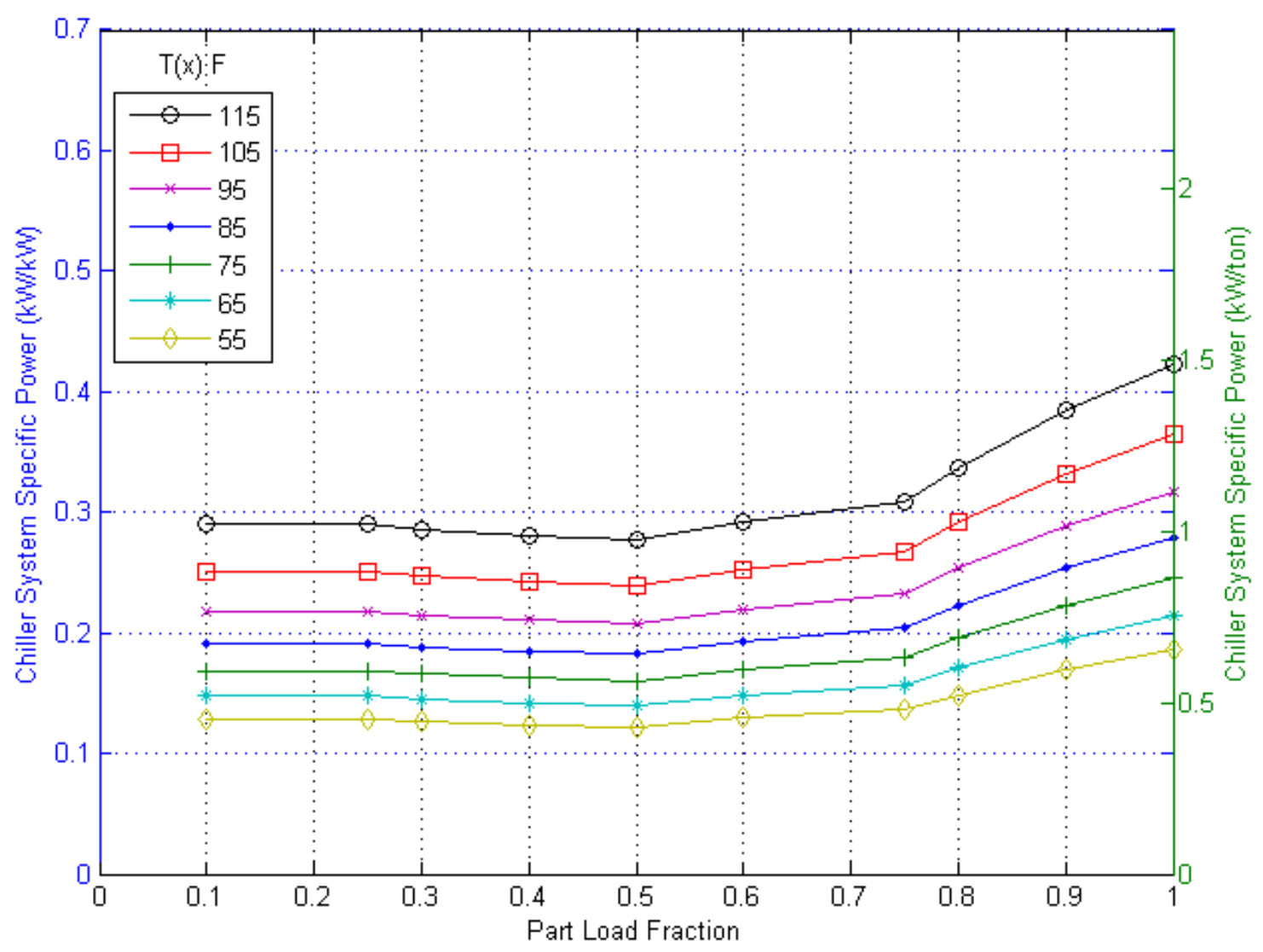

Figure 6 Performance Map of a Typical Conventional Air-Cooled Chiller

\section{Comparison of Prototype Chiller Performance to Ideal Low-Lift Chiller}

The RCP-Chiller performance map for the prototype chiller is compared to the ideal low-lift RCP-chiller performance in Figure 7.

\section{Comparison of Prototype Chiller Performance to Conventional Chiller}

The RCP-Chiller performance map for the prototype chiller is compared to the ideal low-lift RCP-chiller performance in Figure 8. 

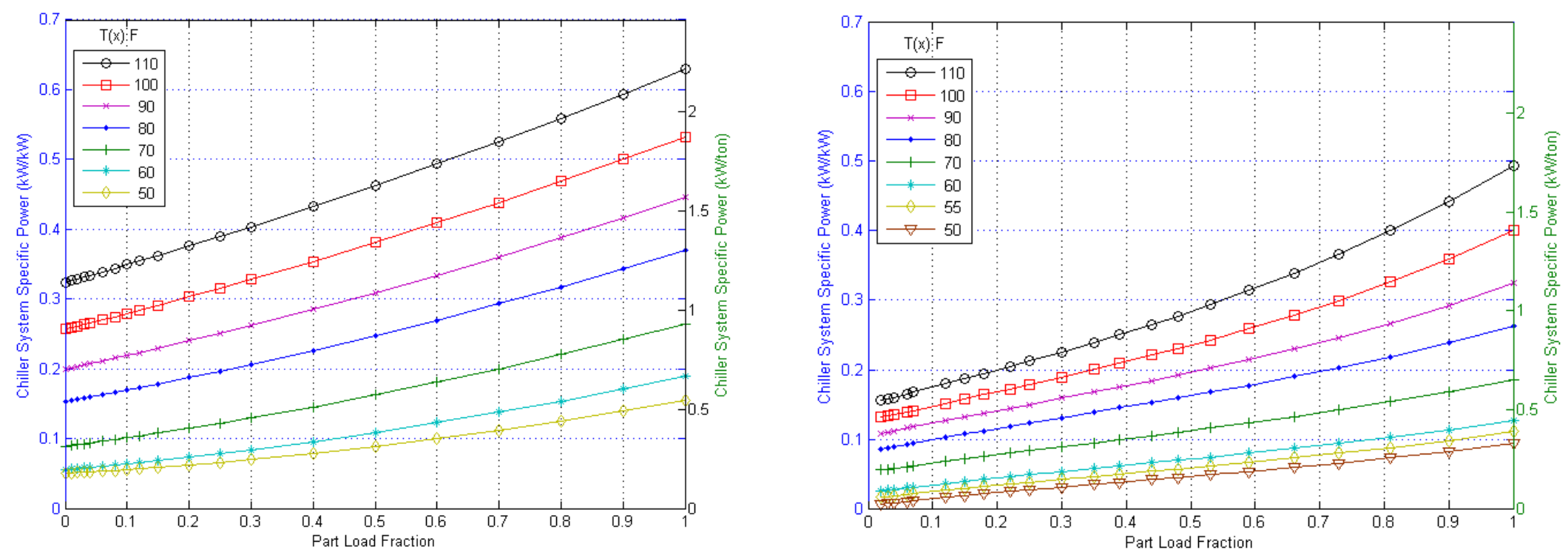

Figure 7 Comparison of Prototype Low-Lift VAV-Chiller System Performance Map (left) at $\mathrm{Tz}=72^{\circ} \mathrm{F}$ with $\mathrm{Tx}$ ranging from $110^{\circ} \mathrm{F}$ (topmost curve) to $50^{\circ} \mathrm{F}$ in $10 \mathrm{R}$ increments with Ideal Low-Lift VAV-Chiller Performance (right) 

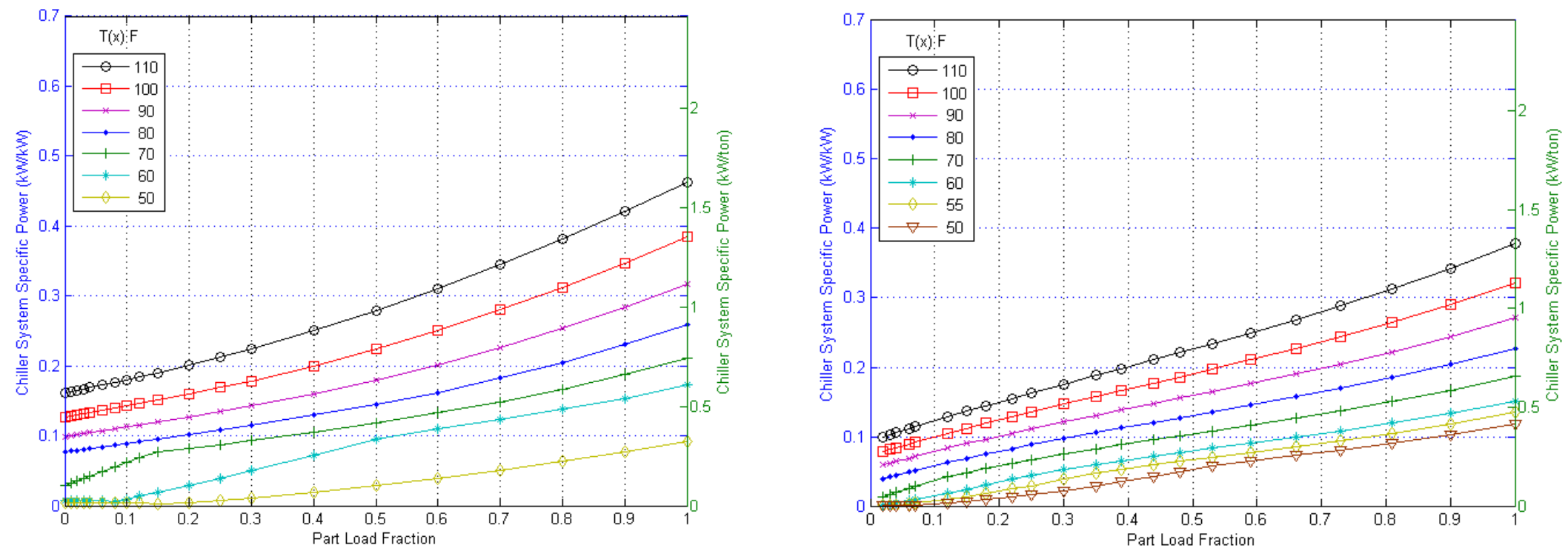

Figure 8 Comparison of Prototype Low-Lift RCP-Chiller System Performance Map (left) at $\mathrm{Tz}=72^{\circ} \mathrm{F}$ with Tx ranging from $110^{\circ} \mathrm{F}$ (topmost curve) to $50^{\circ} \mathrm{F}$ in $10 \mathrm{R}$ increments with Ideal Low-Lift RCP-Chiller Performance (right) 


\section{Commercial Building Benchmarks}

To estimate the Pacific Northwest Regional energy savings potential, energy use for a number of prototypical buildings for which this LLCS applies has to be simulated and scaled to a regional level. The U.S. Department of Energy (DOE) and the American Society of Heating, Refrigeration and Air Condition (ASHRAE) have defined prototypical buildings, also referred to as Commercial Building Benchmarks ${ }^{11}$ (Torcellini et al. 2008). The ASHRAE prototypes are derived from the DOE prototypes and reflect minor changes made by the ASHRAE 90.1 committee. In this report, we will refer to these as ASHRAE-Reviewed Benchmarks.

A combination of benchmarks (EnergyPlus input files) from DOE and ASHRAE was used for this work. In this section, the two sets of templates are first introduced and then the sources of the templates used in this study are identified. Although some minor changes were made to EnergyPlus input files, the focus of this study was not to develop the EnergyPlus inputs or to validate the EnergyPlus models. Validation of these models was done as part of other DOE and ASHRAE work.

\section{Commercial Building Benchmarks}

The DOE Benchmark building models are comprised of two parts - the building models consisting of the energy modeling descriptions and the regional sector model consisting of the sets of building types and locations, and weighting factors. Because these models are regularly updated, in this report the discussion pertains to version 2.2 of the benchmarks. These cover 15 building types and 21 U.S. locations. Although as part of the DOE benchmark development effort, building weights for each building type were developed, for this study, PNNL developed its own weights from the McGraw-Hill Construction Projects Starts Database because the weights developed for benchmark were for the nation and not for the Pacific Northwest.

Table 5 lists the 15 benchmark building prototypes along with the CBECS (Commercial Buildings End Use Consumption Survey) Principal Building Activity (PBA) and CBECS Specific Building Activity categories represented and used in the development of each benchmark building type. The CBECS Specific Building Activities used in the development of and represented by these 15 benchmark building types represent 3,279 buildings (out of a total of 5,215 CBECS buildings) from the full CBECS data set. The selected set of building types represents 44 billion $\mathrm{ft}^{2}$ or $62 \%$ of the total weighted floor area in the survey. They also represent $65 \%$ of the total energy consumption for commercial buildings in the survey.

\footnotetext{
${ }^{11} \underline{\mathrm{http}} / / \mathrm{www} 1$. eere.energy.gov/buildings/commercial_initiative/benchmark_models.html
} 
Table 5 Categorization of 2003 CBECS Data for Benchmark Buildings

\begin{tabular}{|c|c|c|c|c|}
\hline Number & Name & $\begin{array}{c}\text { Floor } \\
\text { Area }\left(\mathrm{ft}^{2}\right)\end{array}$ & $\begin{array}{c}2003 \text { CBECS } \\
\text { Principal Building } \\
\text { Activity }\end{array}$ & $\begin{array}{c}2003 \text { CBECS More Specific Building } \\
\text { Activity }\end{array}$ \\
\hline 1 & Large Office & 460,240 & Office & $\begin{array}{c}\text { Administrative/professional office; } \\
\text { bank/other financial; government } \\
\text { office; medical office (non-diagnostic); } \\
\text { mixed-use office; other office; }\end{array}$ \\
\hline 2 & Medium Office & 53,630 & Office & $\begin{array}{l}\text { Administrative/professional office; } \\
\text { bank/other financial; government } \\
\text { office; medical office (non-diagnostic); } \\
\text { mixed-use office; other office; }\end{array}$ \\
\hline 3 & Small Office & 5,500 & Office & $\begin{array}{c}\text { Administrative/professional office; } \\
\text { bank/other financial; government } \\
\text { office; medical office (non-diagnostic); } \\
\text { mixed-use office; other office; }\end{array}$ \\
\hline 4 & Warehouse & 52,050 & $\begin{array}{l}\text { Non-refrigerated } \\
\text { warehouse }\end{array}$ & $\begin{array}{l}\text { Distribution/shipping center; non- } \\
\text { refrigerated; warehouse }\end{array}$ \\
\hline 5 & $\begin{array}{c}\text { Stand-alone } \\
\text { Retail }\end{array}$ & 41,790 & $\begin{array}{l}\text { Retail other than } \\
\text { mall }\end{array}$ & Retail store \\
\hline 6 & Strip Mall & 24,010 & $\begin{array}{l}\text { Strip shopping } \\
\text { mall' }\end{array}$ & Strip shopping mall \\
\hline 7 & Primary School & 73,960 & Education & Elementary/middle school \\
\hline 8 & $\begin{array}{l}\text { Secondary } \\
\text { School }\end{array}$ & 210,890 & Education & High school \\
\hline 9 & Supermarket & 45,000 & Food sales & Grocery store/food market \\
\hline 10 & Fast Food & 2,500 & Food service & Fast food \\
\hline 11 & Restaurant & 5,500 & Food service & Restaurant/cafeteria \\
\hline 12 & Hospital & 201,250 & Public assembly & Hospital/inpatient health \\
\hline 13 & $\begin{array}{l}\text { Outpatient } \\
\text { Healthcare }\end{array}$ & 10,000 & $\begin{array}{l}\text { Outpatient health } \\
\text { care }\end{array}$ & $\begin{array}{l}\text { Medical office (diagnostic); clinic/other } \\
\text { outpatient health }\end{array}$ \\
\hline 14 & Small Hotel & 21,080 & Lodging & Motel or inn \\
\hline 15 & Large Hotel & 100,820 & Lodging & Hotel \\
\hline
\end{tabular}

\section{Building Prototypes and Climate Locations Used for Low-Lift Energy Savings Analysis}

Motel, fast food, and restaurant buildings are not included in this analysis because they are generally not suitable for TES applications, which is one of the components in the LLCS. For motels, this is largely the result of the combination of 24-hour occupancy, which prohibits use of intrinsic building mass in combination with the use of HVAC equipment that is generally not suitable for use in conjunction with discrete TES.

Fast food and restaurants are not suitable for three reasons: high ventilation rates and internal gains relative to building size both of which limit the value of intrinsic building mass; and finally, because the ability to use DOAS equipment with energy recovery is complicated by the high ventilation requirements for kitchen hoods. The public assembly (movie theater/cinema) building type is also not used, primarily because of its variability in occupant and ventilation 
loads. ${ }^{12}$ The remainder of the non-residential building types will be included in the energy savings analysis.

PNNL is developing a set of prototypes in EnergyPlus by modifying the DOE Benchmark, developing additional prototypes and incorporating information from Advanced Energy Design Guide Prototypes ${ }^{13}$ to be used for ASHRAE 90.1 work. These prototypes (referred to as ASHRAE-modified prototypes) incorporate the review comments from both PNNL and the ASHRAE 90.1 simulation working group.

For all but three building types, PNNL chose to use the ASHRAE-modified benchmarks for this analysis, in large measure because of the greater review provided by industry members and because these modifications will eventually be incorporated into the next iteration of the DOE benchmarks. For three building types, standalone retail, supermarket and outpatient buildings, PNNL used the original DOE benchmarks because no ASHRAE benchmarks exist at this time. Table 6 highlights additional changes made to the benchmarks by PNNL for this analysis.

Table 7 summarizes the city locations selected for this analysis. The 21 climate locations were selected by mapping each county in the Pacific Northwest to the TMY2 (typical meteorological year version 2) weather location that best approximated the climate in that county.

Table 8 lists the major features of the commercial building benchmark used in the study to estimate the energy savings for the various combinations of the LLCS (referred to as "low-lift" prototypes.)

\footnotetext{
${ }^{12}$ We do not rule out that future developments in occupancy forecasting may make some theater applications of LLCS attractive and feasible.

${ }^{13} \mathrm{http}: / /$ www.ashrae.org/technology/page/938
} 
Table 6 Modifications to the DOE and ASHRAE-Modified Benchmarks Made by PNNL for Analysis of Low-Lift Cooling

\begin{tabular}{|l|l|l|}
\hline \multicolumn{1}{|c|}{$\begin{array}{c}\text { Building } \\
\text { Prototype }\end{array}$} & \multicolumn{1}{|c|}{ Benchmark Model } & \multicolumn{1}{c|}{ Changes for Low Lift } \\
\hline Large Office & ASHRAE 30\% June 2008 model & $\begin{array}{l}\text { Removed latent heat to the occupied space } \\
\text { as a result of service hot water } \\
\text { consumption. }\end{array}$ \\
\hline Medium Office & ASHRAE 30\% June 2008 model & $\begin{array}{l}\text { Removed latent heat to the occupied space } \\
\text { as a result of service hot water } \\
\text { consumption. }\end{array}$ \\
\hline Small Office & ASHRAE 30\% June 2008 model & $\begin{array}{l}\text { Removed latent heat to the occupied space } \\
\text { as a result of service hot water } \\
\text { consumption. }\end{array}$ \\
\hline Hospital & ASHRAE 30\% June 2008 model & $\begin{array}{l}\text { Removed latent heat to the occupied space } \\
\text { as a result of service hot water } \\
\text { consumption. } \\
\text { Removed exhaust fan when ERV }\end{array}$ \\
\hline $\begin{array}{l}\text { Outpatient } \\
\text { Healthcare }\end{array}$ & DOE benchmark \\
\hline $\begin{array}{l}\text { Standalone } \\
\text { Retail }\end{array}$ & ASHRAE 30\% June 2008 model & $\begin{array}{l}\text { Removed latent heat to the occupied space } \\
\text { as a result of service hot water } \\
\text { consumption. }\end{array}$ \\
\hline Strip Mall & ASHRAE 30\% June 2008 model & No changes made. \\
\hline Primary School & ASHRAE 30\% June 2008 model & NA \\
\hline $\begin{array}{l}\text { Secondary } \\
\text { School }\end{array}$ & ASHRAE 30\% June 2008 model & $\begin{array}{l}\text { Remod exhaust fan when ERV } \\
\text { Removed exhaust fan when ERV }{ }^{14} \text { is used. }\end{array}$ \\
\hline Supermarket & DOE benchmark model 3.0 & $\begin{array}{l}\text { Removed latent heat to the occupied space } \\
\text { as a result of service hot water } \\
\text { consumption. } \\
\text { Removed exhaust fan when ERV }{ }^{14} \text { is used. }\end{array}$ \\
\hline Large Hotel & ASHRAE 30\% June 2008 model & $\begin{array}{l}\text { Removed latent heat to the occupied space } \\
\text { as a result of service hot water } \\
\text { consumption. } \\
\text { Removed exhaust fan when ERV }{ }^{14} \text { is used. }\end{array}$ \\
\hline Warehouse & ASHRAE 30\% June 2008 model & NA \\
\hline & &
\end{tabular}

${ }^{14}$ This is a limitation of EnergyPlus. 
Table 7 Selected Commercial Building Benchmark Locations for the Pacific Northwest

\begin{tabular}{|c|c|}
\hline Number & Representative City \\
\hline 1 & Pendleton, OR \\
\hline 2 & Spokane, WA \\
\hline 3 & Missoula, MT \\
\hline 4 & Boise, ID \\
\hline 5 & Pocatello, ID \\
\hline 6 & Helena, MT \\
\hline 7 & Astoria, OR \\
\hline 8 & Salem, OR \\
\hline 9 & Eugene, OR \\
\hline 10 & North Bend, OR \\
\hline 11 & Arcata, CA \\
\hline 12 & Medford, OR \\
\hline 13 & Redmond, OR \\
\hline 14 & Portland, OR \\
\hline 15 & Yakima, WA \\
\hline 16 & Burns, OR \\
\hline 17 & Olympia, WA \\
\hline 18 & Quillayuta, WA \\
\hline 19 & Seattle, WA \\
\hline 20 & Kalispell, MT \\
\hline 21 & Cut Bank, MT \\
\hline
\end{tabular}


Table 8 Low-Lift Building Prototypes

\begin{tabular}{|c|c|c|c|c|c|c|c|c|c|}
\hline \multirow{2}{*}{$\begin{array}{l}\text { Building } \\
\text { Type }\end{array}$} & \multirow{2}{*}{$\begin{array}{l}\text { Building } \\
\text { Prototype }\end{array}$} & \multirow{2}{*}{$\begin{array}{l}\text { Floor Area } \\
\left(\mathrm{ft}^{2}\right)\end{array}$} & \multicolumn{3}{|c|}{ Envelope } & \multicolumn{3}{|c|}{ HVAC } & \multirow{2}{*}{ Model Source } \\
\hline & & & Roof & Wall & $W W R^{a}$ & Heating & Cooling & System & \\
\hline \multirow{3}{*}{ Office } & Small Office & 5,500 & Attic & $\begin{array}{l}\text { Wood } \\
\text { Frame }\end{array}$ & $20 \%$ & $\begin{array}{l}\text { Gas } \\
\text { Furnace }\end{array}$ & Unitary DX & $\mathrm{PSZ}^{\mathrm{C}}$ & $\begin{array}{l}\text { ASHRAE- } \\
\text { modified } \\
\text { benchmark }\end{array}$ \\
\hline & Medium Office & 53,627 & $\begin{array}{l}\text { Insulation entirely } \\
\text { above deck }\end{array}$ & $\begin{array}{l}\text { Steel } \\
\text { Frame }\end{array}$ & $33 \%$ & $\begin{array}{c}\text { Gas } \\
\text { Furnace }\end{array}$ & Unitary DX & $\begin{array}{l}\mathrm{VAV}^{\mathrm{d}}+ \\
\text { electric } \\
\text { reheat }\end{array}$ & $\begin{array}{l}\text { ASHRAE- } \\
\text { modified } \\
\text { benchmark }\end{array}$ \\
\hline & Large Office & 498,588 & $\begin{array}{l}\text { Insulation entirely } \\
\text { above deck }\end{array}$ & Mass & $40 \%$ & $\begin{array}{l}\text { Gas } \\
\text { Boiler }\end{array}$ & $\begin{array}{l}\text { Water } \\
\text { Cooled } \\
\text { Chiller }\end{array}$ & $\begin{array}{l}\text { VAV + hot } \\
\text { water reheat }\end{array}$ & $\begin{array}{l}\text { modified DOE } \\
\text { benchmark }\end{array}$ \\
\hline \multirow[b]{2}{*}{ Mercantile } & $\begin{array}{l}\text { Stand-alone } \\
\text { Retail }\end{array}$ & 24,692 & $\begin{array}{l}\text { Insulation entirely } \\
\text { above deck }\end{array}$ & Mass & $40 \%{ }^{\mathrm{e}}$ & $\begin{array}{c}\text { Gas } \\
\text { Furnace }\end{array}$ & Unitary DX & $P S Z^{d}$ & DOE benchmark \\
\hline & Strip Mall & 22,500 & $\begin{array}{c}\text { Insulation entirely } \\
\text { above deck }\end{array}$ & $\begin{array}{c}\text { Steel } \\
\text { Frame }\end{array}$ & $45 \%{ }^{f}$ & $\begin{array}{c}\text { Gas } \\
\text { Furnace }\end{array}$ & Unitary DX & PSZ & $\begin{array}{l}\text { Modified DOE } \\
\text { benchmark }\end{array}$ \\
\hline \multirow{2}{*}{ School } & Primary school & 73,960 & $\begin{array}{l}\text { Insulation entirely } \\
\text { above deck }\end{array}$ & $\begin{array}{l}\text { Steel } \\
\text { Frame }\end{array}$ & $35 \%$ & $\begin{array}{l}\text { Gas } \\
\text { Boiler }\end{array}$ & Unitary DX & $\begin{array}{l}\text { VAV + hot } \\
\text { water reheat; } \\
\text { PSZ (kitchen } \\
\text { and gym) }\end{array}$ & $\begin{array}{l}\text { Modified DOE } \\
\text { benchmark }\end{array}$ \\
\hline & $\begin{array}{l}\text { Secondary } \\
\text { school }\end{array}$ & 210,886 & $\begin{array}{l}\text { Insulation entirely } \\
\text { above deck }\end{array}$ & $\begin{array}{l}\text { Steel } \\
\text { Frame }\end{array}$ & $35 \%$ & $\begin{array}{l}\text { Gas } \\
\text { Boiler }\end{array}$ & $\begin{array}{l}\text { Water } \\
\text { Cooled } \\
\text { Chiller }\end{array}$ & $\begin{array}{l}\text { VAV + hot } \\
\text { water reheat; } \\
\text { PSZ (kitchen } \\
\text { and gym) }\end{array}$ & $\begin{array}{l}\text { Modified DOE } \\
\text { benchmark }\end{array}$ \\
\hline Food Sales & Supermarket & 45,000 & $\begin{array}{c}\text { Insulation entirely } \\
\text { above deck }\end{array}$ & Mass & $14 \%$ & $\begin{array}{c}\text { Gas } \\
\text { Furnace }\end{array}$ & Unitary DX & PSZ & DOE benchmark \\
\hline \multirow[b]{2}{*}{ Health Care } & $\begin{array}{l}\text { Outpatient health } \\
\text { care }\end{array}$ & 10,005 & Attic & $\begin{array}{l}\text { Steel } \\
\text { Frame }\end{array}$ & $15 \%$ & $\begin{array}{c}\text { Gas } \\
\text { Furnace }\end{array}$ & Unitary DX & PSZ & DOE benchmark \\
\hline & Hospital & 241,501 & $\begin{array}{l}\text { Insulation entirely } \\
\text { above deck }\end{array}$ & Mass & $14 \%$ & $\begin{array}{l}\text { Gas } \\
\text { Boiler }\end{array}$ & $\begin{array}{l}\text { Water } \\
\text { Cooled } \\
\text { Chiller }\end{array}$ & $\begin{array}{l}\mathrm{VAV}+\text { hot } \\
\text { water reheat }\end{array}$ & $\begin{array}{l}\text { Modified DOE } \\
\text { benchmark }\end{array}$ \\
\hline Lodging & Large hotel & 100,816 & $\begin{array}{l}\text { Insulation entirely } \\
\text { above deck }\end{array}$ & Mass & $22 \%$ & $\begin{array}{l}\text { Gas } \\
\text { Boiler }\end{array}$ & $\begin{array}{l}\text { Water } \\
\text { Cooled } \\
\text { Chiller }\end{array}$ & $\begin{array}{l}\text { VAV + hot } \\
\text { water reheat }\end{array}$ & $\begin{array}{l}\text { Modified DOE } \\
\text { benchmark }\end{array}$ \\
\hline Warehouse & $\begin{array}{l}\text { Non-refrigerated } \\
\text { warehouse }\end{array}$ & 52,045 & $\begin{array}{c}\text { Insulation entirely } \\
\text { above deck }\end{array}$ & Mass & $<10 \%$ & $\begin{array}{c}\text { Gas } \\
\text { Furnace }\end{array}$ & Unitary DX & $\begin{array}{l}\text { PSZ and unit } \\
\text { heater }\end{array}$ & $\begin{array}{l}\text { Modified DOE } \\
\text { benchmark }\end{array}$ \\
\hline
\end{tabular}

a: WWR - window wall ratio; b: DX - direct expansion; c: PSZ - packaged single zone; d: VAV - variable air volume;

e: $40 \%$ on primary front wall surface, no fenestration on other walls; f: $45 \%$ on primary front wall surface, no fenestration on other walls; 


\section{Market Assessment of Low-Lift Cooling System}

An assessment of the potential market for LLCS was performed by Navigant Consulting Inc. (NCI) under a subcontract to PNNL. The market assessment, primarily focused to the Pacific Northwest region, consisted of four steps: A review of the proposed technology and models, identification of potential benefits and barriers to market penetration, validation of those benefits and barriers through surveys and discussions with stakeholders, and recommendation of initiatives that BPA/DOE can take to accelerate market adoption of the proposed low-lift solutions.

The following subsection was drafted by NCI and it summarizes the findings from the market assessment.

\section{NCI Summary of Market Assessment}

An earlier study was conducted on LLCS that focused on identifying technical and market barriers for the overall new construction market in the U.S. (Katipamula et al. 2010). This study focuses on states in the Pacific Northwest region that fall within BPA's territory, such as Washington, Oregon, Idaho, and Montana. Table 9 compares these Pacific Northwest states to other U.S. states based on relevant LLCS market characteristics. This comparison highlights the low cost of energy, low cooling demand, and low emissions of the Pacific Northwest region relative to other U.S. states and suggests that other U.S. regions may be better suited for LLCS technologies.

\section{Approach}

This study assessed the market potential for low-lift base-load cooling technology in the Pacific Northwest new construction market over the next 20 years. As part of this assessment, NCI identified barriers preventing adoption and recommended strategies for overcoming these barriers. After conducting background research to better understand regional characteristics, NCI interviewed 11 stakeholders with a variety of backgrounds and experience working across the Pacific Northwest. Table 10 lists these stakeholders by category and major office location. While most of the office locations only list one state, many of the stakeholders also had extensive experience working on projects in other parts of the Pacific Northwest.

The stakeholders listed in Table 10 were asked a number of questions regarding regional barriers, customer acceptance levels of technology, customer demographic, acceptable paybacks, and technology purchase decisions. A copy of the survey can be found in Appendix A (Appendix: Market Assessment Supporting Material). NCI then synthesized results from these interviews and other research in addition to developing recommendations on how to best increase market adoption in the Pacific Northwest. 
Table 9 State Rankings for Key Market Attributes Associated with Low Lift Cooling Applications

\begin{tabular}{|c|c|c|c|c|}
\hline State & Energy Costs & $\begin{array}{l}\text { Energy Efficiency } \\
\text { Program Support }\end{array}$ & $\begin{array}{l}\text { Cooling } \\
\text { Demand }\end{array}$ & 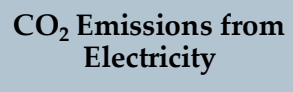 \\
\hline California & 0 & $\bullet$ & $\odot$ & $\odot$ \\
\hline New York & 0 & - & $\odot$ & $\odot$ \\
\hline Texas & $\odot$ & $\odot$ & 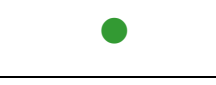 & $\bullet$ \\
\hline Oregon & O & $\bullet$ & O & $\mathrm{O}$ \\
\hline Washington & O & $\bullet$ & $\bigcirc$ & $\bigcirc$ \\
\hline Idaho & $\mathrm{O}$ & $\odot$ & O & O \\
\hline Montana & O & 0 & 0 & O \\
\hline Sources & $\begin{array}{l}\text { EIA Retail Price of } \\
\text { Electricity }\end{array}$ & $\begin{array}{l}\text { ACEEE } 2008 \text { State } \\
\text { Energy Efficiency } \\
\text { Scorecard }\end{array}$ & Weather Map & $\begin{array}{l}\text { EIA State Energy } \\
\text { Profiles }\end{array}$ \\
\hline & & & \multicolumn{2}{|c|}{ Low $\bigcirc$ Medium $\odot$} \\
\hline
\end{tabular}

Table 10 Stakeholder Interview List

\begin{tabular}{|c|c|c|}
\hline \multicolumn{3}{|r|}{ Interviewee List } \\
\hline Stakeholder & Office Location(s) & Organization, Position \\
\hline \multirow[b]{2}{*}{ Architect } & Montana & CTAArchitect, Architect \\
\hline & Washington & CTA Architect, Architect \\
\hline \multirow[b]{2}{*}{ Building Owner } & Oregon & State of Oregon, DAS Sustainability Coordinator \\
\hline & $\begin{array}{l}\text { Washington } \\
\text { (experience in Idaho) }\end{array}$ & General Services Administration, Regional Energy Manager \\
\hline $\begin{array}{l}\text { Energy Service } \\
\text { Provider }\end{array}$ & Washington & JCI, Service Branch Manager \\
\hline \multirow{4}{*}{$\begin{array}{l}\text { LEED and HVAC } \\
\text { Engineers/Consul } \\
\text { tants }\end{array}$} & Oregon & Glumac, Principal Engineer \\
\hline & Oregon & PAE Consulting, Consultant \\
\hline & $\begin{array}{l}\text { Washington } \\
\text { (experience in Idaho) }\end{array}$ & Coffman Engineers, Mechanical Engineer \\
\hline & $\begin{array}{l}\text { Washington and } \\
\text { Oregon }\end{array}$ & Interface Engineering, Principal Engineer \\
\hline \multirow{2}{*}{$\begin{array}{l}\text { Utility } \\
\text { Representative } \\
\end{array}$} & Oregon & BPA, Mechanical Engineer \\
\hline & Oregon & Eugene Water \& Electric Board, Staff Engineer \\
\hline
\end{tabular}




\section{Results and Conclusions}

Table 11 summarizes the current customer acceptance level of each technology in the Pacific Northwest region based on feedback obtained during the interviews. Regional climate characteristics explained the low acceptance of enthalpy wheel and radiant cooling technology as the moderate humidity and low cooling demand relative to other regions of the U.S. were not favorable in the Pacific Northwest.

\section{Table 11 Regional Customer Acceptance Level of Each Technology}

\begin{tabular}{|l|l|}
\hline \multicolumn{2}{|c|}{ Low Lift Technology Options - Customer Acceptance Level in the Pacific Northwest Region } \\
\hline Technology & \multicolumn{1}{|c|}{ Customer Acceptance Level } \\
\hline Variable Capacity Chillers & $\begin{array}{l}\text { High - Industry is moving in this direction and there is a need to migrate } \\
\text { designs into large size chillers. }\end{array}$ \\
\hline Advanced Controls & $\begin{array}{l}\text { Medium/High - Significant opportunity exists in coupling systems to achieve } \\
\text { higher efficiencies. Requires better user interfaces and must focus on enabling } \\
\text { diagnostics and prognostics of the full HVAC system (supervisory level). } \\
\text { Requires better training for operators and other users. }\end{array}$ \\
\hline $\begin{array}{l}\text { Dedicated Outdoor Air System } \\
\text { (DOAS) + Enthalpy Wheel }\end{array}$ & $\begin{array}{l}\text { Medium-Humidity is not a major concern in many parts of the Pacific } \\
\text { Northwest, and temperate climate in both winter and summer reduces ERV } \\
\text { benefit. More product offerings of this type entering the marketplace but there } \\
\text { is limited awareness and regional specific field data on the units. }\end{array}$ \\
\hline Thermal energy storage (TES) & $\begin{array}{l}\text { Medium - Limited time-of-use rates offered by utilities in the BPA region } \\
\text { lengthen paybacks for this technology, but that could change if TOU pricing } \\
\text { becomes more widespread. However, with nuclear and hydro resources, TOU } \\
\text { pricing may be less critical Also, requires significant technology improvements } \\
\text { and implementing this as an integrated solution with radiant cooling and low } \\
\text { lift cooling options to further demonstrate benefits is required. }\end{array}$ \\
\hline Radiant cooling/heating & $\begin{array}{l}\text { Low/Medium - Low cooling demand limits cooling applications. Requires } \\
\text { significant improvement in implementer and consumer awareness. Also, initial } \\
\text { failures with technology have discouraged adoption. }\end{array}$ \\
\hline
\end{tabular}

TOU $=$ Time of Use

Figure 9 summarizes the major regional barriers NCI identified through primary and secondary research and lists corresponding strategies to overcome each barrier. These potential strategies were developed based on both NCI's experience and stakeholder feedback. 
Major Regional Barrier

Inexpensive and clean energy

- Low energy costs lengthen payback period of efficiency improvements

- Time-of-use pricing is not currently common

- Low carbon emission rates

\section{Regional Climate}

- Low cooling demand

- Micro-climates and variable humidity levels depending on region

Lack of Experience with Technology

- Building owners and contractors are risk adverse to being an early adopter

- Lack of awareness with performance, installation, and O\&M requirements
Potential Strategy

Targeted Incentives

- Offer additional state and utility incentives for this technology that target institutional facilities and regions with higher energy rates (e.g. government facilities in larger cities like Portland)

Customized System Configurations

- Offer customized applications (e.g. optional enthalpy wheel for humidity control)

- Combine cooling technology with heating applications to improve equipment payback

- Make enthalpy wheel and radiant cooling optional

Informational Program and Resources

- Publish results of regional case studies tracking long-term performance

- Develop public database of local installations with performance data

- Offer complimentary feasibility studies

Figure 9 Major Regional Barriers Identified and Potential Strategy to Overcome Barrier

While the acceptance of low-lift cooling technology in the Pacific Northwest could be impeded by low electricity costs and low levels of $\mathrm{CO}_{2}$ emissions from power generation, the market still has some early adopters and strong support for LEED (Leadership in Energy and Environmental Design) and other green buildings, which increases adoption potential. Furthermore, the increasing electricity demands in the region are likely to be met with additional fossil-fuelpowered plants and if these enter the generation mix, the appeal and case for energy efficiency and LLCS would likely improve. Other key findings from this study include:

- Low energy costs and the low cooling demand in the Pacific Northwest lengthen payback of low-lift cooling technology.

- Institutional customers (e.g., government buildings) are more accepting of longer energy efficiency paybacks $(\leq 10 \mathrm{yrs})$ than private sector facilities $(\leq 3 \mathrm{yrs})$ and therefore are better potential targets for LLCS technology.

- Site constraints and regional climates limit the potential for thermal energy storage and radiant cooling technologies.

- In areas with high acceptance of LEED standards, there is sufficient communication between architects and engineers in the early planning stages of building energy systems.

- There is a general lack of understanding and local experience with the technology. 


\section{Recommendations}

While other regions of the U.S. are better suited for LLCS technology, the Pacific Northwest market still has some potential for adoption. Additionally, an effective program to promote these technologies would provide educational information on the technology and target customers with the highest value proposition. NCI makes the following recommendations to expedite market adoption in the Pacific Northwest:

- Evaluate and focus on market segments where technology has the highest value proposition such as government and other institutional facilities that are more accepting of technologies with longer paybacks.

- Target regions with higher electricity rates, high cooling demand, and a track-record for support of energy efficiency and green buildings.

- Offer some customization of systems to accommodate micro-climates (e.g., exclude radiant cooling system or provide optional enthalpy wheel to control humidity).

- Develop and publish informational resources with lessons learned from local case-studies to increase understanding of the technology.

- Implement effective training practices and resources for engineers and contractors in target regions and markets.

\section{PNNL Conclusion of Market Assessment}

In general PNNL agrees with the findings presented by NCI in this section. Many of the findings are consistent with PNNL's own experience. The recommendation made by NCI should be valuable for BPA, because these recommendations apply to most integrated technology options that are going to be used in high performance and net-zero energy buildings.

PNNL agrees the limitation and barriers noted by NCI for the use of active TES. Although PNNL has investigated the active TES option, PNNL does not think that active TES is essential to realize the savings. A significant fraction of the savings that can be attributed to TES can be achieved by passive TES (using thermal mass). PNNL has not evaluated passive TES as an option because of simulation limitations. 


\section{Incremental Cost Estimates for the Low-Lift Cooling System}

One of the objectives of this study was to conduct a simple economic analysis of the LLCS. Because of limited resources, PNNL decided to estimate simple payback, rather than conducting a detailed life-cycle cost analysis. To estimate the simple payback, the incremental cost and energy savings estimates are need. The energy savings estimates were estimated through simulations (see next section). Again because of limited resources, the incremental cost was estimated for four buildings types.

Estimating incremental cost of emerging technology is difficult because of limited availability of information that is available in the open literature. To estimate the incremental cost for the components that make up the LLCS, PNNL hired NCI. The following subsection was drafted by $\mathrm{NCI}$ and it summarizes the incremental cost estimates.

\section{NCI Summary of Incremental Cost Estimates}

As part of this assessment, NCI analyzed the HVAC systems at the component level. After identifying and sizing the essential HVAC components within each building type, NCI developed a spreadsheet to calculate the baseline and low-lift component costs using RS Means Mechanical Cost Data 2007 and inputs from various component suppliers. Table 12 lists these components and the inputs used to derive the costs of each component. PNNL provided EnergyPlus building sizing files to list and size the baseline HVAC systems, and also provided parameters for sizing and pricing the low-lift system. For details of the incremental cost estimation process refer to the Appendix B (Appendix: Incremental Cost Supporting Material).

\section{Table 12 HVAC System Components and Cost Sources}

\begin{tabular}{|c|c|c|}
\hline \multicolumn{3}{|c|}{ Component Cost Sources } \\
\hline Component & Baseline Costs & Low-Lift Costs \\
\hline Chiller, Rooftop Units & RS Means 2007 & Suppliers, RS Means 2007 \\
\hline Boiler & RS Means 2007 & RS Means 2007 \\
\hline Furnaces & RS Means 2007 & RS Means 2007 \\
\hline Control System & \multicolumn{2}{|c|}{ Assumed no incremental } \\
\hline Ductwork & Suppliers, RS Means 2007 & Suppliers, RS Means 2007 \\
\hline Air-Handlers & RS Means 2007 & RS Means 2007 \\
\hline DX HP Coils & - & RS Means 2007 \\
\hline Enthalpy Wheel & - & RS Means 2007 \\
\hline Radiant Cooling & - & Suppliers \\
\hline
\end{tabular}

HP: Heat Pump 
Each system was sized and priced according to the specific system requirements provided by PNNL. NCI calculated the costs based on the national average provided in RS Means, and then applied a cost index for material and labor to calculate each component cost for the other cities in the Pacific Northwest region.

Incremental costs were calculated for each HVAC sub-system, by subtracting the cost of the baseline components to the equivalent low-lift components. Incremental costs were derived for both the national average and 21 cities in the Pacific Northwest.

Incremental costs were divided by sub-system as follows:

1. Low-lift chiller incremental cost

2. Radiant cooling system incremental cost

3. DOAS with DX HP and energy recovery ventilator (ERV) incremental cost

4. Heating system.

\section{Results}

The charts in Figure 10 through Figure 13 show the results of the incremental cost study, for each of the four building type: medium office, large office, supermarket and secondary schools. These costs reflect the national average cost. Using the city cost index from RS Means, the national cost can be translated to each of the 21 cities in the Pacific Northwest, as described in the Economic Analysis Section.

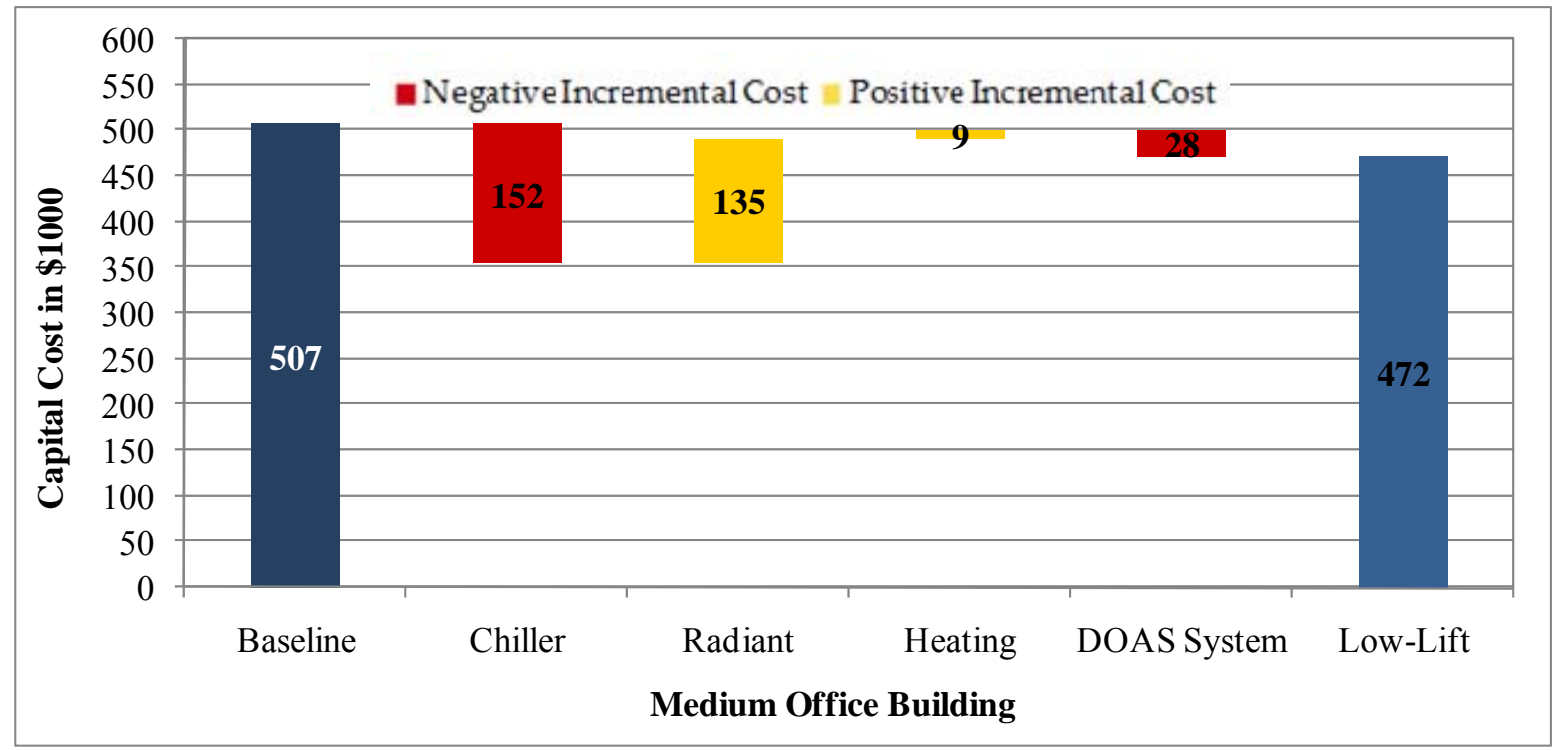

Figure 10 Incremental Cost (National Average) for Medium Office Building Using LowLift Cooling 


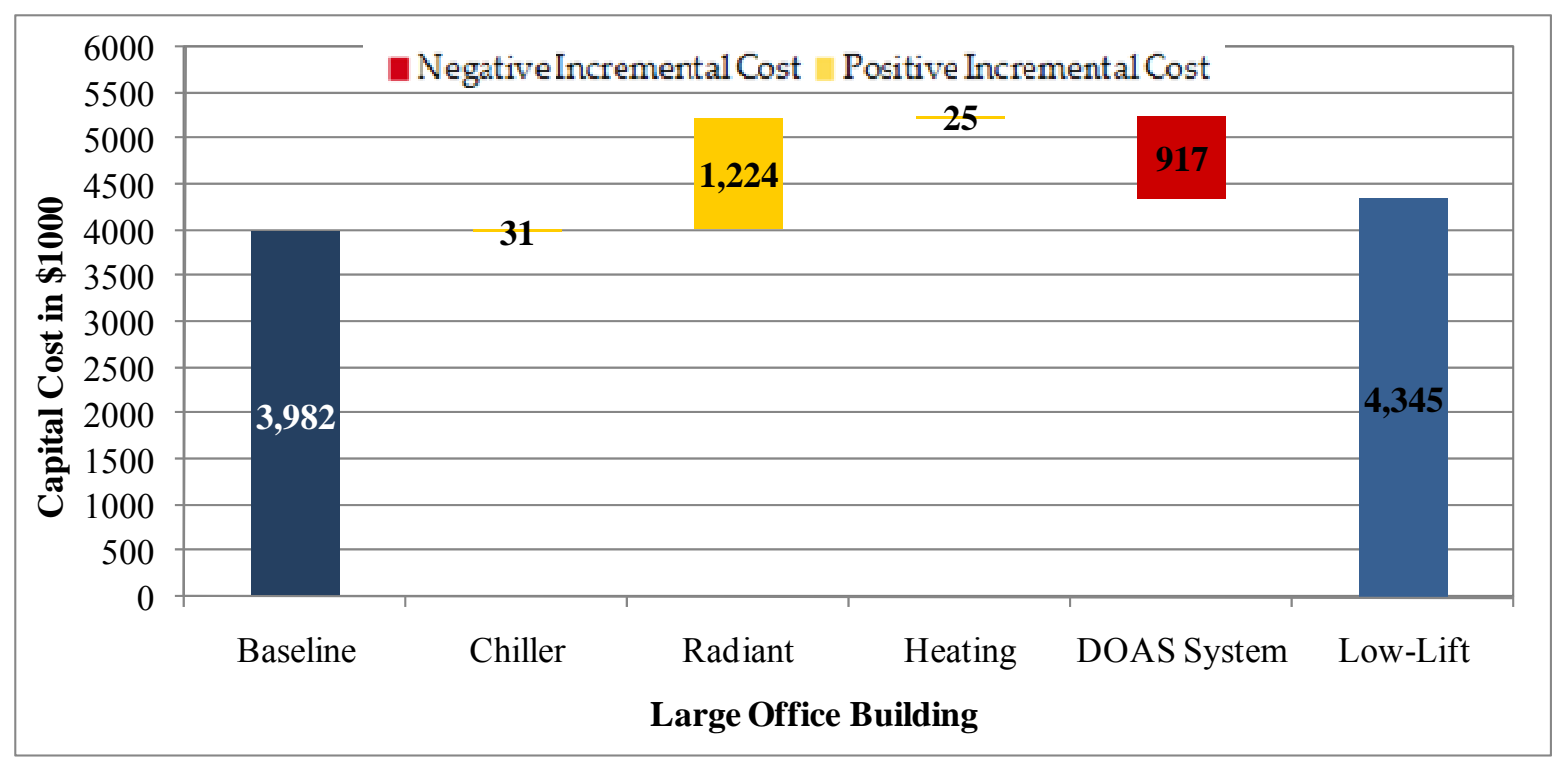

Figure 11 Incremental Cost (National Average) for Large Office Building Using Low-Lift Cooling

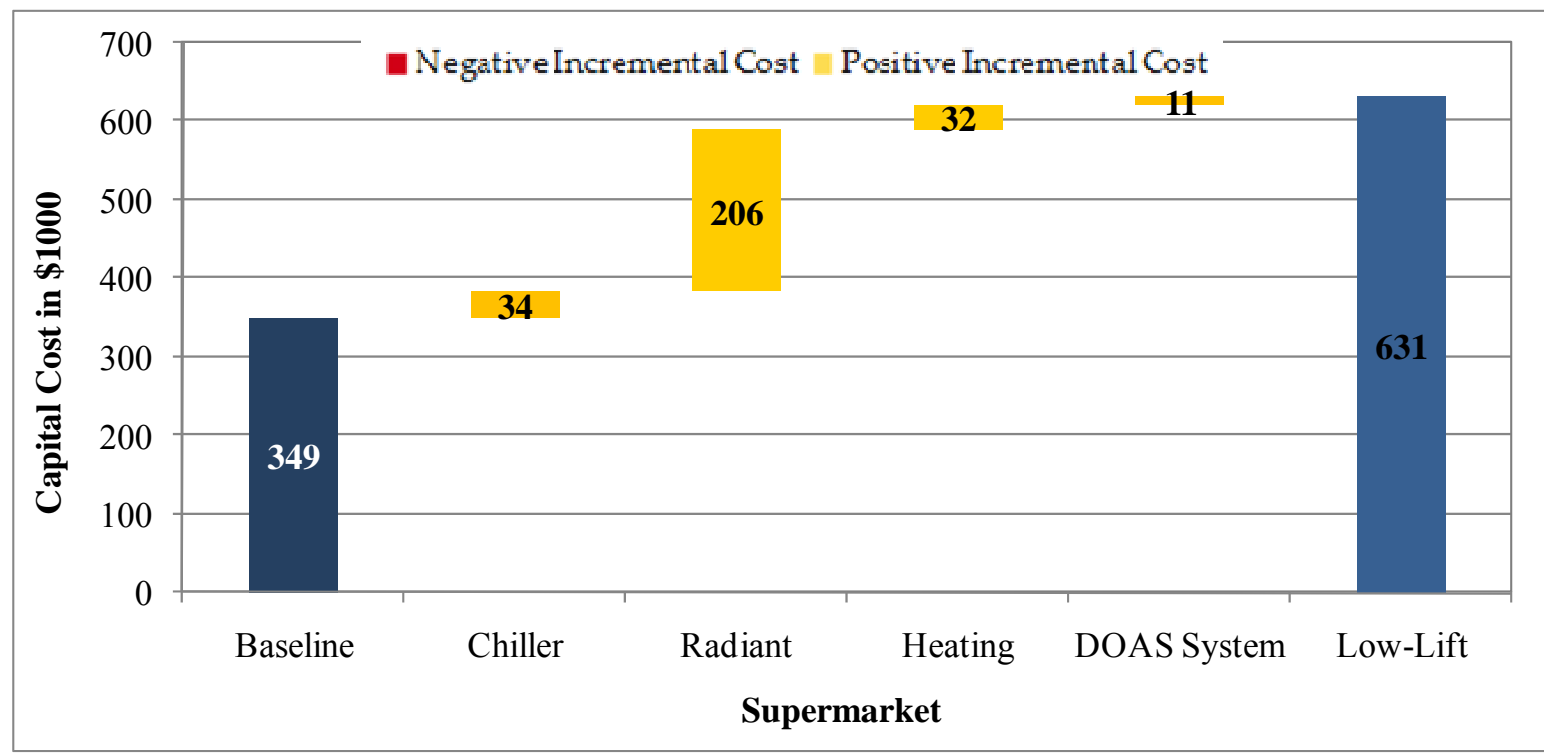

Figure 12 Incremental Cost (National Average) for Supermarket Building Using Low-Lift Cooling 


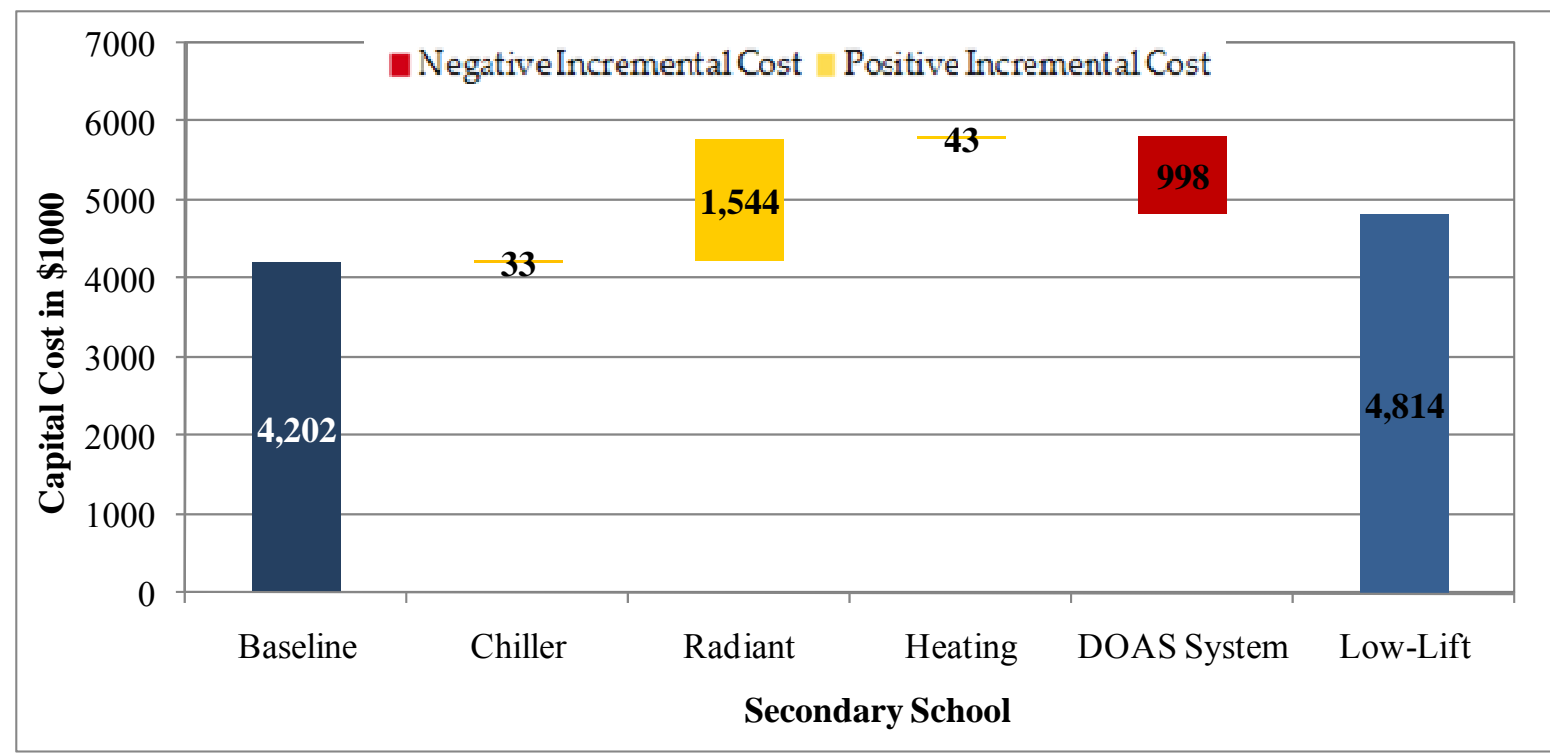

Figure 13 Incremental Cost (National Average) for Secondary School Building Using LowLift Cooling

The charts show that the cost of a radiant cooling system drives most of the overall cost incremental. In medium office buildings, the high cost of multi-zone rooftop air-conditioning units compared to a similar-sized chiller results in virtually no incremental cost for the low-lift cooling system. For the large office building and secondary school building, large reductions in the sizing of the ductwork drove negative incremental costs for the ducting systems. The supermarket buildings typically use inexpensive single-zone packaged units; therefore, these building will have difficulty competing with variable speed chillers.

\section{Findings}

The key conclusions in the overall analysis of the incremental costs for the low-lift systems are:

- Office buildings may be the most ideal first application for low-lift cooling technologies/systems, particularly those using multi-zone rooftop systems.

- The large cost of the multi-zone rooftop systems (with respect to a similar-sized chiller) allows for a favorable cost comparison for low-lift chiller systems in medium office buildings.

- While inexpensive single-zone packaged units make supermarkets unfavorable cost comparison for low-lift chiller system, large office buildings show a low incremental cost per square foot, because of small increases in chiller costs, and large savings from the smaller ductwork as a result of the DOAS system.

- Radiant cooling drives the cost increment for all of the building types. A large portion of these costs is associated with the labor required for installation. 
- The cost advantage resulting from reduction of the ductwork for large buildings is a large factor and needs to be validated further.

In addition, there are additional items to consider:

- Some components of the low-lift system, particularly the radiant cooling system, can be considered emerging technologies. There is often a 10 to $20 \%$ premium associated with emerging technologies that may gradually decline as the technology is commoditized.

- Potential additional benefits of the low-lift system include reducing the amount of materials used in construction, particularly the ductwork material.

\section{Recommendations}

The component-based cost approach for estimating baseline and advanced system costs is limited in scope, and only covers a portion of the total costs required for incorporation of HVAC systems into buildings. Some of the key recommendations that need to be addressed include:

- The common practice of equipment sizing by cooling load and cubic feet per minute (cfm), and not by square footage. This however can be addressed through the use of a detailed design process to understand costs on a square foot basis (possibly by picking a candidate building that can serve as a future test bed).

- Sizing by cooling load is very effective for calculating the cost of the main components, but not as effective for finding the cost of the distribution systems.

- The design process will also help in assuring that material costs are better estimated (ducts, piping, valves, etc.) that also require further exploration.

As a next step, NCI recommends proceeding through this detailed costing exercise for a candidate building (large office) along with an associated payback/economic analysis for various parts of the country. An economic analysis will help identify whether the cost premium for lowlift systems is justified and help identify candidate regions for pilot projects.

\section{PNNL Conclusions on Incremental Cost Estimates}

In general PNNL agrees with NCI findings. As noted by NCI, these are the best estimates given the limited time, resources and the approach that was taken to estimate the costs. PNNL believes that these cost estimates are conservative for a number of reasons:

1. Limited availability of cost information for the emerging technologies.

2. Emerging technologies generally have a premium when introduced but generally the cost go down significantly as the market is transformed (e.g., compact fluorescent lamps).

3. Low-lift chiller size has not been optimized to reflect the lower size needed when used with passive thermal storage option. 
4. Redundant heating systems have been added for the building with low-lift system, which may not be needed.

Widespread use of these technologies, and building design and optimization for inclusion of LLCS could potentially lower the cost by between 20 and $30 \%$ from the current estimates. 


\section{Energy Use Estimation Methodology}

To estimate the energy consumption of a prototype building with baseline equipment, a modified prototype with LLCS equipment or some subset of the LLCS, a detailed simulation model is needed. The existing mainstream detailed simulation models (DOE- $2^{15}$ and EnergyPlus ${ }^{16}$ ) currently lack the capability to simulate the full LLCS. Although EnergyPlus can model many the elements of the LLCS, it still lacks a low-lift chiller, thermal storage and advanced controls needed to optimize the operation. Because some of the proposed technologies, such as ERV and economizers directly influence the required heating and cooling loads, the benchmark templates had to first be modified to include these components. In addition, several other minor changes were made. Table 6 lists the changes made to the benchmark templates.

The energy consumption estimates and the savings were computed in two steps: 1) building thermal loads were estimated for 12 different building types (two performance levels) and 21 climate locations using EnergyPlus simulations and 2) using the thermal loads as a basis, the systems were simulated with a set of component models that were previously developed as part of the DOE effort (Jiang et al. 2008; Armstrong et al. 2009a, b).

Performance map models or mathematical models of the key components - chiller, DOAS, and radiant panels - were developed for use with loads simulated by Energy Plus. The modeling and simulation activities (application of the component models) are described below. Details of the component models are presented and reported in Jiang et al. (2008). A semi-empirical compressor performance model was developed based on published performance data for an existing reciprocating compressor designed for operation over a 4:1 speed range. Compressors in the model line have similar performance for machines rated from 10 to $30 \mathrm{hp} \mathrm{(7} \mathrm{to} 20$ ton). Chiller component models were developed to be assembled into a higher level program that models overall chiller performance. The component models include the previously mentioned compressor, an air-cooled condenser and condenser fan, a water-cooled evaporator and chilled water pump, and two types of distribution heat transfer equipment (a radiant cooling panel system and a CAV- or VAV-fan-coil system). The condenser fan and chilled water pump were modeled with variable-speed controls.

A performance-optimized chiller model that includes load-side transport power, as well as compressor and condenser fan power, was developed based on the above component models. The chiller model solves for the saturated condenser and evaporator refrigerant temperatures that minimize input power given cooling load and the external load-side and outdoor thermal conditions. The primary mechanism for reducing chiller input power is the adjustment of fan, pump and compressor speeds to match saturated condenser and evaporator refrigerant temperatures with chiller load and external conditions.

Three versions of the chiller model were developed to produce two chiller performance maps. The first performance map is for the ideal low-lift chiller RCP system (Figure 1), which includes

\footnotetext{
${ }^{15} \mathrm{http://www.doe2.com/}$

16 http://apps1.eere.energy.gov/buildings/energyplus/
} 
both compressor and refrigerant-side economizer operation. The chiller model for economizer operation uses the same components as the chiller for compressor operation except that the compressor is replaced by a flow-pressure characteristic of the compressor bypass branch used during economizer operation. At each performance evaluation, the two maps are evaluated and the mode of operation (compressor or economizer) is determined by which map evaluation returns the lower $\mathrm{kW} /$ ton number.

The VAV system uses an air-side economizer so only one chiller model is needed to produce a ideal chiller performance map (Figure 3). However, the map has three regions corresponding to a chilled water supply temperature reset schedule, which is a function of outdoor temperature. Two-speed operation of the compressor, condenser fan and chilled water pump is simulated by performance curves derived from the variable-speed performance map. The low- and high-speed specific power curves - functions of outdoor temperature only - are obtained by evaluating the variable-speed performance map at part-load fractions of 0.5 and 1.0.

In addition, to the ideal chiller performance maps, chiller performance maps were also developed using the test data from the prototype low-lift chiller. Like the ideal chiller, two maps where used: 1) prototype RCP-chiller map (Figure 4) and 2) prototype VAV-chiller map (Figure 5) The prototype RCP-chiller map is used with the radiant cooling option and prototype VAVchiller map is used with the conventional HVAC configuration.

Energy recovery ventilation is modeled in EnergyPlus. The remaining latent load is satisfied by a DX dehumidifier modeled as two subsystems: the wetted evaporator coil and a scaled-down version of the variable-speed chiller with heat rejection to the ventilation supply air. The resulting sensible load is added to the building sensible load and can therefore be treated as peak"shiftable" load. Air flow and fan power are determined by ventilation demand, while compressor power is determined by the latent load remaining after enthalpy recovery and the evaporator inlet conditions.

The annual energy simulations use EnergyPlus-generated load sequences to which DOAS reheat has been added for the cases that use DOAS. For systems without TES, the appropriate chiller map is applied directly to the baseline load sequence of interest.

For systems with TES, annual energy is evaluated in 365 daily sub-simulations and the 24-hour peak-shifting algorithm applies the appropriate chiller performance map to each 24-hour load sequence plugged into its objective function. The solution to this sub-problem is the 24-hour load sequence that minimizes chiller input energy for the day in question.

\section{Building Performance Levels}

The building prototypes used for the low-lift analysis had two permutations, baseline and highperformance. The baseline buildings complied with Standard 90.1-2004 (ASHRAE 2004) requirements. Where the Standard did not have a specification, typical construction practice was used within the benchmark prototype. This is consistent with the current benchmark development process. The baseline building prototypes were modified to create highperformance prototypes, as shown in Table 13. The goal of specifying the high-performance 
building is to assess the benefits of low-lift when applied to future near-zero energy buildings (near ZEB).

Table 13 Comparison of Key Parameters for the Baseline and High-Performance Buildings

\begin{tabular}{|c|c|c|}
\hline \multicolumn{3}{|c|}{ Component Performance Levels to be Analyzed } \\
\hline Component & Baseline & High Performance \\
\hline Wall-Roof U-Factor & $90.1-2004^{(a)}$ & $4 / 9^{\text {th }}$ of $90.1-2004$ \\
\hline $\begin{array}{c}\text { Window U-Factor and } \\
\text { SHGC }\end{array}$ & $90.1-2004^{(a)}$ & $4 / 9^{\text {th }}$ of $90.1-2004$ \\
\hline Window-to-Wall-Ratio & $40 \%$ & $20 \%+$ Shading ${ }^{(\mathrm{b})}$ \\
\hline $\begin{array}{l}\text { Lighting and Plug Load }^{(\mathrm{c})} \\
\text { Power Density (W/sf) }\end{array}$ & $1.3+0.63$ & $0.58+0.21$ \\
\hline Fan Power (W/scfm) ${ }^{(\mathrm{d})}$ & 0.8 & 0.356 \\
\hline
\end{tabular}

(a) Because the values vary by climate locations, the values are not listed in this table

(b) Completely shade the solar direct beam

(c) Load density during hours of the highest loads

(d) Total HVAC fan power divided by total HVAC fan flow rate

(e) SHGC: solar heat gain coefficient.

The building designs address the non-HVAC aspects of a building's energy performance, including U-factors for the wall and roof, window-to-wall ratio coefficients, and plug loads. Note, for example, that in the "high-performance" design case, the performance assumptions are much more aggressive than 90.1-2004. This wide range of non-HVAC energy performance allows us to investigate the LLCS across two distinctly different cases - "high-performance" buildings being well on the way to net-zero energy performance.

\section{Energy Savings Analysis Grid}

As noted earlier, the energy savings analysis for this study is based on a combination of simulation runs: EnergyPlus and Matlab component models. The analysis grid is based on the following combination of runs:

1. 12 building types

2. 21 climate locations

3. 2 building performance levels (standard and high performance)

4. 3 base systems combinations (with economizer, without economizer and with energy recovery ventilation)

5. 2 chiller performance curves, and

6. 8 different low-loft combinations.

These combination of simulations resulted in 1,512 EnergyPlus runs and 24,192 Matlab simulation runs. The energy savings estimates are summarized in the next section. 


\section{Energy Savings Estimates for the Various LLCS Combinations}

The potential energy savings for the LLCS for each of the building prototypes for which the LLCS is applicable, and in each of the 21 climate locations is summarized in this section. First, the general approach to the estimation of energy savings is described, followed by the savings estimates by building type and climate locations with the LLCS. Second, the energy use estimates for the various combinations of HVAC systems are discussed, followed by the percentage savings potential from use of the LLCS compared to the baseline equipment configuration for each building prototype. The default baseline building is an ASHRAE Standard 90.1-2004 compliant version of the building.

To condition the occupied spaces, first, the buildings are modeled using the base HVAC systems (Table 8) with EnergyPlus. This configuration is referred to "Case 0" or baseline in this report. For Case 0, the thermal loads and the HVAC energy consumption estimates are from EnergyPlus simulations. In addition to the base case, energy consumption for each building type in 21 climate locations is calculated with eight different combinations of the LLCS with two different chiller performance curves.

Because the prototype buildings use different HVAC systems, the energy consumption for each building was also estimated with a standard air distribution system (either constant volume or VAV system depending on the building type) fed by a central chiller. This is referred to as Case 1. For Case 1, the modeling of the chiller and distribution system energy is done through postprocessing of the building cooling loads generated from the EnergyPlus simulation. The chiller and a simple fan model described in Appendix B of Jiang et al. (2008) are used. The purpose of using specially developed system performance curves is to provide for a comparable evaluation by using identical chiller components for the low-lift baseline as well as all partial and full LLCS configurations. In addition to the base HVAC system (Case 0 below), eight alternative HVAC systems (low-lift baseline, six partial LLCS configurations and the full LLCS configuration) were analyzed. The fan and DOAS consumption is estimated for the entire year (i.e., both cooling and heating seasons). There are additional reheat savings, for some building types (6 out of 12) that use reheat. These savings are also estimated independently and described and presented later in the section.

The nine different sets of simulations are as follows:

1. Case 0: the base case HVAC configuration case (different of each building, see Table 8).

2. Case 1: two-speed chiller with VAV or CAV AHU, depending on building type - this is referred to as low-lift base case HVAC configuration.

3. Case 2: low-lift variable-speed chiller and VAV AHU - this configuration uses VAV AHU from Case 1 but with variable-speed low-lift chiller, pump and fan equipment.

4. Case 3: two-speed chiller with RCP/DOAS - this configuration replaces AHU from Case 1 with a hydronic distribution system serving radiant cooling/heating panels and a DOAS for ventilation. 
5. Case 4: low-lift variable-speed chiller with RCP/DOAS - combines the alternatives provided separately in Case 2 and Case 3.

6. Case 5: two-speed chiller with VAV AHU and TES - this case adds TES to Case 1.

7. Case 6: variable-speed chiller, VAV AHU and TES - this case adds TES to Case 2.

8. Case 7: two-speed chiller with RCP/DOAS and TES - this case adds TES to Case 3.

9. Case 8: low-lift variable-speed chiller with RCP/DOAS and TES - this case adds TES to Case 4.

Case 8 noted above is the full LLCS, consisting of: 1) peak-shifting with active or passive thermal storage (implemented here as idealized discrete TES), 2) radiant cooling/heating (implemented using zone radiant cooling panels) with DOAS (implemented as enthalpy heat recovery from exhaust air and a variable-speed DX dehumidifier), and 3) low-lift variable-speed vapor compression chiller (achieved using high turn-down ratio compressor with a refrigerantside economizer and assuming condenser and evaporator heat exchangers identical in size with the low-lift base case).

Cases 2, 4, 6 and 8 use advanced variable-speed compressor and transport (fan and pump) controls to optimize the instantaneous hourly operation of the chiller and distribution systems. Cases 5, 6, 7 and 8 implement a 24-hour look-ahead algorithm to optimize charging of the TES.

The energy savings from these technologies (RCP/DOAS, TES and low-lift chiller) are assessed individually and in combination, as described previously. This approach not only provides the energy savings potential associated with the LLCS, but also demonstrates the synergisms of the component technologies and thus illustrates the importance of systems integration in achieving truly exemplary levels of energy performance.

In addition to the "baseline" (ASHRAE Standard 90.1-2004 compliant) building design, one other higher performance building design was also simulated as described previously (Table 13).

\section{Energy Use Estimates for the Various LLCS and Building Configurations}

The energy use estimates for the base case and eight LLCS configurations for selected building types are presented in this section, while the reminder of the results that are included in Appendix C (Appendix: Energy Use Estimate Tables and Figures). Results of annual energy simulations for the nine equipment cases are summarized, in terms of the annual energy to operate the chiller, pumps, fan and ventilation. Although the chiller and pump energy consumption only represents cooling, the ventilation and fan energy consumption used to compute the annual energy is for the entire year.

Table 14 and Table 15 show the annual energy consumption (chiller, fan, and pump) for the standard- and high-performance medium office building designs for various HVAC combinations across 21 climate locations. The second column (following the climate location labels) represents the annual energy consumption for the base case HVAC system (for medium office, which is packaged multi-zone VAV system). The third column represents the low-lift base case (for medium office, it is two-speed chiller with a VAV AHU). The reminder of the columns provides the annual energy consumption for the various low-lift combinations, as 
described previously. The savings for each building type and climate location are computed as the difference between Case 0 and Case 8 . In addition to computing the ultimate savings, savings from individual technologies can also be computed.

For example, the difference between Case 0 and Case 1 results in savings from going from a packaged direct expansion system to a two-speed chiller and the difference between Case 1 and Case 2 results in savings from going from two-speed chiller to a variable-speed chiller. Although savings in fan energy can be computed as a difference of Case 1 and Case 5 or Case 2 and Case 6, it is only an approximation because switching from a conventional VAV system to radiant cooling, increases the chilled water temperature, which will reduce the chiller energy consumption. Therefore, the difference can be viewed as net reduction in fan energy consumption.

Similarly, the savings associated with thermal storage can be computed as a difference between Case 1 and Case 3, Case 2 and Case 4, Case 5 and Case 7, and Case 6 and Case 8. Each of these differences will yield slightly different energy savings for the thermal storage because of the other system interactions. The annual consumption of the two designs (standard- and highperformance) for large office, supermarket and secondary schools is shown in Table 15 through Table 21. The tables for the rest of the building types are included in Appendix C (Appendix: Energy Use Estimate Tables and Figures).

Figure 14 through Figure 21 compare the annual energy consumption for 4 selected standard buildings (medium office, large office, supermarket and secondary school) for 9 different combinations of the systems (Case 0 through Case 8) in 21 climate locations. In all cases, the base case is significantly higher than the full LLCS (Case 8).

For standard medium office (Figure 14), the reduction in energy consumption between Case 0 and Case 8 ranges from $57 \%$ to $67 \%$, with an average reduction of $62 \%$. In general, the trend across all climate locations is similar. The difference between low-lift base case (Case 1) and the full LLCS (Case 8 ) ranges from $38 \%$ to $61 \%$, with an average reduction of $51 \%$, significantly lower than the difference between Case 0 and Case 8 . The reason for the difference between the two base cases, Case 0 and Case 1, is the use of two-speed chiller with a VAV system for Case 1, which is more efficient than the packaged multi-zone VAV system used for Case 0. 
Table 14 Annual Energy Consumption (Chiller, Fan, and Pump) for the StandardPerformance Medium Office Building Design for Various HVAC Combinations across 21 Climate Locations (units in kWh)

\begin{tabular}{|c|c|c|c|c|c|c|c|c|c|}
\hline & Case 0 & Case 1| & Case 2 & Case 3 & Case 4 & Case 5 & Case 6 & Case 7 & Case 8 \\
\hline Pendleton, OR & 79,175 & 70,064 & 66,179 & 56,766 & 49,369 & 45,168 & 39,988 & 38,867 & 31,355 \\
\hline Spokane, WA & 64,622 & 56,247 & 53,162 & 47,242 & 41,628 & 36,435 & 32,673 & 32,022 & 26,391 \\
\hline Missoula, MT & 62,728 & 52,971 & 50,231 & 42,137 & 37,981 & 33,347 & 29,755 & 29,925 & 23,448 \\
\hline Boise, ID & 77,956 & 70,203 & 66,631 & 55,259 & 49,383 & 43,911 & 39,327 & 38,411 & 30,856 \\
\hline Pocatello, ID & 68,392 & 59,713 & 56,580 & 46,482 & 41,972 & 37,492 & 33,688 & 32,555 & 25,567 \\
\hline Helena, MT & 63,531 & 53,166 & 50,327 & 44,719 & 39,572 & 34,231 & 30,464 & 30,791 & 24,804 \\
\hline Astoria, OR & 44,450 & 28,672 & 26,824 & 27,781 & 25,054 & 21,914 & 18,142 & 21,137 & 16,658 \\
\hline Salem, OR & 65,589 & 49,259 & 46,003 & 40,537 & 35,055 & 32,800 & 27,934 & 29,408 & 22,301 \\
\hline Eugene, OR & 66,006 & 49,098 & 45,736 & 40,765 & 35,120 & 32,493 & 27,657 & 29,494 & 22,009 \\
\hline North Bend, OR & 42,258 & 27,691 & 26,126 & 27,143 & 24,762 & 21,594 & 17,618 & 20,768 & 16,283 \\
\hline Arcata, CA & 35,808 & 24,996 & 23,846 & 24,514 & 22,897 & 19,765 & 16,319 & 18,941 & 15,492 \\
\hline Medford, OR & 82,800 & 72,786 & 68,988 & 53,221 & 47,427 & 45,606 & 40,398 & 37,431 & 28,675 \\
\hline Redmond, OR & 64,342 & 55,730 & 52,576 & 43,543 & 39,194 & 36,957 & 32,657 & 31,701 & 24,596 \\
\hline Portland, OR & 64,469 & 46,568 & 43,095 & 41,495 & 35,041 & 31,816 & 26,683 & 29,720 & 22,693 \\
\hline Yakima, WA & 72,383 & 61,725 & 58,046 & 50,266 & 43,038 & 39,937 & 35,264 & 35,091 & 27,670 \\
\hline Burns, OR & 64,394 & 55,786 & 52,628 & 43,561 & 39,217 & 36,998 & 32,691 & 31,724 & 24,579 \\
\hline Olympia, WA & 58,097 & 42,930 & 40,200 & 36,127 & 31,939 & 28,959 & 24,860 & 26,065 & 20,485 \\
\hline Quillayuta, WA & 39,467 & 27,741 & 26,074 & 26,773 & 24,364 & 21,238 & 18,068 & 20,205 & 16,604 \\
\hline Seattle, WA & 54,336 & 37,870 & 35,051 & 35,334 & 30,769 & 27,173 & 22,703 & 25,832 & 20,095 \\
\hline Kalispell, MT & 55,169 & 45,078 & 42,765 & 38,620 & 33,884 & 29,630 & 26,419 & 26,616 & 21,206 \\
\hline Cut Bank, MT & 50,711 & 41,009 & 38,689 & 37,326 & 33,265 & 28,008 & 24,709 & 25,965 & 21,127 \\
\hline
\end{tabular}

Table 15 Annual Energy Consumption (Chiller, Fan, and Pump) for the High-Performance Medium Office Building Design for Various HVAC Combinations across 21 Climate Locations (units in kWh)

\begin{tabular}{|l|r|r|r|r|r|r|r|r|r|}
\hline & Case 0 & Case 1 & Case 2 & Case 3 & Case 4 & Case 5 & Case 6 & Case 7 & Case 8 \\
\hline Pendleton, OR & 30,872 & 27,034 & 25,253 & 21,000 & 19,153 & 15,556 & 13,943 & 13,799 & 10,904 \\
\hline Spokane, WA & 24,469 & 21,557 & 20,280 & 17,291 & 15,983 & 12,802 & 11,705 & 11,350 & 9,368 \\
\hline Missoula, MT & 22,944 & 19,621 & 18,552 & 14,959 & 13,984 & 11,647 & 10,757 & 9,829 & 8,489 \\
\hline Boise, ID & 29,475 & 26,501 & 25,009 & 19,970 & 18,506 & 15,419 & 14,026 & 13,644 & 10,858 \\
\hline Pocatello, ID & 24,222 & 21,256 & 19,994 & 15,799 & 14,671 & 13,200 & 12,052 & 10,680 & 9,113 \\
\hline Helena, MT & 22,642 & 19,036 & 17,891 & 15,180 & 13,955 & 11,866 & 10,819 & 10,371 & 8,841 \\
\hline Astoria, OR & 20,961 & 14,579 & 13,755 & 14,219 & 13,214 & 7,113 & 6,678 & 7,013 & 6,465 \\
\hline Salem, OR & 26,300 & 19,716 & 18,233 & 15,917 & 14,439 & 10,668 & 9,596 & 9,513 & 7,724 \\
\hline Eugene, OR & 26,022 & 19,594 & 18,096 & 15,983 & 14,410 & 10,526 & 9,449 & 9,567 & 7,713 \\
\hline North Bend, OR & 21,089 & 14,881 & 14,173 & 14,696 & 13,738 & 6,648 & 6,269 & 6,612 & 6,138 \\
\hline Arcata, CA & 19,447 & 14,405 & 13,867 & 14,210 & 13,563 & 6,432 & 6,112 & 6,341 & 6,018 \\
\hline Medford, OR & 31,958 & 27,704 & 25,891 & 19,541 & 17,895 & 15,546 & 14,069 & 12,365 & 9,896 \\
\hline Redmond, OR & 24,247 & 21,161 & 19,853 & 16,218 & 15,133 & 12,572 & 11,341 & 9,605 & 8,580 \\
\hline Portland, OR & 25,928 & 18,907 & 17,364 & 16,165 & 14,467 & 10,343 & 9,190 & 9,931 & 7,929 \\
\hline Yakima, WA & 27,497 & 23,062 & 21,342 & 17,779 & 16,193 & 13,332 & 11,807 & 11,549 & 9,250 \\
\hline Burns, OR & 24,222 & 21,141 & 19,829 & 16,185 & 15,096 & 12,599 & 11,364 & 9,636 & 8,600 \\
\hline Olympia, WA & 23,981 & 18,023 & 16,852 & 15,115 & 13,897 & 9,580 & 8,762 & 8,640 & 7,437 \\
\hline Quillayuta, WA & 18,617 & 13,857 & 13,148 & 13,350 & 12,547 & 7,240 & 6,842 & 6,994 & 6,586 \\
\hline Seattle, WA & 22,283 & 16,136 & 14,943 & 14,914 & 13,423 & 8,681 & 7,874 & 8,513 & 7,227 \\
\hline Kalispell, MT & 20,522 & 16,912 & 15,959 & 13,657 & 12,775 & 10,151 & 9,443 & 8,429 & 7,759 \\
\hline Cut Bank, MT & 17,761 & 14,377 & 13,467 & 12,572 & 11,672 & 9,649 & 8,845 & 8,746 & 7,821 \\
\hline
\end{tabular}


Table 16 Annual Energy Consumption (Chiller, Fan, and Pump) for the StandardPerformance Large Office Building Design for Various HVAC Combinations across 21 Climate Locations (units in kWh)

\begin{tabular}{|l|r|r|r|r|r|r|r|r|r|}
\hline & Case 0 & Case 1 & Case 2 & Case 3 & Case 4 & Case 5 & Case 6 & Case 7 & Case 8 \\
\hline Pendleton, OR & 625,525 & 709,849 & 680,198 & 622,919 & 577,091 & 466,000 & 423,626 & 407,906 & 348,313 \\
\hline Spokane, WA & 535,300 & 597,716 & 577,289 & 526,634 & 493,144 & 385,521 & 359,501 & 337,375 & 300,854 \\
\hline Missoula, MT & 530,947 & 580,793 & 563,338 & 511,436 & 480,529 & 366,507 & 341,547 & 318,899 & 285,125 \\
\hline Boise, ID & 655,594 & 770,135 & 745,507 & 673,307 & 632,489 & 474,101 & 440,741 & 408,687 & 363,479 \\
\hline Pocatello, ID & 708,539 & 827,382 & 811,444 & 744,836 & 717,250 & 404,085 & 382,885 & 353,318 & 327,394 \\
\hline Helena, MT & 628,500 & 727,039 & 712,242 & 664,208 & 639,730 & 374,937 & 354,539 & 332,040 & 305,548 \\
\hline Astoria, OR & 337,961 & 260,779 & 244,766 & 251,795 & 228,418 & 237,439 & 195,693 & 226,731 & 174,674 \\
\hline Salem, OR & 479,758 & 459,266 & 431,286 & 414,395 & 371,572 & 342,529 & 296,089 & 308,904 & 248,317 \\
\hline Eugene, OR & 479,953 & 457,731 & 429,111 & 413,326 & 369,628 & 341,672 & 295,068 & 308,088 & 247,256 \\
\hline North Bend, OR & 322,697 & 252,760 & 238,106 & 246,985 & 225,057 & 244,702 & 197,509 & 231,974 & 173,363 \\
\hline Arcata, CA & 297,758 & 232,250 & 222,867 & 225,639 & 211,286 & 221,361 & 177,249 & 208,475 & 160,466 \\
\hline Medford, OR & 568,231 & 729,989 & 700,050 & 628,828 & 577,889 & 469,047 & 424,502 & 402,747 & 342,412 \\
\hline Redmond, OR & 558,967 & 618,897 & 599,485 & 535,407 & 503,575 & 403,847 & 375,935 & 339,978 & 305,987 \\
\hline Portland, OR & 471,625 & 435,311 & 405,932 & 400,888 & 355,895 & 332,260 & 284,426 & 308,802 & 242,340 \\
\hline Yakima, WA & 573,644 & 615,286 & 586,406 & 547,111 & 500,129 & 413,488 & 375,706 & 362,718 & 310,850 \\
\hline Burns, OR & 559,294 & 619,213 & 599,798 & 535,691 & 503,855 & 403,944 & 376,027 & 340,050 & 306,052 \\
\hline Olympia, WA & 426,075 & 393,651 & 370,473 & 357,271 & 322,114 & 300,875 & 259,599 & 273,737 & 222,561 \\
\hline Quillayuta, WA & 307,169 & 253,585 & 239,029 & 243,878 & 225,082 & 228,604 & 192,888 & 214,051 & 174,060 \\
\hline Seattle, WA & 404,817 & 351,121 & 327,419 & 330,388 & 295,934 & 287,398 & 245,305 & 270,238 & 212,095 \\
\hline Kalispell, MT & 466,128 & 484,425 & 468,335 & 433,766 & 407,475 & 323,538 & 300,923 & 282,803 & 254,078 \\
\hline Cut Bank, MT & 494,103 & 564,578 & 552,444 & 529,372 & 506,746 & 309,418 & 294,711 & 276,110 & 255,455 \\
\hline
\end{tabular}

Table 17 Annual Energy Consumption (Chiller, Fan, and Pump) for the High-Performance Large Office Building Design for Various HVAC Combinations across 21 Climate Locations (units in kWh)

\begin{tabular}{|l|r|r|r|r|r|r|r|r|r|}
\hline & Case 0 & Case 1 & Case 2 & Case 3 & Case 4 & Case 5 & Case 6 & Case 7 & Case 8 \\
\hline Pendleton, OR & 206,939 & 227,285 & 212,605 & 194,299 & 168,015 & 180,065 & 164,621 & 161,436 & 139,812 \\
\hline Spokane, WA & 165,517 & 177,020 & 167,137 & 149,233 & 132,122 & 151,051 & 141,226 & 135,790 & 121,006 \\
\hline Missoula, MT & 159,408 & 167,093 & 159,110 & 141,688 & 123,221 & 142,807 & 134,220 & 129,888 & 116,259 \\
\hline Boise, ID & 199,594 & 230,864 & 219,529 & 194,321 & 167,573 & 185,229 & 173,145 & 164,592 & 146,115 \\
\hline Pocatello, ID & 189,386 & 209,140 & 202,212 & 159,605 & 146,577 & 164,622 & 157,708 & 135,885 & 126,392 \\
\hline Helena, MT & 175,889 & 183,936 & 177,411 & 148,511 & 136,758 & 152,016 & 145,132 & 131,255 & 121,354 \\
\hline Astoria, OR & 140,856 & 98,034 & 90,771 & 95,879 & 86,691 & 82,183 & 74,415 & 80,997 & 72,122 \\
\hline Salem, OR & 178,058 & 160,039 & 146,887 & 145,800 & 124,879 & 128,091 & 113,068 & 120,199 & 99,997 \\
\hline Eugene, OR & 175,872 & 157,301 & 144,018 & 143,704 & 123,515 & 125,958 & 111,550 & 118,397 & 98,672 \\
\hline North Bend, OR & 133,075 & 96,512 & 90,627 & 95,005 & 86,891 & 80,510 & 72,101 & 79,298 & 69,680 \\
\hline Arcata, CA & 126,258 & 90,145 & 86,130 & 88,726 & 83,521 & 73,412 & 68,959 & 72,745 & 67,798 \\
\hline Medford, OR & 217,231 & 240,640 & 225,175 & 200,798 & 170,575 & 183,490 & 166,766 & 163,321 & 137,954 \\
\hline Redmond, OR & 167,856 & 175,160 & 165,757 & 145,383 & 124,437 & 150,900 & 140,826 & 133,204 & 119,865 \\
\hline Portland, OR & 174,053 & 149,909 & 136,199 & 139,259 & 119,497 & 122,657 & 107,332 & 117,531 & 96,588 \\
\hline Yakima, WA & 191,369 & 194,656 & 179,870 & 173,213 & 149,355 & 156,644 & 141,918 & 144,587 & 122,810 \\
\hline Burns, OR & 167,883 & 175,183 & 165,778 & 145,301 & 124,434 & 150,966 & 140,893 & 133,246 & 119,909 \\
\hline Olympia, WA & 162,886 & 139,549 & 129,074 & 128,060 & 111,986 & 111,152 & 99,524 & 105,296 & 90,256 \\
\hline Quillayuta, WA & 124,592 & 93,802 & 87,730 & 91,165 & 83,769 & 83,730 & 77,448 & 81,880 & 74,767 \\
\hline Seattle, WA & 148,019 & 119,433 & 108,912 & 113,661 & 99,403 & 104,631 & 92,463 & 101,737 & 85,789 \\
\hline Kalispell, MT & 141,589 & 137,417 & 129,956 & 122,231 & 107,221 & 124,306 & 116,651 & 115,227 & 104,058 \\
\hline Cut Bank, MT & 139,664 & 124,299 & 119,056 & 108,602 & 99,412 & 118,487 & 113,014 & 109,483 & 101,695 \\
\hline
\end{tabular}


Table 18 Annual Energy Consumption (Chiller, Fan, and Pump) for the StandardPerformance Supermarket Building Design for Various HVAC Combinations across 21 Climate Locations (units in kWh)

\begin{tabular}{|c|c|c|c|c|c|c|c|c|c|}
\hline & Case 0 & Case 1 & Case 2 & Case 3 & Case 4 & Case 5 & Case 6 & Case 7 & Case 8 \\
\hline Pendleton, OR & 202,942 & 194,761 & 192,633 & 185,442 & 183,065 & 67,863 & 65,133 & 64,938 & 60,238 \\
\hline Spokane, WA & 200,614 & 193,651 & 192,245 & 186,934 & 185,505 & 63,979 & 62,004 & 61,456 & 58,204 \\
\hline Missoula, MT & 235,408 & 227,344 & 226,107 & 220,170 & 218,936 & 63,664 & 61,825 & 61,503 & 57,797 \\
\hline Boise, ID & 211,431 & 202,949 & 200,963 & 192,975 & 190,953 & 67,840 & 65,332 & 65,058 & 60,172 \\
\hline Pocatello, ID & 261,675 & 253,546 & 252,029 & 244,518 & 242,906 & 66,185 & 64,080 & 63,059 & 58,741 \\
\hline Helena, MT & 269,236 & 261,224 & 260,045 & 255,014 & 253,616 & 64,192 & 62,262 & 62,304 & 58,685 \\
\hline Astoria, OR & 152,547 & 146,322 & 146,131 & 145,927 & 145,615 & 55,104 & 53,691 & 54,652 & 53,007 \\
\hline Salem, OR & 175,083 & 165,623 & 164,240 & 160,320 & 158,727 & 60,966 & 58,621 & 59,418 & 55,598 \\
\hline Eugene, OR & 173,656 & 164,305 & 162,891 & 158,989 & 157,525 & 60,724 & 58,356 & 59,318 & 55,408 \\
\hline North Bend, OR & 149,531 & 143,671 & 143,571 & 143,498 & 143,327 & 54,774 & 53,622 & 54,213 & 52,734 \\
\hline Arcata, CA & 148,997 & 143,740 & 143,713 & 143,555 & 143,480 & 54,229 & 53,174 & 53,563 & 52,702 \\
\hline Medford, OR & 194,706 & 185,601 & 183,405 & 171,154 & 169,218 & 70,199 & 67,368 & 65,272 & 59,641 \\
\hline Redmond, OR & 202,653 & 194,933 & 193,509 & 188,086 & 186,976 & 63,240 & 61,140 & 60,238 & 57,020 \\
\hline Portland, OR & 171,717 & 162,825 & 161,490 & 159,419 & 157,501 & 60,001 & 57,609 & 59,044 & 55,516 \\
\hline Yakima, WA & 197,844 & 187,985 & 186,029 & 179,799 & 177,787 & 65,728 & 63,107 & 62,974 & 58,906 \\
\hline Burns, OR & 203,028 & 195,353 & 193,924 & 188,463 & 187,374 & 63,304 & 61,195 & 60,278 & 57,065 \\
\hline Olympia, WA & 174,017 & 165,526 & 164,617 & 161,080 & 160,092 & 59,556 & 57,612 & 57,859 & 54,930 \\
\hline Quillayuta, WA & 156,289 & 150,289 & 150,062 & 149,802 & 149,536 & 54,939 & 53,711 & 54,385 & 53,057 \\
\hline Seattle, WA & 162,047 & 154,388 & 153,627 & 152,776 & 151,628 & 57,375 & 55,563 & 56,611 & 54,196 \\
\hline Kalispell, MT & 232,578 & 224,794 & 223,853 & 220,035 & 219,005 & 61,407 & 59,768 & 59,109 & 56,860 \\
\hline Cut Bank, MT & 266,031 & 258,719 & 257,998 & 256,047 & 255,221 & 60,455 & 58,860 & 59,332 & 57,010 \\
\hline
\end{tabular}

Table 19 Annual Energy Consumption (Chiller, Fan, and Pump) for the High-Performance Supermarket Building Design for Various HVAC Combinations across 21 Climate Locations (units in kWh)

\begin{tabular}{|c|c|c|c|c|c|c|c|c|c|}
\hline & Case 0 & Case 1 & Case 2 & Case 3 & Case 4 & Case 5 & Case 6 & Case 7 & Case 8 \\
\hline Pendleton, OR & 76,131 & 70,475 & 69,824 & 67,112 & 66,622 & 35,290 & 34,748 & 34,362 & 32,930 \\
\hline Spokane, WA & 76,214 & 71,218 & 70,943 & 68,729 & 68,453 & 34,416 & 34,183 & 33,107 & 32,534 \\
\hline Missoula, MT & 78,386 & 72,928 & 72,678 & 70,599 & 70,372 & 34,146 & 33,916 & 32,796 & 32,460 \\
\hline Boise, ID & 79,222 & 73,796 & 73,288 & 70,215 & 69,760 & 35,592 & 35,158 & 34,171 & 33,112 \\
\hline Pocatello, ID & 80,311 & 74,906 & 74,604 & 72,042 & 71,767 & 34,658 & 34,382 & 32,998 & 32,574 \\
\hline Helena, MT & 82,817 & 77,461 & 77,252 & 75,555 & 75,328 & 34,114 & 33,909 & 33,132 & 32,706 \\
\hline Astoria, OR & 60,808 & 55,814 & 55,804 & 55,690 & 55,669 & 31,204 & 31,177 & 31,117 & 31,077 \\
\hline Salem, OR & 67,164 & 61,440 & 61,092 & 59,638 & 59,366 & 32,924 & 32,603 & 31,985 & 31,525 \\
\hline Eugene, OR & 66,817 & 61,067 & 60,713 & 59,322 & 59,023 & 32,890 & 32,570 & 31,992 & 31,486 \\
\hline North Bend, OR & 58,406 & 53,476 & 53,476 & 53,449 & 53,446 & 31,091 & 31,077 & 31,066 & 31,052 \\
\hline Arcata, CA & 58,503 & 53,568 & 53,579 & 53,517 & 53,514 & 31,091 & 31,091 & 31,061 & 31,056 \\
\hline Medford, OR & 73,189 & 67,902 & 67,188 & 62,538 & 62,029 & 36,682 & 36,085 & 34,048 & 32,944 \\
\hline Redmond, OR & 76,628 & 71,218 & 70,933 & 69,019 & 68,799 & 33,718 & 33,464 & 32,325 & 32,051 \\
\hline Portland, OR & 65,922 & 60,255 & 59,956 & 58,961 & 58,686 & 32,543 & 32,253 & 32,249 & 31,493 \\
\hline Yakima, WA & 74,417 & 68,621 & 68,063 & 65,697 & 65,297 & 34,604 & 34,129 & 33,391 & 32,444 \\
\hline Burns, OR & 76,792 & 71,330 & 71,043 & 69,116 & 68,896 & 33,744 & 33,488 & 32,344 & 32,064 \\
\hline Olympia, WA & 67,125 & 61,784 & 61,643 & 60,232 & 60,082 & 32,650 & 32,491 & 31,729 & 31,499 \\
\hline Quillayuta, WA & 62,506 & 57,500 & 57,482 & 57,366 & 57,343 & 31,237 & 31,207 & 31,124 & 31,093 \\
\hline Seattle, WA & 63,847 & 58,686 & 58,609 & 57,991 & 57,869 & 31,893 & 31,814 & 31,576 & 31,260 \\
\hline Kalispell, MT & 77,472 & 72,080 & 71,904 & 70,588 & 70,416 & 33,355 & 33,185 & 32,349 & 32,144 \\
\hline Cut Bank, MT & 82,067 & 76,767 & 76,665 & 76,030 & 75,918 & 32,960 & 32,850 & 32,490 & 32,319 \\
\hline
\end{tabular}


Table 20 Annual Energy Consumption (Chiller, Fan, and Pump) for the Standard Performance Secondary School Building Design for Various HVAC Combinations across 21 Climate Locations (units in kWh)

\begin{tabular}{|c|c|c|c|c|c|c|c|c|c|}
\hline & Case 0 & Case 1 & Case 2 & Case 3 & Case 4 & Case 5 & Case 6 & Case 7 & Case 8 \\
\hline Pendleton, OR & 802,983 & 718,847 & 706,568 & 631,138 & 604,540 & 361,413 & 349,323 & 319,593 & 297,356 \\
\hline Spokane, WA & 702,242 & 632,509 & 623,734 & 580,333 & 561,392 & 313,571 & 305,237 & 289,853 & 275,185 \\
\hline Missoula, MT & 726,628 & 662,773 & 654,896 & 590,316 & 572,816 & 323,715 & 314,923 & 295,961 & 281,487 \\
\hline Boise, ID & 793,361 & 730,422 & 720,057 & 636,474 & 609,496 & 367,576 & 355,796 & 327,977 & 307,505 \\
\hline Pocatello, ID & 728,178 & 669,054 & 660,832 & 592,721 & 572,854 & 336,206 & 327,146 & 302,621 & 286,992 \\
\hline Helena, MT & 732,267 & 662,788 & 654,671 & 602,483 & 583,202 & 323,126 & 314,374 & 295,094 & 280,200 \\
\hline Astoria, OR & 518,700 & 433,968 & 427,526 & 424,804 & 413,938 & 213,421 & 210,025 & 210,979 & 206,342 \\
\hline Salem, OR & 669,486 & 562,168 & 549,627 & 522,026 & 498,522 & 276,941 & 266,704 & 260,955 & 243,736 \\
\hline Eugene, OR & 670,319 & 560,981 & 548,342 & 523,472 & 500,086 & 275,868 & 265,849 & 260,433 & 243,042 \\
\hline North Bend, OR & 484,289 & 413,868 & 409,427 & 407,765 & 398,291 & 201,522 & 198,872 & 200,348 & 196,999 \\
\hline Arcata, CA & 467,536 & 399,340 & 395,998 & 394,160 & 387,924 & 201,056 & 199,827 & 200,364 & 199,183 \\
\hline Medford, OR & 813,169 & 725,476 & 711,414 & 622,720 & 588,140 & 368,716 & 355,404 & 321,317 & 296,740 \\
\hline Redmond, OR & 711,289 & 640,032 & 631,088 & 564,295 & 546,173 & 320,521 & 310,617 & 286,426 & 271,949 \\
\hline Portland, OR & 662,236 & 550,455 & 537,896 & 520,155 & 495,377 & 271,088 & 260,398 & 259,846 & 241,340 \\
\hline Yakima, WA & 744,086 & 652,407 & 639,366 & 596,104 & 567,091 & 328,164 & 314,217 & 303,670 & 281,016 \\
\hline Burns, OR & 712,003 & 640,880 & 631,921 & 565,221 & 546,914 & 320,794 & 310,861 & 286,650 & 272,139 \\
\hline Olympia, WA & 625,336 & 524,151 & 514,475 & 486,752 & 467,352 & 259,040 & 251,274 & 246,521 & 234,056 \\
\hline Quillayuta, WA & 519,483 & 435,059 & 429,583 & 424,338 & 416,018 & 216,161 & 213,090 & 211,653 & 207,653 \\
\hline Seattle, WA & 585,142 & 493,033 & 483,656 & 474,935 & 457,306 & 243,355 & 236,486 & 237,211 & 225,540 \\
\hline Kalispell, MT & 659,825 & 601,206 & 594,741 & 549,236 & 534,802 & 294,293 & 287,608 & 273,730 & 261,815 \\
\hline Cut Bank, MT & 662,458 & 592,255 & 585,486 & 563,240 & 550,770 & 288,995 & 281,552 & 275,547 & 264,489 \\
\hline
\end{tabular}

Table 21 Annual Energy Consumption (Chiller, Fan, and Pump) for the High Performance Secondary School Building Design for Various HVAC Combinations across 21 Climate Locations (units in kWh)

\begin{tabular}{|c|c|c|c|c|c|c|c|c|c|}
\hline & Case 0 & Case 1 & Case 2 & Case 3 & Case 4 & Case 5 & Case 6 & Case 7 & Case 8 \\
\hline Pendleton, OR & 339,264 & 291,514 & 285,251 & 242,258 & 225,143 & 171,837 & 167,046 & 149,189 & 138,516 \\
\hline Spokane, WA & 280,167 & 245,089 & 240,963 & 212,151 & 200,806 & 148,034 & 145,036 & 132,338 & 125,680 \\
\hline Missoula, MT & 277,278 & 242,775 & 239,202 & 203,580 & 192,929 & 144,085 & 141,108 & 129,928 & 122,491 \\
\hline Boise, ID & 333,867 & 298,523 & 293,469 & 241,317 & 224,343 & 176,326 & 172,079 & 151,765 & 141,159 \\
\hline Pocatello, ID & 288,739 & 255,768 & 251,710 & 212,520 & 200,657 & 153,946 & 150,597 & 135,965 & 127,950 \\
\hline Helena, MT & 275,933 & 242,856 & 239,124 & 207,686 & 196,995 & 148,587 & 146,089 & 132,068 & 124,632 \\
\hline Astoria, OR & 220,217 & 174,617 & 171,456 & 169,122 & 163,612 & 104,166 & 103,059 & 102,829 & 101,198 \\
\hline Salem, OR & 283,981 & 227,577 & 221,209 & 203,257 & 189,899 & 131,735 & 127,786 & 122,701 & 115,439 \\
\hline Eugene, OR & 282,244 & 225,448 & 219,050 & 203,262 & 187,918 & 129,329 & 125,866 & 121,577 & 114,685 \\
\hline North Bend, OR & 208,964 & 172,097 & 170,422 & 168,518 & 164,277 & 101,100 & 100,435 & 100,689 & 99,898 \\
\hline Arcata, CA & 206,736 & 167,114 & 166,383 & 163,201 & 160,242 & 102,414 & 101,739 & 101,991 & 101,234 \\
\hline Medford, OR & 351,444 & 307,052 & 299,865 & 241,100 & 222,836 & 180,527 & 175,434 & 152,180 & 139,589 \\
\hline Redmond, OR & 291,486 & 251,112 & 246,253 & 207,469 & 197,747 & 150,160 & 146,354 & 130,249 & 123,081 \\
\hline Portland, OR & 277,589 & 219,258 & 212,760 & 201,251 & 188,335 & 126,639 & 122,605 & 121,138 & 113,797 \\
\hline Yakima, WA & 307,633 & 256,917 & 250,079 & 226,058 & 209,249 & 147,185 & 141,860 & 135,697 & 125,481 \\
\hline Burns, OR & 291,547 & 251,153 & 246,288 & 207,460 & 197,740 & 150,236 & 146,435 & 130,455 & 123,142 \\
\hline Olympia, WA & 265,439 & 212,504 & 207,663 & 189,376 & 178,097 & 124,098 & 121,196 & 117,004 & 111,626 \\
\hline Quillayuta, WA & 220,111 & 173,098 & 170,324 & 165,995 & 161,348 & 106,600 & 105,045 & 103,702 & 101,565 \\
\hline Seattle, WA & 238,639 & 192,157 & 187,138 & 182,237 & 173,426 & 114,009 & 111,266 & 111,215 & 106,778 \\
\hline Kalispell, MT & 249,097 & 219,906 & 216,510 & 191,948 & 182,687 & 131,613 & 129,185 & 121,090 & 115,389 \\
\hline Cut Bank, MT & 238,931 & 203,945 & 200,502 & 189,397 & 182,009 & 126,262 & 123,804 & 121,022 & 116,737 \\
\hline
\end{tabular}




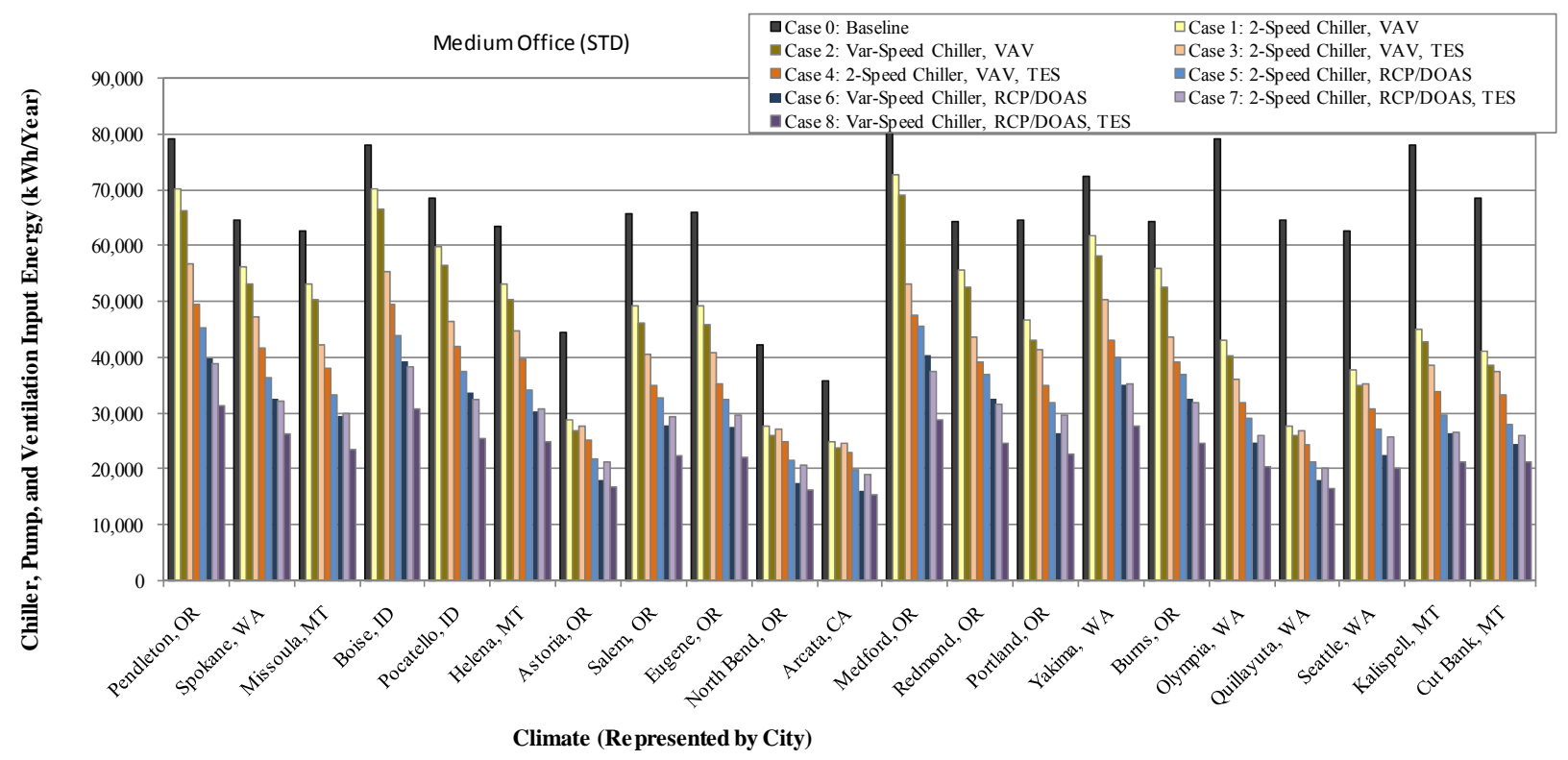

Figure 14 Comparison of Annual Chiller and Distribution Energy Consumption for Standard-Performance Medium Office Building for Various System Configurations in 21 Locations

For high-performance medium office (Figure 15), the reduction in energy consumption between Case 0 and Case 8 ranges from $56 \%$ to $71 \%$ with an average reduction of $66 \%$. In general, the trend across all climate locations is similar. The difference between low-lift base case (Case 1) and the full LLCS (Case 8 ) ranges from $46 \%$ to $64 \%$ with an average reduction of $57 \%$, lower than the difference between Case 0 and Case 8 .

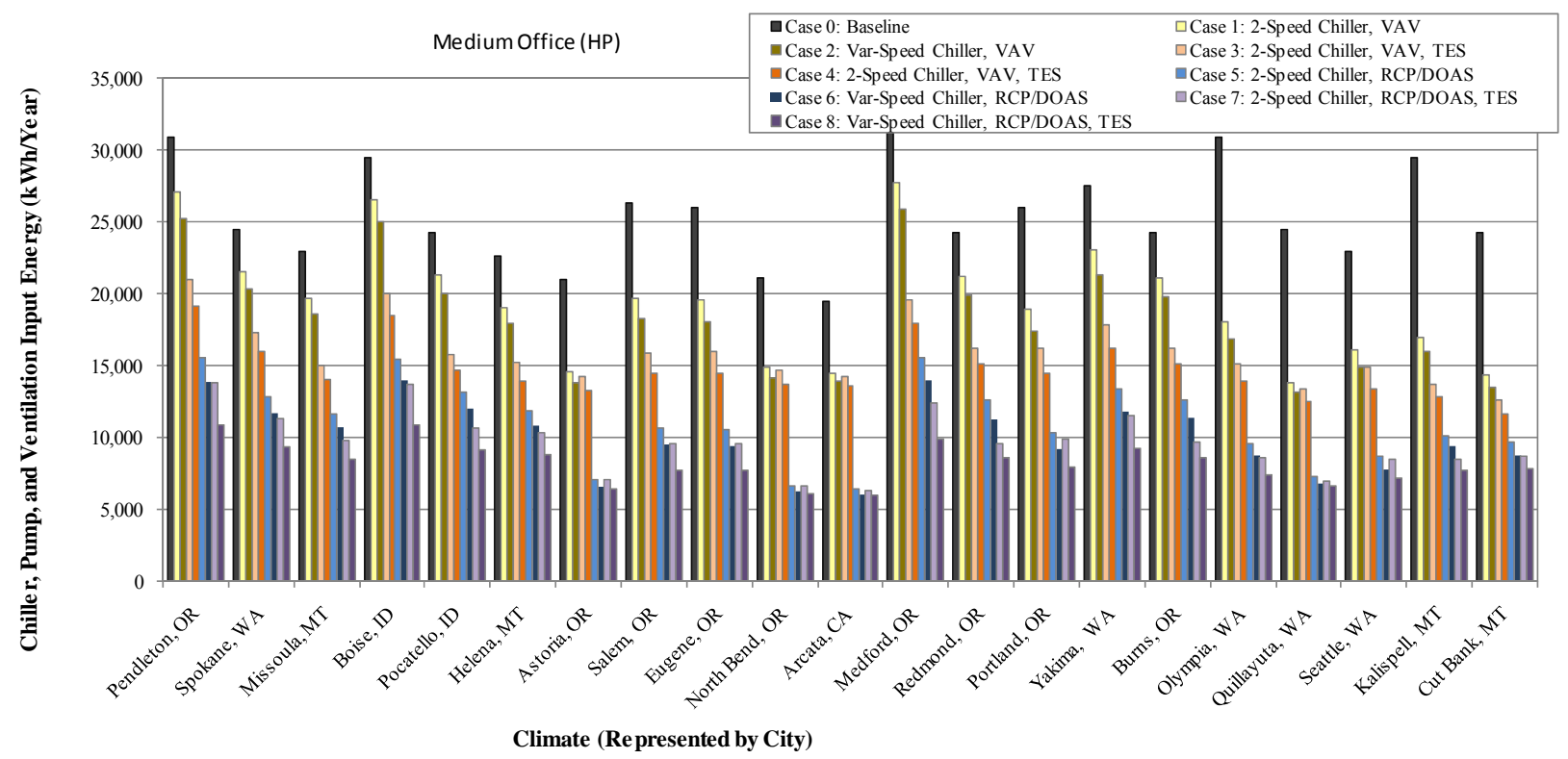

Figure 15 Comparison of Annual Chiller and Distribution Energy Consumption for HighPerformance Medium Office Building for Various System Configurations in 16 Locations 
For standard-performance large office building (Figure 16), the reduction in energy consumption between Case 0 and Case 8 ranges from $40 \%$ to $54 \%$ with an average reduction of $47 \%$. In general, the trend across all climate locations is similar. The difference between low-lift base case (Case 1) and the full LLCS (Case 8) ranges from 18\% to $43 \%$, with an average reduction of $32 \%$; this is slightly lower than the difference between Case 0 and Case 8 . The large office building uses a water-cooled chiller with VAV system as the base case (Case 0 ) and 2-speed aircooled chiller with VAV system as the low-lift base case (Case 1). The water-cooled chiller is generally more efficient than air-cooled chiller in non-humid climates, therefore, in many climate locations, the Case 1 uses more energy than Case 0. In wet-climates (Olympia, Seattle) the aircooled perform slightly better than the water-cooled, because of high wet-bulb temperatures that limit the water-cooled chiller efficiency.

For high-performance large office building (Figure 17), the reduction in energy consumption between Case 0 and Case 8 ranges from $27 \%$ to $49 \%$ with an average reduction of $36 \%$. It is worth noting that the difference between the low-lift base case (Case 1) and the full LLCS (Case 8 ) is lower and ranges from $18 \%$ to $43 \%$, with an average reduction of just $32 \%$.

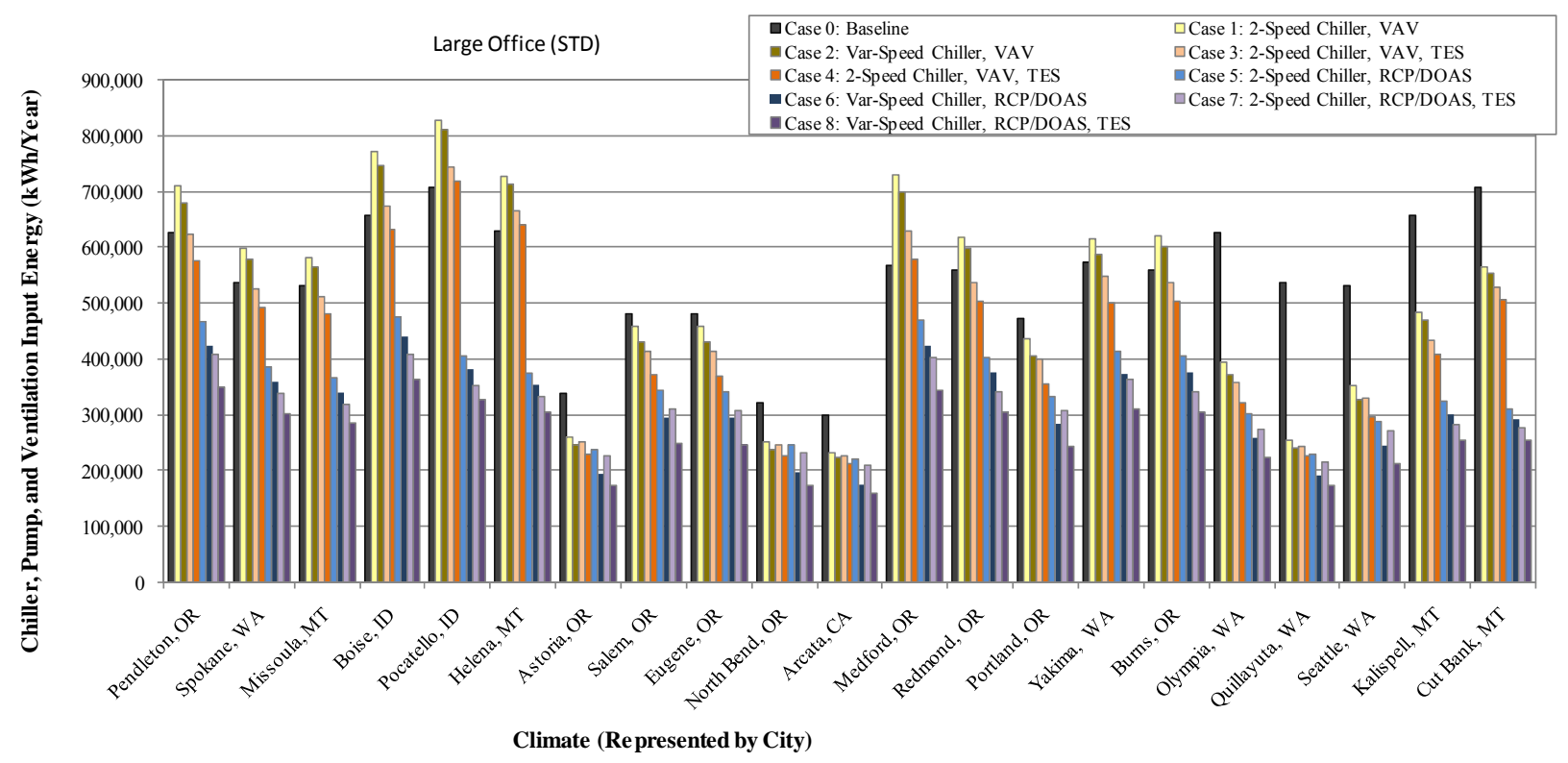

Figure 16 Comparison of Annual Chiller and Distribution Energy Consumption for Standard-Performance Large Office Building for Various System Configurations in 21 Locations 


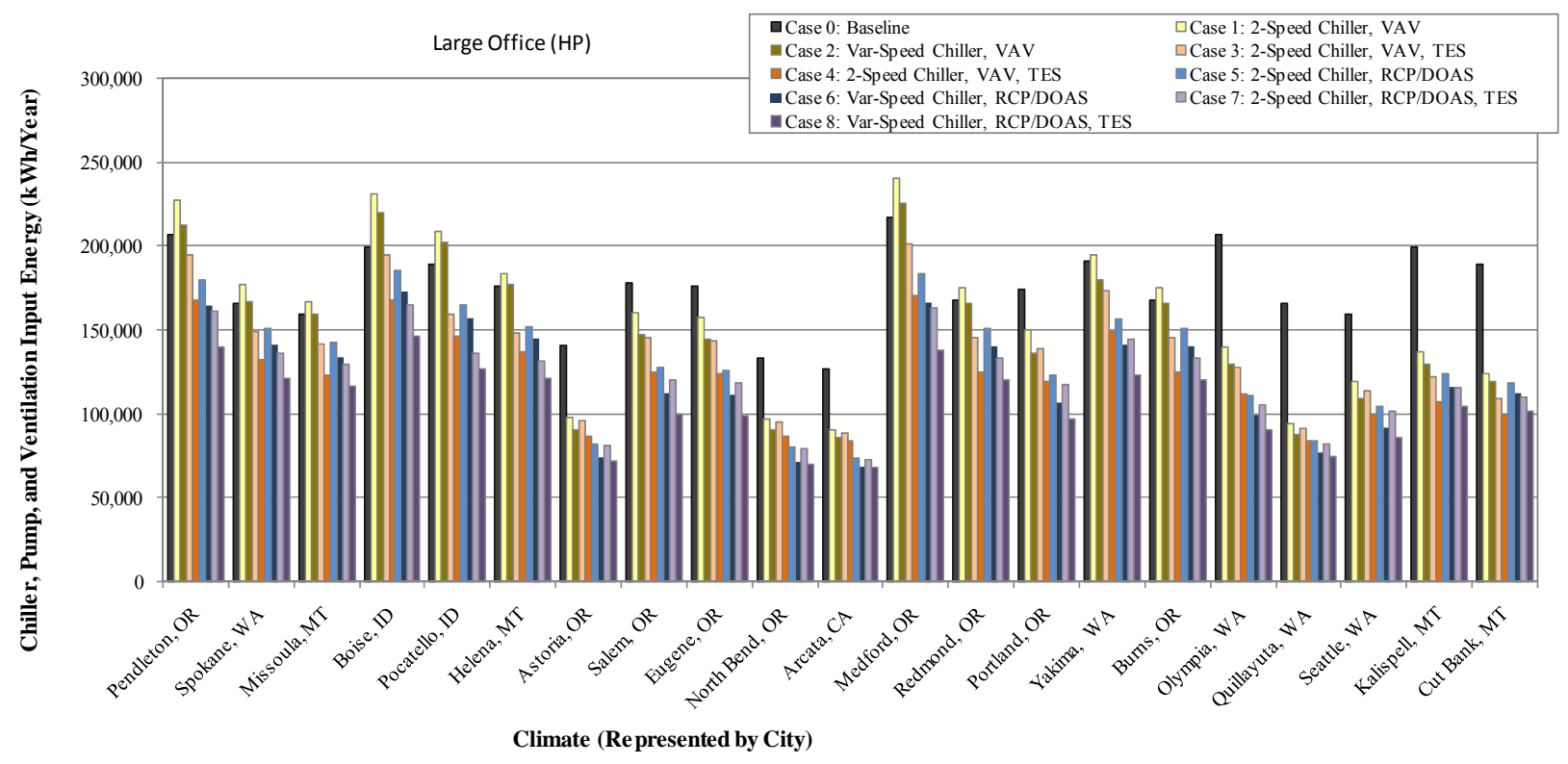

Figure 17 Comparison of Annual Chiller and Distribution Energy Consumption for HighPerformance Large Office Building for Various System Configurations in 21 Locations

For standard-performance supermarket building (Figure 18), the reduction in energy consumption between Case 0 and Case 8 ranges from $65 \%$ to $79 \%$ with an average reduction of $71 \%$. In general, the trend across all climate locations is similar. The difference between lowlift base case (Case 1) and the full LLCS (Case 8) ranges from 63\% to 78\% with an average reduction of $69 \%$. The reason for the large difference in both comparisons is that the both base cases, Case 0 and Case 1, use constant speed fans, while all the low-lift options (Case 5 through Case 8) use VAV or RCP.

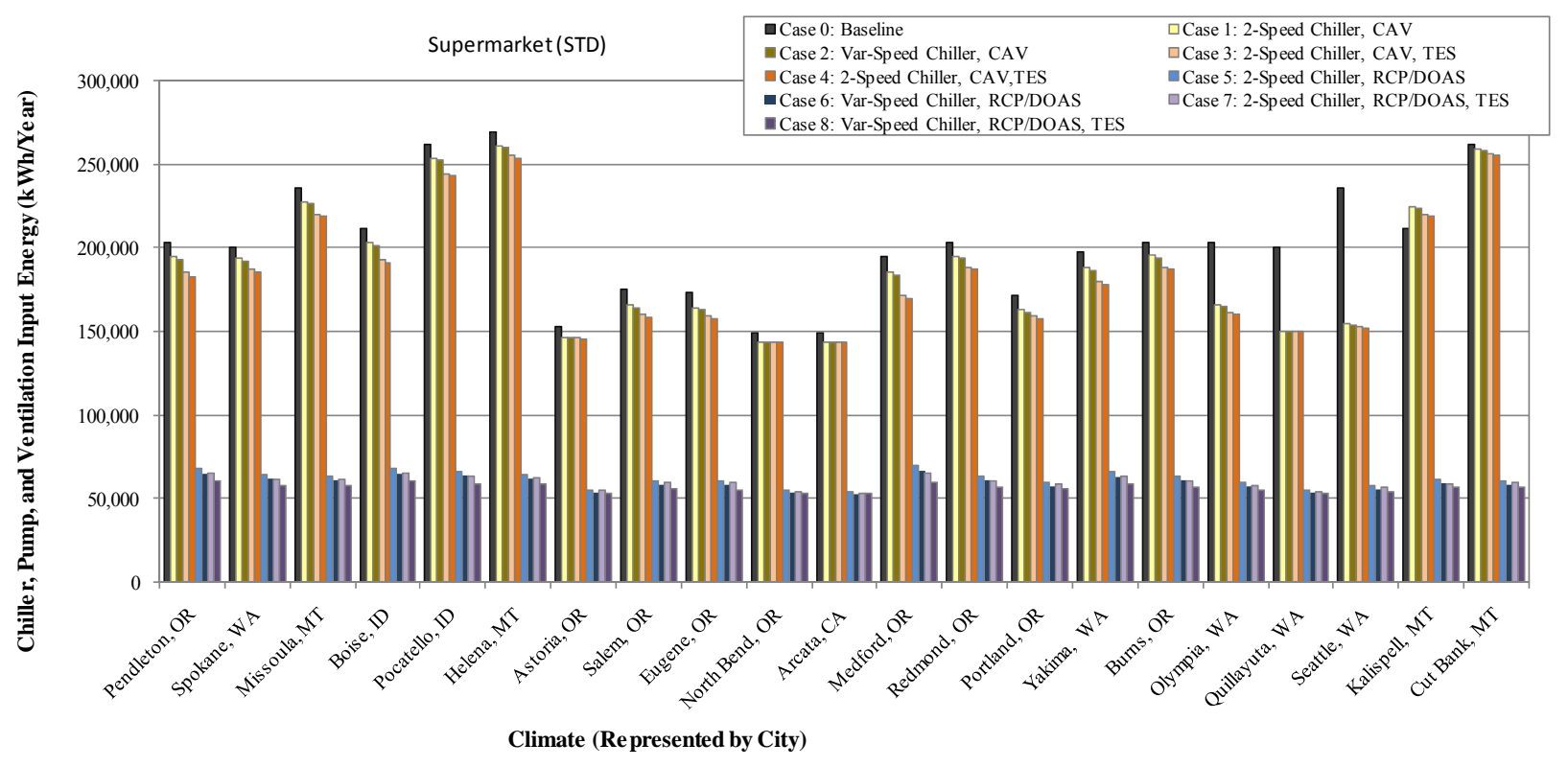

Figure 18 Comparison of Annual Chiller and Distribution Energy Consumption for Standard-Perforamance Supermarket Building for Various System Configurations in 21 Locations 
For high-performance supermarket (Figure 19), the reduction in energy consumption between Case 0 and Case 8 ranges from $47 \%$ to $61 \%$ with an average reduction of $55 \%$. In general, the trend across all climate locations is similar. The difference between low-lift base case (Case 1) and the full LLCS (Case 8 ) ranges from $42 \%$ to $58 \%$ with an average reduction of $51 \%$, slightly lower than the difference between Case 0 and Case 8 .

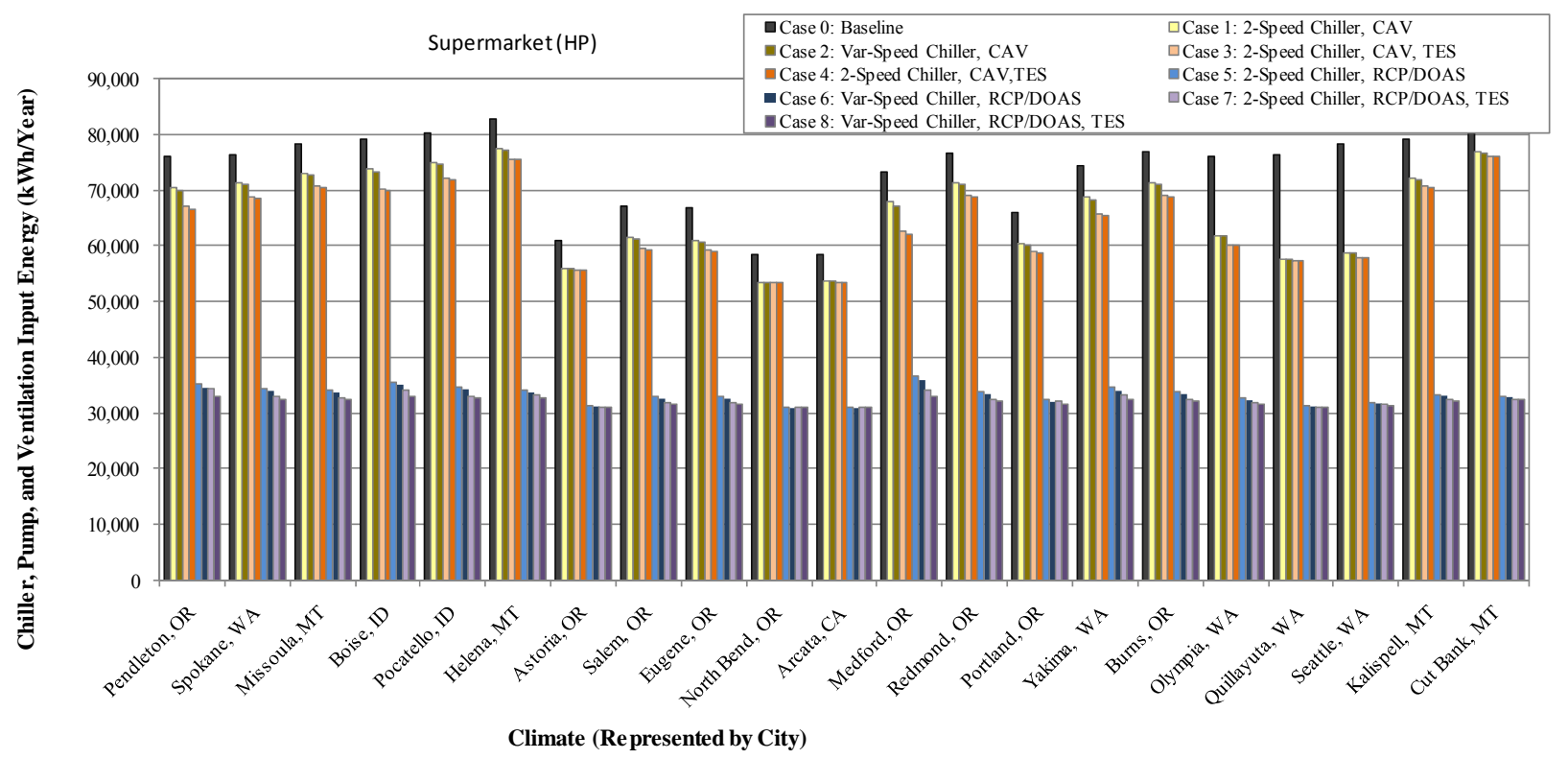

Figure 19 Comparison of Annual Chiller and Distribution Energy Consumption for HighPerformance Supermarket Building for Various System Configurations in 21 Locations

For standard secondary school (Figure 20), the reduction in energy consumption between Case 0 and Case 8 ranges from $57 \%$ to $69 \%$ with an average reduction of $61 \%$. In general, the trend across all climate locations is similar. The difference between low-lift base case (Case 1) and the full LLCS (Case 8 ) ranges from $50 \%$ to $59 \%$, with an average reduction of $56 \%$; this is slightly lower than the difference between Case 0 and Case 8 . The secondary school uses a water-cooled chiller with VAV system as the base case (Case 0 ) to condition a significant portion of the school area and a packaged constant-speed single-zone DX unit for the kitchen and gymnasium, and two-speed air-cooled chiller with VAV system for Case 1.

For high-performance secondary school (Figure 21), the reduction in energy consumption between Case 0 and Case 8 ranges from $51 \%$ to $60 \%$ with an average reduction of $56 \%$. It is worth noting that the difference between the low-lift base case (Case 1) and the full LLCS (Case 8 ) is lower and ranges from $39 \%$ to $55 \%$, with an average reduction of just $48 \%$. 


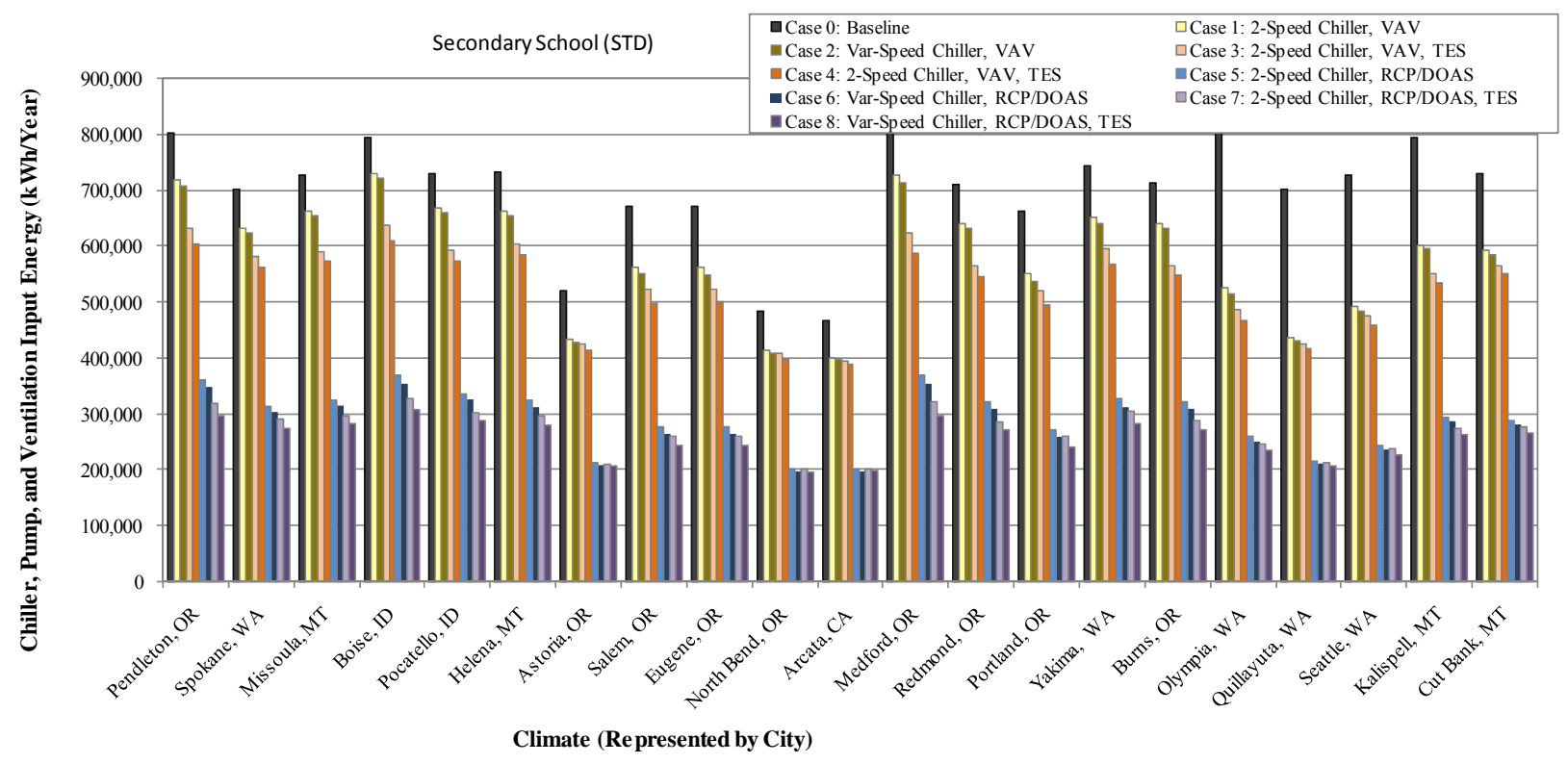

Figure 20 Comparison of Annual Chiller and Distribution Energy Consumption for Standard-Performance Secondary School Building for Various System Configurations in 21 Locations

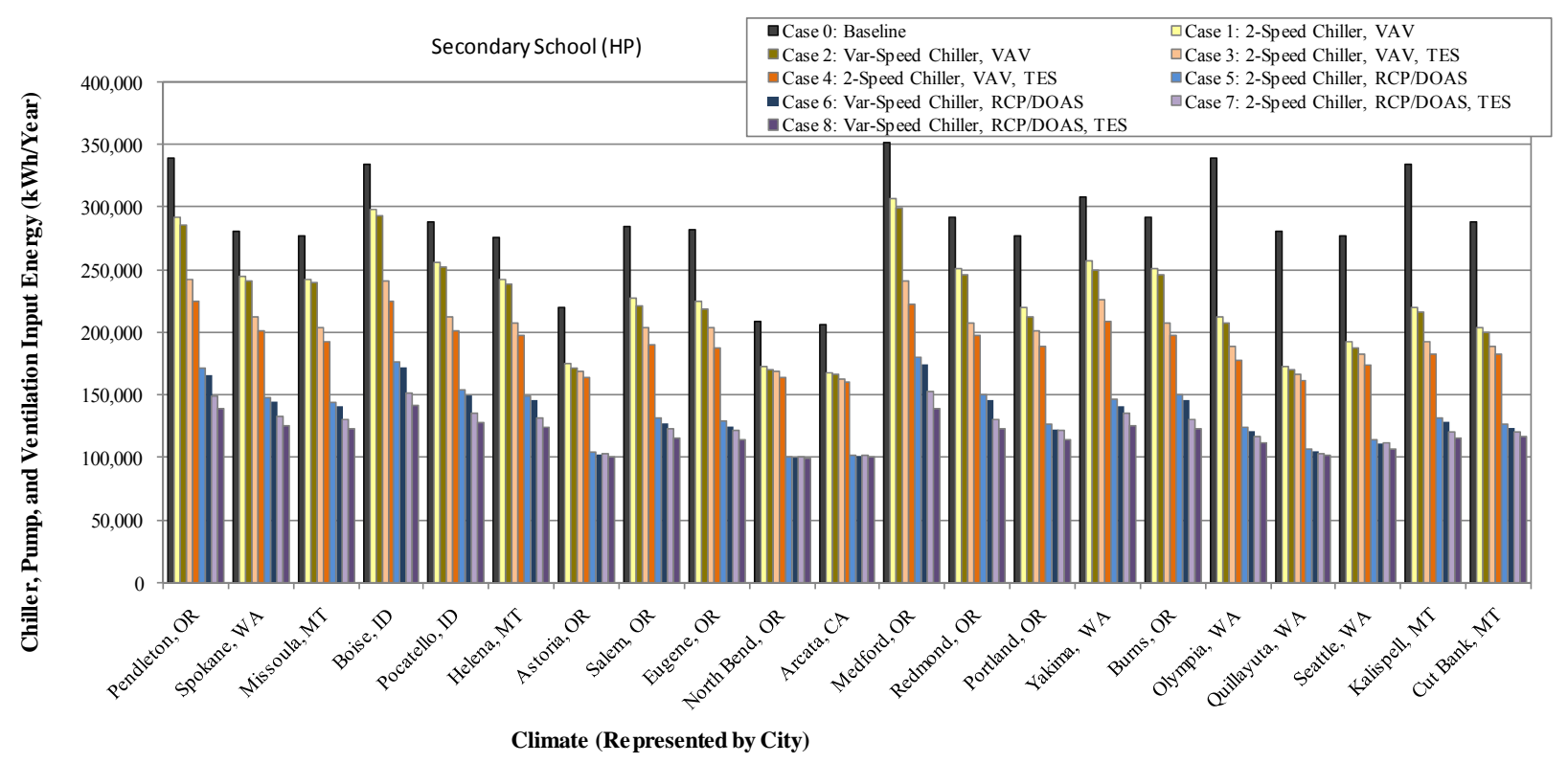

Figure 21 Comparison of Annual Chiller and Distribution Energy Consumption for HighPerformance Secondary School Building for Various System Configurations in 21 Locations

The comparison figures for the rest of the building (similar to Figure 14) are included in Appendix C (Appendix: Energy Use Estimate Tables and Figures). The range of percent energy savings across the climate locations for all building types with respect to the base case are shown in Table 22 (Case 0 as reference) and Table 23 (Case 1 as reference). For each row, percent savings are computed with reference to the corresponding Case 0 or Case 1 energy consumption. The general trends are similar to the four building types discussed previously in this section. 
Although there are significant percent savings in the large hotel from use of the full LLCS, the saving are only from central HVAC systems used in the common areas and conference rooms and not the individual rooms. Therefore, the percent savings are not computed for Hotels. Note that for the primary and the secondary schools, the percent saving are also high, even considering that these buildings usually have high ventilation requirements. The savings for the warehouses (non-refrigerated) are for the office portion of the warehouse and not the entire warehouse.

Table 22 Range of Energy Reduction (between Case 0 and Case 8) in Annual Chiller and Distribution Energy Consumption for both Standard and High-Performance Buildings in Various Climate Locations

\begin{tabular}{|l|r|r|r|r|r|r|}
\hline & \multicolumn{2}{|c|}{ Standard-Performance Building } & \multicolumn{3}{|c|}{ High-Performance Building } \\
\hline Building Type & Minimum & Maximum & Average & Minimum & Maximum & Average \\
\hline Office Small & $77 \%$ & $82 \%$ & $81 \%$ & $14 \%$ & $54 \%$ & $44 \%$ \\
\hline Office Medium & $57 \%$ & $67 \%$ & $62 \%$ & $56 \%$ & $71 \%$ & $66 \%$ \\
\hline Office Large & $40 \%$ & $54 \%$ & $47 \%$ & $27 \%$ & $49 \%$ & $36 \%$ \\
\hline Retail Standalone & $70 \%$ & $77 \%$ & $75 \%$ & $46 \%$ & $63 \%$ & $57 \%$ \\
\hline Retail Strip Mall & $54 \%$ & $69 \%$ & $65 \%$ & $-8 \%$ & $47 \%$ & $30 \%$ \\
\hline Primary School & $46 \%$ & $63 \%$ & $58 \%$ & $31 \%$ & $53 \%$ & $46 \%$ \\
\hline Secondary School & $57 \%$ & $64 \%$ & $61 \%$ & $51 \%$ & $60 \%$ & $56 \%$ \\
\hline Hotel Large & & & & & & \\
\hline Supermarket & $65 \%$ & $79 \%$ & $71 \%$ & $47 \%$ & $61 \%$ & $55 \%$ \\
\hline Warehouse & $51 \%$ & $80 \%$ & $68 \%$ & $-11 \%$ & $48 \%$ & $17 \%$ \\
\hline Outpatient & $81 \%$ & $86 \%$ & $84 \%$ & $39 \%$ & $69 \%$ & $61 \%$ \\
\hline Hospital & $68 \%$ & $75 \%$ & $72 \%$ & $57 \%$ & $67 \%$ & $62 \%$ \\
\hline
\end{tabular}


Table 23 Range of Energy Reduction (between Case 1 and Case 8) in Annual Chiller and Distribution Energy Consumption for both Standard- and High-Performance Buildings in Various Climate Locations

\begin{tabular}{|l|r|r|r|r|r|r|}
\hline & \multicolumn{2}{|c|}{ Standard-Performance Building } & \multicolumn{3}{c|}{ High-Performance Building } \\
\hline Building Type & Minimum & \multicolumn{1}{c|}{ Maximum } & Average & Minimum & Maximum & Average \\
\hline Office Small & $76 \%$ & $82 \%$ & $80 \%$ & $12 \%$ & $52 \%$ & $41 \%$ \\
\hline Office Medium & $38 \%$ & $61 \%$ & $51 \%$ & $46 \%$ & $64 \%$ & $57 \%$ \\
\hline Office Large & $31 \%$ & $60 \%$ & $46 \%$ & $18 \%$ & $43 \%$ & $32 \%$ \\
\hline Retail Standalone & $70 \%$ & $77 \%$ & $74 \%$ & $46 \%$ & $61 \%$ & $55 \%$ \\
\hline Retail Strip Mall & $54 \%$ & $68 \%$ & $64 \%$ & $-9 \%$ & $45 \%$ & $26 \%$ \\
\hline Primary School & $39 \%$ & $57 \%$ & $52 \%$ & $24 \%$ & $45 \%$ & $37 \%$ \\
\hline Secondary School & $50 \%$ & $59 \%$ & $56 \%$ & $39 \%$ & $55 \%$ & $48 \%$ \\
\hline Hotel Large & & & & & & \\
\hline Supermarket & $63 \%$ & $78 \%$ & $69 \%$ & $42 \%$ & $58 \%$ & $51 \%$ \\
\hline Warehouse & $50 \%$ & $79 \%$ & $67 \%$ & $-11 \%$ & $47 \%$ & $16 \%$ \\
\hline Outpatient & $81 \%$ & $85 \%$ & $84 \%$ & $39 \%$ & $67 \%$ & $60 \%$ \\
\hline Hospital & $64 \%$ & $75 \%$ & $70 \%$ & $47 \%$ & $57 \%$ & $53 \%$ \\
\hline
\end{tabular}

\section{Reheat Savings}

In the previous section, the cooling and fan (for both cooling and heating) savings were presented. In addition to the cooling and fan savings, there will be reheat savings for some building types. When a multi-zone system is used, there is some reheat that is unavoidable. However, with a radiant cooling system, reheat can be fully avoided. The reheat savings are computed when one or more zones is in the heating mode and the central cooling coil is active (i.e., mechanical cooling is ON). The supply loop for a VAV system is shown graphically in Figure 22. The reheating penalty occurs when both the central cooling $(\mathrm{C} / \mathrm{C})$ and the zone heating coils $(H / C)$ are active. This condition occurs when the $T_{z, i}>T_{\text {supply. }}$. The reheating penalty $\left(\mathrm{E}_{\text {reheat }}\right)$ is estimated using the following equations:

$$
\begin{aligned}
& E_{\text {reheat }}=m_{z, i} c_{p}\left(T_{z, i}-T_{c c}\right) \quad \text { if } T_{z, i}<T_{\text {mix }} \\
& E_{\text {reheat }}=m_{z, i} c_{p}\left(T_{\text {mix }}-T_{c c}\right) \quad \text { if } T_{z, i} \geq T_{\text {mix }}
\end{aligned}
$$




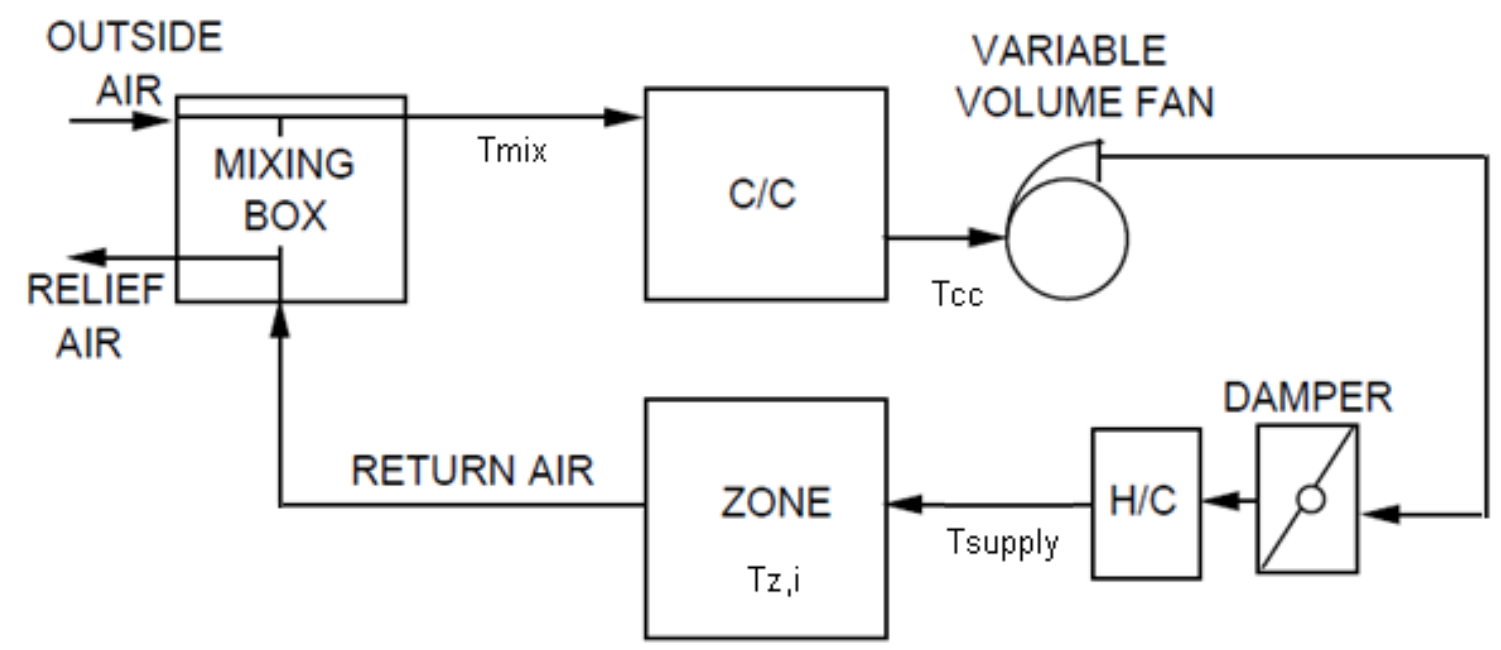

\section{Figure 22 Variable Air Volume System with Terminal Reheat}

The reheating penalty is computed for each zone and aggregated in Table 24. Although the absolute energy reheat penalty is significant, it is a very small fraction of the total heating energy use, as shown in Table 25. In reality, the reheating penalty is going to be significantly higher than what the simulation has estimated. Because it is common to have different set point in different zones, which will lead to increased reheat. Also, while simulating buildings, the controls are assumed to perfect, so the controls are idealized.

Table 24 Reheat Savings for Selected Building Types in Different Climate Locations (million Btus)

\begin{tabular}{|c|c|c|c|c|c|c|}
\hline & Hospital & Hotel Large & Office Large & Office Medium & School Primary & School Secondary \\
\hline Arcata, CA & $1,203.4$ & 136.9 & $\begin{array}{r}806.6 \\
\end{array}$ & 60.5 & 21.7 & 143.5 \\
\hline Astoria, OR & $1,363.5$ & 157.9 & 904.7 & 65.1 & 30.1 & 128.2 \\
\hline Boise, ID & $1,480.3$ & 121.5 & $1,444.5$ & 71.9 & 50.4 & 237.3 \\
\hline Burns, OR & $1,417.6$ & 95.3 & $1,315.1$ & 70.5 & 39.3 & 231.2 \\
\hline Cut Bank, MT & $1,694.5$ & 80.9 & $1,855.6$ & 74.9 & 34.0 & 223.7 \\
\hline Eugene, OR & $1,370.1$ & 158.7 & $1,009.2$ & 76.4 & 45.1 & 130.7 \\
\hline Helena, MT & $1,160.9$ & 101.9 & $2,348.4$ & 77.1 & 39.3 & 259.6 \\
\hline Kalispell, MT & $1,169.1$ & 93.3 & $1,031.2$ & 65.0 & 30.6 & 200.9 \\
\hline Medford, OR & $1,383.3$ & 129.0 & $1,025.8$ & 79.2 & 50.4 & 212.9 \\
\hline Missoula, MT & $1,379.9$ & 115.2 & $1,209.7$ & 69.9 & 35.4 & 211.1 \\
\hline North Bend, OR & $1,215.2$ & 157.0 & 876.8 & 62.5 & 23.2 & 131.2 \\
\hline Olympia, WA & $1,312.2$ & 139.1 & 956.7 & 70.2 & 41.5 & 127.2 \\
\hline Pendleton, OR & $1,277.5$ & 149.9 & $1,253.6$ & 80.0 & 52.5 & 254.0 \\
\hline Pocatello, ID & $1,462.6$ & 96.3 & $2,848.2$ & 72.1 & 38.3 & 214.5 \\
\hline Portland, OR & $1,445.8$ & 177.5 & $1,011.5$ & 75.3 & 46.7 & 128.9 \\
\hline Quillayuta, WA & $1,360.3$ & 124.0 & 942.4 & 63.8 & 26.9 & 162.2 \\
\hline Redmond, OR & $1,414.9$ & 94.9 & $1,316.4$ & 70.3 & 39.3 & 230.2 \\
\hline Salem, OR & $1,294.0$ & 151.0 & 940.3 & 73.0 & 43.9 & 127.6 \\
\hline Seattle, WA & $1,427.2$ & 163.8 & 997.7 & 73.8 & 40.7 & 131.5 \\
\hline Spokane, WA & $1,257.3$ & 108.9 & $1,274.1$ & 70.0 & 35.8 & 198.9 \\
\hline Yakima, WA & $1,291.4$ & 124.2 & 941.0 & 72.0 & 40.1 & 174.1 \\
\hline
\end{tabular}


Table 25 Reheating Savings as a Fraction of the Total Heating

\begin{tabular}{|c|c|c|c|c|c|c|}
\hline & Hospital & Hotel Large & Office Large & Office Medium & School Primary & School Secondary \\
\hline Arcata, CA & $0.025 \%$ & $0.003 \%$ & $0.014 \%$ & $0.006 \%$ & $0.001 \%$ & $0.002 \%$ \\
\hline Astoria, OR & $0.031 \%$ & $0.004 \%$ & $0.016 \%$ & $0.007 \%$ & $0.001 \%$ & $0.002 \%$ \\
\hline Boise, ID & $0.021 \%$ & $0.002 \%$ & $0.013 \%$ & $0.004 \%$ & $0.001 \%$ & $0.001 \%$ \\
\hline Burns, OR & $0.015 \%$ & $0.001 \%$ & $0.008 \%$ & $0.003 \%$ & $0.000 \%$ & $0.001 \%$ \\
\hline Cut Bank, MT & $0.025 \%$ & $0.001 \%$ & $0.019 \%$ & $0.005 \%$ & $0.001 \%$ & $0.001 \%$ \\
\hline Eugene, OR & $0.008 \%$ & $0.001 \%$ & $0.003 \%$ & $0.002 \%$ & $0.000 \%$ & $0.000 \%$ \\
\hline Helena, MT & $0.004 \%$ & $0.000 \%$ & $0.005 \%$ & $0.001 \%$ & $0.000 \%$ & $0.000 \%$ \\
\hline Kalispell, MT & $0.014 \%$ & $0.001 \%$ & $0.006 \%$ & $0.002 \%$ & $0.000 \%$ & $0.001 \%$ \\
\hline Medford, OR & $0.028 \%$ & $0.004 \%$ & $0.015 \%$ & $0.010 \%$ & $0.004 \%$ & $0.005 \%$ \\
\hline Missoula, MT & $0.039 \%$ & $0.005 \%$ & $0.045 \%$ & $0.012 \%$ & $0.003 \%$ & $0.007 \%$ \\
\hline North Bend, OR & $0.018 \%$ & $0.003 \%$ & $0.009 \%$ & $0.004 \%$ & $0.000 \%$ & $0.001 \%$ \\
\hline Olympia, WA & $0.008 \%$ & $0.001 \%$ & $0.003 \%$ & $0.002 \%$ & $0.000 \%$ & $0.000 \%$ \\
\hline Pendleton, OR & $0.004 \%$ & $0.001 \%$ & $0.003 \%$ & $0.001 \%$ & $0.000 \%$ & $0.000 \%$ \\
\hline Pocatello, ID & $0.017 \%$ & $0.001 \%$ & $0.017 \%$ & $0.003 \%$ & $0.000 \%$ & $0.001 \%$ \\
\hline Portland, OR & $0.029 \%$ & $0.006 \%$ & $0.015 \%$ & $0.010 \%$ & $0.003 \%$ & $0.003 \%$ \\
\hline Quillayuta, WA & $0.038 \%$ & $0.005 \%$ & $0.035 \%$ & $0.011 \%$ & $0.003 \%$ & $0.006 \%$ \\
\hline Redmond, OR & $0.056 \%$ & $0.007 \%$ & $0.135 \%$ & $0.029 \%$ & $0.009 \%$ & $0.025 \%$ \\
\hline Salem, OR & $0.094 \%$ & $0.012 \%$ & $0.150 \%$ & $0.075 \%$ & $0.038 \%$ & $0.046 \%$ \\
\hline Seattle, WA & $0.011 \%$ & $0.002 \%$ & $0.004 \%$ & $0.002 \%$ & $0.000 \%$ & $0.000 \%$ \\
\hline Spokane, WA & $0.028 \%$ & $0.005 \%$ & $0.026 \%$ & $0.011 \%$ & $0.004 \%$ & $0.009 \%$ \\
\hline Yakima, WA & $0.023 \%$ & $0.004 \%$ & $0.016 \%$ & $0.007 \%$ & $0.003 \%$ & $0.004 \%$ \\
\hline
\end{tabular}




\section{Pacific Northwest Regional Energy Savings Estimation Methodology}

In the previous section, the potential energy savings for the LLCS for 21 building prototypes in 21 climate locations was summarized. To estimate the regional energy savings potential, however, requires the "translation" from savings per building to savings across the commercial buildings' sector in the Pacific Northwest Region. This translation requires a set of factors that weight the results of each building prototype in each climate location proportionately into the national aggregate energy savings estimates. Because the LLCS is more suitable for new construction or major retrofit, the individual building savings estimates have to be scaled to the potential new commercial building stock. The building weights developed by Northwest Power Planning Council ${ }^{17}$ (NWPC) were used to calculate the new construction building weights by building type and climate location needed to estimate the energy savings.

The NWPC developed the new construction weights from the McGraw-Hill Construction (MCH) Projects Starts Database. The MHC dataset is drawn from permit data on new commercial building starts in the U.S. and represents an overwhelming sample of over $90 \%$ of the new commercial buildings as described in Jarnagin and Bandyopadhyay (2010). This dataset covers construction data for most new buildings as well as additions to existing facilities over a 6 year period (2002-2007).

To estimate the number of equivalent prototype buildings (Table 26), weights, based on square footage, were assigned by 21 climate locations and by building prototype or category of building type (i.e., large office, supermarket). These weights were then converted to number of equivalent prototype buildings by dividing by the area of each representative prototype (Table 26). The number of equivalent buildings built each year for each building type and climate location are shown in Table 27.

${ }^{17}$ The data was provided by Charlie Grist from NW Power Planning Council 
Table 26 Benchmark Building Prototype Areas

\begin{tabular}{|l|r|}
\hline Building Type & Area (sf) \\
\hline Supermarket & 45,000 \\
\hline Hospital & 241,501 \\
\hline Hotel Large & 100,816 \\
\hline Office Large & 498,588 \\
\hline Office Medium & 53,627 \\
\hline Outpatient Health Care & 10,005 \\
\hline School Primary & 73,960 \\
\hline Retail Stand-Alone & 24,692 \\
\hline School Secondary & 210,886 \\
\hline Office Small & 5,500 \\
\hline Retail Strip Mall & 22,500 \\
\hline Warehouse & 52,045 \\
\hline
\end{tabular}


Table 27 Annual New Construction Weights (number of buildings per year) by Building Type and Climate Location

\begin{tabular}{|c|c|c|c|c|c|c|c|c|c|c|c|c|}
\hline & $\begin{array}{l}\text { Office } \\
\text { Small }\end{array}$ & $\begin{array}{l}\text { Office } \\
\text { Medium }\end{array}$ & $\begin{array}{l}\text { Office } \\
\text { Large }\end{array}$ & $\begin{array}{c}\text { Retail Stand- } \\
\text { Alone }\end{array}$ & $\begin{array}{c}\text { Retail } \\
\text { Strip Mall }\end{array}$ & \begin{tabular}{|c|} 
School \\
Primary
\end{tabular} & $\begin{array}{c}\text { School } \\
\text { Secondary }\end{array}$ & Hospital & $\begin{array}{l}\text { Outpatient } \\
\text { Health Care }\end{array}$ & Warehouse & $\begin{array}{l}\text { Hotel } \\
\text { Large }\end{array}$ & Supermarket \\
\hline Spokane, WA & 15.97 & 15.97 & 15.97 & \begin{tabular}{r|}
15.97 \\
\end{tabular} & 15.97 & \begin{tabular}{|l|}
15.97 \\
\end{tabular} & \begin{tabular}{r|}
15.97 \\
\end{tabular} & 15.97 & 15.97 & 15.97 & 15.97 & 15.97 \\
\hline Pendleton, OR & 4.85 & 4.85 & 4.85 & 4.85 & 4.85 & 4.85 & 4.85 & 4.85 & 4.85 & 4.85 & 4.85 & 4.85 \\
\hline Missoula, MT & 2.09 & 1.38 & 0.00 & 1.10 & 0.83 & 0.00 & 0.01 & 0.01 & 0.49 & 0.62 & 0.09 & 0.71 \\
\hline Boise, ID & 49.03 & 9.87 & 0.31 & 9.64 & 10.61 & 4.37 & 1.51 & 0.48 & 13.36 & 6.13 & 2.07 & 1.25 \\
\hline Pocatello, ID & 8.07 & 2.63 & 0.07 & 4.57 & 2.51 & 0.97 & 0.44 & 0.50 & 4.77 & 2.92 & 0.36 & 0.31 \\
\hline Helena, MT & 0.65 & 0.99 & 0.00 & 0.59 & 0.49 & 0.17 & 0.06 & 0.05 & 1.25 & 0.12 & 0.00 & 0.00 \\
\hline Astoria, OR & 0.73 & 0.22 & 0.00 & 0.46 & 0.08 & 0.07 & 0.09 & 0.01 & 0.00 & 0.29 & 0.30 & 0.32 \\
\hline Salem, OR & 9.97 & 3.45 & 0.95 & 6.72 & 3.71 & 1.00 & 0.33 & 0.48 & 6.31 & 2.78 & 0.76 & 0.99 \\
\hline Eugene, OR & 8.67 & 2.13 & 0.14 & 1.51 & 2.35 & 0.84 & 0.29 & 1.15 & 8.54 & 2.68 & 0.32 & 0.49 \\
\hline North Bend, OR & 1.10 & 0.34 & 0.00 & 0.36 & 0.02 & 0.00 & 0.01 & 0.00 & 0.26 & 0.04 & 0.00 & 0.00 \\
\hline Arcata, CA & 0.00 & 0.03 & 0.00 & 0.00 & 0.00 & 0.00 & 0.10 & 0.00 & 0.00 & 0.00 & 0.00 & 0.00 \\
\hline Medford, OR & 5.85 & 2.10 & 0.00 & 3.68 & 0.92 & 0.84 & 0.16 & 0.49 & 7.09 & 1.40 & 0.77 & 0.20 \\
\hline Redmond, OR & 6.32 & 3.61 & 0.00 & 3.87 & 2.18 & 0.80 & 0.14 & 0.39 & 6.74 & 1.64 & 0.29 & 0.23 \\
\hline Portland, OR & 28.92 & 15.54 & 1.10 & 24.31 & 17.66 & 5.30 & 1.39 & 1.40 & 51.61 & 34.56 & 0.84 & 5.89 \\
\hline Yakima, WA & 5.71 & 2.10 & 0.10 & 3.12 & 1.35 & 0.84 & 0.39 & 0.03 & 3.64 & 7.42 & 0.90 & 0.98 \\
\hline Burns, OR & 0.26 & 0.08 & 0.00 & 0.00 & 0.05 & 0.00 & 0.01 & 0.04 & 0.09 & 0.02 & 0.00 & 0.00 \\
\hline Olympia, WA & 9.63 & 4.60 & 0.17 & 10.42 & 2.65 & 1.00 & 0.30 & 0.36 & 6.99 & 8.85 & 1.45 & 0.54 \\
\hline Quillayuta, WA & 0.31 & 0.18 & 0.00 & 1.33 & 0.22 & 0.01 & 0.02 & 0.01 & 5.91 & 0.01 & 0.08 & 0.05 \\
\hline Seattle, WA & 43.54 & 26.98 & 4.05 & 41.13 & 21.06 & 8.39 & 3.93 & 2.64 & 64.56 & 44.21 & 7.54 & 7.33 \\
\hline Kalispell, MT & 1.48 & 0.53 & 0.00 & 2.45 & 0.18 & 0.29 & 0.20 & 0.07 & 0.94 & 0.34 & 0.16 & 0.27 \\
\hline Cut Bank, MT & 0.21 & 0.00 & 0.00 & 0.00 & 0.00 & 0.00 & 0.07 & 0.00 & 0.43 & 0.00 & 0.00 & 0.00 \\
\hline
\end{tabular}




\section{Pacific Northwest Regional Technical Energy Savings Potential}

The annual regional energy savings potential (cooling, fan and pump) from widespread use of the LLCS was estimated by applying the previously described methodology to the energy savings estimated for each building performance level and 21 climate locations. Table 28 summarizes the regional energy saving for the full LLCS (Case 8), compared to the baseline buildings that are compliant with ASHRAE 90.1-2004 (Case 0). Note that these annual estimates are for new construction and building-types and climate locations for which the full LLCS is applicable (see previous section). Although it is likely that parts of the LLCS are applicable for a large portion of the existing commercial building stock and the full LLCS may be applicable to a substantial fraction of the existing building stock, the savings were not estimated for that potential in this study, because the primary market - as with most advanced systems - is new construction. In this sense, the technical potential presented here is conservative.

Table 28 Summary of Regional Technical Site Electricity Savings Potential for the Year 2010 for the Low-Lift Cooling Design Option Set - Case 8 (assuming 100\% Penetration) in Comparison to Case 0

\begin{tabular}{|l|r|r|r|}
\hline $\begin{array}{c}\text { Building Performance } \\
\text { Level }\end{array}$ & \multicolumn{3}{|c|}{ Cooling and Fan and Pump Electricity Savings } \\
\cline { 2 - 4 } & million kWh/year & $\begin{array}{c}\text { Peak Reduction } \\
\text { aMW }\end{array}$ & $\begin{array}{c}\text { Percentage Electricity } \\
\text { Savings }\end{array}$ \\
\hline Standard & $\mathbf{5 6 . 8}$ & 6.5 & $\mathbf{7 4 . 1 \%}$ \\
\hline High Performance & $\mathbf{1 5 . 5}$ & 1.8 & $63.5 \%$ \\
\hline
\end{tabular}

For baseline buildings that are compliant with ASHRAE 90.1-2004, the full LLCS saves about 57 million $\mathrm{kWh}$ of site electricity use in 1 year of new construction with the full LLCS. The corresponding average peak reductions are about 6.2 MW. The annual site electricity savings are about 15.5 million $\mathrm{kWh}$ for high-performance buildings and the average peak reduction is about 1.8 MW. The energy saving for the full LLCS (Case 8) compared to the conventional VAV system with two-speed chiller (Case 1) are shown in Table 29.

Table 29 - Summary of Regional Technical Site Electricity Savings Potential for the Year 2010 for the Low-Lift Cooling Design Option Set - Case 8 (assuming 100\% Penetration) Compared to Case 1

\begin{tabular}{|l|r|r|r|}
\hline \multirow{2}{*}{$\begin{array}{c}\text { Building Performance } \\
\text { Level }\end{array}$} & \multicolumn{3}{|c|}{ Cooling and Fan and Pump Electricity Savings } \\
\cline { 2 - 4 } & million kWh/year & $\begin{array}{c}\text { Peak Reduction } \\
\text { aMW }\end{array}$ & $\begin{array}{c}\text { Percentage Electricity } \\
\text { Savings }\end{array}$ \\
\hline Standard & $\mathbf{4 2 . 1}$ & 4.8 & $\mathbf{7 1 . 1 \%}$ \\
\hline High Performance & $\mathbf{1 1 . 3}$ & 1.3 & $61.0 \%$ \\
\hline
\end{tabular}

The annual regional technical energy savings for different system configurations compared to the baseline building (Case 0) are shown in Figure 23. For baseline buildings, the savings range from 15 million $\mathrm{kWh} /$ year for conventional system (Case 1) to $57 \mathrm{million} \mathrm{kWh} / \mathrm{year}$ for the full LLCS. 
The annual regional technical energy savings for different system configurations compared to the conventional VAV system with two-speed chiller (Case 1) are shown in Figure 24. For baseline buildings, the savings range from 1.2 million $\mathrm{kWh} /$ year to 0.002 trillion Btu/year for variablespeed chiller system configured with conventional VAV distribution to 44 million $\mathrm{kWh} / \mathrm{year}$ for the full LLCS.

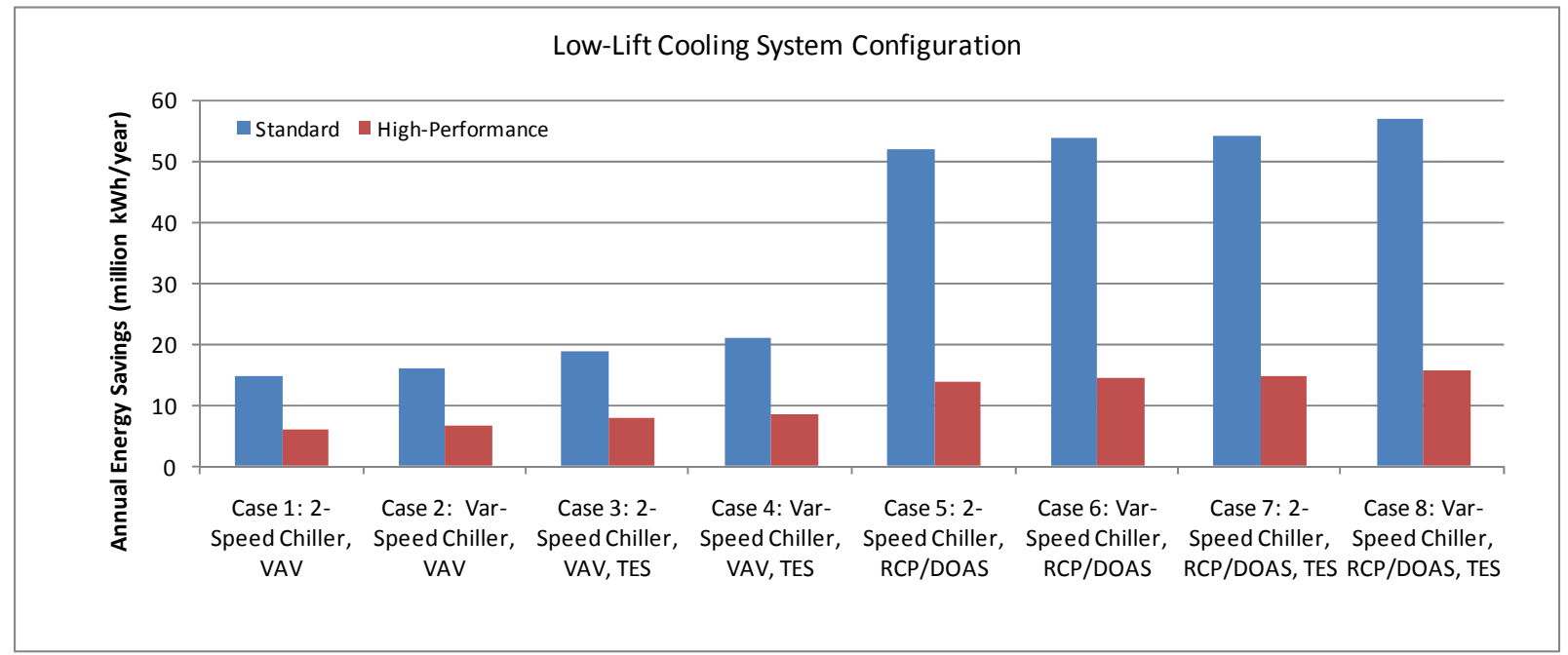

Figure 23 Comparison of Regional Technical Site Electricity Savings Potential for the Year 2010 for Various Low-Lift Cooling Design Option Sets (assuming 100\% Penetration) in Comparison to Case 0

Low-Lift Cooling System Configuration

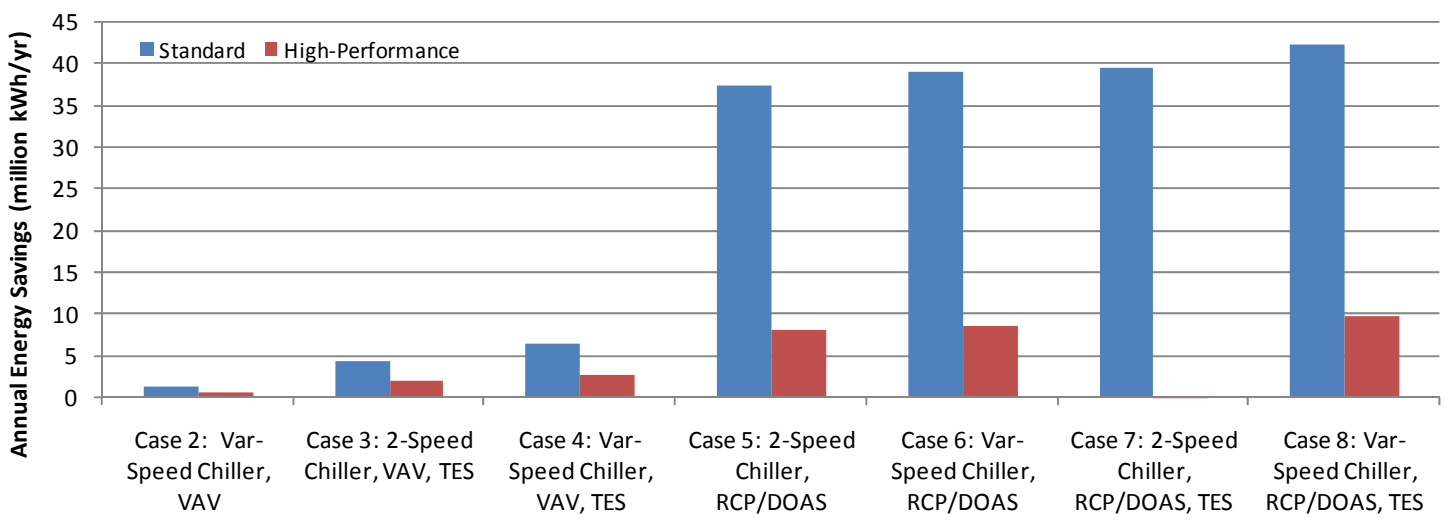

Figure 24 Comparison of Regional Technical Site Electricity Savings Potential for the Year 2010 for Various Low-Lift Cooling Design Option Sets (assuming 100\% Penetration) in Comparison to Case 1

Assuming a new construction growth rates (1\%) remain the same for the next decade (through the year 2020), the total regional technical site energy savings potential (again assuming 100\% penetration) from new construction between 2010 and 2020 for the baseline building would be 625 million kWh/year (Figure 25 and Figure 26). To reiterate, all of these savings are in site 
energy terms; to calculate source energy savings at the power plant, using average "busbar" savings of $7.25 \%$, the previous estimates should be multiplied by 1.0725 . The total savings potential - relative to the baseline building - is therefore 670 million $\mathrm{kWh} /$ year.

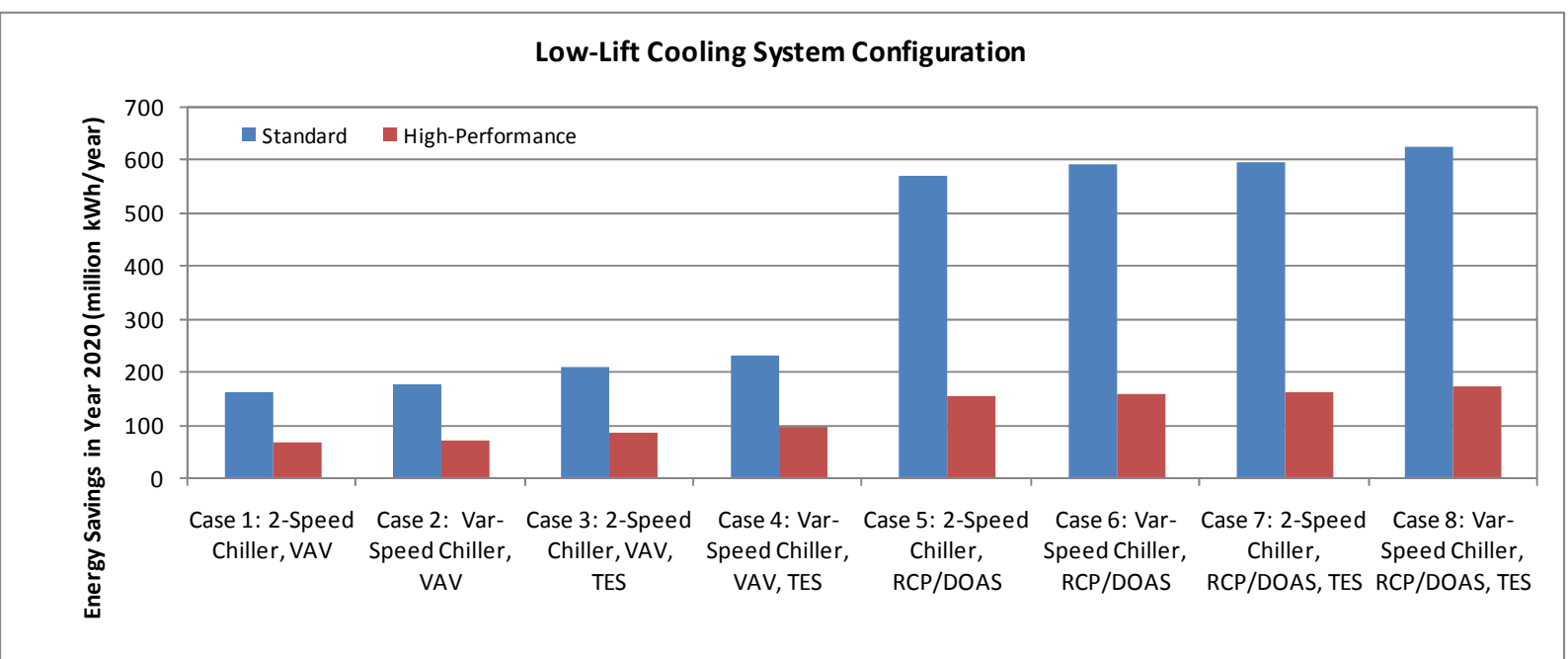

Figure 25 Pacific Northwest Regional Technical Site Electricity Savings in 2020 over the Standard HVAC System (Case 0) for Different System Configurations for 2020 Assuming $100 \%$ Penetration

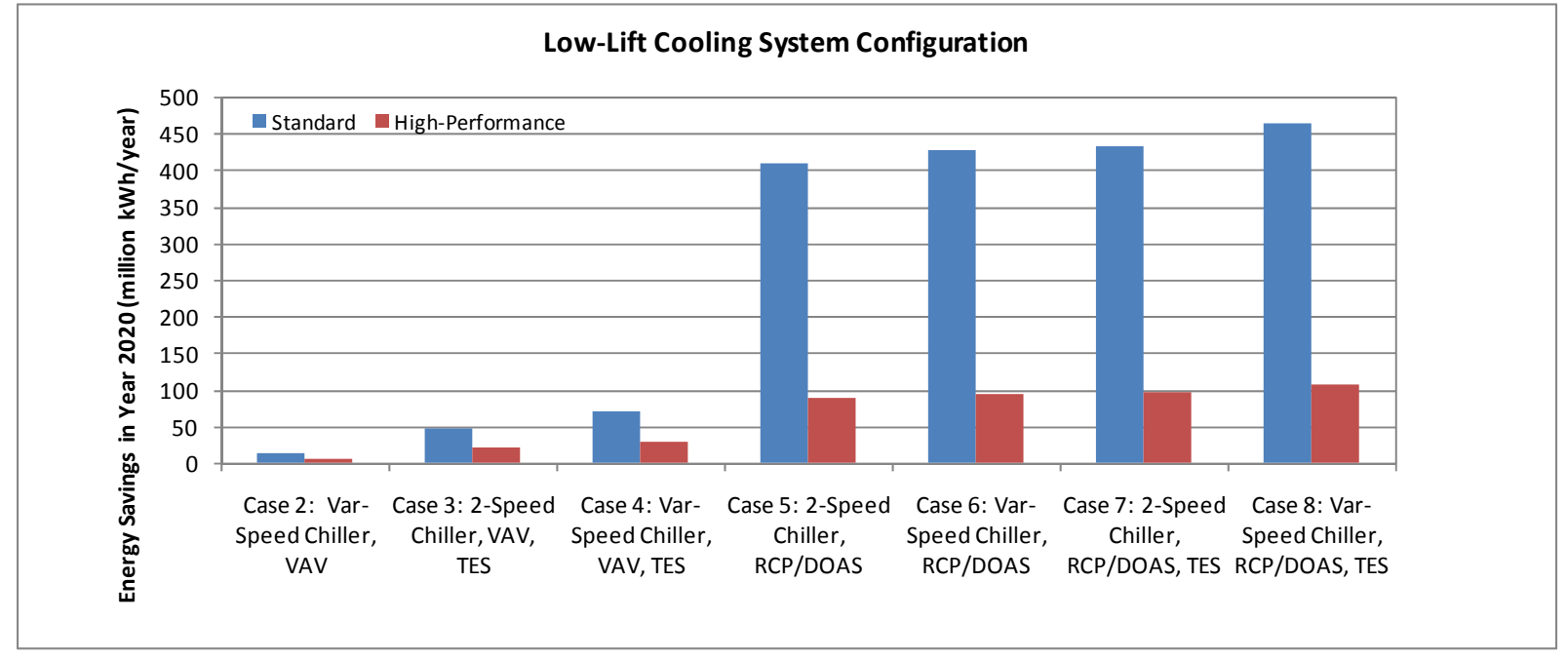

Figure 26 Pacific Northwest Regional Savings Technical Site Electricity Savings in 2020 over Case 1 for Different System Configurations for 2020 Assuming 100\% Penetration 


\section{Economic Analysis}

Unless the benefits (energy cost savings) are significant compared to the incremental cost of the LLCS, it is unlikely that these technologies will find widespread acceptance. Although the incremental cost estimates have some uncertainty, they provide qualitative assessment for the economics of the LLCS. NCI's incremental cost estimates are for Case 7 - variable-speed lowlift chiller, radiant cooling, and dedicated outdoor-air system with energy recovery system. Incremental cost of TES was not estimated because discrete TES is not going to be cost-effective on just energy savings alone. Unless there are significant peak demand savings, TES will not be cost-effective. A significant portion of the discrete TES savings can be captured by using passive (thermal mass of the building). Because this case (passive TES) was not analyzed for this study, the benefits from TES will not be used in studying the economics of the LLCS.

The national average incremental cost for four building types (medium office, large office, supermarket and secondary schools) was estimated to be $\$ 0, \$ 383,000, \$ 276,000, \$ 624,000$, respectively. Using the incremental cost and the energy savings, simple payback can be estimated. The energy savings was converted into cost savings using the typical electricity ${ }^{18}$ (cooling and fan) and gas ${ }^{19}$ (heating) cost for each of the regions published by the Energy Information Agency. The energy savings has two components - cooling and fan (Case 0 - Case 7 ) and the reheat penalty. Although there is also some demand savings, it is not included in the cost savings. Because the incremental cost savings are based on the national average, these costs have to be adjusted for each climate location. RS Means provides the city cost indices for each city, as shown in Table 30. The national cost can be multiplied by the index shown in Table 30 to get an estimate of the incremental cost in each climate location (Table 31).

The energy cost savings for the four building types in the 21 climate location is shown in Table 32. Simple payback is estimated as a ratio of the incremental cost (Table 31) and cost savings (Table 32) and reported in Table 33. Because the incremental cost of the medium office is negative, the LLCS has a zero payback. Large office and secondary school buildings have 8 to 30 year paybacks, which is probably a little bit high even for an emerging technology. Although the technology is applicable to supermarkets, it is difficult to complete with the relatively inexpensive single-zone packaged units. The aggregate payback (weighted by the new construction volume) for large office and secondary schools is reasonable, 17 and 23 years, respectively. The aggregated payback was estimated by weighting the payback periods of each location by their respective new construction volumes (see the next section of more information on new construction volumes). It appears that in the Pacific Northwest, this LLCS may not be favorable, without innovation breakthroughs in technology or provision of other incentives.

\footnotetext{
${ }^{18}$ Electricity Prices: Table 5.6.A http://www.eia.doe.gov/cneaf/electricity/epm/table5 3.html (December 2009)

${ }^{19}$ Natural Gas Prices: http://tonto.eia.doe.gov/dnav/ng/ng_pri_sum_dcu_nus_m.htm (December 2009)
} 
Table 30 City Cost Index (RS Means $2009^{20}$ )

\begin{tabular}{|l|r|}
\hline Spokane, WA & 0.95 \\
\hline Pendleton, OR & 1 \\
\hline Missoula, MT & 0.882 \\
\hline Boise, ID & 0.898 \\
\hline Pocatello, ID & 0.902 \\
\hline Helena, MT & 0.899 \\
\hline Astoria, OR & 1 \\
\hline Salem, OR & 1.002 \\
\hline Eugene, OR & 0.997 \\
\hline North Bend, OF & 1 \\
\hline Arcata, CA & 1.07 \\
\hline Medford, OR & 1.001 \\
\hline Redmond, OR & 1 \\
\hline Portland, OR & 1.01 \\
\hline Yakima, WA & 0.98 \\
\hline Burns, OR & 1 \\
\hline Olympia, WA & 1.02 \\
\hline Quillayuta, WA & 1.02 \\
\hline Seattle, WA & 1.039 \\
\hline Kalispell, MT & 0.882 \\
\hline Cut Bank, MT & 0.912 \\
\hline
\end{tabular}

${ }^{20}$ http://rsmeans.reedconstructiondata.com/60020.aspx (December 2009) 
Table 31 Incremental Cost of the LLCS by Building Type in each Climate Location

\begin{tabular}{|c|c|c|c|c|c|c|c|}
\hline & Medium Office & Lar & Office & Sup & narket & $\sec$ & y School \\
\hline Spokane, WA & $\$ 0$ & $\$$ & 363,850 & $\$$ & 262,200 & $\$$ & 592,800 \\
\hline Pendleton, OR & $\$ 0$ & $\$$ & 383,000 & $\$$ & 276,000 & $\$$ & 624,000 \\
\hline Missoula, MT & $\$ 0$ & $\$$ & 337,806 & $\$$ & 243,432 & $\$$ & 550,368 \\
\hline Boise, ID & $\$ 0$ & $\$$ & 343,934 & $\$$ & 247,848 & $\$$ & 560,352 \\
\hline Pocatello, ID & $\$ 0$ & $\$$ & 345,466 & $\$$ & 248,952 & $\$$ & 562,848 \\
\hline Helena, MT & $\$ 0$ & $\$$ & 344,317 & $\$$ & 248,124 & $\$$ & 560,976 \\
\hline Astoria, OR & $\$ 0$ & $\$$ & 383,000 & $\$$ & 276,000 & $\$$ & 624,000 \\
\hline Salem, OR & $\$ 0$ & $\$$ & 383,766 & $\$$ & 276,552 & $\$$ & 625,248 \\
\hline Eugene, OR & $\$ 0$ & $\$$ & 381,851 & $\$$ & 275,172 & $\$$ & 622,128 \\
\hline North Bend, OR & $\$ 0$ & $\$$ & 383,000 & $\$$ & 276,000 & $\$$ & 624,000 \\
\hline Arcata, CA & $\$ 0$ & $\$$ & 409,810 & $\$$ & 295,320 & $\$$ & 667,680 \\
\hline Medford, OR & $\$ 0$ & $\$$ & 383,383 & $\$$ & 276,276 & $\$$ & 624,624 \\
\hline Redmond, OR & $\$ 0$ & $\$$ & 383,000 & $\$$ & 276,000 & $\$$ & 624,000 \\
\hline Portland, OR & $\$ 0$ & $\$$ & 386,830 & $\$$ & 278,760 & $\$$ & 630,240 \\
\hline Yakima, WA & $\$ 0$ & $\$$ & 375,340 & $\$$ & 270,480 & $\$$ & 611,520 \\
\hline Burns, OR & $\$ 0$ & $\$$ & 383,000 & $\$$ & 276,000 & $\$$ & 624,000 \\
\hline Olympia, WA & $\$ 0$ & $\$$ & 390,660 & $\$$ & 281,520 & $\$$ & 636,480 \\
\hline Quillayuta, WA & $\$ 0$ & $\$$ & 390,660 & $\$$ & 281,520 & $\$$ & 636,480 \\
\hline Seattle, WA & $\$ 0$ & $\$$ & 397,937 & $\$$ & 286,764 & $\$$ & 648,336 \\
\hline Kalispell, MT & $\$ 0$ & $\$$ & 337,806 & $\$$ & 243,432 & $\$$ & 550,368 \\
\hline Cut Bank, MT & $\$ 0$ & $\$$ & 349,296 & $\$$ & 251,712 & $\$$ & 569,088 \\
\hline
\end{tabular}


Table 32 Energy Cost Savings by Building Type in each Climate Location

\begin{tabular}{|c|c|c|c|c|c|c|c|c|}
\hline \multirow[b]{2}{*}{ Spokane, WA } & \multicolumn{2}{|c|}{ Office Medium } & \multicolumn{2}{|c|}{ Office Large } & \multicolumn{2}{|c|}{ Supermarket } & \multicolumn{2}{|c|}{ Secondary School } \\
\hline & $\$$ & 2,727 & $\$$ & 36,348 & $\$$ & 9,115 & $\$$ & 28,773 \\
\hline Pendleton, OR & $\$$ & 3,706 & $\$$ & 28,337 & $\$$ & 9,909 & $\$$ & 37,283 \\
\hline Missoula, MT & $\$$ & 3,275 & $\$$ & 27,579 & $\$$ & 14,225 & $\$$ & 37,014 \\
\hline Boise, ID & $\$$ & 2,623 & $\$$ & 24,550 & $\$$ & 7,524 & $\$$ & 25,869 \\
\hline Pocatello, ID & $\$$ & 2,434 & $\$$ & 41,642 & $\$$ & 10,209 & $\$$ & 23,635 \\
\hline Helena, MT & $\$$ & 3,330 & $\$$ & 44,116 & $\$$ & 16,927 & $\$$ & 37,957 \\
\hline Astoria, OR & $\$$ & 2,334 & $\$$ & 17,160 & $\$$ & 7,029 & $\$$ & 23,394 \\
\hline Salem, OR & $\$$ & 3,340 & $\$$ & 22,385 & $\$$ & 8,305 & $\$$ & 30,678 \\
\hline Eugene, OR & $\$$ & 3,396 & $\$$ & 22,573 & $\$$ & 8,209 & $\$$ & 30,755 \\
\hline North Bend, OR & $\$$ & 2,176 & $\$$ & 15,405 & $\$$ & 6,844 & $\$$ & 21,718 \\
\hline Arcata, CA & $\$$ & 2,508 & $\$$ & 16,054 & $\$$ & 12,235 & $\$$ & 35,071 \\
\hline Medford, OR & $\$$ & 4,061 & $\$$ & 22,283 & $\$$ & 9,293 & $\$$ & 37,474 \\
\hline Redmond, OR & $\$$ & 2,977 & $\$$ & 24,615 & $\$$ & 10,225 & $\$$ & 31,836 \\
\hline Portland, OR & $\$$ & 3,259 & $\$$ & 21,947 & $\$$ & 8,090 & $\$$ & 30,199 \\
\hline Yakima, WA & $\$$ & 3,207 & $\$$ & 24,072 & $\$$ & 8,834 & $\$$ & 30,154 \\
\hline Burns, OR & $\$$ & 3,061 & $\$$ & 29,077 & $\$$ & 10,249 & $\$$ & 32,885 \\
\hline Olympia, WA & $\$$ & 2,840 & $\$$ & 20,096 & $\$$ & 7,608 & $\$$ & 26,158 \\
\hline Quillayuta, WA & $\$$ & 1,936 & $\$$ & 16,066 & $\$$ & 6,675 & $\$$ & 21,878 \\
\hline Seattle, WA & $\$$ & 2,679 & $\$$ & 21,526 & $\$$ & 6,906 & $\$$ & 25,365 \\
\hline Kalispell, MT & $\$$ & 2,885 & $\$$ & 23,719 & $\$$ & 14,190 & $\$$ & 33,282 \\
\hline Cut Bank, MT & $\$$ & 2,658 & $\$$ & 33,529 & $\$$ & 16,908 & $\$$ & 33,542 \\
\hline
\end{tabular}


Table 33 Simple Payback by Building Type for each Climate Location

\begin{tabular}{|l|r|r|r|r|}
\cline { 2 - 5 } \multicolumn{1}{l|}{} & Office Medium & Office Large & Supermarket & Secondary School \\
\hline Spokane, WA & 0 & 10.0 & 28.8 & 20.6 \\
\hline Pendleton, OR & 0 & 13.5 & 27.9 & 16.7 \\
\hline Missoula, MT & 0 & 12.2 & 17.1 & 14.9 \\
\hline Boise, ID & 0 & 14.0 & 32.9 & 21.7 \\
\hline Pocatello, ID & 0 & 8.3 & 24.4 & 23.8 \\
\hline Helena, MT & 0 & 7.8 & 14.7 & 14.8 \\
\hline Astoria, OR & 0 & 22.3 & 39.3 & 26.7 \\
\hline Salem, OR & 0 & 17.1 & 33.3 & 20.4 \\
\hline Eugene, OR & 0 & 16.9 & 33.5 & 20.2 \\
\hline North Bend, OR & 0 & 24.9 & 40.3 & 28.7 \\
\hline Arcata, CA & 0 & 25.5 & 24.1 & 19.0 \\
\hline Medford, OR & 0 & 17.2 & 29.7 & 16.7 \\
\hline Redmond, OR & 0 & 15.6 & 27.0 & 19.6 \\
\hline Portland, OR & 0 & 17.6 & 34.5 & 20.9 \\
\hline Yakima, WA & 0 & 15.6 & 30.6 & 20.3 \\
\hline Burns, OR & 0 & 13.2 & 26.9 & 19.0 \\
\hline Olympia, WA & 0 & 19.4 & 37.0 & 24.3 \\
\hline Quillayuta, WA & 0 & 24.3 & 42.2 & 29.1 \\
\hline Seattle, WA & 0 & 18.5 & 41.5 & 25.6 \\
\hline Kalispell, MT & 0 & 14.2 & 17.2 & 16.5 \\
\hline Cut Bank, MT & 0 & 10.4 & 14.9 & 17.0 \\
\hline & 0 & & & \\
\hline Aggregate & 0 & 17.3 & 37.5 & \\
\hline Payback & 0 & & & \\
\hline
\end{tabular}




\section{Discussion and Recommendations}

Electrical power for HVAC, which in most buildings translates to electrical power for cooling (compressors and package equipment) and transport (pumps and fans), may be treated as the quotient of cooling load and cooling system efficiency. The path to reduced cooling loads is well understood as a matter of improving window, window-shading, and envelope performance; of recovering ventilation enthalpy and better controlling ventilation rates; of improving lighting efficiencies; and of reducing end-user equipment loads.

This analysis shows that significant cooling system efficiency gains can be achieved by integrating low-lift cooling technologies: variable-speed compressor and transport motor controls, radiant cooling with dedicated ventilation air transport and dehumidification, and cool storage. The cooling energy savings for a standard-performance building range from $47 \%$ to $84 \%$ and, for a high-performance building, from $17 \%$ to $66 \%$.

For baseline buildings that are compliant with ASHRAE 90.1-2004, the full LLCS saves about 54 million $\mathrm{kWh}$ of site electricity use in 1 year with the full LLCS being applied to (assuming $100 \%$ penetration) a total new construction in 2010 Pacific Northwest new commercial building stock. The corresponding peak reductions are about 6.2 MW. The annual site electricity savings and peak reduction are about 15.5 million $\mathrm{kWh}$ and $1.8 \mathrm{MW}$, respectively for high-performance buildings. Assuming the new construction growth rates remain the same for the next 10 years (through the year 2020), the total regional technical site energy savings potential (again assuming $100 \%$ penetration) for all buildings built between 2010 and 2020 for the baseline standard would be $625 \mathrm{million} \mathrm{kWh} / \mathrm{year}$ in 2020. To reiterate, all of these savings are in site energy terms; to calculate the "busbar" savings, the previous estimates should be multiplied by factor of 1.0725 (using the average transmission loss of 7.625\%). ${ }^{21}$ The total savings potential - relative to the baseline building - is therefore 670 million kWh in 2020.

Cooling plant savings result from efficient compressor operation at low-pressure ratios and over a wide speed range. So far, compressor and chiller performance in these regions has not been given much attention. The chiller and DX-dehumidifier equipment modeled in the analysis exhibit performance typical of existing package equipment at typical design conditions but represent a significant improvement in performance under part-load and low-lift conditions because compressor and transport motor speeds were independently controlled for optimal performance.

Low-lift operation does not benefit much from two well known, but costly and complex, measures: multi-stage compression and liquid recycle or other forms of inter-cooling. Low discharge temperature is achieved instead by low suction superheat, low internal pressure drops, large heat-transfer capacity per unit refrigerant mass flow and the external design factors-RCP, night pre-cooling, and variable-speed (VS) compressor operation - that result in low pressure ratios.

${ }^{21}$ Personal communication Erik Boyer, BPA. 
There are significant savings from use of two-speed or variable-speed (VS) chiller for some building types that use DX systems. When compared to a two-speed chiller case (Case 1), the three low-lift technologies, when combined, result in consistently large savings in spite of wide variations in savings when applied one at a time. For example, the RCP/DOAS element alone results in average savings (for various building types, across 21 climate locations) of between 9 and $57 \%$. A significant portion of savings attributed to RCP/DOAS is from fan energy savings. The VS chiller alone results in savings of only 0.5 to $6 \%$, but when a VS chiller is added to HVAC configurations that already include RCP/DOAS and/or TES, the average incremental savings are slightly higher.

The variable-speed savings, when added after TES, are largest because the load shifting process results in almost all the load being shifted from a high to a low part-load operating range, where a variable-speed reciprocating chiller becomes very efficient. Even the best variable-speed centrifugal chillers start to lose efficiency below about 35\% rated capacity (Conry et al. 2002). Although TES is a synergistic technology that enhances the LLCS savings, discrete TES is not a good solution because of its first cost. Use of the passive thermal mass in buildings can provide significant savings associated with discrete TES.

The proper design and integration of low-lift technologies requires careful attention to controls. Controls, in turn, can become a maintenance issue with associated loss, over time, of system efficiency. Integrated delivery of the low-lift system, similar to the approach used for variablerefrigerant-volume (VRV) DX cooling equipment, is one possible way to address both of these issues. However, for broadest market penetration, it would be preferable for manufacturers to supply integrated controls with less of a "black box" approach. A controls package with options that permit flexibility in terms of hydronic distribution-e.g., active-core, ceiling panels, or the two combined - and in the coordination of RCP and DOAS systems would be extremely desirable.

The foregoing analysis is based on the use of vapor-compression equipment for both the sensible and latent cooling loads. Similar low-lift benefits can be expected with absorption cooling plants, thermally-regenerated desiccant dehumidification equipment and direct or indirect evaporative cooling, and a vapor compression system coupled with ground source. The role of TES will generally be diminished in solar-powered cooling applications. It would be interesting, nevertheless, to compare the solar aperture area needed for a state-of-the-art solar-thermalpowered absorption and desiccant cooling system to the apertures needed by state-of-the-art photovoltaic-powered and state-of-the-art solar-thermal-turbine-powered vapor-compression systems for the standard-, mid- and high-performance building prototypes simulated in a few desert and sun-belt climates.

The market assessment indicates that the LLCS package seems to be an attractive option worthy of further research, development and deployment. The stakeholders were generally very receptive, and there did not seem to be any "deal-breakers." Stakeholders all seem to be most interested in packaged solutions, rather than individual technologies. It also appears that the timing is good, because more and more stakeholders are realizing the importance of energy efficiency and are becoming interested in green buildings. One of the most important steps 
moving forward will be case studies and demonstrations of benefits, including cost and energy savings.

Based on simple payback economic analysis, office buildings appear to be the most ideal first application for LLCS, particularly those using multi-zone rooftop systems medium and small office buildings. The large cost of the multi-zone rooftop systems (with respect to a similarsized chiller) allows for a favorable cost comparison for LLCS in small/medium office buildings. Large office buildings show a low incremental cost per square foot and also reasonable payback in most climate locations, because small increases in chiller costs, and large savings from the smaller ductwork required as a result of use of the DOAS system. Radiant cooling drives the cost increment for all of the building types. A large portion of these costs is associated with the labor required for installation. Secondary (and probably primary) schools also appear to be a good target building for LLCS. It appears that in mild (Los Angeles, San Francisco and Seattle) and heating-dominated (Chicago, Minneapolis, Duluth and Fairbanks) climates, LLCS may not be favorable, unless other incentives are provided. As more buildings adopt LLCS, over time the incremental cost will decrease.

Although there could be significant cost savings from demand reductions for use of LLCS, those savings were not considered in this analysis. Because the demand rates vary significantly with different utilities, it would take a lot of effort to compute accurate demand savings. Also, the analysis did not consider any carbon tax. Assessing the impact of carbon tax on the relative economics is simple and will be considered in future work.

The analysis also clearly indicates that different (climate) regions need different sets of integrated technology solutions that are optimized for that region. While LLCS with a conventional vapor compression system may be good choice for many of the hot and humid climates, alternate low-lift cooling (evaporative, ground source) may be better suited for mild and heating-dominated climates. The primary focus of this study was cooling needs; there is also a need to look at heating technologies, such as heat pump chillers, which can be integrated with RCP/DOAS. Work for DOE next year (2010 and 2011), will include identifying both alternate low-lift cooling technologies and high-efficiency heating technologies that can be integrated with RCP/DOAS. 


\section{References}

Armstrong, P.R, W. Jiang, D.W. Winiarski, S. Katipamula, L.K. Norford, and R.A. Willingham 2009a. Efficient Low-Lift Cooling with Radiant Distribution, Thermal Storage and VariableSpeed Chiller Controls - Part I: Component and Subsystem Models. ASHRAE HVAC\&R Research, 15(2):366-401.

Armstrong, P.R, W. Jiang, D.W. Winiarski, S. Katipamula and L.K. Norford. 2009b. Efficient Low-Lift Cooling with Radiant Distribution, Thermal Storage and Variable-Speed Chiller Controls - Part II: Component and Subsystem Models. ASHRAE HVAC\&R Research, 15(2):402-432.

ASHRAE., 2004. ANSI/ASHRAE/IESNA Standard 90.1-2004, Energy Standard for Buildings Except Low-Rise Residential Buildings. ASHRAE, Atlanta, Georgia.

Conry, R. L. Whelan, and J. Ostman. 2002. Magnetic bearings, centrifugal compressor and digital controls applied in a small tonnage refrigeration compressor design. International Compressor Engineering Conference at Purdue, Purdue University, West Lafayette, IN.

Jarnagin, R.E, and G.K Bandyopadhya. 2010. Weighting Factors for the Commercial Building Prototypes Used in the Development of ANSI/ASHRAE/IESNA Standard 90.1-2010. PNNL19116, Pacific Northwest National Laboratory, Richland, WA.

Jiang, W, D.W. Winiarski, S. Katipamula, and P.R. Armstrong. 2008. Cost-Effective Integration of Efficient Low-Lift Base Load Cooling Equipment . PNNL-17157, Pacific Northwest National Laboratory, Richland, WA. http://www.pnl.gov/main/publications/external/technical reports/PNNL-17157.pdf

Katipamula, S, P.R. Armstrong, W. Wang, N. Fernandez, H. Cho, W. Goetzler, J Burgos, R Radhakrishnan, and C. Ahlfeldt. 2010. Cost-Effective Integration of Efficient Low-Lift Baseload Cooling Equipment: FY08 Final Report. PNNL-19114, Pacific Northwest National Laboratory, Richland, WA.

Torcellini, P. et al., 2008, “DOE Commercial Building Benchmark Models.” ACEEE 2008 summer study on energy efficiency in buildings, NREL Conference Paper NREL/CP-550-43291. Available at: http://www.nrel.gov/docs/fy08osti/43291.pdf 


\section{A Appendix: Market Assessment Supporting Material}




\section{Questionnaire A: Survey A - Low-Lift Cooling Technologies}

Date:

Interviewee:

Title:

Company:

Business Type:

Location:

Type of Buildings:

Phone:

\section{Subject: Low-Lift Cooling Technologies for Buildings}

\section{Introduction}

Hi, my name is Rakesh Radhakrishnan, calling from Navigant Consulting's Energy group. We're conducting a study on behalf of the Department of Energy Building Technologies Program focused on understanding the market that exists and could evolve for "Low-Lift" cooling technologies. These technologies are intended to help the DOE meet near term objectives of nearly $30 \%$ reduced energy consumption for buildings with the ultimate goal of being incorporated into a "net zero energy" building by 2020. Low-lift cooling technologies considered for this study could be incorporated individually or as a combination to offer a more systems type solution. The range of energy benefits for a specific building type for these technologies and technology combinations have been recently evaluated by PNNL through a series of modeling studies, which found energy benefits in the range of $2 \%$ to $75 \%$ over baseline HVAC systems. The technologies considered in this study included:

1. Peak-load shifting by means of active or passive thermal energy storage (TES)

2. Dedicated outdoor air supply with enthalpy heat recovery from exhaust air

3. Radiant heating and cooling panels or floor system

4. Low-lift vapor compression cooling equipment (variable-speed compressors, refrigerant flows etc.)

5. Advanced controls at the HVAC equipment and HVAC system (supervisory) levels

The objective of this interview is to understand some of the perceived benefits, barriers and enablers that may enhance the adoption of low-lift technologies for buildings in the future. With this focus, there are five main areas that I would like to review today:

1. How are decisions to install new HVAC equipment made?

2. What is the familiarity of the market with low-lift cooling approaches?

3. What are the barriers to market penetration for low-lift technology options?

4. What are the enablers that could enhance market penetration for low-lift and are the stakeholders aware of these drivers?

5. What paybacks are attractive for the market currently for cooling equipment? Are customers willing to pay more for energy efficiency (low-lift technologies) in the current environment?

\section{Specific questions}




\section{How are decisions to install new HVAC equipment made?}

a) Who makes decisions to install new HVAC equipment in a new building/retrofit?

b) What drives their decisions to install new HVAC equipment i.e., what are the key needs (new buildings versus retrofits)?

\section{What is the familiarity of the market with low-lift cooling technologies?}

a) How familiar are you with active/passive thermal energy storage technologies?

i) Very familiar - worked on this before

ii) Somewhat familiar - heard about it

iii) Not familiar - no knowledge whatsoever

Repeat question for: Dedicated outdoor air systems with enthalpy recovery, radiant heating/cooling panels or floor system, low-lift vapor compression cooling equipment (variable speed compressors, etc.), advanced controls at the HVAC equipment and supervisory controls level.

\section{What are the barriers to market penetration for low lift technology options?}

Active/passive TES technologies barriers

a) Do you perceive TES as being expensive from a first cost and operating cost perspective (requires more maintenance)?

b) Do you perceive TES as a technology that does not provide sufficient energy savings to warrant adoption?

c) Do you perceive TES as being difficult to design and install in a building (requires a very large footprint)?

d) Do you anticipate any safety concerns with TES solutions?

e) Is there any other barrier that prevents larger scale adoption of TES for buildings?

DOAS+enthalpy wheel technology barriers

a) Do you perceive DOAS with an enthalpy wheel as being expensive from a first cost and operating cost perspective (requires more maintenance)?

b) Do you see zoning costs as a specific issue for DOAS systems?

c) Do you see fouling of enthalpy wheels as a major issue preventing adoption of these technologies?

d) Do you see pressure drop issues as being a major concern for enthalpy wheel based systems?

e) Do you perceive DOAS+enthalpy wheel as a technology that does not provide sufficient energy savings to warrant adoption?

f) Do you anticipate any safety concerns with DOAS+enthalpy wheel solutions?

g) Is there any other barrier that prevents larger scale adoption of DOAS+enthalpy wheels for buildings?

Radiant heating/cooling technologies barriers 
a) Do you perceive radiant panels as being expensive from a first cost and operating cost perspective (requires more maintenance)?

b) Do you see the architectural implications of installing radiant heating/cooling as being a significant issue?

c) Do you see condensation issues with radiant panels as being a significant issue preventing technology adoption?

d) Do you perceive radiant panels as a technology that does not provide sufficient energy savings to warrant adoption?

e) Do you anticipate any safety concerns with radiant panel solutions?

f) Is there any other barrier that prevents larger scale adoption of radiant panels for buildings?

Low-lift vapor compression technologies barriers

a) Do you perceive variable-speed chillers as being expensive from a first cost and operating cost perspective (requires more maintenance)?

b) Do you see refrigerant leaks as being a significant issue in variable-speed machines?

c) Do you see the lack of a brand name (e.g., Daikin, Carrier etc.) offering as being a significant market barrier preventing adoption of variable-speed chillers?

d) Do you perceive variable-speed chillers as a technology that does not provide sufficient energy savings to warrant adoption?

e) Do you anticipate any safety concerns with variable-speed chillers?

f) Is there any other barrier that prevents larger scale adoption of variable-speed chillers for buildings?

Advanced controls technology barriers

a) Do you perceive advanced HVAC controls as being expensive from a first cost and operating cost perspective (requires more maintenance)?

b) Do you see a lack of understanding of controls technology and its benefits as being a significant market barrier preventing the adoption of this technology?

c) Do you see complexity in implementing advanced control designs as being a significant market barrier preventing the adoption of this technology?

d) Do you see the lack of trained personnel and complicated troubleshooting protocols as being a major issue preventing adoption of advanced control technologies in HVAC systems?

e) Do you anticipate any safety concerns with advanced control technologies?

f) Is there any other barrier that prevents larger scale adoption of advanced controls for building HVAC systems?

\section{What are the enablers that could enhance market penetration for low lift and are the stakeholders aware of these drivers?}

i. Energy efficiency and/or LEED awareness

ii. Climate change awareness

iii. U.S. government push towards energy efficiency for federal buildings

iv. Other? 
4. What paybacks are attractive for the market currently for cooling equipment? Are customers willing to pay more for energy efficiency (low-lift technologies) in the current environment?

5. Is there any question that you expected me to ask that I did not? 
Date:

Interviewee:

Title:

Company:

Business Type:

Location:

Type of Buildings:

Phone:

\section{Subject: Low Lift Cooling Technologies for Buildings}

\section{(INTRO SECTION BELOW CAN BE SOMETHING THAT IS DISCUSSED WITH AN} AUDIENCE IN PRESENTATION FORMAT BEFORE HANDING OFF THE SURVEY)

\section{Introduction}

We're conducting a study on behalf of the Department of Energy Building Technologies Program focused on understanding the market that exists and could evolve for "Low-Lift" cooling technologies. These technologies are intended to help the DOE meet near term objectives of nearly $30 \%$ reduced energy consumption for buildings with the ultimate goal of being incorporated into a "net zero energy" building by 2020. Low-lift cooling technologies considered for this study could be incorporated individually or as a combination to offer a more systems type solution. The range of energy benefits for a specific building type for these technologies and technology combinations have been recently evaluated by PNNL through a series of modeling studies, which found energy benefits in the range of $2 \%$ to $75 \%$ over baseline HVAC systems. The technologies considered in this study included:

1. Peak-load shifting by means of active or passive thermal energy storage (TES)

2. Dedicated outdoor air supply with enthalpy heat recovery from exhaust air

3. Radiant heating and cooling panels or floor system

4. Low-lift vapor compression cooling equipment (variable-speed compressors, refrigerant flows etc.)

5. Advanced controls at the HVAC equipment and HVAC system (supervisory) levels

The objective of this interview is to understand some of the perceived benefits, barriers and enablers that may enhance the adoption of low-lift technologies for buildings in the future. With this focus, there are five main areas that I would like to review today:

6. How are decisions to install new HVAC equipment made?

7. What is the familiarity of the market with low-lift cooling approaches?

8. What are the barriers to market penetration for low-lift technology options?

9. What are the enablers that could enhance market penetration for low lift and are the stakeholders aware of these drivers?

10. What paybacks are attractive for the market currently for cooling equipment? Are customers willing to pay more for energy efficiency (low-lift technologies) in the current environment? 


\section{LOW-LIFT COOLING TECHNOLOGIES SURVEY}

1) Please assign your relative familiarity to each of the technologies presented based on the scale shown below.

Familiar - Some of our facilities currently use this technology or are considering using it. Somewhat Familiar - We've heard of this type of technology being applied elsewhere. Not familiar - First time we are hearing about this technology.

\begin{tabular}{|l|l|l|l|}
\hline \multicolumn{1}{|c|}{ Technology } & Familiar & \multicolumn{1}{c|}{$\begin{array}{c}\text { Somewhat } \\
\text { Familiar }\end{array}$} & Not familiar \\
\hline Low-Lift Cooling & & & \\
\hline Radiant Cooling/Heating & & & \\
\hline $\begin{array}{l}\text { Thermal Energy Storage } \\
\text { (Passive - Building materials) }\end{array}$ & & & \\
\hline $\begin{array}{l}\text { Thermal Energy Storage } \\
\text { (Active - Tank) }\end{array}$ & & & \\
\hline $\begin{array}{l}\text { Dedicated Outdoor Air } \\
\text { Supply with Enthalpy Wheels }\end{array}$ & & & \\
\hline $\begin{array}{l}\text { Variable-Speed / Capacity } \\
\text { Chillers }\end{array}$ & & & \\
\hline Advanced Controls & & & \\
\hline
\end{tabular}


2) Please check boxes that apply as potential benefits when adopting these technologies.

Energy Efficiency - Technology provides net energy savings.

First Cost Savings - Technology could provide first cost savings from downsizing other equipment in the building (e.g., smaller HVAC).

Operational Cost Savings - Technology is easy to maintain or provides features that enable monitoring health of equipment to extend life before critical failures emerge.

\begin{tabular}{|l|l|l|l|l|}
\hline \multicolumn{1}{|c|}{ Technology } & $\begin{array}{c}\text { Energy } \\
\text { Efficiency }\end{array}$ & $\begin{array}{c}\text { First } \\
\text { Cost } \\
\text { Savings }\end{array}$ & $\begin{array}{c}\text { Operational } \\
\text { Costs } \\
\text { Savings }\end{array}$ & $\begin{array}{c}\text { Other (please comment } \\
\text { below) }\end{array}$ \\
\hline Low-Lift Cooling & & & & \\
\hline Radiant & & & \\
Cooling/Heating & & & & \\
\hline Thermal Energy & & & & \\
Storage (Passive- \\
Building materials) & & & & \\
\hline Thermal Energy & & & & \\
Storage (Active- & & & & \\
Tank) & & & & \\
\hline Dedicated Outdoor & & & & \\
Air Supply with & & & & \\
Enthalpy Wheels & & & & \\
\hline Variable-Speed / & & & \\
Capacity Chillers & & & & \\
\hline Advanced Controls & & & & \\
\hline
\end{tabular}

(Please include technology name and a brief sentence on other benefits in space provided below) 
3) Please check boxes that apply as potential barriers to adopting these technologies.

High First Cost - Technology is too expensive to implement currently in new construction. Complexity - Technology is too complex to implement in new construction today.

Inadequate Energy Savings - Technology does not or may not provide sufficient energy savings to warrant adoption.

\begin{tabular}{|l|l|l|l|l|}
\hline \multicolumn{1}{|c|}{ Technology } & $\begin{array}{c}\text { High } \\
\text { First Cost }\end{array}$ & Complexity & $\begin{array}{c}\text { Inadequate } \\
\text { energy savings }\end{array}$ & $\begin{array}{c}\text { Other issues } \\
\text { (please comment } \\
\text { below) }\end{array}$ \\
\hline Low-Lift Cooling & & & & \\
\hline Radiant & & & \\
Cooling/Heating & & & & \\
\hline Thermal Energy & & & & \\
Storage (Passive- \\
Building material)
\end{tabular}

(Please include technology name and a brief sentence on other benefits in space provided below) 
4) Please check boxes that apply as potential enablers that will facilitate adoption of these technologies over the next 15 years.

LEED/ASHRAE standards - Emerging green building standards will enhance adoption of the technology.

Climate change - Awareness of climate change issues will enhance the adoption of the technology.

Technology maturation - Technology improvements will drive down costs and increase market penetration for the technology.

Government legislation - Government legislation and/or subsidies will enable adoption of the technology

\begin{tabular}{|c|c|c|c|c|c|}
\hline Technology & $\begin{array}{c}\text { LEED } \\
\text { ASHRAE }\end{array}$ & $\begin{array}{l}\text { Climate } \\
\text { change }\end{array}$ & $\begin{array}{l}\text { Technology } \\
\text { maturation }\end{array}$ & $\begin{array}{l}\text { Government } \\
\text { legislation }\end{array}$ & $\begin{array}{c}\text { Other issues } \\
\text { (please comment } \\
\text { below) }\end{array}$ \\
\hline Low-Lift Cooling & & & & & \\
\hline $\begin{array}{l}\text { Radiant } \\
\text { Cooling/Heating }\end{array}$ & & & & & \\
\hline $\begin{array}{l}\text { Thermal Energy } \\
\text { Storage (Passive- } \\
\text { Building material) }\end{array}$ & & & & & \\
\hline $\begin{array}{l}\text { Thermal Energy } \\
\text { Storage (Active - } \\
\text { Tank) }\end{array}$ & & & & & \\
\hline $\begin{array}{l}\text { Dedicated Outdoor } \\
\text { Air Supply with } \\
\text { Enthalpy Wheels }\end{array}$ & & & & & \\
\hline $\begin{array}{l}\text { Variable-Speed / } \\
\text { Capacity Chillers }\end{array}$ & & & & & \\
\hline Advanced Controls & & & & & \\
\hline
\end{tabular}

(Please include technology name and a brief sentence on other benefits in space provided below) 


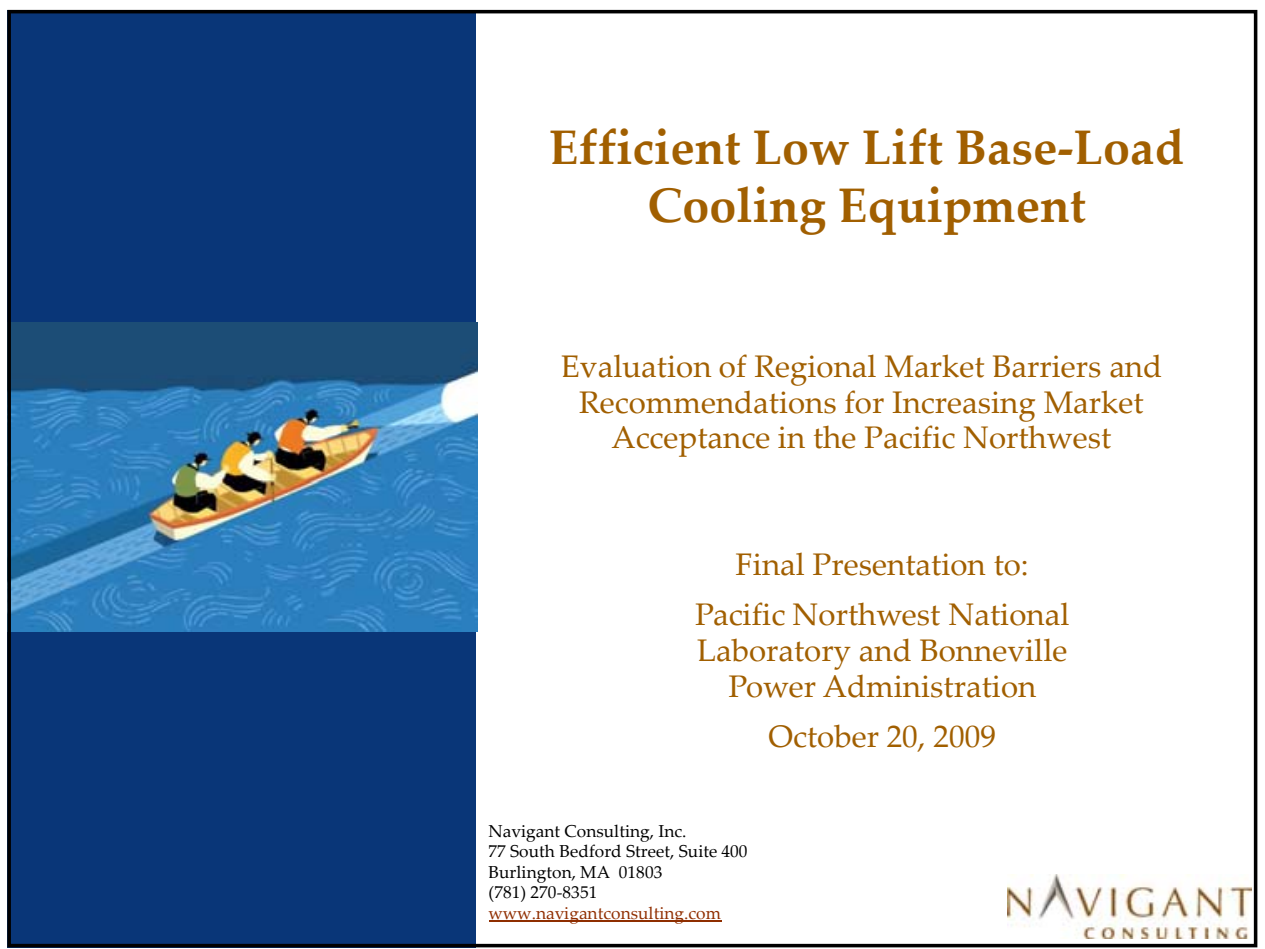

Table of Contents

1 Overview

2 Regional Benefits and Barriers

3 Conclusions and Recommendations

4 Appendix 
NCI has reviewed the market potential and incremental cost of low lift base-load cooling (LLC) technology nationally and in the Pacific Northwest region.

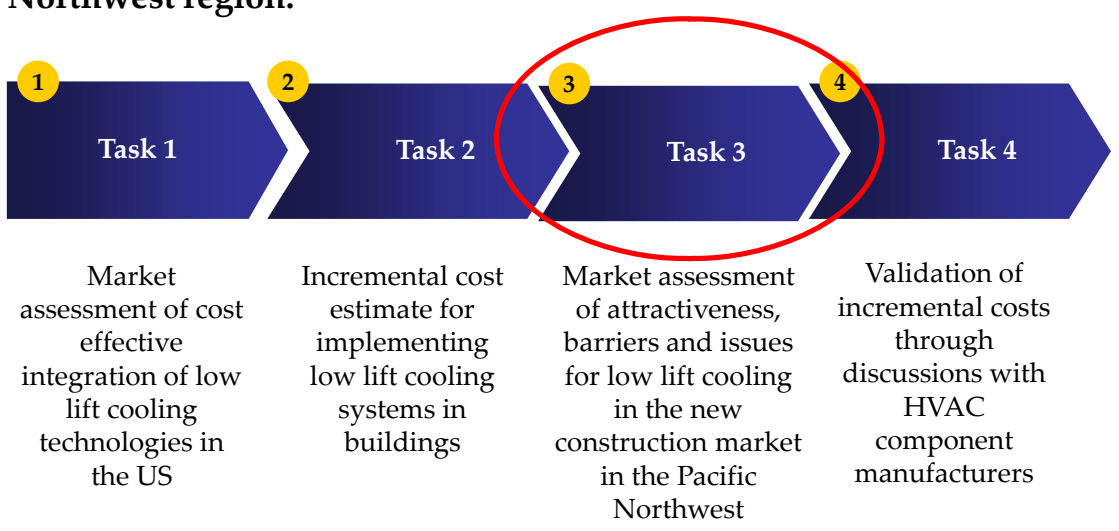

This report focuses on Task 3 of the market assessment for LLC equipment.

Start

with

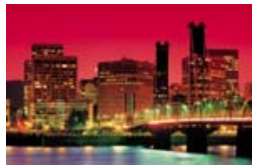

Peak-Shifting (PS) by Cooling at Night

- Proven demand savings technology

- Use Building Mass or Thermal Energy Storage (TES)

- Improves chiller load factor; milder conditions

Radiant Cooling Panels (RCP) and Dedicated Outside Air Supply (DOAS)

- Emerging Technology - Popular in Europe

- $60^{\circ} \mathrm{F}$ Panels provide "cool" instead of $50^{\circ} \mathrm{F}$ air

- DOAS with enthalpy recovery for fresh air

- Eliminates wasteful reheat; reduces fan power
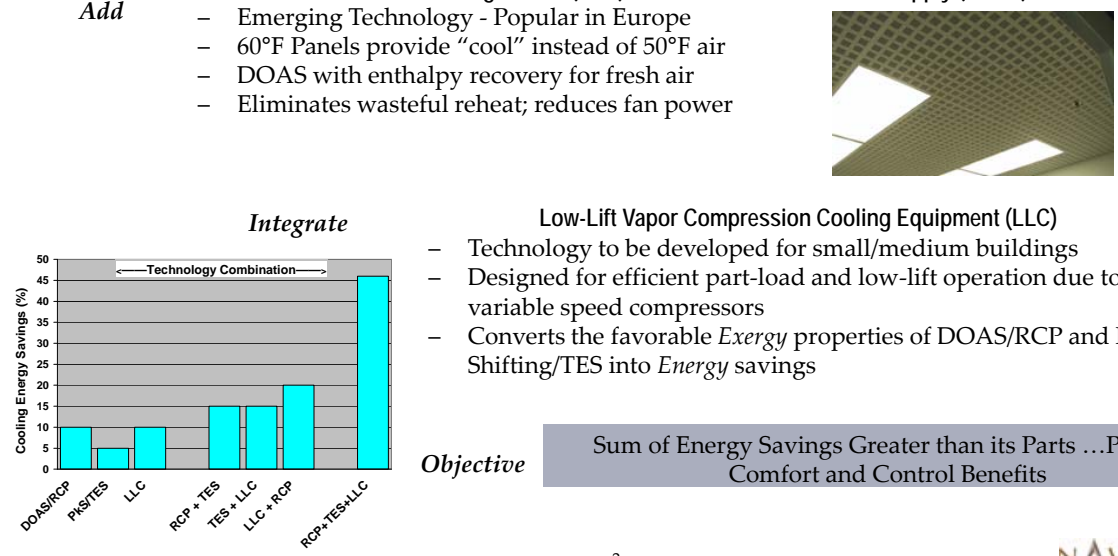

Low-Lift Vapor Compression Cooling Equipment (LLC)

- Technology to be developed for small/medium building

- Designed for efficient part-load and low-lift operation due to variable speed compressors

- Converts the favorable Exergy properties of DOAS/RCP and PeakShifting/TES into Energy savings

Objective Comfort and Control Benefits 


\section{Overview » Low-Lift Cooling Application}

These three technologies achieve higher efficiency when used in combination and are best suited for new building applications.

- Radiant Cooling Panels (RCP)

- Zone control without wasteful reheat

- 55- $60^{\circ} \mathrm{F}$ chilled water temperature

- Eliminate $80 \%$ of fan transport energy

- Increase water-side free-cooling capacity \& hrs/yr

\section{- Peak-Shifting/TES}

- Reduce condensing temperature 10-20F

- Reduce peak and median load on chiller

- Increase annual free-cooling load fraction

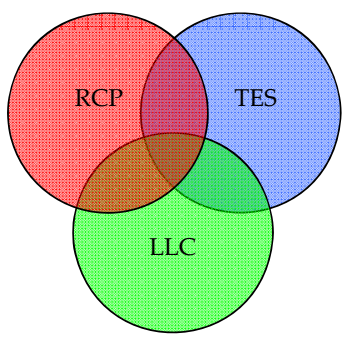

- Low-Lift Cooling Equipment (LCC)

- Design for efficient part-load, low-lift operation

- Good match for RCP

- Good match for TES

- Can be packaged for small-medium buildings

Overview » Low Lift Cooling Technology and Components

Low lift cooling requires a customized building design and reduces energy by combining HVAC technologies and advanced controls.

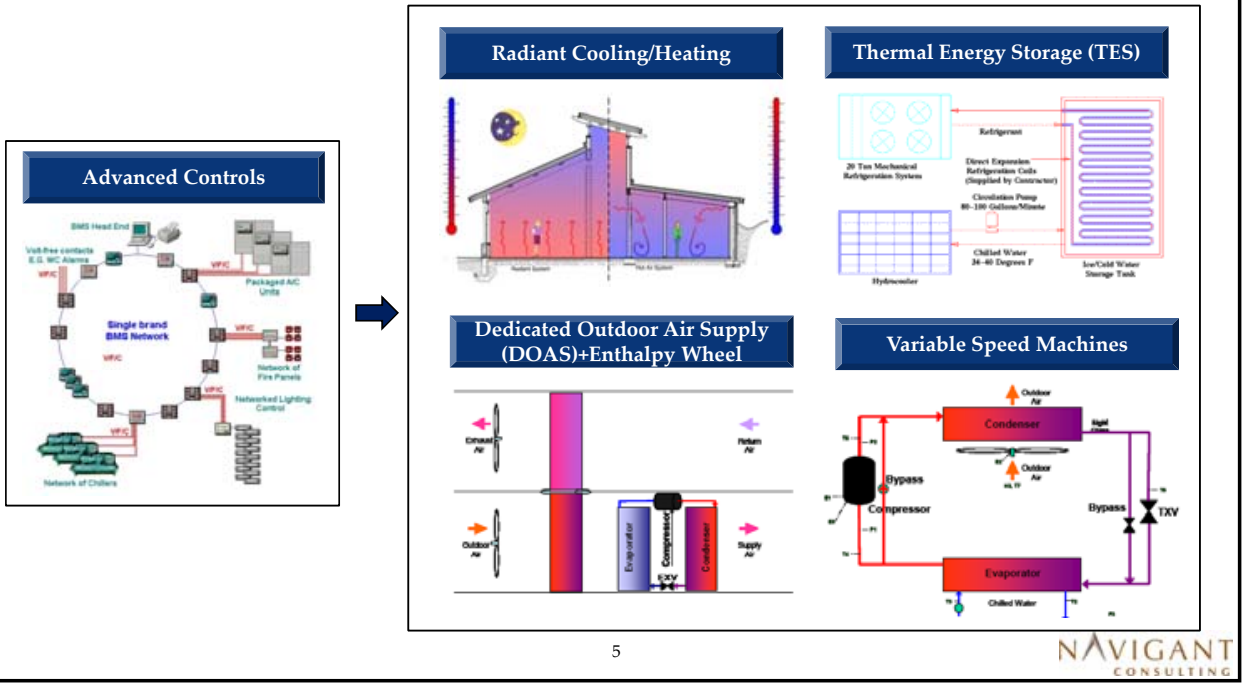


For task 3, NCI assessed market potential and barriers on low lift cooling technology in the Pacific Northwest region.

Low Lift Base-Load Cooling Technology in the Pacific Northwest Market over the next 20 years.
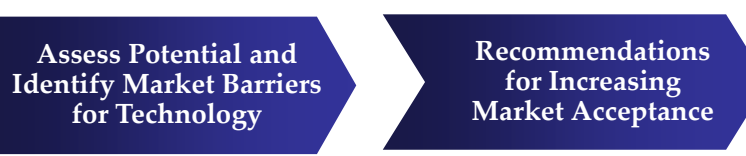

- Conduct

research

-Synthesize

stakeholder

-Interview

stakeholders

feedback

-Summarize

recommendations

Bonneville Power Administration (BPA) is a federal agency that generates and sells wholesale electricity in the Pacific Northwest .

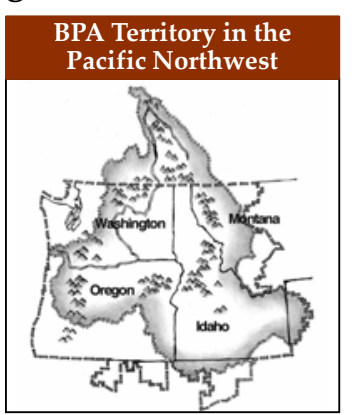

- As part of its responsibilities, BPA promotes energy efficiency, renewable resources, and new technologies

- While BPA's energy rates tend to be low and fairly constant across its territory, regional utilities that purchase BPA electricity vary rates depending on local taxes and measures

- BPA markets wholesale electric power from hydro and nuclear facilities to publicly and investor-owned utilities

- Due to its resource mix, efficiency measures in BPA territory have a smaller impact on greenhouse gas emissions relative to other parts of the US with higher emission rates

BPA 2008 Average Resource Mix (8,549 MW)

Sources: 2008 BPA Fact Sheet; BPA Website 
Climate variation such as fluctuations in humidity across regions in the Pacific Northwest make the impact of the LLC concept variable.

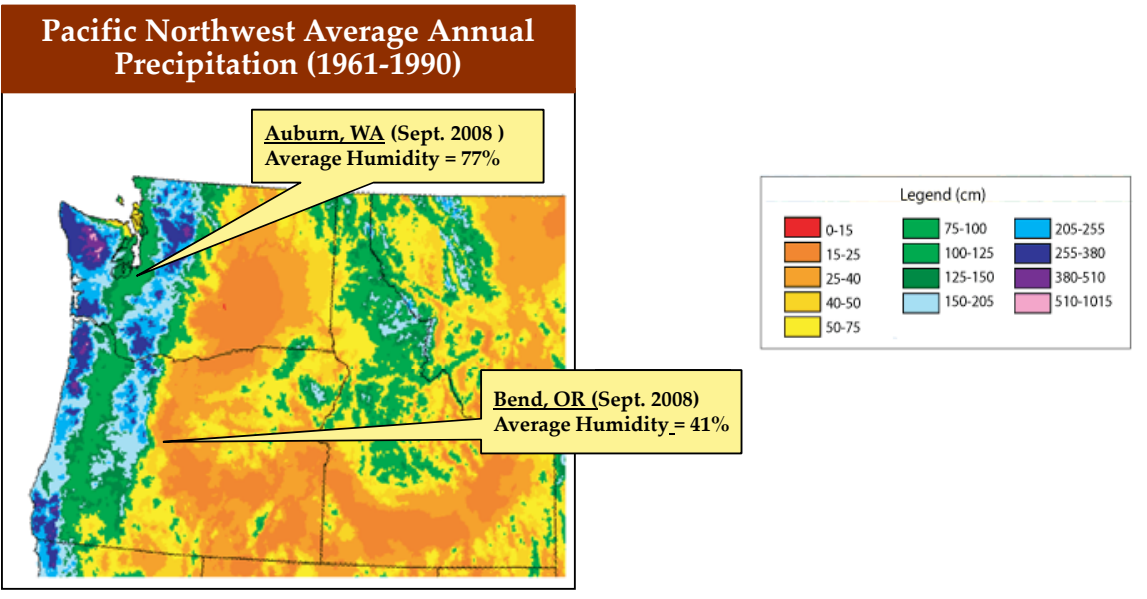

Sources: Oregon Climate Service (Oregon State University); Bend, OR and Auburn WA Weather Stations

Overview » Electricity Rates

The Pacific Northwest has significantly lower average electricity costs relative to other regions of the US.

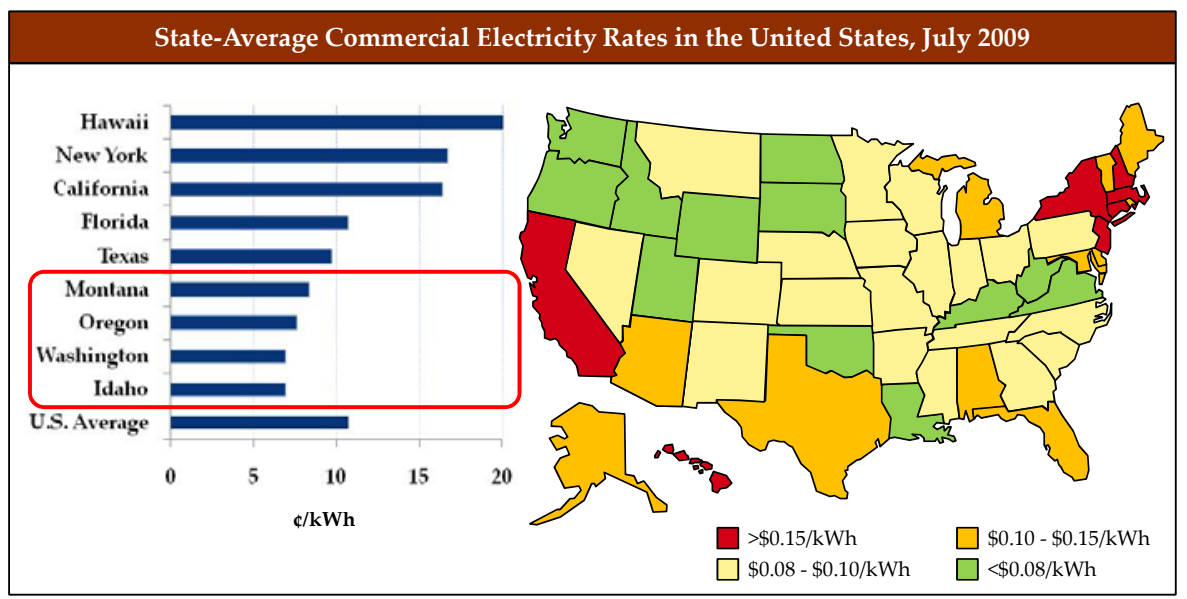

Source: EIA Retail Price of Electricity 
Overview » Key Market Attributes Comparison

Oregon and Washington are likely the best markets in the Pacific Northwest for Low Lift Cooling but these lag behind others in the US.

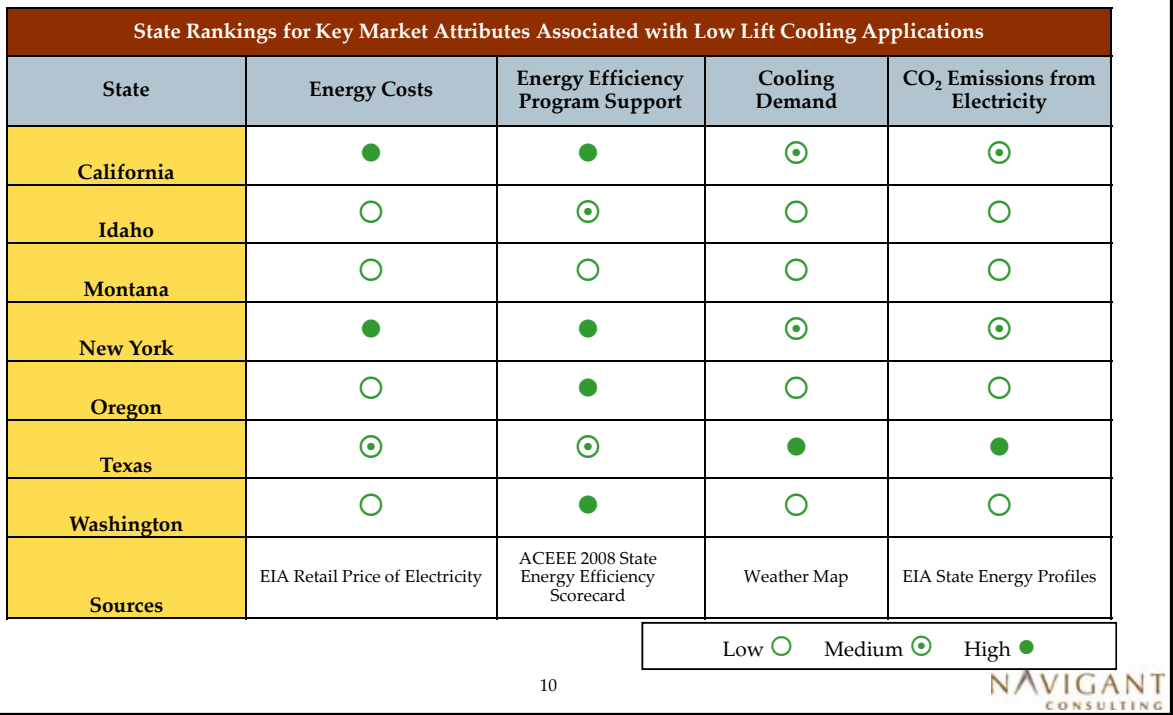

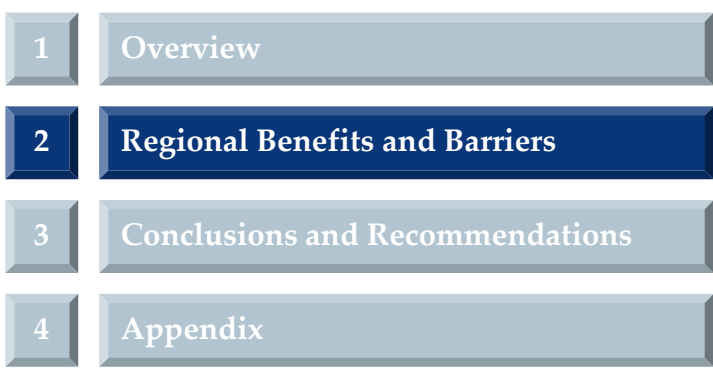


The technology options under consideration improve energy efficiency and offer various market and technical benefits.

\begin{tabular}{|c|c|c|}
\hline \multicolumn{3}{|c|}{ Low Lift Technology Options Benefits } \\
\hline Technology & Market Benefit & Technical Benefit \\
\hline Advanced Controls & $\begin{array}{l}\text { Allows for occupancy based optimization } \\
\text { of energy consumption in building which } \\
\text { results in savings and also helps in } \\
\text { diagnostics and prognostics to help defer } \\
\text { major O\&M costs. }\end{array}$ & $\begin{array}{l}\text { Ability to monitor health of the equipment and } \\
\text { performance of the building HVAC system } \\
\text { critical in avoiding future technical problems in } \\
\text { the building, e.g., maintenance and comfort } \\
\text { issues. }\end{array}$ \\
\hline Variable Capacity Chillers & $\begin{array}{l}\text { Allows for actively managing building } \\
\text { energy consumption that results in energy } \\
\text { and cost savings for customer. }\end{array}$ & $\begin{array}{l}\text { System is managed at low lift conditions with } \\
\text { chilled water temperatures at } \sim 60^{\circ} \mathrm{F} \text {. }\end{array}$ \\
\hline $\begin{array}{l}\text { Dedicated Outdoor Air System } \\
\text { (DOAS) + Enthalpy Wheel }\end{array}$ & $\begin{array}{l}\text { Allows for better humidity control, comfort } \\
\text { and IEQ for building occupants. }\end{array}$ & $\begin{array}{l}\text { Active humidity control can help in separating } \\
\text { sensible load and latent load handling which } \\
\text { reduces "high lift" operation of other HVAC } \\
\text { equipment. }\end{array}$ \\
\hline Thermal energy storage (TES) & $\begin{array}{l}\text { Facilitating load shifting from off peak to } \\
\text { peak hours in places with large differences } \\
\text { between day time and night time rates can } \\
\text { result in energy cost savings. }\end{array}$ & $\begin{array}{l}\text { Ability to actively manage loads with other } \\
\text { HVAC systems in the building based on } \\
\text { demand changes that are driven by occupancy } \\
\text { and weather conditions. }\end{array}$ \\
\hline Radiant cooling/heating & $\begin{array}{l}\text { Ability to downsize HVAC equipment and } \\
\text { defer first costs in new construction. }\end{array}$ & $\begin{array}{l}\text { Integration possibilities with existing } \\
\text { water/steam lines. }\end{array}$ \\
\hline
\end{tabular}

Various barriers have prevented low lift technologies from achieving higher market penetrations to date.

\begin{tabular}{|l|l|l|}
\hline \multicolumn{3}{|c|}{ Low Lift Technology Options Barriers } \\
\hline \multicolumn{1}{|c|}{ Technology } & \multicolumn{1}{|c|}{ Market Barriers } & \multicolumn{1}{c|}{ Technical Barriers } \\
\hline Variable Speed Chillers & $\begin{array}{l}\text { Expensive equipment and limited familiarity among } \\
\text { operators and contractors because few major HVAC } \\
\text { suppliers provide variable speed compressors and their } \\
\text { product range is limited. }\end{array}$ & $\begin{array}{l}\text { Requires sophisticated programming and } \\
\text { variable speed equipment that has limited } \\
\text { availability. }\end{array}$ \\
\hline Advanced Controls & $\begin{array}{l}\text { Lack of trained, computer savvy operators. User resistance } \\
\text { to advanced controls, no manager wants to deal with } \\
\text { complex operation. }\end{array}$ & Complexity in implementation. \\
\hline $\begin{array}{l}\text { Dedicated Outdoor Air } \\
\text { System (DOAS) + } \\
\text { Enthalpy Wheel }\end{array}$ & $\begin{array}{l}\text { Not suited for retrofits (outside of roof top units) in most } \\
\text { cases because it requires additional ducting. Need co- } \\
\text { located supply and exhaust. }\end{array}$ & $\begin{array}{l}\text { Ductwork needs to be modified to take } \\
\text { advantage of energy recovery configuration. }\end{array}$ \\
\hline $\begin{array}{l}\text { Thermal energy storage } \\
\text { (TES) }\end{array}$ & $\begin{array}{l}\text { Space constraints exist in many applications. Similar issues } \\
\text { as radiant cooling/heating for large tank storage systems. } \\
\text { Unproven technologies such as paraffins that could be } \\
\text { incorporated into insulting materials may have fire code } \\
\text { compliance issues. Historical reliability issues. Economics } \\
\text { dependent on night/day differential electricity rates. }\end{array}$ & $\begin{array}{l}\text { Space constraint and need for additional } \\
\text { controls. }\end{array}$ \\
\hline Radiant cooling/heating & $\begin{array}{l}\text { Requires early engagement between architect and engineer } \\
\text { for new construction due to footprint and/or construction } \\
\text { requirements. Difficult and costly for retrofits. Must be } \\
\text { combined with other systems. May be difficult to } \\
\text { implement in high humidity climates. Not hearing HVAC } \\
\text { equipment may cause some occupants to wonder if it is } \\
\text { operating properly. Also, initial failures have discouraged } \\
\text { adoption. }\end{array}$ & $\begin{array}{l}\text { Condensation problems often reported with } \\
\text { radiant cooling panels in humid climates, so } \\
\text { fareful engineering is necessary. Lack of } \\
\text { in achievingective mixing may be a problem } \\
\text { additional controls to enperatures. Requires } \\
\text { envelope is appropriately controlled. }\end{array}$ \\
\hline
\end{tabular}


NCI interviewed 11 stakeholders with a variety of backgrounds and experience working in the Pacific Northwest.

\begin{tabular}{|c|c|c|c|}
\hline \multicolumn{3}{|r|}{ Interviewee List } & \\
\hline Stakeholder & $\begin{array}{c}\text { Office } \\
\text { Location(s) }\end{array}$ & Organization, Position & \\
\hline \multirow[b]{2}{*}{ Architect } & Montana & CTA Architect, Architect & \\
\hline & Washington & CTA Architect, Architect & \\
\hline \multirow[b]{2}{*}{ Building Owner } & Oregon & State of Oregon, DAS Sustainability Coordinator & \\
\hline & Washington & General Services Administration, Regional Energy Manager & \\
\hline $\begin{array}{l}\text { Energy Service } \\
\text { Provider }\end{array}$ & Washington & JCI, Service Branch Manager & \\
\hline \multirow{4}{*}{$\begin{array}{l}\text { LEED and HVAC } \\
\text { Engineers/Consul } \\
\text { tants }\end{array}$} & Oregon & Glumac, Principal Engineer & \\
\hline & Oregon & PAE Consulting, Consultant & \\
\hline & Washington & Coffman Engineers, Mechanical Engineer & \\
\hline & $\begin{array}{l}\text { Washington and } \\
\text { Oregon }\end{array}$ & Interface Engineering, Principal Engineer & \\
\hline \multirow{2}{*}{$\begin{array}{l}\text { Utility } \\
\text { Representative }\end{array}$} & Oregon & BPA, Mechanical Engineer & \\
\hline & Oregon & Eugene Water \& Electric Board, Staff Engineer & \\
\hline
\end{tabular}

Validate Barriers » Interview Results - Technology Priorities

The impact of various low lift cooling elements will vary due to regional micro-climates local customer acceptance.

\begin{tabular}{|l|l|}
\hline \multicolumn{2}{|c|}{ Low Lift Technology Options - Customer Acceptance Level in the Pacific Northwest Region } \\
\hline \multicolumn{1}{|c|}{ Technology } & \multicolumn{1}{c|}{ Customer Acceptance Level } \\
\hline Variable Capacity Chillers & $\begin{array}{l}\text { High - Industry is moving in this direction and there is a need to migrate } \\
\text { designs into large size chillers. }\end{array}$ \\
\hline Advanced Controls & $\begin{array}{l}\text { Medium/High - Significant opportunity exists in coupling systems to achieve } \\
\text { higher efficiencies. Requires better user interfaces and must focus on enabling } \\
\text { diagnostics and prognostics of the full HVAC system (supervisory level). } \\
\text { Requires better training for operators and other users. }\end{array}$ \\
\hline $\begin{array}{l}\text { Dedicated Outdoor Air System } \\
\text { (DOAS) + Enthalpy Wheel }\end{array}$ & $\begin{array}{l}\text { Medium- Humidity is not a major concern in many parts of the Pacific } \\
\text { Northwest, and temperate climate in both winter and summer reduces ERV } \\
\text { benefit. More product offerings of this type entering the marketplace but there } \\
\text { is limited awareness and regional specific field data on the units. }\end{array}$ \\
\hline Thermal energy storage (TES) & $\begin{array}{l}\text { Medium - Limited time-of-use rates offered by utilities in the BPA region } \\
\text { lengthen paybacks for this technology, but that could change if TOU pricing } \\
\text { becomes more widespread. However, with nuclear and hydro resources, TOU } \\
\text { pricing may be less critical Also, requires significant technology improvements } \\
\text { and implementing this as an integrated solution with radiant cooling and low } \\
\text { lift cooling options to further demonstrate benefits is required. }\end{array}$ \\
\hline Radiant cooling/heating & $\begin{array}{l}\text { Low/Medium - Short cooling season limits cooling applications. Requires } \\
\text { significant improvement in implementer and consumer awareness. Also, initial } \\
\text { failures with technology have discouraged adoption. }\end{array}$ \\
\hline
\end{tabular}


Stakeholders consistently identified three general barriers preventing higher adoption of low lift cooling technology.

\begin{tabular}{|c|c|c|c|}
\hline \multicolumn{4}{|c|}{ Major Barriers Identified by Stakeholder Type } \\
\hline Stakeholder & $\begin{array}{l}\text { Low Energy Costs in the } \\
\text { Pacific Northwest }\end{array}$ & Regional Climate & $\begin{array}{c}\text { Lack of Experience with } \\
\text { Technology }\end{array}$ \\
\hline Architects & & & \\
\hline Building Owners & & & \\
\hline $\begin{array}{l}\text { Energy Service } \\
\text { Provider }\end{array}$ & $\sqrt{ }$ & $\sqrt{ }$ & \\
\hline $\begin{array}{l}\text { LEED and HVAC } \\
\text { Engineers/Consul } \\
\text { tants }\end{array}$ & & & \\
\hline $\begin{array}{l}\text { Utility } \\
\text { Representatives }\end{array}$ & $\sqrt{ }$ & & \\
\hline
\end{tabular}

Significant regional barriers to low lift equipment exist, but can potentially be overcome with properly designed measures.

\section{Major Regional Barrier}

Inexpensive and clean energy

- Low energy costs lengthen payback period of efficiency improvements

- Time-of-use pricing is not currently common

- Low carbon emission rates

Regional Climate

- Short cooling season

- Micro-climates and variable humidity levels depending on region

Lack of Experience with Technology

- Building owners and contractors are risk adverse to being an early adopter

- Lack of awareness with performance, installation, and O\&M requirements

\section{Potential Solutions}

Targeted Incentives

- Offer additional state and utility incentives for this technology that target institutional facilities and regions with higher energy rates (e.g. government facilities in larger cities like Portland)

Customized System Configurations

- Offer customized applications (e.g. optional enthalpy wheel for humidity control)

- Combine cooling technology with heating applications to improve equipment payback

- Make enthalpy wheel and radiant cooling optional

Informational Program and Resources

- Publish results of regional case studies

tracking long-term performance

- Develop public database of local

installations with performance data

- Offer complimentary feasibility studies 
Overview

Regional Benefits and Barriers

3 Conclusions and Recommendations

4. Appendix

The acceptance of low lift cooling technology in the Pacific Northwest could be impeded by low electricity costs and $\mathrm{CO}_{2}$ emissions, but the market has some early adopters and is a strong market for LEED and other green buildings, which could enhance the adoption potential.

Conclusions

- Low energy costs and the short cooling season in the Pacific Northwest lengthen payback of low lift cooling technology.

- Institutional customers (e.g. government buildings) are more accepting of longer energy efficiency paybacks $(\leq 10 \mathrm{yrs})$ than private sector facilities $(\leq$ 3 yrs).

- Site constraints and regional climates limit the potential for thermal energy storage and radiant cooling technologies.

- In areas with high acceptance of LEED standards, there is sufficient communication between architects and engineers in the early planning stages of building energy systems

- There is generally a lack of understanding and local experience with the technology. 
An effective program administered by BPA would provide educational information on the technology and target customers with the highest value proposition.

\begin{tabular}{|l|}
\hline \multicolumn{2}{|c|}{ Recommendations } \\
\hline - Evaluate and focus on market segments where technology has the highest \\
value proposition such as government and other institutional facilities that \\
are more accepting of technologies with longer paybacks. \\
- Target regions with higher electricity rates, high cooling demand, and a \\
track-record for support of energy efficiency and green buildings. \\
- Offer some customization of systems to accommodate micro-climates (e.g. \\
exclude radiant cooling system or provide optional enthalpy wheel to \\
control humidity). \\
- Develop and publish informational resources with lessons learned from \\
local case-studies to increase understanding of the technology. \\
- Implement effective training practices and resources for engineers and \\
contractors in target regions and markets.
\end{tabular}

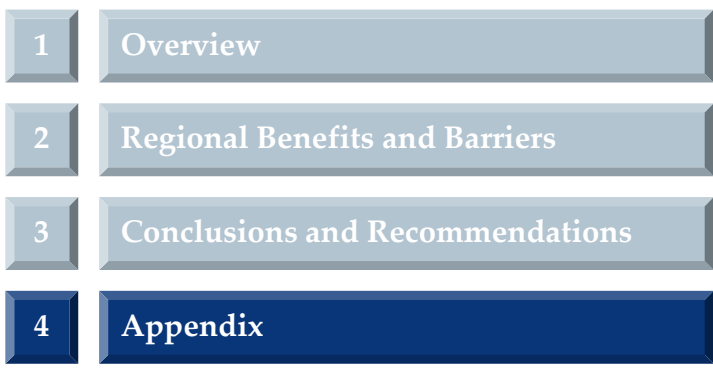


While low lift cooling technology is new to most utilities, a variety of energy efficiency programs for HVAC equipment exist.

\begin{tabular}{|c|c|c|}
\hline $\begin{array}{l}\text { Utility/ } \\
\text { Agency }\end{array}$ & Program Type & Program Description \\
\hline $\begin{array}{l}\text { Avista, Pacific } \\
\text { Gas \& Electric, } \\
\text { and Southern } \\
\text { California } \\
\text { Edison }\end{array}$ & $\begin{array}{l}\text { HVAC Efficiency } \\
\text { Program }\end{array}$ & $\begin{array}{l}\text { - Administered by Portland Energy Conservation, Inc. (PECI) to offer a } \\
\text { comprehensive HVAC efficiency program designed to small and medium- } \\
\text { sized commercial customers. } \\
\text { - Program targets contractors with training, tools, quality control and } \\
\text { incentives for new and existing rooftop units. } \\
\qquad \mathrm{P}|\mathrm{E}| \mathrm{C} \mid \mathrm{I}\end{array}$ \\
\hline $\begin{array}{l}\text { Portland } \\
\text { General } \\
\text { Electric (PGE) }\end{array}$ & $\begin{array}{l}\text { Building } \\
\text { Performance } \\
\text { Incentives and } \\
\text { HVAC Equipment } \\
\text { Rebates }\end{array}$ & $\begin{array}{l}\text { - Partners with the Energy Trust of Oregon to offer energy efficiency } \\
\text { informational classes to the public and rebates for efficient AC systems } \\
\text { (based on SEER rating), chillers, and demand control ventilation. } \\
\text { - Offers up to } \$ 500,000 \text { per project for newly constructed buildings based on } \\
\text { commissioning results ( } \$ 0.10 \text { per kilowatt hour and } \$ 0.80 \text { per therm for the } \\
\text { project's first year annual savings) }\end{array}$ \\
\hline $\begin{array}{l}\text { Bonneville } \\
\text { Power } \\
\text { Administration } \\
\text { (BPA) }\end{array}$ & $\begin{array}{l}\text { Energy Smart and } \\
\text { Performance Tested } \\
\text { Comfort System } \\
\text { (PTCS) }\end{array}$ & $\begin{array}{l}\text { - The EnergySmart Program cofunded by BPA and local utilities provides } \\
\text { customers with energy audits and information about efficient technology, } \\
\text { operations, and management that illuminate the possibilities and impacts of } \\
\text { increasing efficiency. } \\
\text { - BPA partnered with Ecos Consulting to administer the PTCS to ensure } \\
\text { new HVAC equipment is properly sized, installed and charged. }\end{array}$ \\
\hline
\end{tabular}

Sources: http://www.aircare-plus.com/; http://www.aircare-plus.com/; http://www.bpa.gov/energy/n/projects/

Once the technology matures, an effective incentive program would target customers with highest value proposition.

Program Design

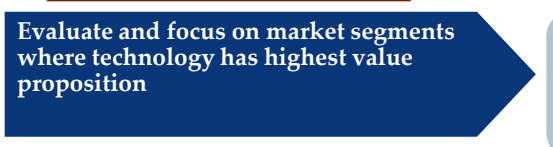

Assign appropriate program point of

contact or $3^{\text {rd }}$ party that can interface with

customers and answer broad scope of

policy, technical, and economic questions

Establish clear, well-documented, and simple incentive application procedures

Implement effective training practices and resources for engineers and contractors that target specified market segments

\section{Expected Impact}

- Provide tailored efficiency and economic analysis of technology for specific market sectors (e.g. institutional facilities or office buildings)

- Avoid confusion and waiting time associated with main customer service hotline

- Facilitate and streamlines adoption by interested customers

- Increase understanding and awareness in specific market sectors

NAVIGAN 


\section{Sources:}

1. EIA State Energy Profiles--http://tonto.eia.doe.gov/state/index.cfm

2. ACEEE 2008 State Energy Efficiency Scorecard--http://www.aceee.org/pubs/e086_es.pdf

3. EIA Retail Price of Electricity--

http://www.eia.doe.gov/cneaf/electricity/epm/table5_6_a.html

4. Oregon Climate Service (Oregon State University)--

http://cses.washington.edu/cig/pnwc/pnwc.shtml

5. Bend, Oregon Weather Station:

http://www.wunderground.com/weatherstation/WXDailyHistory.asp?ID=KORBEND33

6. Auburn, Washington Weather Station:

http://www.wunderground.com/weatherstation/WXDailyHistory.asp?ID=KWALAKET1

7. Weather Map: Wunderground.com

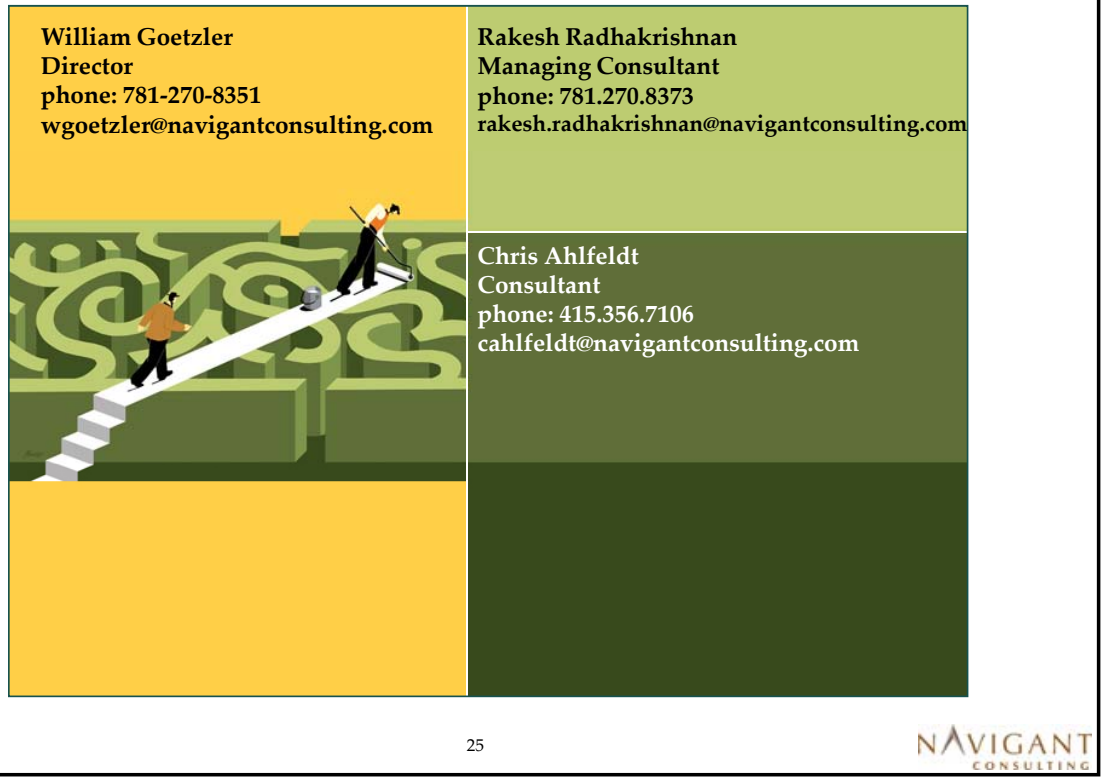


B Appendix: Incremental Cost Supporting Material 


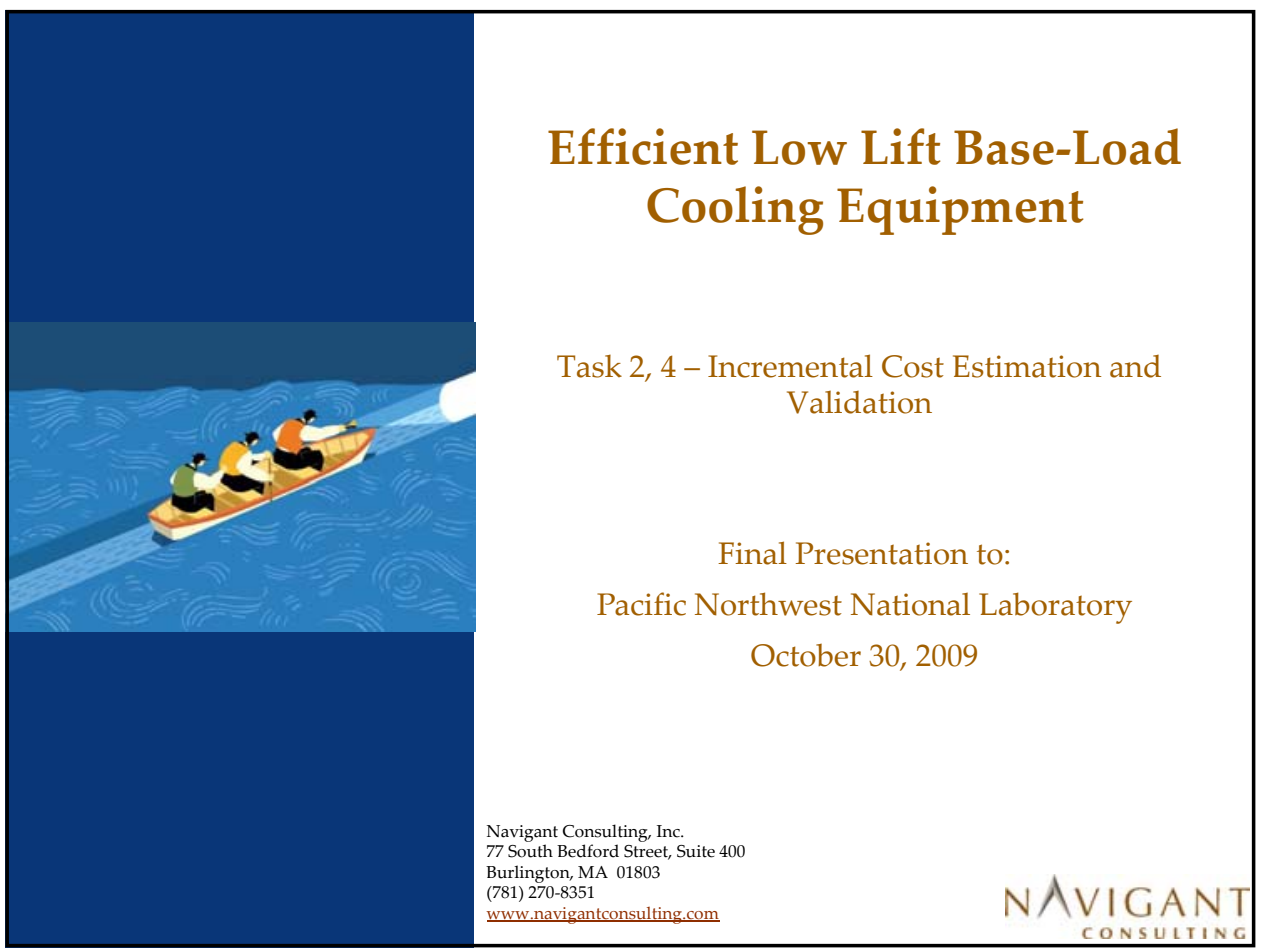

Table of Contents

\begin{tabular}{|l|l|}
\hline 1 & Introduction \\
\hline 2 & Baseline System Costs \\
\hline 3 & Advanced System Costs \\
\hline 4 & Final Incremental Costs \\
\hline 5 & Future Work \\
\hline 6 & Appendix \\
\hline
\end{tabular}




\section{Introduction}
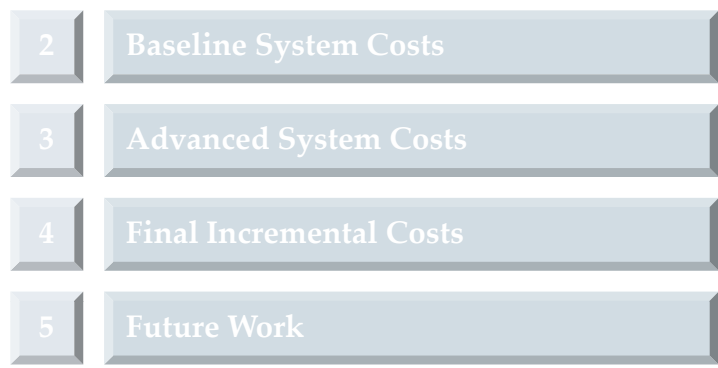

6

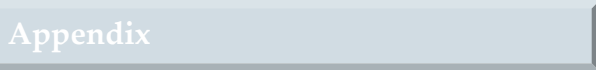

Overview » Introduction

NCI has completed the incremental cost (LLC) technology nationally and in the Houston region.

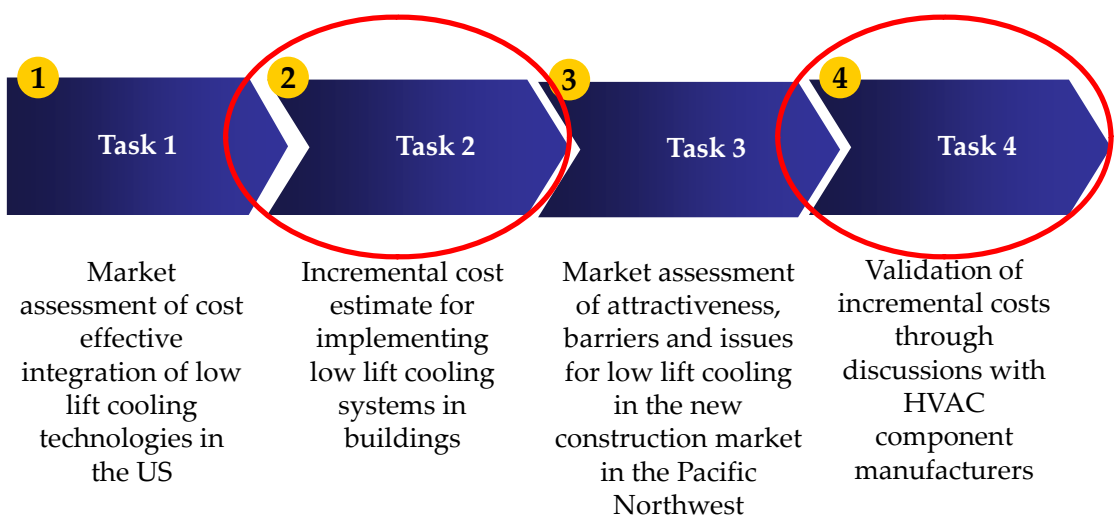

This report focuses on Task 2 of the market assessment for LLC equipment. 


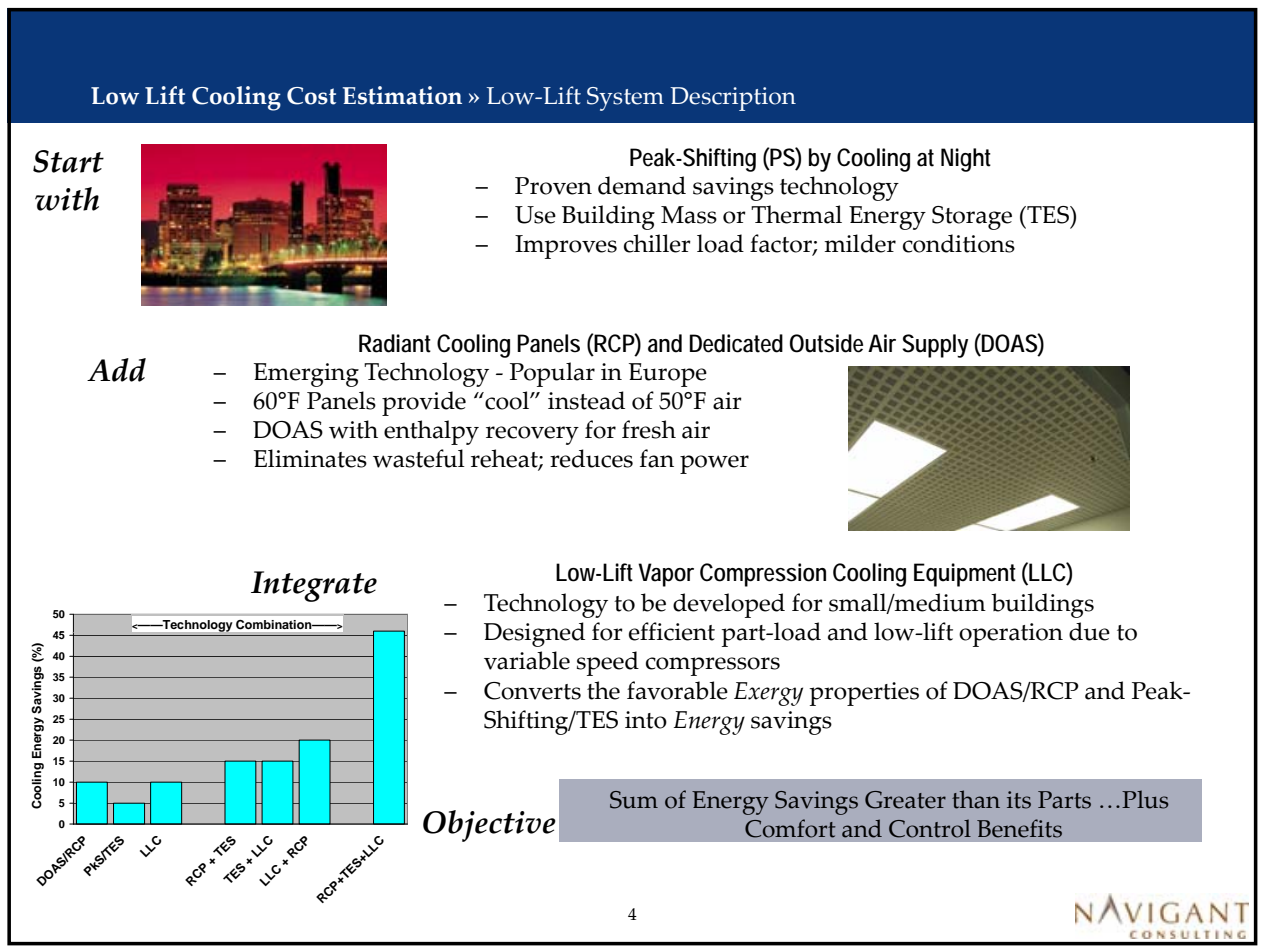

Low Lift Cooling Cost Estimation » Low-Lift System Benefits

Benefits of combining three technologies are greater than its parts, and approach is ideally suited for new construction of energy efficient buildings.

- Radiant Cooling Panels (RCP)

- Zone control without wasteful reheat

- 55- $60^{\circ} \mathrm{F}$ chilled water temperature

- Eliminate $80 \%$ of fan transport energy

- Increase water-side free-cooling capacity \& hrs/yr

- Peak-Shifting/TES

- Reduce condensing temperature 10-20F

- Reduce peak and median load on chiller

- Increase annual free-cooling load fraction

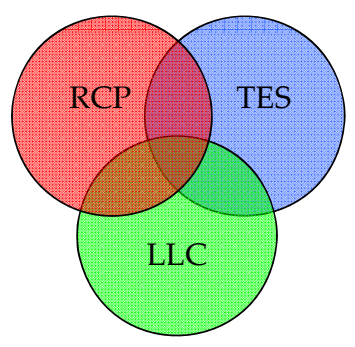

- Low-Lift Cooling Equipment (LCC)

- Design for efficient part-load, low-lift operation

- Good match for RCP

- Good match for TES

- Can be packaged for small-medium buildings 
Low Lift Cooling Cost Estimation » Low-Lift System Technologies

Low lift cooling uses a combination of HVAC technologies and advanced controls to reduce the energy consumption of building HVAC systems in buildings designed specifically for low-lift cooling.

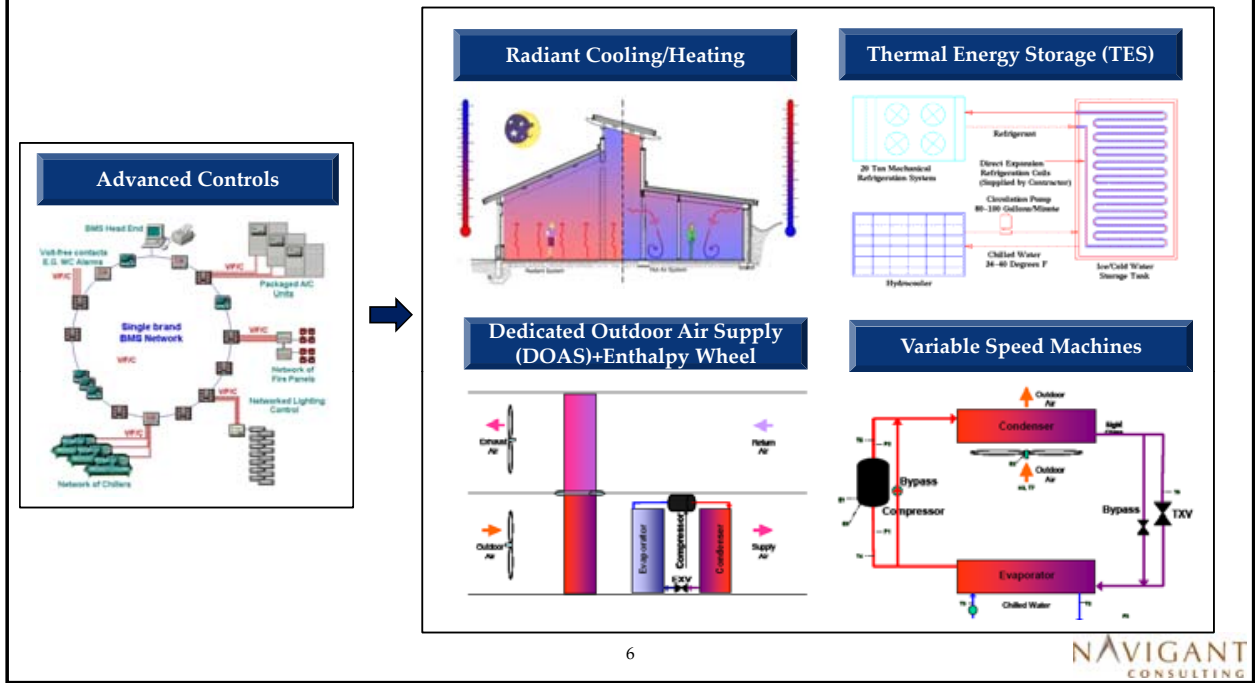

Low Lift Cooling Cost Estimation » Overview

As part of Task 2, NCI was tasked with calculating incremental costs for installing low-lift cooling technologies in commercial buildings.

\begin{tabular}{|c|c|}
\hline $\begin{array}{l}\text { PNNL } \\
\text { provided: }\end{array}$ & $\begin{array}{l}\text { - Energy Plus outputs with equipment sizing information for baseline } \\
\text { cooling systems } \\
\text { - Low-lift cooling system configurations } \\
\text { - Low-lift cooling system sizing estimates } \\
\text { - U.S. region to analyze }\end{array}$ \\
\hline
\end{tabular}

NCI product:

- Incremental costs for a set of low-lift cooling technologies

- Based on commercial buildings and costs in Houston, TX 
The overall methodology used by NCI to estimate incremental costs is summarized below.
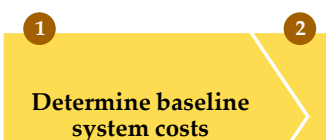

Size advanced cooling systems using baseline system inputs

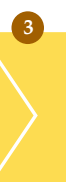

Determine

advanced system costs

Low Lift Cooling Cost Estimation » Location of Analysis

Incremental low-lift cooling costs were calculated for commercial buildings specific to the city of Houston.

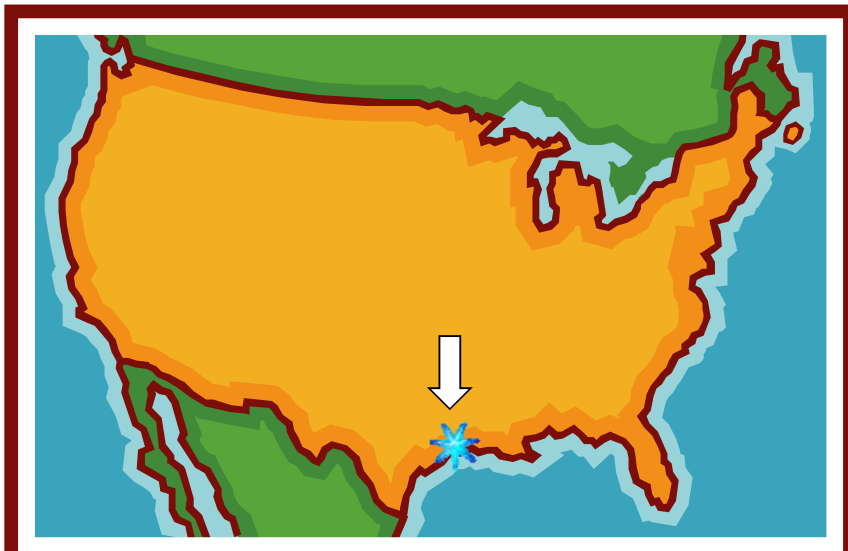

Ms - HOUSTON

- Hot humid region

- 2700 CDD in 2003

${ }^{*} \mathrm{CDD}$ data is from $:$ http://www.climate-zone.com/climate/united-states/texas/houston/ 
PNNL selected four representative commercial building types to develop incremental costs for.

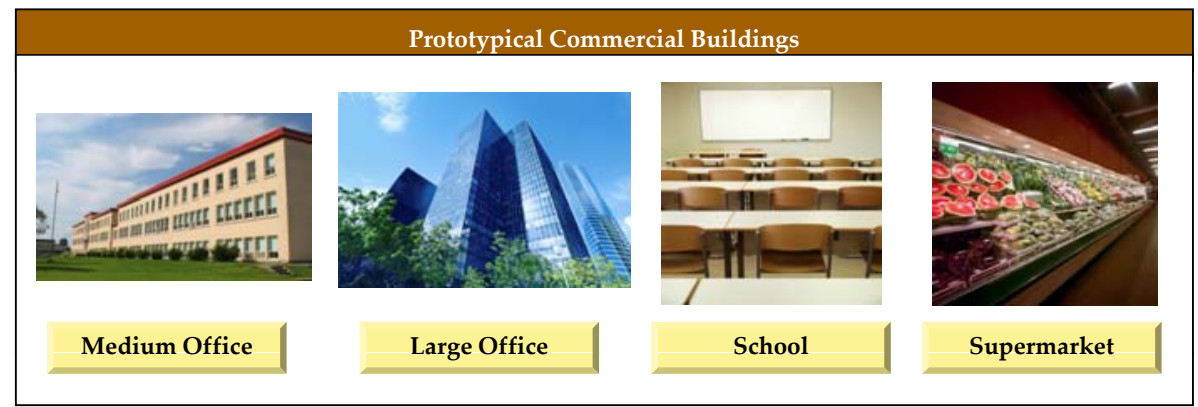

- PNNL developed baseline system specifications for each building type, specific to the Houston region.

- Each building had a different set of equipment needs and sizes.

Low Lift Cooling Cost Estimation » Cost Model Development

EnergyPlus files were used to size the baseline and advanced systems for each building.

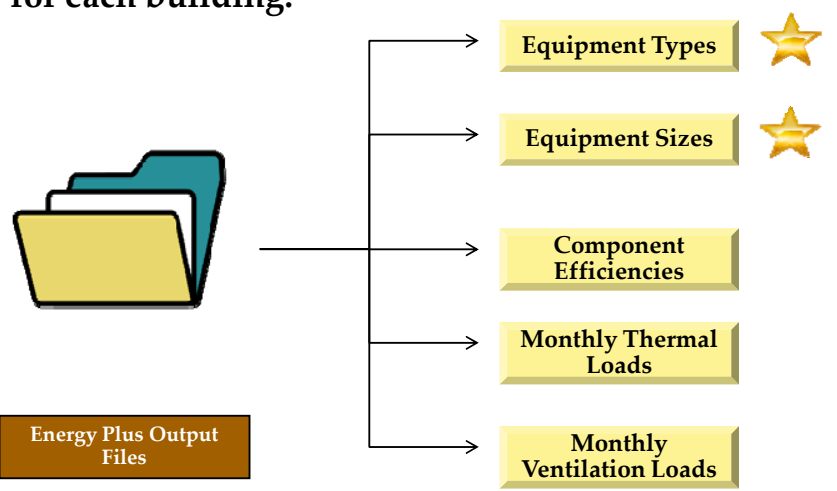

PNNL provided Energy Plus Files for each building Type.

- NCI relied on the equipment sizes provided for each building to size the baseline system and advanced system components. 


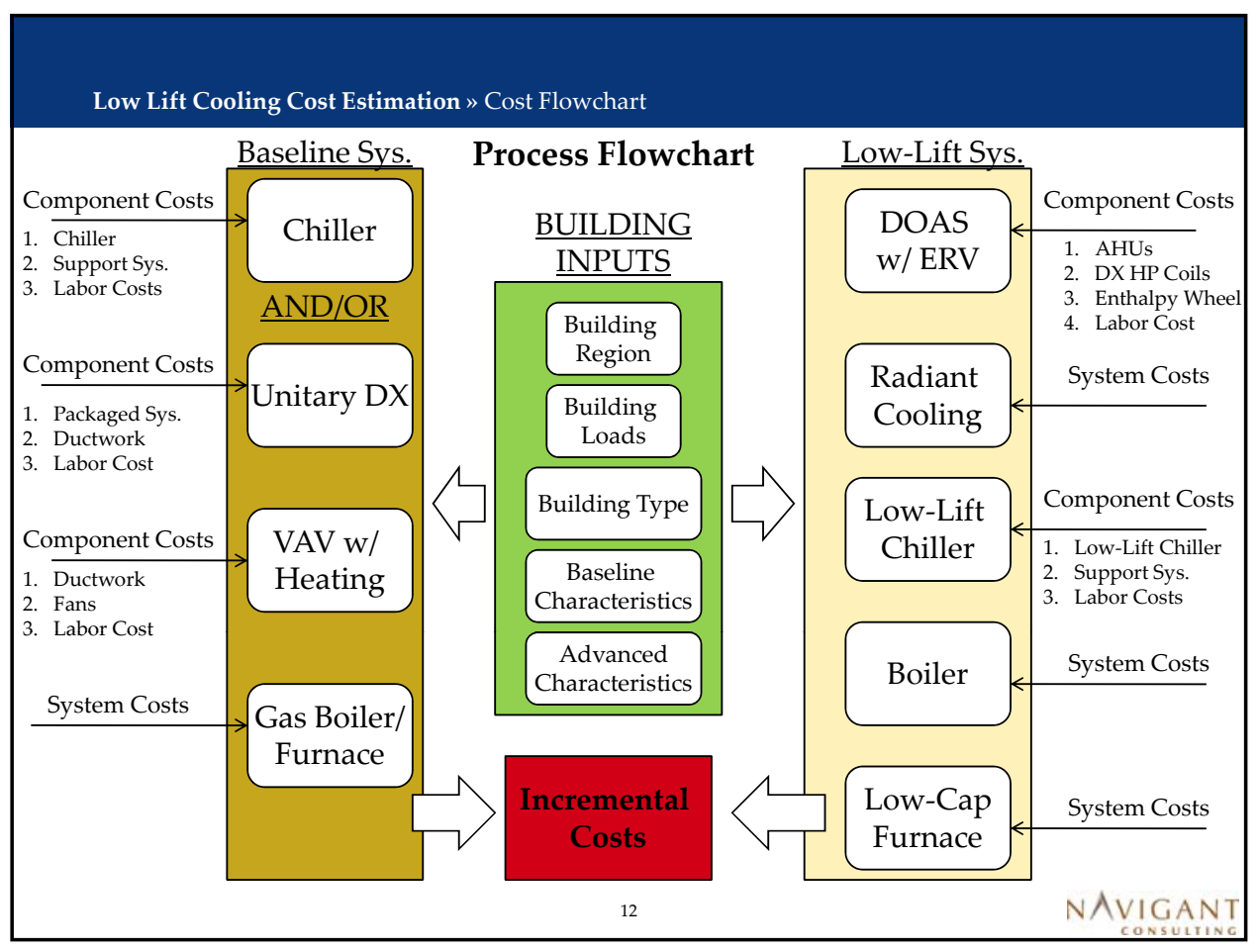

Low Lift Cooling Cost Estimation » Proposed Sources for Costs

Costs for the low-lift technologies were developed from a variety of sources.

\begin{tabular}{|c|c|c|}
\hline \multicolumn{3}{|c|}{ Component Cost Sources } \\
\hline Component & Baseline Costs & Low-Lift Costs \\
\hline Chiller, Rooftop Units & RS Means 2007 & Suppliers, RS Means 2007 \\
\hline Boiler & RS Means 2007 & RS Means 2007 \\
\hline Furnaces & RS Means 2007 & RS Means 2007 \\
\hline Control System & \multicolumn{2}{|c|}{ Assumed no incremental } \\
\hline Ductwork & Suppliers, RS Means 2007 & Suppliers, RS Means 2007 \\
\hline Air-Handlers & RS Means 2007 & RS Means 2007 \\
\hline DX HP Coils & - & RS Means 2007 \\
\hline Enthalpy Wheel & - & RS Means 2007 \\
\hline Radiant Cooling & - & Suppliers \\
\hline
\end{tabular}

- For the low-lift chiller costs, the cost premiums for advanced chillers were provided through suppliers, while the component costs for the chiller sizes were taken from RS Means. 
Low Lift Cooling Cost Estimation » Spreadsheet Tool for Cost Modeling

NCI developed a spreadsheet to track individual components costs and calculate incremental costs and metrics.

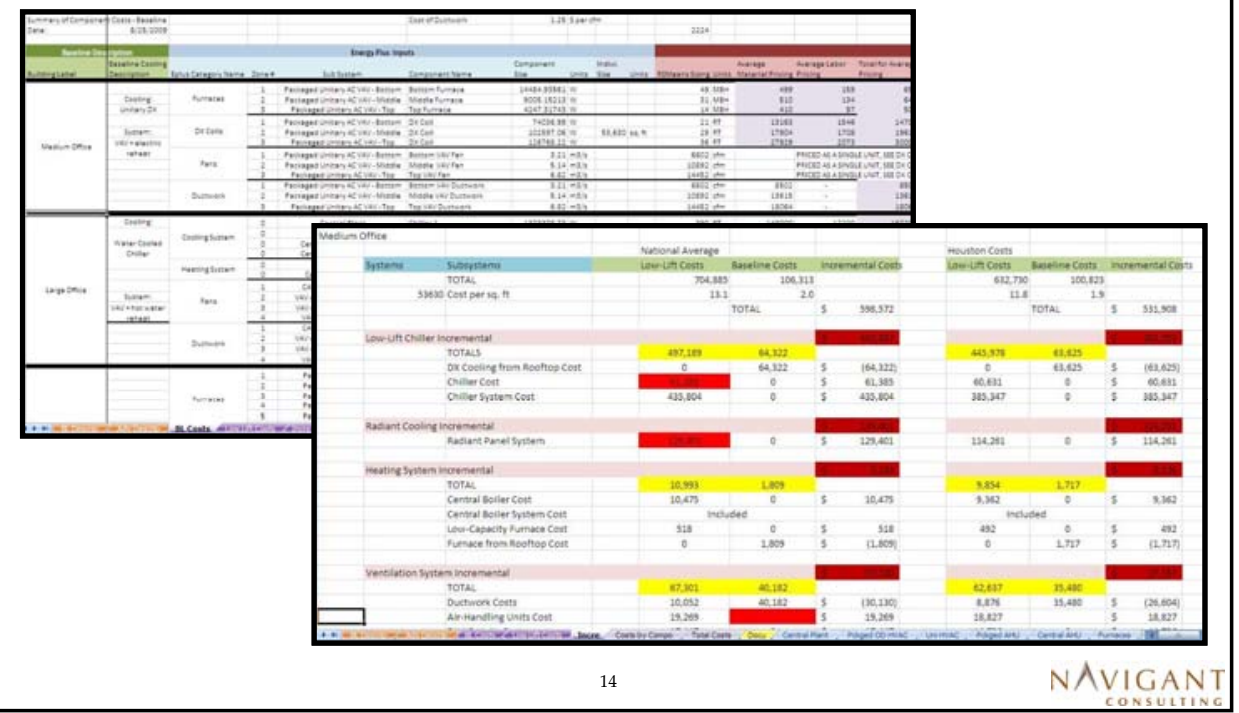

Table of Contents

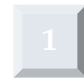

2 Baseline System Costs
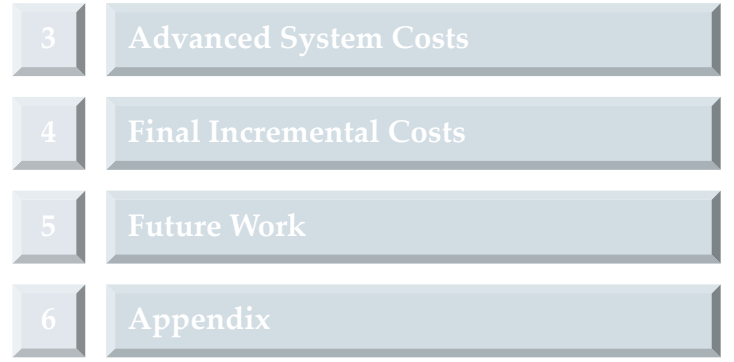
The baseline system costs were calculated from RS Means using the baseline inputs provided by PNNL.

Determine baseline system cost

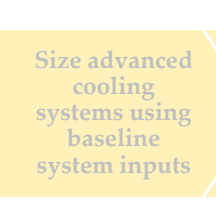

(1)

\begin{tabular}{|c|c|}
\hline & $\begin{array}{l}\text { - Used the baseline component sizes provided in the EnergyPlus data } \\
\text { from PNNL to determine baseline component costs. } \\
\text { - Pulled material and labor costs from } 2007 \text { RS Means - Mechanical } \\
\text { Cost Data book. }\end{array}$ \\
\hline System Costs & $\begin{array}{l}\text { - Ductwork material costs were calculated at } \$ 1.25 \text { per CFM, with } \\
\text { multipliers of } 4 \text { (single-zone) and } 5 \text { (multi-zone) to include labor } \\
\text { costs. } \\
\text { - Adjusted RS Means costs using regional cost indexes for the } \\
\text { Houston area. }\end{array}$ \\
\hline
\end{tabular}

16

Low Lift Cooling Cost Estimation » Baseline system configurations

The baseline system configurations provided by PNNL are listed below.

\begin{tabular}{|c|c|c|c|c|c|}
\hline & \multicolumn{5}{|c|}{$\begin{array}{c}\text { Baseline System Assumptions of each Building Type for the Houston } \\
\text { Region }\end{array}$} \\
\hline & $\begin{array}{c}\text { Square } \\
\text { Footage } \\
(\mathrm{ft} 2)\end{array}$ & $\begin{array}{l}\text { HVAC } \\
\text { Heating }\end{array}$ & $\begin{array}{l}\text { HVAC } \\
\text { Cooling }\end{array}$ & Ventilation System & Envelope - Wall \\
\hline $\begin{array}{l}\text { Medium } \\
\text { Office }\end{array}$ & 53,630 & $\begin{array}{c}\text { Gas } \\
\text { Furnace }\end{array}$ & $\begin{array}{c}\text { Unitary } \\
\text { DX }\end{array}$ & $\begin{array}{c}\text { VAV + Elec. } \\
\text { Reheat }\end{array}$ & Steel Frame \\
\hline Large Office & 460,240 & $\begin{array}{l}\text { Gas } \\
\text { Boiler }\end{array}$ & $\begin{array}{l}\text { Water } \\
\text { Chilled } \\
\text { Cooler }\end{array}$ & $\begin{array}{c}\text { VAV + Hot Water } \\
\text { Reheat }\end{array}$ & Mass \\
\hline Supermarket & 45,000 & $\begin{array}{l}\text { Gas } \\
\text { Furnace }\end{array}$ & $\begin{array}{l}\text { Unitary } \\
\text { DX }\end{array}$ & $\mathrm{PSZ}^{*}$ & Mass \\
\hline $\begin{array}{l}\text { Secondary } \\
\text { School }\end{array}$ & 210,890 & $\begin{array}{l}\text { Gas } \\
\text { Boiler }\end{array}$ & $\begin{array}{l}\text { Water } \\
\text { Chilled } \\
\text { Cooler }\end{array}$ & $\begin{array}{l}\text { VAV + Hot Water } \\
\text { Reheat; PSZ** }\end{array}$ & Steel Frame \\
\hline
\end{tabular}

*PSZ - Packaged Single Zone

**PSZ in the school is used for the kitchen and gym 
NCI used RS Means to determine the material and labor costs of the baseline systems.

Steps for calculating baseline costs using RS Means:

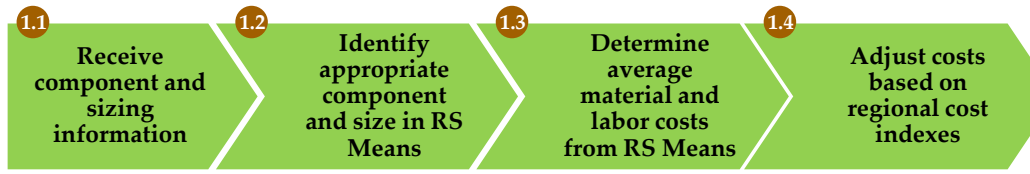

Reference - 2007 RSMeans Mechanical Cost Data

\begin{tabular}{|c|c|c|c|c|}
\hline 2352 & Heating Boilers & & & \\
\hline 235223 - & Cast-Iron Boilers & ..... & 2007 Bare & sts \\
\hline 235223.20 & Gas-Fired Boilers & ....... & Material & Labor \\
\hline 0010 Gas- 1 & ired Boilers, Natural or propane, sta & & & \\
\hline $1000 \quad C$ & st iron, with insulated jacket & & & \\
\hline 3000 & Hot Water, gross output, $80 \mathrm{MBH}$ & & $\$ 1,575$ & $\$ 945$ \\
\hline 3020 & $100 \mathrm{MBH}$ & & $\$ 1,800$ & $\$ 1,025$ \\
\hline 3040 & $122 \mathrm{MBH}$ & & $\$ 1,925$ & $\$ 1,250$ \\
\hline 3060 & $163 \mathrm{MBH}$ & & $\$ 2,350$ & $\$ 1,375$ \\
\hline
\end{tabular}

Low Lift Cooling Cost Estimation » Sizing and Descriptions Provided

PNNL provided sizing and description of components from the EnergyPlus package.

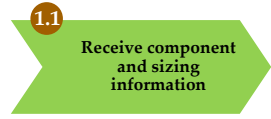

\begin{tabular}{|l|c|c|c|c|}
\cline { 2 - 5 } \multicolumn{1}{c|}{} & \multicolumn{3}{c|}{ Equipment Specifications- EnergyPlus Baseline Information } \\
\cline { 2 - 5 } \multicolumn{1}{c|}{} & $\begin{array}{c}\text { Medium } \\
\text { Office }\end{array}$ & Large Office & Supermarket & School \\
\hline Building Size & 53,630 sq. ft & 460,240 sq. ft & 45,000 sq. ft & 210,890 sq. ft \\
\hline Total Cooling Load & 86 RT & 780 RT & 131 RT & 985 RT \\
\hline Ventilation Type & $\begin{array}{c}\text { Packaged } \\
\text { AC Unitary }\end{array}$ & VAV & $\begin{array}{c}\text { Packaged } \\
\text { Single Zone }\end{array}$ & $\begin{array}{c}\text { VAV + Packaged } \\
\text { Single Zone }\end{array}$ \\
\hline Central Plant & No & Yes & No & Yes \\
\hline
\end{tabular}

- RT - Refrigeration Tons

- VAV - Variable Air Volume

- Notice that the size of the building is not a good predictor of the required cooling load supplied by the building's equipment.

- More information can be found in the Appendix. 
NCI selected components in RS Means based on the system descriptions provided by the files.
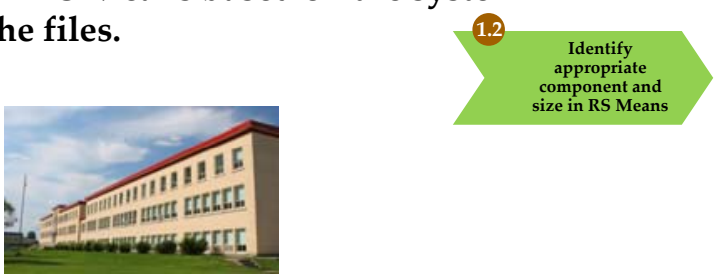

Medium Office

HVAC System Description

- Unitary DX Cooling

- Gas Furnace Heating

- VAV + electric reheat Ventilation

Energy Plus Description

- Packaged Air Conditioner

- One PACU for each zone

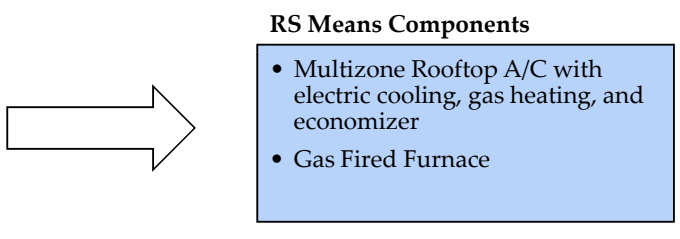

20

NCI selected the following components in RS Means for pricing components in the baseline HVAC systems

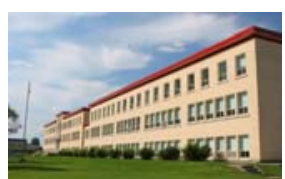

Medium Office

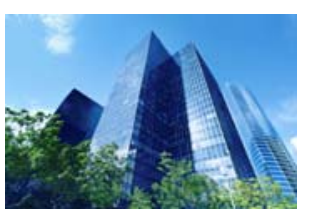

Large Office
RS Means Components

3 Zones - Each with:

1 Multi zone Rooftop Air

Conditioner

1 Gas-fired Furnace

RS Means Components

1 Central Plant with:

2 Centrifugal Chillers

1 Gas/Oil Fired Boiler

3 Zones - Each with:

1 Central-Station AHU

with VAV 
NCI selected the following components in RS Means for the pricing of components listed in the baseline systems

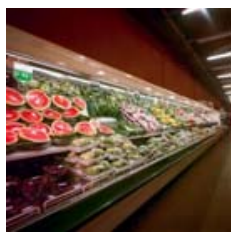

Supermarket

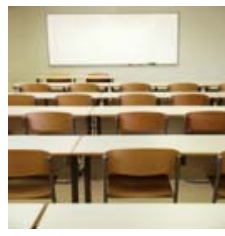

School
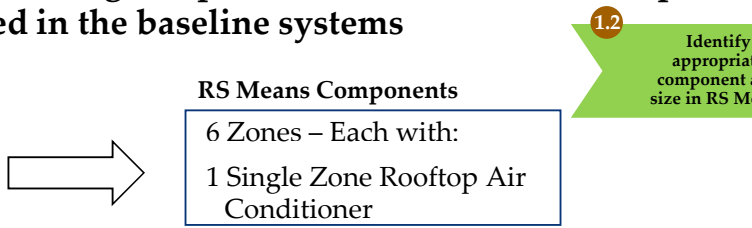

appropriate component and size in RS Means Conditioner

RS Means Components

1 Central Plant:

1 Centrifugal Chillers

1 Gas/Oil Fired Boiler

3 VAV Pods - Each with:

1 Central-Station AHU

5 PSZ Zones - Each with:

1 Single Zone Rooftop Air

Conditioner

Low Lift Cooling Cost Estimation » Using RSMeans for Pricing

NCI used RS Means to determine the material and labor costs of the baseline components.

2007 RSMeans Mechanical Cost Data

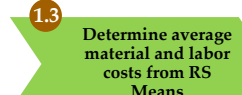

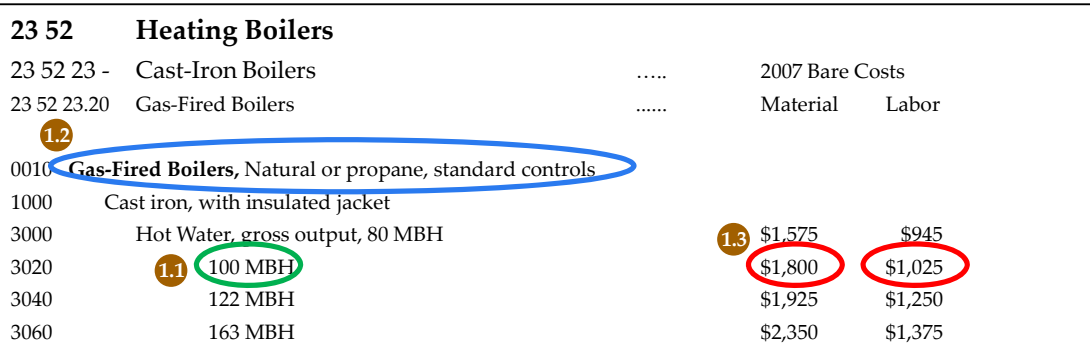

- After each component was properly sized and identified, RS Means was used to find the material and labor costs.

- When a component's size fell between two listed sizes, NCI interpolated based on size to find the appropriate material and labor costs.

- When a component's size was larger than the sizes provided in RS Means, NCI split the load among several smaller components, as appropriate. 
Low Lift Cooling Cost Estimation » Adjustment for Region

To account for regional costs, $\mathrm{NCI}$ used the city cost indexes found in RS Means to adjust the labor costs.

RSMeans City Cost $=$ RSMeans National Average Cost $\times$ City Cost Index / 100

\begin{tabular}{|c|c|c|c|}
\hline \multicolumn{4}{|c|}{ RS Means City Cost Index Values - Houston } \\
\hline Division & $\begin{array}{c}\text { Materials } \\
\text { Cost Index }\end{array}$ & $\begin{array}{c}\text { Labor Cost } \\
\text { Index }\end{array}$ & $\begin{array}{c}\text { Total Cost } \\
\text { Index }\end{array}$ \\
\hline $\begin{array}{c}\text { Weighted } \\
\text { Average }\end{array}$ & 101.4 & 71.4 & 88.5 \\
\hline
\end{tabular}

- The RS Means National Average Cost is based on the 30 City Average from 2007 RS Means - Mechanical Cost Data. The 30 City Average is the average of 30 major U.S. cities. Please see 2007 RS Means - Mechanical Cost Data to view the 30 major U.S. cities used.

- NOTE: Houston is one of the cities listed.

Low Lift Cooling Cost Estimation » Baseline Costs - by System

The baseline component costs show that larger buildings are significantly more expensive, because of supporting costs.

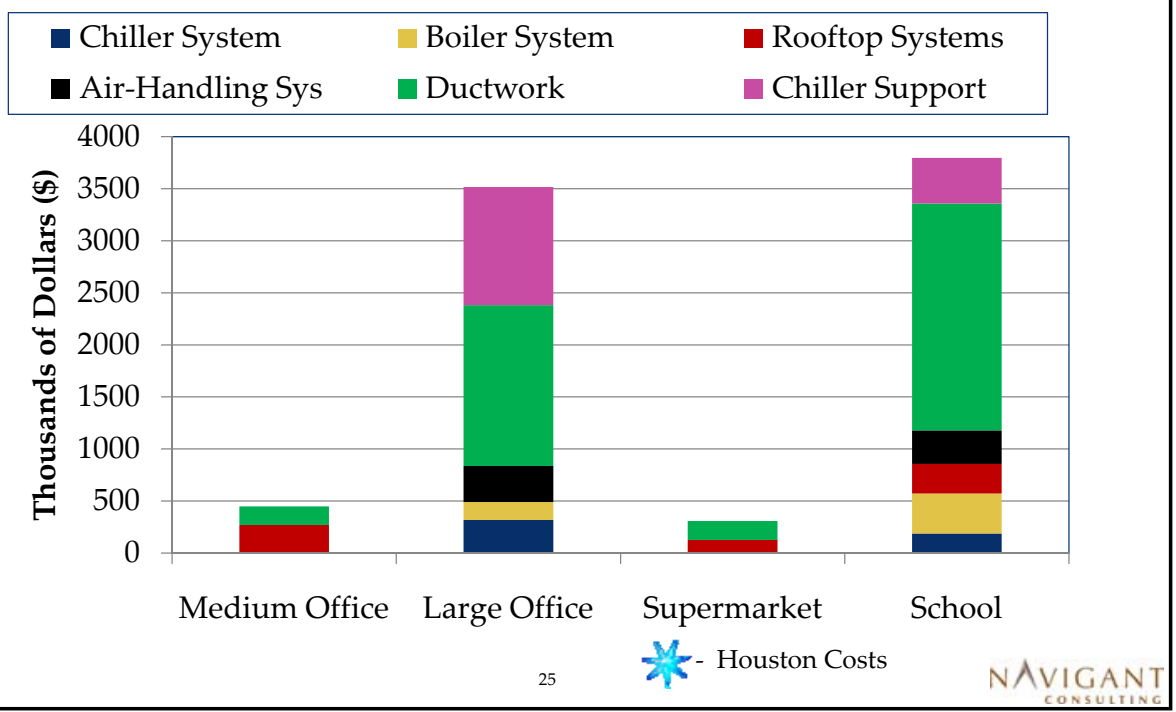


The Houston costs were slightly lower than the national average, with savings in labor costs driving the difference.

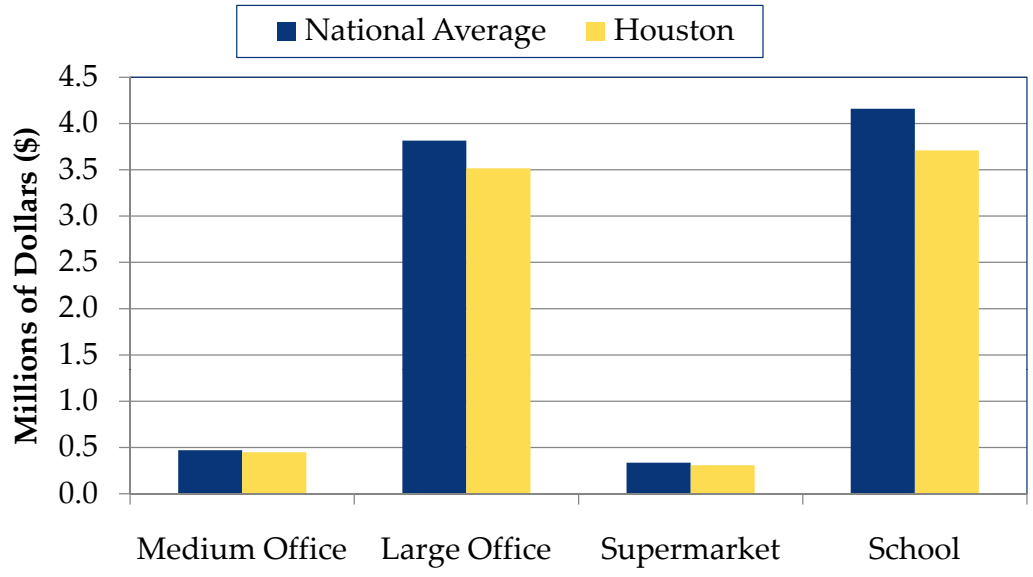

26

Low Lift Cooling Cost Estimation » Baseline Costs - Cost per sq. ft.

Calculating the cost per refrigeration ton allows for comparison of the cost of each system normalized by the cooling size of the building.

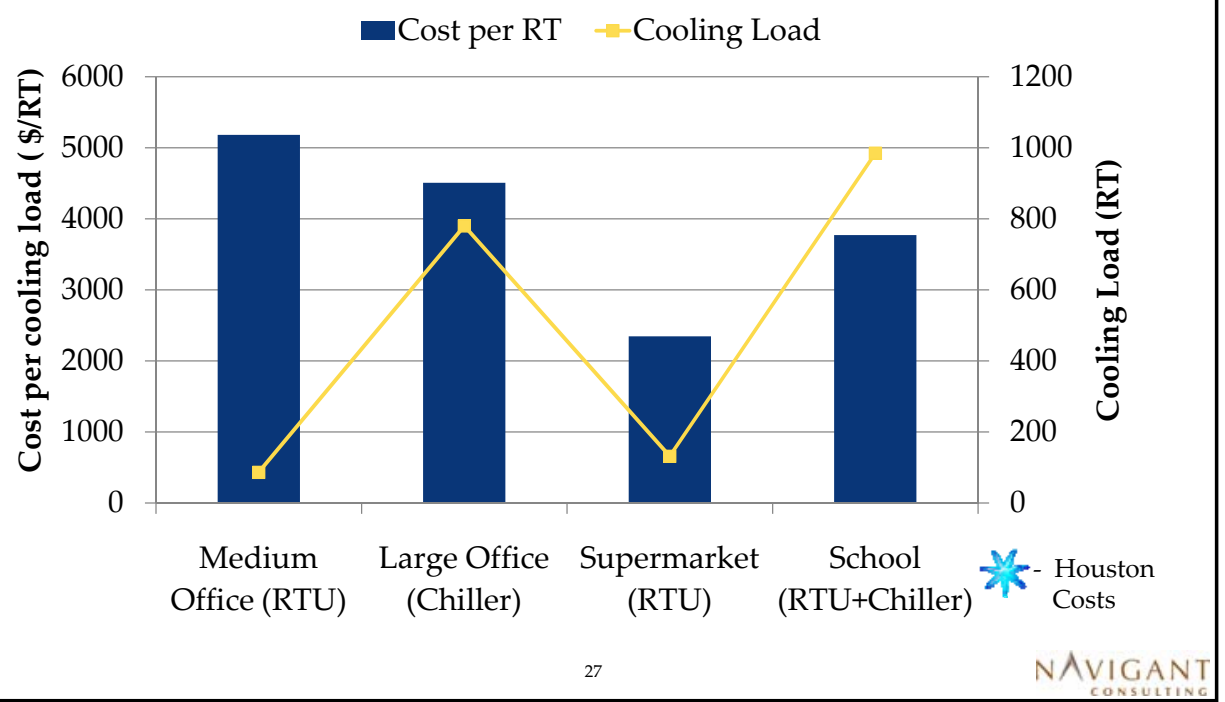




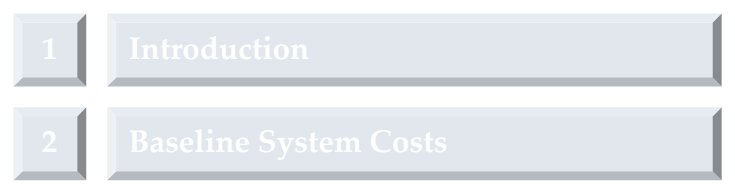

3 Advanced System Costs

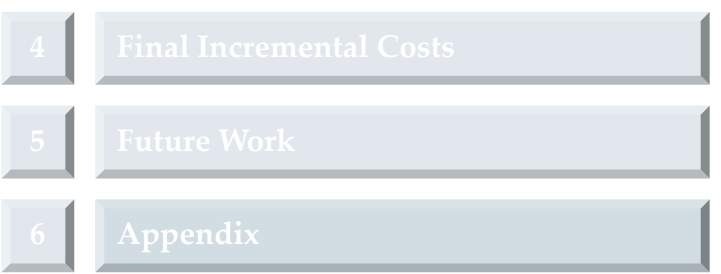

Low Lift Cooling Cost Estimation » Low-Lift System Configuration

The low-lift cooling systems were designed to meet the same building requirements as the baseline systems.

\begin{tabular}{|c|c|c|c|c|}
\hline & \multicolumn{4}{|c|}{ Advanced System Assumptions of each Building Type for the Houston Region } \\
\hline & $\begin{array}{c}\text { Square } \\
\text { Footage } \\
(\mathrm{ft} 2)\end{array}$ & $\begin{array}{l}\text { HVAC } \\
\text { Heating }\end{array}$ & HVAC Cooling & $\begin{array}{l}\text { Radiant Panel } \\
\text { Distribution }\end{array}$ \\
\hline $\begin{array}{l}\text { Medium } \\
\text { Office }\end{array}$ & 53,630 & $\begin{array}{l}\text { Gas } \\
\text { Boiler }\end{array}$ & $\begin{array}{c}\text { Low-Lift Chiller Air Cooled } \\
\text { DOAS w/ DX HP coil and Gas Furnace }\end{array}$ & $\begin{array}{l}\text { Radiant Slab in Ceiling } \\
\text { for Cooling }\end{array}$ \\
\hline Large Office & 460,240 & $\begin{array}{l}\text { Gas } \\
\text { Boiler }\end{array}$ & $\begin{array}{c}\text { Low-Lift Chiller Water Cooled } \\
\text { DOAS w/ DX HP coil and Gas Furnace }\end{array}$ & $\begin{array}{l}\text { Radiant Slab in } \\
\text { Concrete for Both } \\
\text { Heating and Cooling }\end{array}$ \\
\hline Supermarket & 45,000 & $\begin{array}{l}\text { Gas } \\
\text { Boiler }\end{array}$ & $\begin{array}{c}\text { Low-Lift Chiller Air Cooled } \\
\text { DOAS w/ DX HP coil and Gas Furnace }\end{array}$ & $\begin{array}{l}\text { Radiant Slab in } \\
\text { Concrete for Both } \\
\text { Heating and Cooling }\end{array}$ \\
\hline $\begin{array}{l}\text { Secondary } \\
\text { School }\end{array}$ & 210,890 & $\begin{array}{l}\text { Gas } \\
\text { Boiler }\end{array}$ & $\begin{array}{c}\text { Low-Lift Chiller Water Cooled } \\
\text { DOAS w/ DX HP coil and Gas Furnace }\end{array}$ & $\begin{array}{l}\text { Radiant Panel for Both } \\
\text { Heating and Cooling }\end{array}$ \\
\hline
\end{tabular}

- Based on the requirements for each U.S. region, the low-capacity furnace used for the transitional season may not be required for every region. 
The low-lift system costs were calculated from RS Means and supplier information using the baseline inputs provided by PNNL.

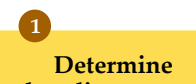
baseline system

costs

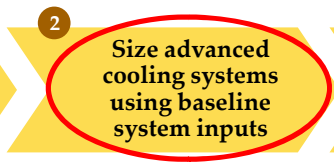
3

\section{Determine \\ advanced}

system costs

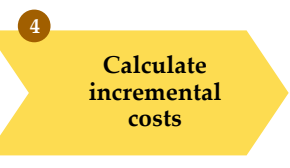

Calcemental

2

\begin{tabular}{|l|l|}
\hline $\begin{array}{l}\text { Low-lift } \\
\text { cooling } \\
\text { system sizing }\end{array}$ & $\begin{array}{l}\text { NCI used the component sizing and ventilation load information } \\
\text { provided by PNNL for the baseline systems to size the advanced } \\
\text { systems. } \\
\text { - NCI sized each advanced system component separately, using the } \\
\text { files from EnergyPlus for sizing information. } \\
\text { - NCI relied on input from PNNL on appropriate sizing on the low- } \\
\text { lift chiller, low-capacity furnace and the radiant cooling systems. }\end{array}$ \\
\hline
\end{tabular}

Low Lift Cooling Cost Estimation » Proposed Sizing and Sources

NCI sized the low-lift system components using the baseline equipment sizing and EnergyPlus data.

\begin{tabular}{|c|c|c|}
\hline \multicolumn{2}{|c}{ Low-lift Cooling System - Sizing Methods } \\
\hline Component & Sizing Method & Pricing Source \\
\hline Advanced Chiller & Sensible Cooling Load (72\% of total cooling) & Suppliers \\
\hline Advanced Boiler & $\begin{array}{c}\text { (1) Baseline Boiler Capacity OR } \\
\text { (2) Sum of Baseline Furnace Capacities }\end{array}$ & RS Means \\
\hline $\begin{array}{c}\text { Low-capacity } \\
\text { Furnace }\end{array}$ & $20 \%$ of Low-Lift Boiler Capacity & RS Means \\
\hline Radiant Cooling & Sensible Cooling Load (72\% of total cooling) & Suppliers \\
\hline DOAS Size & Average Outdoor Air Supply Requirements & Suppliers, RS Means \\
\hline DX HP Size & Baseline Latent Cooling Load (by Zone) & RS Means \\
\hline Enthalpy Wheel & Low-Lift DOAS Size (by Zone) & RS Means \\
\hline Concrete & Square Footage of the Radiant System & RS Means \\
\hline
\end{tabular}

- Information for the advanced component sizing was taken from the Energy Plus files. NCI also relied on inputs from PNNL and suppliers to size and cost the systems.

- Cost estimates derived from RS Means used the same procedure as was used for the baseline cost estimates. 
The low-lift system costs were calculated using RS Means and inputs from suppliers, using the sizing information provided by PNNL.

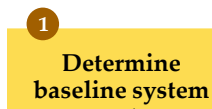
baseline system costs
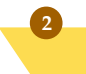

Size advanced cooling systems using baseline system inputs

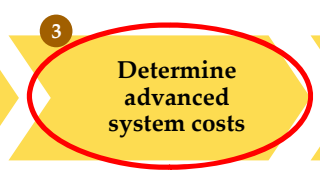

(4) increment costs

3

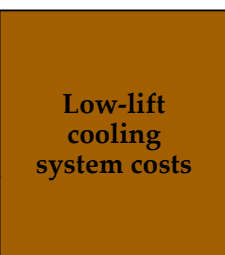

- Using the sizing information calculated for each advanced component, NCI determined the cost of each component.

- NCI relied on RS Means and component vendors for cost data

- Assorted chiller manufacturers provided advanced chiller costs.

- Radiant Panel manufacturers and contractors provided cost and sizing information for radiant cooling panels.

The two larger buildings experienced the largest increases in costs. The cost incremental from single-zone RTUs to a chiller system was significant (supermarket), while the cost incremental from multi-zone RTUs was very small (medium office).

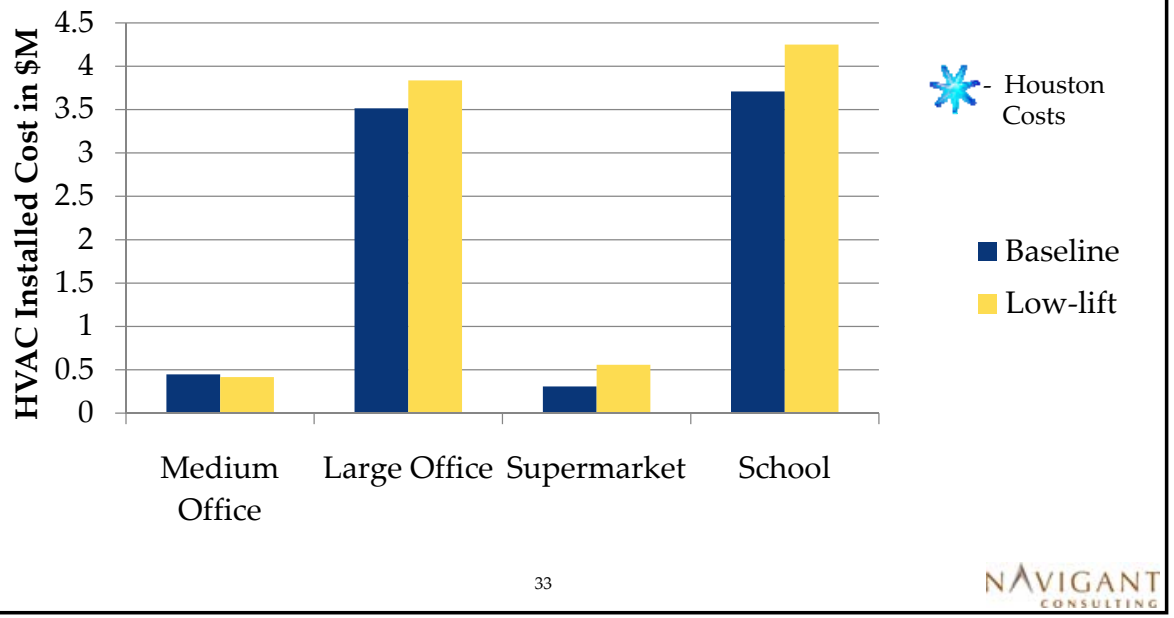




\section{Low Lift Cooling Cost Estimation » Low-Lift Costs - by System}

The installed costs for each component show that the chiller, radiant panel and DOAS costs account for most of the overall cost.

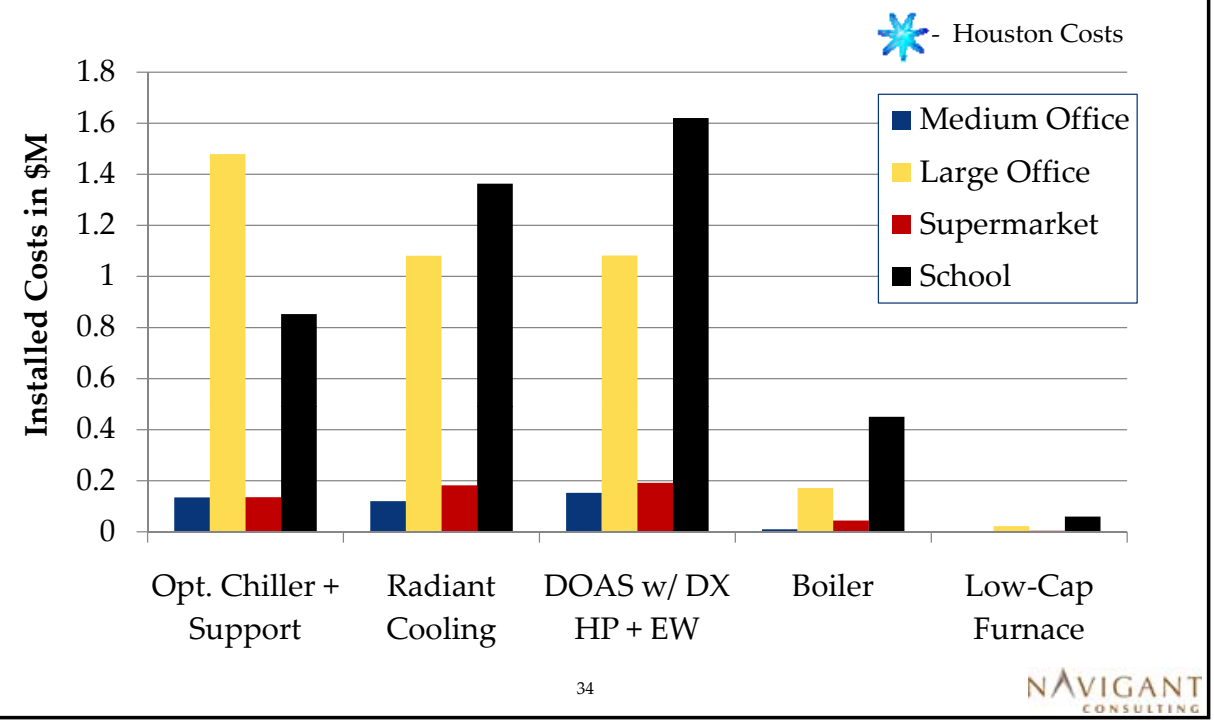

Low Lift Cooling Cost Estimation » Low-Lift Costs - by System

The Houston costs were slightly lower than the national average, with savings in labor costs driving the difference.

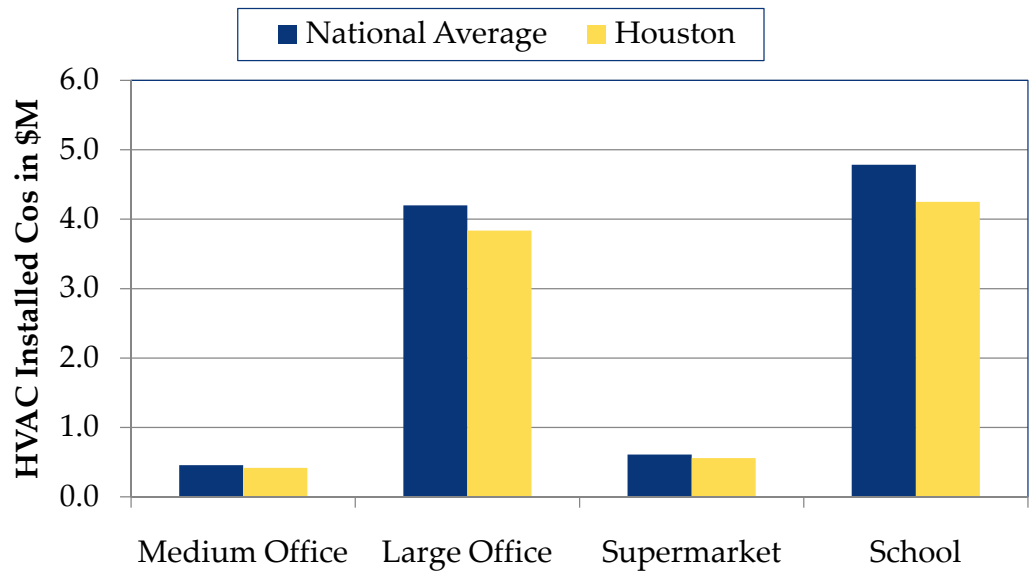


The cost of each chiller system represents the cost of the individual chiller and the supporting system.

\begin{tabular}{|l|c|c|c|}
\cline { 2 - 4 } \multicolumn{1}{c|}{} & \multicolumn{3}{c|}{ Low-Lift Chiller Costs by Components for each building } \\
\cline { 2 - 4 } \multicolumn{1}{c|}{} & $\begin{array}{c}\text { Chiller Installed } \\
\text { Cost }\end{array}$ & $\begin{array}{c}\text { Chiller Supporting } \\
\text { System }\end{array}$ & $\begin{array}{c}\text { TOTAL Installed } \\
\text { costs }\end{array}$ \\
\hline Medium Office & $\$ 54,564$ & $\$ 80,071$ & $\$ 134,635$ \\
\hline Large Office & $\$ 344,829$ & $\$ 1,134,858$ & $\$ 1,479,687$ \\
\hline Supermarket & $\$ 75,447$ & $\$ 60,045$ & $\$ 135,493$ \\
\hline Secondary School & $\$ 301,007$ & $\$ 551,859$ & $\$ 852,866$ \\
\hline
\end{tabular}

- Chiller costs include a low-lift cost premium: $15 \%$ for air-cooled, $16 \%$ for water-cooled

- Chiller supporting system costs include:

- For air-cooled: Fan Coil AC unit and Chilled Water Coil Connections (D3030 110)

- For water-cooled: Cooling Tower, Cooling Tower pumps and piping, chilled water unit coil connections, and Fan Coil AC unit. (D3030 115)

- More information can be found in the Appendix.

\section{NCI made some assumptions about the treatment of certain systems.}

\section{System}

Chiller and Boiler for the School

\section{DOAS Systems with DX HP and EW}

Radiant Cooling Systems

\section{Assumption}

- The baseline system for the school used both a chiller and boiler system, and rooftop units.

- For the low-lift system, NCI grew the size of the chiller and boiler systems and eliminated the rooftop units.

- The final cost of the DOAS system includes the ductwork, the DX Heat Pump Coils, and the enthalpy wheels.

- The cost for radiant cooling was assumed to be $\mathbf{\$ 1 0}$ per square foot, minus the cost of concrete slab installation (\$2.74/S.F) requested by PNNL

- Cooling capacity of the radiant system was established at $40 \mathrm{Btu} / \mathrm{hr} / \mathrm{S}$.F., and sized to meet the full sensible cooling load.

- Suppliers did not indicate a cost difference between panel and slab methods, so no distinction was made between the two. 
NCI made some assumptions about the treatment of certain systems.

\section{System}

Ventilation Sizing of Low-Lift Systems

Chiller and Boiler Plants

\section{Assumption}

NCI took the average of the maximum and minimum CFM requirements specified for each building through EnergyPlus, and found the cost of the low-lift DOAS system based on this average

- NCI calculated the cost of the chiller and boiler components using the equipment sizes found in RS Means

- Low-lift chillers were sized to meet the sensible cooling load of the building.

- The supporting system was calculated using square foot costs calculated from RS Means data

- The piping distribution system is not included in the cost, it was assumed to be included in the radiant system costs. 
The baseline system costs were calculated from RS Means using the baseline inputs provided by PNNL.

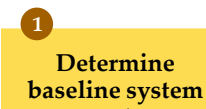

baseline system

costs

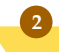

Size advanced cooling systems using baseline system inputs
3

Determine advanced system costs

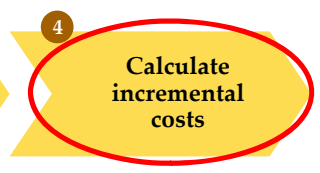

- Subtracting the baseline system costs from the advanced cooling costs, NCI calculated the incremental costs of each low-lift

technology

Incremental Costs
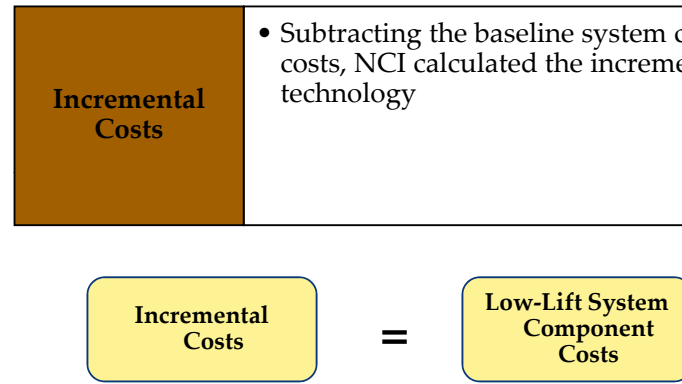

Baseline System Costs

40

Low Lift Cooling Cost Estimation » Incremental Cost Component Separation

To compare the right set of components, systems were separated by their respective functions.

\section{Low-Lift System}

\begin{tabular}{|c|c|c|c|}
\hline $\begin{array}{r}\text { Low Lift Chiller + } \\
\text { Support System }\end{array}$ & Radiant Cooling & $\begin{array}{c}\text { DOAS: DX HP + } \\
\text { EW + Ducts }\end{array}$ & $\begin{array}{l}\text { Boiler System + } \\
\text { Low-Cap Furnace }\end{array}$ \\
\hline
\end{tabular}
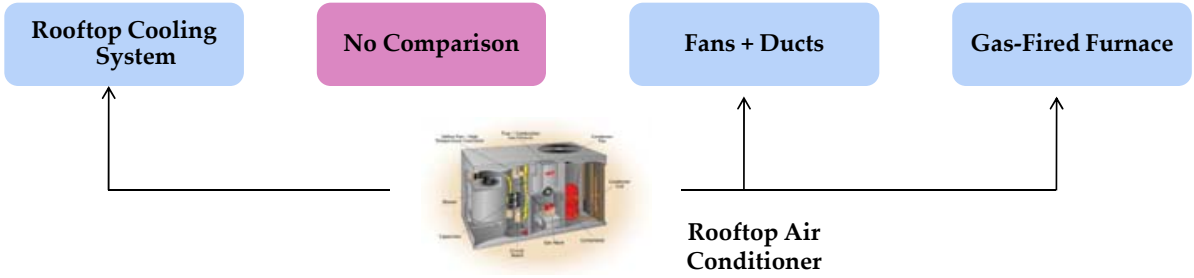

Rooftop Air

Conditioner

\section{Rooftop Baseline System}

Illustration from: http://www.aireserv.com/images/il//PackagedUnitGas.jpg 
Low Lift Cooling Cost Estimation » Incremental Cost Component Separation

To compare the right set of components, systems were separated by their respective functions.

Low-Lift System

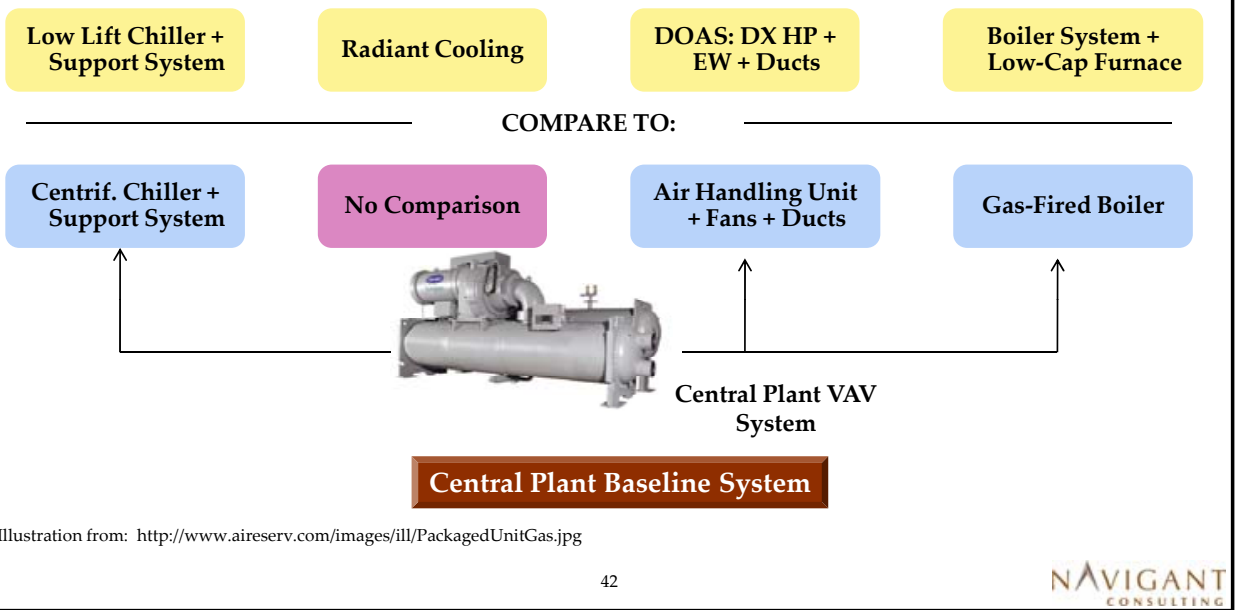

Low Lift Cooling Cost Estimation » Incremental Cost Component Separation

The incremental costs were calculated by comparing similar components within the baseline and low-lift systems.

\section{Low-Lift System}

Low Lift Chiller Incremental

\section{DOAS + DX HP}

Incremental

Radiant Cooling

Incremental

Heating System Incremental
Low-Lift Chiller + Support Sys.

DX Heat Pump

+ Enthalpy Wheel

+ Low-Lift Ductwork

Radiant Cooling System (minus the cost of concrete)

Boiler for Low-Lift System + Low-Capacity Furnace
Baseline System

1. Baseline Chiller + Support System 2. Rooftop Air Conditioner - Cooling

Baseline Ductwork

(+ any air-handling units)

No system for comparison

1. Baseline Gas Boiler

2. Rooftop Air Conditioner - Furnace 


\section{Low Lift Cooling Cost Estimation » Incremental Costs - Medium Office in Houston}

The medium office building had a negative incremental cost, because of the large cost of the multi-zone rooftop units compared to the aircooled chiller system.

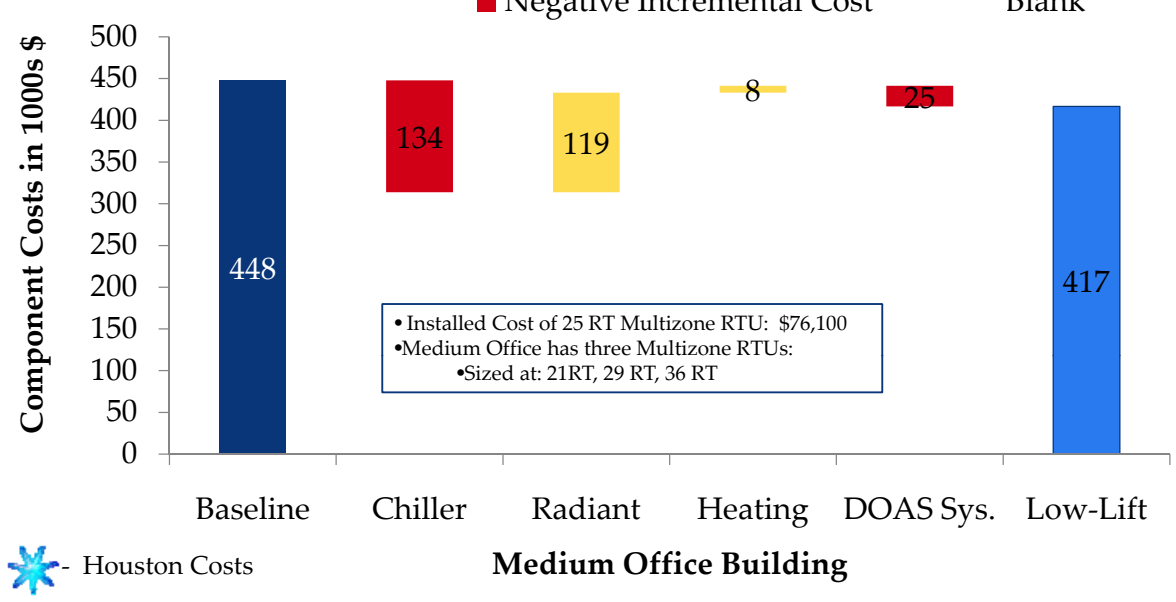

44

The large office chiller was resized to meet the sensible cooling load, offsetting the additional cost of the advanced chiller system. The radiant cooling and ductwork resizing drove the incremental costs.

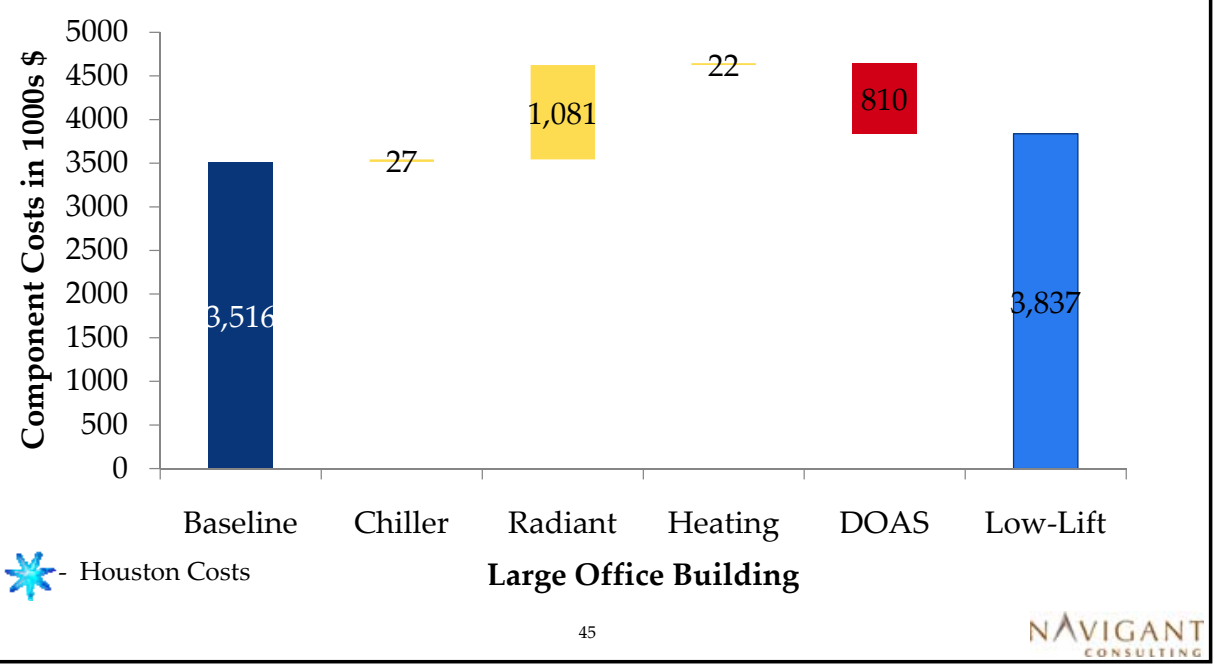


The supermarket system incremental costs are driven by the radiant cooling system. The low cost of single zone vs. multi-zone rooftops differentiates the supermarket from the medium office.

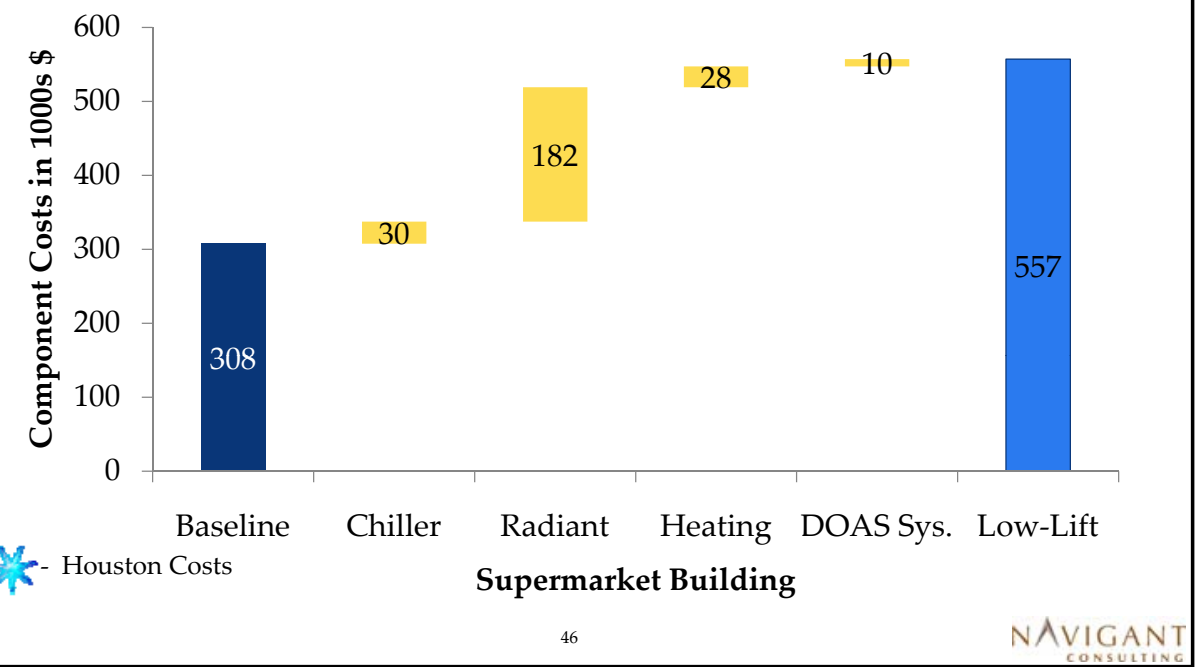

Low Lift Cooling Cost Estimation » Incremental Costs - School in Houston

The chiller system increased in size by replacing a number of rooftop units, but was also downsized to meet the sensible cooling load only. The large radiant cooling system and the ductwork resizing drove the incremental costs.

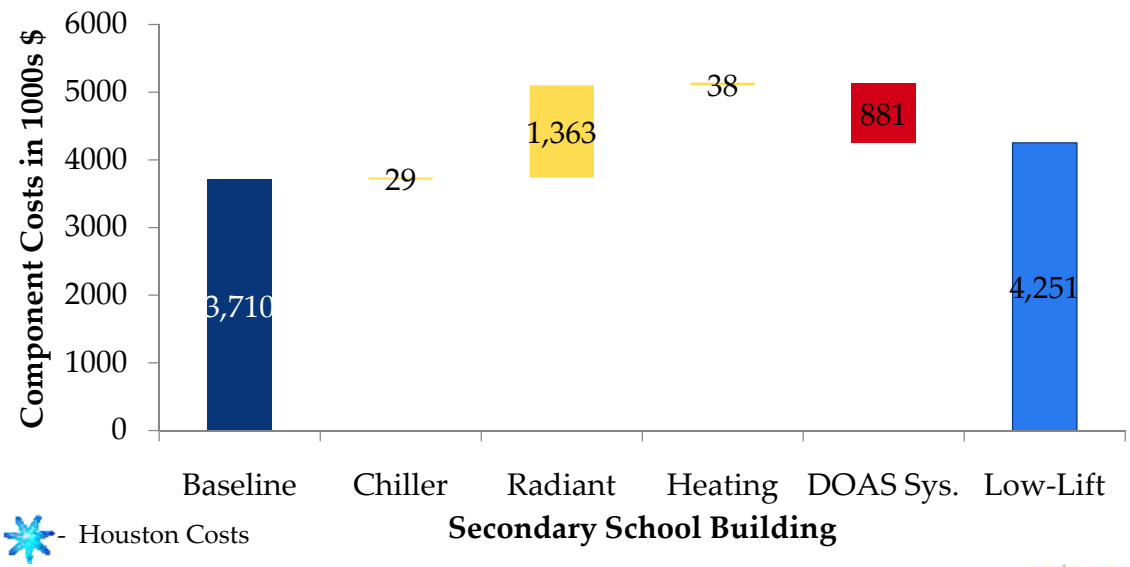


Low Lift Cooling Cost Estimation » Incremental Costs - Comparisons

Incremental cost differences between Houston and national average costs are primarily driven by labor differences.

\begin{tabular}{|l|c|c|c|}
\cline { 2 - 4 } \multicolumn{1}{c|}{} & \multicolumn{3}{c|}{$\begin{array}{c}\text { Incremental Cost Comparisons } \\
\text { Houston vs. National Average }\end{array}$} \\
\cline { 2 - 4 } & Houston & National Average & $\%$ Difference \\
\hline Medium Office & $-\$ 31,000$ & $-\$ 15,000$ & $\sim 52 \%$ \\
\hline Large Office & $\$ 321,000$ & $\$ 383,000$ & $\sim 19 \%$ \\
\hline Supermarket & $\$ 250,000$ & $\$ 276,000$ & $\sim 11 \%$ \\
\hline Secondary School & $\$ 550,000$ & $\$ 624,000$ & $\sim 14 \%$ \\
\hline
\end{tabular}

Low Lift Cooling Cost Estimation » Incremental Costs - Table - Houston per sq. ft

Calculating the incremental cost per square foot allows for a rough comparison between the buildings. The office buildings appear most favorable in this comparison of national average costs.

\begin{tabular}{|l|c|c|c|}
\cline { 2 - 4 } \multicolumn{1}{c|}{} & \multicolumn{2}{c|}{ Cost Increments per Square Foot by Building Type } \\
(HoustonCosts)
\end{tabular}


When compared to other systems, multi-zone rooftop units are the most expensive option.

\begin{tabular}{|l|c|c|c|}
\cline { 2 - 4 } \multicolumn{1}{c|}{} & \multicolumn{3}{c|}{$\begin{array}{c}\text { Component Installed Cost Comparison- National Average } \\
\mathbf{8 0} \text { Cooling Ton Unit (RS Means) }\end{array}$} \\
\cline { 2 - 4 } & $\begin{array}{c}\text { RS Means } \\
\text { Material Costs }\end{array}$ & $\begin{array}{c}\text { RS Means Labor } \\
\text { Costs }\end{array}$ & $\begin{array}{c}\text { RS Means Total } \\
\text { Installed Cost }\end{array}$ \\
\hline Single Zone Rooftop & $\$ 57,500$ & $\$ 6,900$ & $\$ 64,400$ \\
\hline Multi Zone Rooftop & $\$ 173,000$ & $\$ 9,850$ & $\$ 182,850$ \\
\hline $\begin{array}{l}\text { Reciprocating Chiller - } \\
\text { Air-Cooled }\end{array}$ & $\$ 53,500$ & $\$ 5,300$ & $\$ 58,800$ \\
\hline
\end{tabular}

- Multizone rooftop units are significantly more expensive than single zone rooftop units or chillers sized for the same load (based on RS Means costs).

- The medium office building used multi-zone rooftop units, while the supermarket used single zone rooftop units. The result was that the medium office had very low incremental costs, while the supermarket experienced much higher incremental costs.

- The chiller costs do not including the cost of the supporting system, which includes connective piping and the fan coil air conditioning unit. NCI did not consider the cost of distributive piping in this analysis.

For the large office and secondary school, the smaller ductwork size provided a large cost reduction when moving from VAV to DOAS.

- The large office and secondary school have large airflow requirements, particularly the secondary school. Ductwork costs are therefore substantial contributors to the baseline cost of the buildings.

- The use of a DOAS system reduces the size of the ductwork, since the system is now sized by the average airflow requirements, not the maximum airflow requirements. This results in a large cost reduction.

- For the large office and the secondary school, the large size of these buildings meant that the cost of the ductwork would dominate the cost incremental for the air delivery systems. For the medium office and supermarket, the reductions in ductwork were balanced by the cost increases associated with the enthalpy wheels and the DX HP systems. 
Office buildings may be the most ideal first applications for low lift cooling technologies/systems, including those using multi-zone rooftop systems or chillers.

\section{Conclusions}

- The high cost of multi-zone rooftop systems compared to chillers allows for a favorable cost comparison for low-lift chiller systems in medium office buildings.

- Large office buildings show a low incremental cost per square foot, due to a small increase in chiller costs, and large savings from the DOAS system

- Radiant cooling drives the cost incrementals for all of the building types.

- The cost advantage resulting from reduction of the ductwork for large building systems needs to be validated further, to confirm that ductwork costs dominate this comparison.

- Some components of the low-lift system may be considered emerging technologies . There is often a $10-20 \%$ cost premium associated with emerging technologies, which may decrease as the technology becomes more common.

- Other potential benefits of the low lift system include reducing the amount of materials used in construction, for example in ductwork material.

\section{A more detailed costing exercise and associated payback/economic} analysis is warranted.

\section{Recommendations}

- The component costs based approach for estimating baseline and advanced system costs is limited in scope, and only covers a portion of the total costs required for incorporation of HVAC systems into buildings. Some of the key limitations that need to be addressed include:

- Use a detailed design process to understand costs on a square footage basis (possibly by picking a candidate building that could also serve as a future test bed). This will address the current limitation where the equipment was sized by cooling load and CFMs, and not by square footage.

- The detailed design process will also help in better sizing of system components and the balance of plant equipment. This helps address the current limitation where sizing by cooling load is very effective for calculating the cost of the main components, but not as effective for finding the cost of distribution systems. - The design process will also help in assuring that material costs are estimated more precisely (e.g. ducts, piping, valves, etc.)

- As a next step, NCI recommends proceeding through this detailed costing exercise for a candidate building, along with an associated payback/economic analysis using energy savings and electricity rate structures in various regions to assess financial attractiveness of the concept. 


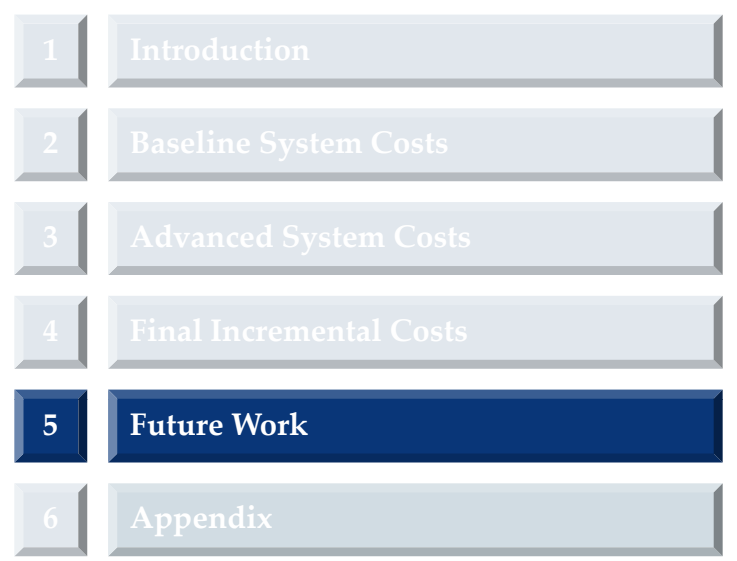

\section{The sizing of the building loads from Energy Plus is different than} what is cited in RS Means.

\section{Sizing of the Building Loads}

- NCI compared the cost per square foot of each building's baseline HVAC system to the square foot costs provided by RS Means for a number of comparable buildings. The calculated costs did not entirely match the expected costs.

- NCI believes that there may be some differences in the way EnergyPlus calculates the cooling loads and equipment sizes for each building, compared to the standard used in RS Means. This difference may be significant in the case of multi-zone ductwork systems.

- In particular, the medium office building appears to be undersized (in terms of cooling load) given its footprint. In an example office building in RS Means, a building with a footprint of 25,000 sq. $\mathrm{ft}$ had equipment sized to provided $80 \mathrm{RT}$. In comparison, the medium office described by EnergyPlus had a footprint of 53,000 sq. $\mathrm{ft}$, and equipment sized to provided $86 \mathrm{RT}$.

A closer analysis of the equipment sizing provided by EnergyPlus may illustrate why there are differences between the calculated square foot costs and the expected square foot costs. 
The sizing of the DOAS system is an important input for determining proper incremental costs.

\section{Sizing of the DOAS systems}

- The sizing of the DOAS system determines the cost of the ductwork and the air-handlers in the low-lift system, and this incremental cost can have a large impact on the overall incremental cost.

- NCI looked at the incremental cost of the DOAS system using the minimum outdoor airflow provided by EnergyPlus, the maximum outdoor airflow provided by EnergyPlus, and an average of the minimum and maximum.

- The DOAS system consisted of the air-handling units, the ductwork, the DX HP systems, and the enthalpy wheels. The air-handling systems, the ductwork, and the enthalpy wheels were all sized using the CFM requirements of the building, while the DX systems were sized using the latent heat requirements of the building.

- There may be savings that are not captured for buildings that use less ductwork than typical buildings, such as the supermarket.

A closer inspection of both the sizing of the DOAS system as well as the cost of ductwork within each building would improve the DOAS cost incremental.

The costs of the distribution systems for chillers were calculated using square foot costs specific to each building type.

\section{Cost of the distribution systems}

- The distribution systems for the chilled water systems were calculated using square foot costs from RS Means. They do not include distributive piping.

- While these costs are distinct for each building type and chiller type, there may be additional costs or savings that are not captured within this broad treatment.

- For example, NCI did not consider any savings associated with combining chiller, radiant cooling, and boiler piping systems.

- This issue is especially important for calculating the incremental cost of moving from a rooftop system to a chiller-based system.

A closer analysis of the distribution systems that accompany the chiller systems would enhance our understanding of the incremental costs associated with chiller cooling systems. 
An economic analysis of the cost premium and associated payback for systems in large office buildings in several regions is warranted.

\section{Systems Economic Modeling}

- Complete an analysis of large office building and associated energy consumptions for several different parts of the US for both baseline and low lift cooling systems with split done by climate zones using a single platform.

- Leverage work on detailed costing exercise for the candidate large office building to estimate cost premium for the different regions/cities of interest.

- Use hour electricity, and natural gas consumption data and local utility rates to estimate the economic value of energy savings and calculate the associated payback period.

An economic analysis will help identify if the cost premium for low lift systems are justified and help identify candidate regions for pilot projects.

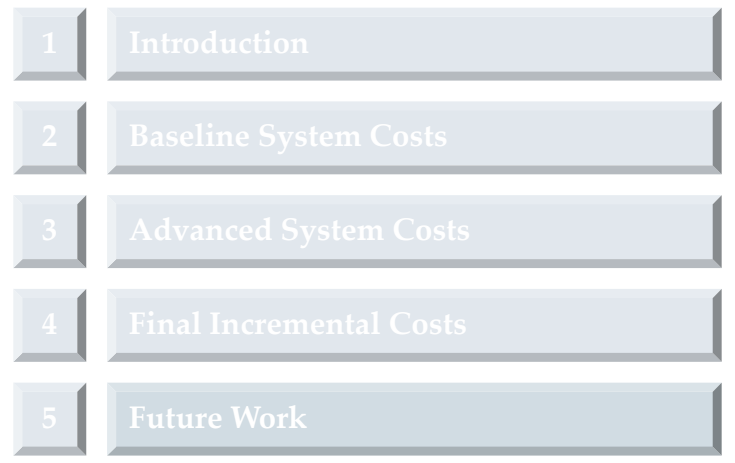


The reference numbers for the components taken from RS Means are displayed in the table below.

\begin{tabular}{|c|c|l|}
\hline \multicolumn{2}{|c|}{2007 RS Means Reference Numbers - Cooling and Heating Components } \\
\hline Component & $\begin{array}{c}\text { RS Means } \\
\text { Reference }\end{array}$ & \multicolumn{1}{c|}{ RS Means Descriptors } \\
\hline Rooftop Units & 23.74 .33 .10 & $\begin{array}{l}1000-\text { Single Zone, Elec. Cool, Gas Heat } \\
2000-\text { Multi Zone, Elec. Cool, GH, econ. }\end{array}$ \\
\hline Chillers & 236416.10 & $\begin{array}{l}0274-\text { Centrifugal, pckd unit, water cooled, ni tower } \\
0494-\text { Water chillers, integral air cooled condenser }\end{array}$ \\
\hline Boilers & 236419.10 & Boiler, Cast Iron, Gas \& Oil, Hot Water \\
& D3020136 & Boiler, Cast Iron, Gas, Hot Water \\
\hline Furnaces & 23546.13 & $3000-$ Gas, AGA certified, upflow, direct drive \\
\hline Chiller System - Water-Cooled & D3030115 & Chilled Water, Cooling Tower Systems \\
\hline Chiller System - Air-Cooled & D3030110 & Chilled Water, Air Cooled Condenser \\
\hline In-place Concrete & 033053.40 & $4820-6$ " Slab on grade, reinforcing \\
\hline
\end{tabular}

Low Lift Cooling Cost Estimation » Proposed Sources for Costs

The reference numbers for the components taken from RS Means are displayed in the table below. (continued)

\begin{tabular}{|c|c|l|}
\hline \multicolumn{2}{|c|}{2007 RS Means Reference Numbers - Ventilation Components } \\
\hline \multirow{2}{*}{ Component } & $\begin{array}{c}\text { RS Means } \\
\text { Reference }\end{array}$ & \multicolumn{1}{c|}{ RS Means Descriptors } \\
\hline \multirow{2}{*}{ Air-Handling Units } & 237413.10 & $\begin{array}{l}\text { 3010 - Constant volume } \\
3200-\text { Variable air volume } \\
\end{array}$ \\
& 237313.10 & 2300-Variable air volume, also incl. heating coil \\
\hline DX HP Coils & D3040 124 & 1010 - Fan coil A/C system, horiz. w/ housing, cntrls \\
\hline Enthalpy Wheel & 237213.10 & 4000 - Enthalpy Recovery Wheel \\
\hline Rooftop System - Multi Zone & D3050 155 & Rooftop Multizone Unit Systems \\
\hline Rooftop System - Single Zone & D3050 150 & Rooftop Single Zone Unit Systems \\
\hline
\end{tabular}


The chiller system costs included some of the following component costs from RS Means model systems.

Reference - 2007 RSMeans Mechanical Cost Data

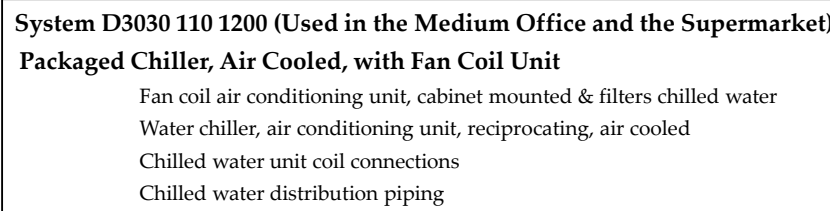

System D3030 1151320 (Used in the Large Office and Secondary School)

Packaged Chiller, Water Cooled with Fan Coil Unit

Fan coil air conditioning unit, cabinet mounted \& filters, chilled water

Water chiller, water cooled, 1 compressor, hermetic scroll

Cooling tower, draw thru single flow, belt drive

Cooling tower pumps \& piping

Chilled water unit coil connections

Chilled water distribution piping

\section{Some of the assumptions associated with the overall costs are listed} below.

\section{Central Plant Assumptions}

- Chillers and Boiler costs include chiller/boiler component costs and some distribution system costs

- From D3030 110 (air cooled): used the 'Fan coil AC unit' and 'Chilled water unit coil connections' costs

- From D3030 115 (water): used 'Cooling tower', 'Cooling tower pumps and piping', 'Chilled water unit coil connection', and 'Fan coil AC unit' costs.

- The rooftop-cooled buildings were converted to air-cooled chillers

- The central plant buildings used water-cooled chillers

- Chillers and Boilers were considered as completely separate systems

- The baseline supporting system for the school was sized at a percentage of the full school, based on the part of the cooling that the system provides.

For the Low-Lift Chiller:

- NCI first calculated the cost of a conventional chiller and distribution system using RS Means. It was sized to meet the sensible cooling load.

- NCI then used cost premiums for costing out advanced chillers: $15 \%$ for an air-cooled chiller, $16 \%$ for a water-cooled chiller. 
Some of the assumptions associated with the overall costs are listed below.

\section{Radiant Cooling Assumptions}

- NCI calculated the cost of radiant panels using a fixed cost of $\$ 10$ per square foot of slab or paneling. To calculate the pure incremental cost, NCI subtracted a cost of $\$ 2.74$ per square foot for work related to the concrete foundation. PNNL requested that the cost of concrete was subtracted from the overall cost.

- The radiant systems were sized to meet the sensible cooling load of the building ( $72 \%$ of the total cooling load). NCI used an assumption of $40 \mathrm{Btu} / \mathrm{hr}$ per square foot to size the system (by square feet) appropriately.

\section{Rooftop Systems}

- NCI calculated the rooftop air-conditioners in RS Means using the cooling size of each device. Ductwork costs were calculated separately.

- NCI determined rooftop costs as a whole package, and then divided the ful cost of the unit into furnace and cooling parts to calculated the incremental costs.

\section{Some of the assumptions associated with the overall costs are listed} below.

\section{Ventilation System}

- NCI calculated the cost of ductwork using a fixed cost of $\$ 5.00$ per CFM for single zone systems or $\$ 6.25$ per CFM for multi-zone systems. These costs account for the both a standard cost per CFM, and the expected cost of ductwork per square foot of building in RS Means (using the system costs incorporating ductwork).

- This allowed for a simple calculation of the incremental cost of ductwork.

- PNNL provided the maximum and minimum airflows handled by the outdoor air controllers

- The conventional VAV and PSZ systems were sized according to the EnergyPlus equipment sizing information (maximum system CFM).

- The low-lift DOAS systems were sized according to the average of the minimum and maximum system CFM requirements.

For the Direct-Expansion Heat Pump Coils:

- DX HP was sized using the latent loads of the building provided by PNNL.

For the Enthalpy Wheels:

- The enthalpy wheels were sized in RS Means using the DOAS system CFM size. 
PNNL provided sizing and description of components from the EnergyPlus package.

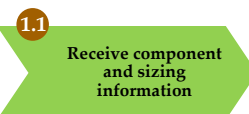

\begin{tabular}{|lc|c|c|c|}
\cline { 2 - 5 } \multicolumn{1}{c|}{} & \multicolumn{4}{c|}{ Equipment Specifications- EnergyPlus Baseline Information } \\
\cline { 2 - 5 } \multicolumn{1}{c|}{} & Large Office & Medium Office & Supermarket & School \\
\hline Building Size & 460,240 sq. ft & 53,630 sq. ft & 45,000 sq. ft & 210,890 sq. ft \\
\hline Chillers & $780 \mathrm{RT}$ & - & - & $509 \mathrm{RT}$ \\
\hline Boilers & $12,577 \mathrm{MBH}$ & - & - & $28,398 \mathrm{MBH}$ \\
\hline DX Coils & - & $86 \mathrm{RT}$ & $131 \mathrm{RT}$ & $476 \mathrm{RT}$ \\
\hline Furnaces & - & $94 \mathrm{MBH}$ & $2224 \mathrm{MBH}$ & - \\
\hline Ventilation Size & $279,856 \mathrm{CFM}$ & $32,145 \mathrm{CFM}$ & $43,736 \mathrm{CFM}$ & $433,653 \mathrm{CFM}$ \\
\hline Ventilation Type & VAV & $\begin{array}{c}\text { Packaged AC } \\
\text { Unitary }\end{array}$ & $\begin{array}{c}\text { Packaged Single } \\
\text { Zone }\end{array}$ & $\begin{array}{c}\text { VAV + Packaged } \\
\text { Single Zone }\end{array}$ \\
\hline \# of Cooling Systems & 3 & 3 & 6 & 10 \\
\hline Central Plant & Yes & No & No & Yes \\
\hline
\end{tabular}

- RT - Refrigeration Tons - VAV - Variable Air Volume

Low Lift Cooling Cost Estimation » Baseline Costs - Square Foot Comparison

NCI compared the component based approach to a square foot approach in RS Means, by comparing the cooling systems.

\begin{tabular}{|l|c|c|c|}
\cline { 2 - 4 } \multicolumn{1}{c|}{} & \multicolumn{3}{c|}{ Cost Analysis - Rooftop System Cost per Square Foot } \\
\cline { 2 - 4 } & System & $\begin{array}{c}\text { Component } \\
\text { based \$ per sq. ft }\end{array}$ & $\begin{array}{c}\text { Square foot based \$ } \\
\text { per sq. ft }\end{array}$ \\
\cline { 2 - 4 } \multicolumn{1}{c|}{} & Rooftop & 8.8 & 16.0 \\
\hline Medium Office & Chiller & 8.3 & 15.7 \\
\hline Large Office & Rooftop & 7.4 & 4.5 \\
\hline Supermarket & Chiller + Rooftop & 19.7 & 18.1 \\
\hline School & \multicolumn{2}{c}{} \\
\hline
\end{tabular}

- The square footage examination was used to confirm the validity of the RS Means Costs independently.

- The results show that the system based approach does not cover the entire expected cost of the cooling system, especially for rooftop systems. Some costs are intentionally not included, such as the cost of the chiller distribution systems.

- There is variation due to the sizing of the systems, which in many of the cases dominates the comparison. 
Low Lift Cooling Cost Estimation » Square foot cost comparison

\section{Comparison of PNNL Buildings to RS Means Square Foot Costs}

\begin{tabular}{|l|c|c|c|c|}
\cline { 2 - 5 } \multicolumn{1}{c|}{} & \multicolumn{4}{c|}{ Cost Analysis - Cost per square foot (PNNL Buildings) } \\
\cline { 2 - 5 } \multicolumn{1}{c|}{} & Floorspace & $\begin{array}{c}\text { Baseline } \\
\text { Cost }\end{array}$ & $\$$ per sq. ft & HVAC Type \\
\hline Medium Office & 53,630 sq. ft & $\$ 470,598$ & 8.8 & Rooftop Multizone \\
\hline Large Office & 460,240 sq. ft & $\$ 3,815,896$ & 8.3 & Central Plant \\
\hline Supermarket & 45,000 sq. ft & $\$ 334,295$ & 7.4 & Rooftop Single Zone \\
\hline School & 210,890 sq. ft & $\$ 4,160,202$ & 19.7 & Central Plant + PSZ \\
\hline
\end{tabular}

\begin{tabular}{|l|c|c|c|c|c|}
\cline { 2 - 6 } \multicolumn{1}{c|}{} & \multicolumn{5}{c|}{ Cost Analysis - Cost per square foot (RS Means Sq. Foot Baselines) } \\
\cline { 2 - 6 } & Floorspace & $\begin{array}{c}\text { Total Cost } \\
\text { per sq. ft }\end{array}$ & $\begin{array}{c}\% \text { of Cost } \\
\text { for HVAC }\end{array}$ & $\begin{array}{c}\text { HVAC \$ } \\
\text { per sq. ft }\end{array}$ & HVAC Type \\
\hline $\begin{array}{l}\text { Office (2-4 } \\
\text { Stories) }\end{array}$ & 20,000 sq. ft & 114.31 & $14.0 \%$ & 16.0 & Rooftop Multizone \\
\hline $\begin{array}{l}\text { Office } \\
\text { (11-20 stories) }\end{array}$ & 260,000 sq. ft & 100.05 & $15.7 \%$ & 15.7 & Central Plant \\
\hline Supermarket & 44,000 sq. ft & 65.80 & $6.8 \%$ & 4.5 & Rooftop Single Zone \\
\hline $\begin{array}{l}\text { High School, 2-3 } \\
\text { Flrs. }\end{array}$ & 130,000 sq. ft & 109.71 & $16.5 \%$ & 18.1 & Central Plant \\
\hline
\end{tabular}

Reference - 2008 RS Means Square Foot Costs (29 th Annual Edition)

Low Lift Cooling Cost Estimation » Incremental Costs - Table - Medium Office

The incremental costs were made up of the costs of the various components for the baseline and low-lift systems.

\begin{tabular}{|c|c|c|c|c|}
\hline & \multicolumn{4}{|c|}{$\begin{array}{l}\text { Incremental Cost - Low-Lift Chiller } \\
\text { (Houston Costs, Medium Office) }\end{array}$} \\
\hline & $\begin{array}{l}\text { DX Coils from } \\
\text { Rooftop }\end{array}$ & Chiller Cost & $\begin{array}{l}\text { Chiller } \\
\text { Distribution } \\
\text { System }\end{array}$ & TOTAL \\
\hline Low-Lift Costs & - & $\$ 54,564$ & $\$ 80,071$ & $\$ 134,635$ \\
\hline Baseline Costs & $\$ 268,710$ & - & - & $\$ 268,710$ \\
\hline Difference & & & & $-\$ 134,075$ \\
\hline
\end{tabular}

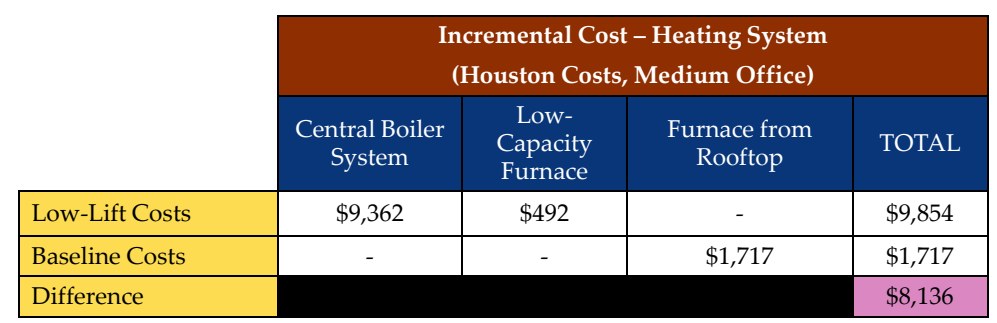


The incremental costs were made up of the costs of the various components for the baseline and low-lift systems.

\begin{tabular}{|l|c|c|c|c|c|}
\cline { 2 - 6 } & \multicolumn{5}{c|}{$\begin{array}{c}\text { Incremental Cost - Ventilation System } \\
\text { (Houston Costs, Medium Office) }\end{array}$} \\
\cline { 2 - 6 } & Ductwork & $\begin{array}{c}\text { Air- } \\
\text { Handling } \\
\text { Units Cost }\end{array}$ & $\begin{array}{c}\text { DX HP Units } \\
\text { Cost }\end{array}$ & $\begin{array}{c}\text { Enthalpy } \\
\text { Wheel Cost }\end{array}$ & TOTAL \\
\hline Low-Lift Costs & $\$ 110,891$ & - & $\$ 14,726$ & $\$ 27,037$ & $\$ 152,653$ \\
\hline Baseline Costs & $\$ 177,401$ & - & - & - & $\$ 177,401$ \\
\hline Difference & & & & $-\$ 24,748$ \\
\hline
\end{tabular}

\begin{tabular}{|l|c|}
\cline { 2 - 2 } \multicolumn{1}{c|}{} & $\begin{array}{c}\text { Incremental Cost - Radiant System } \\
\text { (Houston Costs, Medium Office) }\end{array}$ \\
\cline { 2 - 2 } & TOTAL \\
\hline Low-Lift Costs & $\$ 119,453$ \\
\hline Baseline Costs & - \\
\hline Difference & $\$ 119,453$ \\
\hline
\end{tabular}

Low Lift Cooling Cost Estimation » Incremental Costs - Table - Large Office

The large office did not change cooling systems, it just acquired a more efficient chiller.

\begin{tabular}{|c|c|c|c|c|}
\hline & \multicolumn{4}{|c|}{$\begin{array}{c}\text { Incremental Cost - Low-Lift Chiller } \\
\text { (Houston Costs, Large Office) }\end{array}$} \\
\hline & $\begin{array}{l}\text { DX Coils from } \\
\text { Rooftop }\end{array}$ & Chiller Cost & Chiller Support & TOTAL \\
\hline Low-Lift Costs & - & $\$ 344,828$ & $\$ 1,134,858$ & $\$ 1,452,423$ \\
\hline Baseline Costs & - & $\$ 317,566$ & $\$ 1,134,858$ & $\$ 1,479,687$ \\
\hline Difference & & & & $\$ 27,263$ \\
\hline
\end{tabular}

\begin{tabular}{|c|c|c|c|c|}
\hline & \multicolumn{4}{|c|}{$\begin{array}{l}\text { Incremental Cost - Heating System } \\
\text { (Houston Costs, Large Office) }\end{array}$} \\
\hline & $\begin{array}{l}\text { Central Boiler } \\
\text { System }\end{array}$ & $\begin{array}{l}\text { Low- } \\
\text { Capacity } \\
\text { Furnace }\end{array}$ & $\begin{array}{l}\text { Furnace from } \\
\text { Rooftop }\end{array}$ & TOTAL \\
\hline Low-Lift Costs & $\$ 171,734$ & $\$ 21,819$ & - & $\$ 193,553$ \\
\hline Baseline Costs & $\$ 171,734$ & - & - & $\$ 171,734$ \\
\hline Difference & & & & $\$ 21,819$ \\
\hline
\end{tabular}


The large office did not change cooling systems, it just acquired a more efficient chiller.

\begin{tabular}{|l|c|c|c|c|c|}
\cline { 2 - 6 } & \multicolumn{5}{c|}{$\begin{array}{c}\text { Incremental Cost - Ventilation System } \\
\text { (Houston Costs, Large Office) }\end{array}$} \\
\cline { 2 - 6 } & Ductwork & $\begin{array}{c}\text { Air- } \\
\text { Handling } \\
\text { Units Cost }\end{array}$ & $\begin{array}{c}\text { DX HP Units } \\
\text { Cost }\end{array}$ & $\begin{array}{c}\text { Enthalpy } \\
\text { Wheel Cost }\end{array}$ & TOTAL \\
\hline Low-Lift Costs & $\$ 909,636$ & - & $\$ 23,961$ & $\$ 148,331$ & $\$ 1,081,927$ \\
\hline Baseline Costs & $\$ 1,544,457$ & $\$ 347,215$ & - & - & $\$ 1,891,672$ \\
\hline Difference & & & & $-\$ 809,745$ \\
\hline
\end{tabular}

\begin{tabular}{|l|c|}
\cline { 2 - 2 } \multicolumn{1}{c|}{} & $\begin{array}{c}\text { Incremental Cost - Radiant System } \\
\text { (Houston Costs, Large Office) }\end{array}$ \\
\cline { 2 - 2 } & TOTAL \\
\hline Low-Lift Costs & $\$ 1,081,432$ \\
\hline Baseline Costs & - \\
\hline Difference & $\$ 1,081,432$ \\
\hline
\end{tabular}

Low Lift Cooling Cost Estimation » Incremental Costs - Table - Supermarket

The supermarket used single-zone rooftop units, but the cooling equipment size was larger than the medium office.

\begin{tabular}{|c|c|c|c|c|}
\hline & \multicolumn{4}{|c|}{$\begin{array}{l}\text { Incremental Cost - Low-Lift Chiller } \\
\text { (Houston Costs, Supermarket) }\end{array}$} \\
\hline & $\begin{array}{l}\text { DX Coils from } \\
\text { Rooftop }\end{array}$ & Chiller Cost & $\begin{array}{c}\text { Chiller } \\
\text { Distribution } \\
\text { System }\end{array}$ & TOTAL \\
\hline Low-Lift Costs & - & $\$ 75,447$ & $\$ 60,045$ & $\$ 135,493$ \\
\hline Baseline Costs & $\$ 105,623$ & - & - & $\$ 105,623$ \\
\hline Difference & & & & $\$ 29,870$ \\
\hline
\end{tabular}

\begin{tabular}{|c|c|c|c|c|}
\hline & \multicolumn{4}{|c|}{$\begin{array}{l}\text { Incremental Cost - Heating System } \\
\text { (Houston Costs, Supermarket) }\end{array}$} \\
\hline & $\begin{array}{l}\text { Central Boiler } \\
\text { System }\end{array}$ & $\begin{array}{l}\text { Low- } \\
\text { Capacity } \\
\text { Furnace }\end{array}$ & $\begin{array}{l}\text { Furnace from } \\
\text { Rooftop }\end{array}$ & TOTAL \\
\hline Low-Lift Costs & $\$ 44,281$ & $\$ 3,830$ & - & $\$ 48,111$ \\
\hline Baseline Costs & - & - & $\$ 19,945$ & $\$ 19,945$ \\
\hline Difference & & & & $\$ 28,167$ \\
\hline
\end{tabular}


The supermarket used single-zone rooftop units, but the cooling equipment size was larger than the medium office.

\begin{tabular}{|l|c|c|c|c|c|}
\cline { 2 - 6 } & \multicolumn{5}{c|}{$\begin{array}{c}\text { Incremental Cost - Ventilation System } \\
\text { (Houston Costs, Supermarket) }\end{array}$} \\
\cline { 2 - 6 } & Ductwork & $\begin{array}{c}\text { Air- } \\
\text { Handling } \\
\text { Units Cost }\end{array}$ & $\begin{array}{c}\text { DX HP Units } \\
\text { Cost }\end{array}$ & $\begin{array}{c}\text { Enthalpy } \\
\text { Wheel Cost }\end{array}$ & TOTAL \\
\hline Low-Lift Costs & $\$ 123,813$ & - & $\$ 20,289$ & $\$ 47,881$ & $\$ 191,983$ \\
\hline Baseline Costs & $\$ 182,056$ & - & - & - & $\$ 182,056$ \\
\hline Difference & & & & & $\$ 9,927$ \\
\hline
\end{tabular}

\begin{tabular}{|l|c|}
\cline { 2 - 2 } \multicolumn{1}{c|}{} & $\begin{array}{c}\text { Incremental Cost - Radiant System } \\
\text { (Houston Costs, Supermarket) }\end{array}$ \\
\cline { 2 - 2 } & TOTAL \\
\hline Low-Lift Costs & $\$ 181,654$ \\
\hline Baseline Costs & - \\
\hline Difference & $\$ 181,654$ \\
\hline
\end{tabular}

Low Lift Cooling Cost Estimation » Incremental Costs - Table - School

The secondary school was a mix of rooftop and central plant cooling, which was integrated into one large chiller system.

\begin{tabular}{|c|c|c|c|c|}
\hline & \multicolumn{4}{|c|}{$\begin{array}{l}\text { Incremental Cost - Low-Lift Chiller } \\
\text { (Houston Costs, Secondary School) }\end{array}$} \\
\hline & $\begin{array}{l}\text { DX Coils from } \\
\text { Rooftop }\end{array}$ & Chiller Cost & Chiller Support & TOTAL \\
\hline Low-Lift Costs & - & $\$ 301,007$ & $\$ 551,859$ & $\$ 852,866$ \\
\hline Baseline Costs & $\$ 197,341$ & $\$ 187,603$ & $\$ 438,762$ & $\$ 823,706$ \\
\hline Difference & & & & $\$ 29,160$ \\
\hline
\end{tabular}

\begin{tabular}{|c|c|c|c|c|}
\hline & \multicolumn{4}{|c|}{$\begin{array}{l}\text { Incremental Cost - Heating System } \\
\text { (Houston Costs, Secondary School) }\end{array}$} \\
\hline & $\begin{array}{l}\text { Central Boiler } \\
\text { System }\end{array}$ & $\begin{array}{l}\text { Low- } \\
\text { Capacity } \\
\text { Furnace }\end{array}$ & $\begin{array}{l}\text { Furnace from } \\
\text { Rooftop }\end{array}$ & TOTAL \\
\hline Low-Lift Costs & $\$ 450,120$ & $\$ 59,877$ & - & $\$ 414,246$ \\
\hline Baseline Costs & $\$ 384,101$ & - & $\$ 87,673$ & $\$ 384,583$ \\
\hline Difference & & & & $\$ 38,223$ \\
\hline
\end{tabular}


The secondary school was a mix of rooftop and central plant cooling, which was integrated into one large chiller system.

\begin{tabular}{|l|c|c|c|c|c|}
\cline { 2 - 6 } \multicolumn{1}{c|}{} & \multicolumn{5}{c|}{$\begin{array}{c}\text { Incremental Cost - Ventilation System } \\
\text { (Houston Costs, Secondary School) }\end{array}$} \\
\cline { 2 - 6 } & Ductwork & $\begin{array}{c}\text { Air- } \\
\text { Handling } \\
\text { Units Cost }\end{array}$ & $\begin{array}{c}\text { DX HP Units } \\
\text { Cost }\end{array}$ & $\begin{array}{c}\text { Enthalpy } \\
\text { Wheel Cost }\end{array}$ & TOTAL \\
\hline Low-Lift Costs & $\$ 1,250,769$ & - & $\$ 121,871$ & $\$ 247,604$ & $\$ 1,620,244$ \\
\hline Baseline Costs & $\$ 2,180,366$ & $\$ 320,971$ & - & - & $\$ 2,501,337$ \\
\hline Difference & \multicolumn{5}{|c|}{} \\
\hline
\end{tabular}

\begin{tabular}{|l|c|}
\cline { 2 - 2 } \multicolumn{1}{c|}{} & $\begin{array}{c}\text { Incremental Cost - Radiant System } \\
\text { (Houston Costs, Secondary School) }\end{array}$ \\
\cline { 2 - 2 } & TOTAL \\
\hline Low-Lift Costs & $\$ 1,363,355$ \\
\hline Baseline Costs & - \\
\hline Difference & $\$ 1,363,355$ \\
\hline
\end{tabular}

76

Low Lift Cooling Cost Estimation » Incremental Costs - Table - Houston

The incremental cost for each low-lift technology was determined as the cost difference between the baseline cooling system and low-lift cooling system.

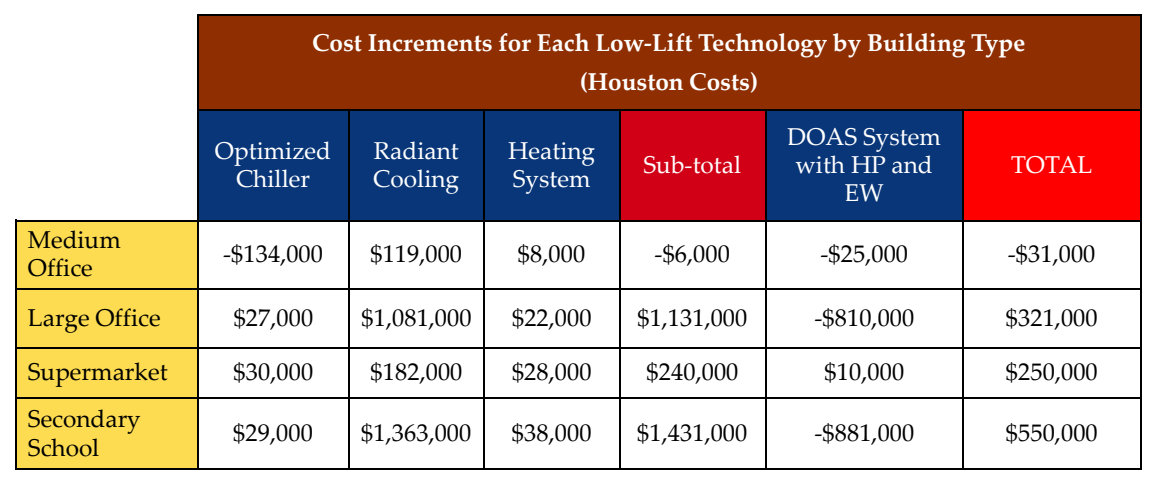

- The reduction in CFM requirements for the ventilation system can have a large impact on the incremental costs. The incremental costs will vary depending on the final CFM requirements chosen. Current DOAS sizing uses the average of the maximum and minimum CFM requirements provided by EnergyPlus. 
The national incremental costs differ from the Houston costs in a few areas, notably in the chiller and DOAS increments, because of the large labor savings taken in the Houston costs.

\begin{tabular}{|l|c|c|c|c|c|c|}
\cline { 2 - 7 } & \multicolumn{6}{|c|}{ Cost Increments for Each Low-Lift Technology by Building Type } \\
(National Average) \\
\cline { 2 - 7 } & $\begin{array}{c}\text { Optimized } \\
\text { Chiller }\end{array}$ & $\begin{array}{c}\text { Radiant } \\
\text { Cooling }\end{array}$ & $\begin{array}{c}\text { Heating } \\
\text { System }\end{array}$ & Sub-total & $\begin{array}{c}\text { DOAS System } \\
\text { with HP and } \\
\text { EW }\end{array}$ & TOTAL \\
\hline $\begin{array}{l}\text { Medium } \\
\text { Office }\end{array}$ & $-\$ 129,000$ & $\$ 135,000$ & $\$ 9,000$ & $\$ 15,000$ & $-\$ 30,000$ & $-\$ 15,000$ \\
\hline Large Office & $\$ 28,000$ & $\$ 1,225,000$ & $\$ 22,000$ & $\$ 1,274,000$ & $-\$ 891,000$ & $\$ 383,000$ \\
\hline Supermarket & $\$ 31,000$ & $\$ 206,000$ & $\$ 33,000$ & $\$ 270,000$ & $\$ 6,000$ & $\$ 276,000$ \\
\hline $\begin{array}{l}\text { Secondary } \\
\text { School }\end{array}$ & $\$ 32,000$ & $\$ 1,544,000$ & $\$ 41,000$ & $\$ 1,616,000$ & $-\$ 992,000$ & $\$ 624,000$ \\
\hline
\end{tabular}

- The reduction in CFM requirements for the ventilation system can have a large impact on the incremental costs. The incremental costs will vary depending on the final CFM requirements chosen. Current DOAS sizing uses the average of the maximum and minimum CFM requirements provided by EnergyPlus.

The incremental cost associated with the DOAS System varied depending on the CFM sizing of the low-lift system, dependent on the costs of the ductwork, additional air-handlers, and enthalpy wheels.

\begin{tabular}{|l|c|c|c|c|c|c|}
\cline { 2 - 7 } \multicolumn{1}{c|}{} & \multicolumn{5}{c|}{ Variation of DOAS System Incremental Costs (Houston Costs) } \\
\cline { 2 - 8 } & $\begin{array}{c}\text { Low-Lift Sized for: } \\
\text { Minimum CFM }\end{array}$ & $\begin{array}{c}\text { Low-Lift Sized for: } \\
\text { Average CFM }\end{array}$ & $\begin{array}{c}\text { Low-Lift Sized for: } \\
\text { Maximum CFM }\end{array}$ \\
\cline { 2 - 8 } & CFM & $\begin{array}{c}\text { DOAS } \\
\text { Incre. } \\
\text { Cost }\end{array}$ & CFM & $\begin{array}{c}\text { DOAS } \\
\text { Incre. } \\
\text { Cost }\end{array}$ & CFM & $\begin{array}{c}\text { DOAS } \\
\text { Incre. Cost }\end{array}$ \\
\hline Medium Office & 8,042 & $-\$ 98,000$ & 20,093 & $-\$ 25,000$ & 32,145 & $\$ 51,000$ \\
\hline Large Office & 49,797 & $-1,535,000$ & 164,826 & $-\$ 810,000$ & 279,856 & $-\$ 120,000$ \\
\hline Supermarket & 14,851 & $-\$ 58,000$ & 28,044 & $\$ 10,000$ & 41,236 & $\$ 78,000$ \\
\hline Secondary School & 123,255 & $-1,684,000$ & 274,862 & $-\$ 881,000$ & 426,470 & $-\$ 103,000$ \\
\hline
\end{tabular}

- The reduction in CFM requirements for the ventilation system can have a large impact on the incremental costs. The incremental costs will vary depending on the final CFM requirements chosen. Current DOAS sizing uses the average of the maximum and minimum CFM requirements provided by EnergyPlus. 
C Appendix: Energy Use Estimate Tables and Figures 
Table: C-1 Annual Energy Consumption (Chiller, Fan, and Pump) for the StandardPerformance Small Office Building Design for Various HVAC Combinations across 21 Climate Locations (units in kWh) with Ideal Low-Lift Chiller for LLCS Configurations

\begin{tabular}{|l|r|r|r|r|r|r|r|r|r|}
\hline & Case 0 & Case 1 & Case 2 & Case 3 & Case 4 & Case 5 & Case 6 & Case 7 & Case 8 \\
\hline Pendleton, OR & 8,231 & 7,107 & 7,058 & 6,315 & 6,167 & 2,378 & 2,265 & 1,877 & 1,507 \\
\hline Spokane, WA & 7,636 & 6,807 & 6,772 & 6,181 & 6,083 & 2,077 & 1,988 & 1,662 & 1,393 \\
\hline Missoula, MT & 7,250 & 6,449 & 6,423 & 5,850 & 5,776 & 1,882 & 1,803 & 1,518 & 1,297 \\
\hline Boise, ID & 8,181 & 7,150 & 7,106 & 6,362 & 6,228 & 2,301 & 2,194 & 1,797 & 1,472 \\
\hline Pocatello, ID & 7,914 & 7,003 & 6,969 & 6,294 & 6,204 & 2,074 & 1,979 & 1,609 & 1,346 \\
\hline Helena, MT & 7,389 & 6,579 & 6,547 & 6,034 & 5,946 & 1,929 & 1,839 & 1,583 & 1,325 \\
\hline Astoria, OR & 5,564 & 5,168 & 5,146 & 5,087 & 5,048 & 1,424 & 1,324 & 1,370 & 1,150 \\
\hline Salem, OR & 7,356 & 6,368 & 6,327 & 5,799 & 5,701 & 1,895 & 1,774 & 1,564 & 1,270 \\
\hline Eugene, OR & 7,317 & 6,337 & 6,295 & 5,790 & 5,692 & 1,868 & 1,748 & 1,549 & 1,261 \\
\hline North Bend, OR & 5,144 & 4,813 & 4,796 & 4,776 & 4,741 & 1,388 & 1,304 & 1,354 & 1,143 \\
\hline Arcata, CA & 4,844 & 4,683 & 4,677 & 4,645 & 4,631 & 1,299 & 1,227 & 1,266 & 1,118 \\
\hline Medford, OR & 8,383 & 7,157 & 7,107 & 6,145 & 6,007 & 2,443 & 2,320 & 1,794 & 1,460 \\
\hline Redmond, OR & 7,678 & 6,751 & 6,711 & 5,996 & 5,909 & 2,166 & 2,058 & 1,634 & 1,354 \\
\hline Portland, OR & 7,200 & 6,247 & 6,200 & 5,833 & 5,726 & 1,801 & 1,671 & 1,592 & 1,264 \\
\hline Yakima, WA & 7,886 & 6,767 & 6,717 & 6,028 & 5,910 & 2,197 & 2,069 & 1,743 & 1,394 \\
\hline Burns, OR & 7,717 & 6,790 & 6,750 & 6,033 & 5,943 & 2,172 & 2,064 & 1,639 & 1,356 \\
\hline Olympia, WA & 6,817 & 6,022 & 5,988 & 5,586 & 5,516 & 1,724 & 1,618 & 1,467 & 1,226 \\
\hline Quillayuta, WA & 5,708 & 5,385 & 5,367 & 5,276 & 5,247 & 1,399 & 1,315 & 1,324 & 1,140 \\
\hline Seattle, WA & 6,569 & 5,877 & 5,842 & 5,636 & 5,553 & 1,610 & 1,505 & 1,498 & 1,209 \\
\hline Kalispell, MT & 6,975 & 6,257 & 6,232 & 5,759 & 5,698 & 1,754 & 1,676 & 1,449 & 1,241 \\
\hline Cut Bank, MT & 6,811 & 6,233 & 6,206 & 5,916 & 5,863 & 1,650 & 1,563 & 1,443 & 1,227 \\
\hline
\end{tabular}

Table: C-2 Annual Energy Consumption (Chiller, Fan, and Pump) for the HighPerformance Small Office Building Design for Various HVAC Combinations across 21 Climate Locations (units in kWh) with Ideal Low-Lift Chiller for LLCS Configurations

\begin{tabular}{|l|r|r|r|r|r|r|r|r|r|}
\hline & Case 0 & Case 1 & Case 2 & Case 3 & Case 4 & Case 5 & Case 6 & Case 7 & Case 8 \\
\hline Pendleton, OR & 1,567 & 1,278 & 1,254 & 1,056 & 1,012 & 933 & 909 & 797 & 729 \\
\hline Spokane, WA & 1,436 & 1,220 & 1,204 & 1,040 & 1,010 & 872 & 856 & 757 & 708 \\
\hline Missoula, MT & 1,369 & 1,142 & 1,129 & 988 & 966 & 795 & 781 & 713 & 674 \\
\hline Boise, ID & 1,514 & 1,249 & 1,229 & 1,038 & 998 & 906 & 886 & 780 & 716 \\
\hline Pocatello, ID & 1,464 & 1,255 & 1,240 & 1,070 & 1,046 & 848 & 832 & 733 & 688 \\
\hline Helena, MT & 1,339 & 1,137 & 1,126 & 997 & 974 & 801 & 789 & 720 & 681 \\
\hline Astoria, OR & 892 & 817 & 813 & 798 & 792 & 666 & 661 & 659 & 651 \\
\hline Salem, OR & 1,353 & 1,077 & 1,059 & 925 & 898 & 792 & 769 & 715 & 672 \\
\hline Eugene, OR & 1,322 & 1,060 & 1,042 & 922 & 895 & 779 & 757 & 712 & 670 \\
\hline North Bend, OR & 797 & 766 & 763 & 760 & 756 & 654 & 652 & 653 & 650 \\
\hline Arcata, CA & 753 & 730 & 729 & 724 & 722 & 653 & 652 & 651 & 650 \\
\hline Medford, OR & 1,656 & 1,285 & 1,262 & 981 & 940 & 978 & 952 & 793 & 725 \\
\hline Redmond, OR & 1,381 & 1,163 & 1,146 & 969 & 947 & 856 & 839 & 734 & 689 \\
\hline Portland, OR & 1,317 & 1,061 & 1,044 & 955 & 928 & 759 & 737 & 710 & 669 \\
\hline Yakima, WA & 1,511 & 1,206 & 1,183 & 1,008 & 974 & 855 & 829 & 752 & 697 \\
\hline Burns, OR & 1,397 & 1,167 & 1,150 & 971 & 948 & 859 & 842 & 735 & 690 \\
\hline Olympia, WA & 1,217 & 991 & 981 & 872 & 853 & 755 & 740 & 698 & 668 \\
\hline Quillayuta, WA & 906 & 852 & 849 & 831 & 825 & 669 & 664 & 659 & 651 \\
\hline Seattle, WA & 1,117 & 950 & 939 & 893 & 875 & 706 & 693 & 683 & 658 \\
\hline Kalispell, MT & 1,311 & 1,127 & 1,116 & 1,002 & 984 & 763 & 749 & 696 & 665 \\
\hline Cut Bank, MT & 1,272 & 1,153 & 1,146 & 1,085 & 1,073 & 717 & 709 & 681 & 661 \\
\hline
\end{tabular}


Table: C-3 Annual Energy Consumption (Chiller, Fan, and Pump) for the Standard-

Performance Medium Office Building Design for Various HVAC Combinations across 21 Climate Locations (units in kWh) with Ideal Low-Lift Chiller for LLCS Configurations

\begin{tabular}{|c|c|c|c|c|c|c|c|c|c|}
\hline & Case 0 & Case 1 & Case 2 & Case 3 & Case 4 & Case 5 & Case 6 & Case 7 & Case 8 \\
\hline Pendleton, OR & 79,175 & 53,671 & 50,502 & 46,511 & 40,163 & 40,668 & 34,234 & 36,150 & 26,297 \\
\hline Spokane, WA & 64,622 & 44,962 & 42,440 & 40,085 & 35,152 & 33,626 & 28,078 & 30,603 & 22,487 \\
\hline Missoula, MT & 62,728 & 42,734 & 40,485 & 38,352 & 32,924 & 31,002 & 25,726 & 28,970 & 20,739 \\
\hline Boise, ID & 77,956 & 54,017 & 51,106 & 47,274 & 40,355 & 39,816 & 33,566 & 35,975 & 25,681 \\
\hline Pocatello, ID & 68,392 & 47,456 & 44,887 & 41,926 & 35,700 & 34,576 & 28,852 & 31,582 & 22,203 \\
\hline Helena, MT & 63,531 & 43,198 & 40,888 & 38,907 & 34,172 & 31,656 & 26,187 & 29,419 & 21,274 \\
\hline Astoria, OR & 44,450 & 25,627 & 24,122 & 24,992 & 22,765 & 21,479 & 17,068 & 21,099 & 15,818 \\
\hline Salem, OR & 65,589 & 39,395 & 36,735 & 35,238 & 30,045 & 30,636 & 24,639 & 28,548 & 20,019 \\
\hline Eugene, OR & 66,006 & 39,257 & 36,501 & 35,450 & 29,781 & 30,381 & 24,388 & 28,472 & 20,053 \\
\hline North Bend, OR & 42,258 & 25,084 & 23,813 & 24,622 & 22,671 & 21,127 & 16,859 & 20,788 & 15,602 \\
\hline Arcata, CA & 35,808 & 23,228 & 22,287 & 22,830 & 21,449 & 19,747 & 15,995 & 19,457 & 15,022 \\
\hline Medford, OR & 82,800 & 55,324 & 52,225 & 45,532 & 38,684 & 41,022 & 34,501 & 35,668 & 25,037 \\
\hline Redmond, OR & 64,342 & 44,444 & 41,876 & 39,171 & 33,448 & 34,181 & 28,249 & 31,159 & 21,634 \\
\hline Portland, OR & 64,469 & 37,582 & 34,729 & 34,826 & 29,890 & 29,877 & 23,507 & 28,534 & 19,888 \\
\hline Yakima, WA & 72,383 & 48,051 & 45,044 & 42,318 & 35,879 & 36,402 & 30,234 & 33,371 & 23,679 \\
\hline Burns, OR & 64,394 & 44,483 & 41,913 & 39,211 & 33,472 & 34,217 & 28,276 & 31,189 & 21,650 \\
\hline Olympia, WA & 58,097 & 35,238 & 33,010 & 31,623 & 27,638 & 27,439 & 22,175 & 25,711 & 18,452 \\
\hline Quillayuta, WA & 39,467 & 25,012 & 23,646 & 24,345 & 22,413 & 21,162 & 16,977 & 20,697 & 15,699 \\
\hline Seattle, WA & 54,336 & 31,968 & 29,657 & 30,542 & 26,912 & 26,028 & 20,453 & 25,192 & 18,034 \\
\hline Kalispell, MT & 55,169 & 37,411 & 35,525 & 34,170 & 29,994 & 27,933 & 23,113 & 26,368 & 19,047 \\
\hline Cut Bank, MT & 50,711 & 35,212 & 33,314 & 33,235 & 29,800 & 26,646 & 21,482 & 25,518 & 18,568 \\
\hline
\end{tabular}

Table: C-4 Annual Energy Consumption (Chiller, Fan, and Pump) for the High-

Performance Medium Office Building Design for Various HVAC Combinations across 21 Climate Locations (units in kWh) with Ideal Low-Lift Chiller for LLCS Configurations

\begin{tabular}{|l|r|r|r|r|r|r|r|r|r|}
\hline & Case 0 & Case 1 & Case 2 & Case 3 & Case 4 & Case 5 & Case 6 & Case 7 & Case 8 \\
\hline Pendleton, OR & 30,872 & 21,007 & 19,524 & 18,556 & 15,804 & 14,065 & 12,162 & 12,839 & 9,589 \\
\hline Spokane, WA & 24,469 & 17,472 & 16,419 & 15,683 & 13,730 & 11,833 & 10,394 & 10,873 & 8,557 \\
\hline Missoula, MT & 22,944 & 15,944 & 15,059 & 13,426 & 12,190 & 10,923 & 9,667 & 10,328 & 7,936 \\
\hline Boise, ID & 29,475 & 20,496 & 19,259 & 17,698 & 15,207 & 13,973 & 12,265 & 12,821 & 9,517 \\
\hline Pocatello, ID & 24,222 & 16,889 & 15,841 & 14,003 & 12,521 & 12,214 & 10,684 & 11,368 & 8,484 \\
\hline Helena, MT & 22,642 & 15,462 & 14,520 & 13,708 & 12,000 & 11,071 & 9,699 & 10,434 & 8,174 \\
\hline Astoria, OR & 20,961 & 13,439 & 12,763 & 13,231 & 12,361 & 7,129 & 6,533 & 7,091 & 6,351 \\
\hline Salem, OR & 26,300 & 16,168 & 14,937 & 14,544 & 12,574 & 10,121 & 8,712 & 9,702 & 7,468 \\
\hline Eugene, OR & 26,022 & 16,110 & 14,863 & 14,677 & 12,561 & 10,012 & 8,603 & 9,615 & 7,434 \\
\hline North Bend, OR & 21,089 & 13,857 & 13,278 & 13,723 & 12,906 & 6,717 & 6,220 & 6,703 & 6,078 \\
\hline Arcata, CA & 19,447 & 13,658 & 13,213 & 13,543 & 12,941 & 6,548 & 6,086 & 6,535 & 5,943 \\
\hline Medford, OR & 31,958 & 21,160 & 19,643 & 17,120 & 14,761 & 14,046 & 12,193 & 12,556 & 9,016 \\
\hline Redmond, OR & 24,247 & 17,188 & 16,105 & 14,554 & 13,104 & 11,675 & 10,108 & 10,822 & 8,076 \\
\hline Portland, OR & 25,928 & 15,675 & 14,394 & 14,789 & 12,632 & 9,850 & 8,382 & 9,555 & 7,481 \\
\hline Yakima, WA & 27,497 & 18,185 & 16,747 & 16,197 & 13,587 & 12,270 & 10,356 & 11,516 & 8,473 \\
\hline Burns, OR & 24,222 & 17,158 & 16,072 & 14,554 & 13,063 & 11,698 & 10,128 & 10,840 & 8,090 \\
\hline Olympia, WA & 23,981 & 15,267 & 14,303 & 13,827 & 12,417 & 9,227 & 8,088 & 8,874 & 7,148 \\
\hline Quillayuta, WA & 18,617 & 12,840 & 12,255 & 12,613 & 11,831 & 7,288 & 6,670 & 7,233 & 6,450 \\
\hline Seattle, WA & 22,283 & 14,055 & 13,071 & 13,595 & 12,109 & 8,473 & 7,418 & 8,335 & 6,950 \\
\hline Kalispell, MT & 20,522 & 14,229 & 13,442 & 12,696 & 11,387 & 9,697 & 8,615 & 9,346 & 7,496 \\
\hline Cut Bank, MT & 17,761 & 12,456 & 11,704 & 11,675 & 10,524 & 9,275 & 8,126 & 9,058 & 7,461 \\
\hline
\end{tabular}


Table: C-5 Annual Energy Consumption (Chiller, Fan, and Pump) for the StandardPerformance Large Office Building Design for Various HVAC Combinations across 21 Climate Locations (units in kWh) with Ideal Low-Lift Chiller for LLCS Configurations

\begin{tabular}{|l|r|r|r|r|r|r|r|r|r|}
\hline & Case 0 & Case 1 & Case 2 & Case 3 & Case 4 & Case 5 & Case 6 & Case 7 & Case 8 \\
\hline Pendleton, OR & 625,525 & 550,594 & 527,093 & 491,699 & 451,060 & 419,146 & 365,081 & 376,221 & 294,789 \\
\hline Spokane, WA & 535,300 & 485,651 & 469,555 & 438,395 & 409,892 & 356,024 & 309,806 & 321,276 & 254,405 \\
\hline Missoula, MT & 530,947 & 476,301 & 462,798 & 424,845 & 398,764 & 337,821 & 295,802 & 304,067 & 241,490 \\
\hline Boise, ID & 655,594 & 608,431 & 589,447 & 540,036 & 504,986 & 428,624 & 379,151 & 380,040 & 305,582 \\
\hline Pocatello, ID & 708,539 & 711,003 & 699,198 & 654,912 & 630,258 & 372,579 & 334,072 & 336,132 & 278,992 \\
\hline Helena, MT & 628,500 & 632,101 & 621,000 & 587,862 & 565,095 & 344,904 & 308,218 & 314,305 & 258,587 \\
\hline Astoria, OR & 337,961 & 230,427 & 217,465 & 223,374 & 203,817 & 232,365 & 183,427 & 227,466 & 163,299 \\
\hline Salem, OR & 479,758 & 365,396 & 342,745 & 332,848 & 296,533 & 319,108 & 262,302 & 297,743 & 216,877 \\
\hline Eugene, OR & 479,953 & 364,139 & 340,892 & 331,926 & 294,800 & 319,149 & 261,796 & 297,856 & 216,148 \\
\hline North Bend, OR & 322,697 & 226,743 & 214,873 & 221,893 & 203,492 & 239,298 & 189,377 & 234,197 & 166,026 \\
\hline Arcata, CA & 297,758 & 214,163 & 206,552 & 208,802 & 196,460 & 224,258 & 176,913 & 219,761 & 156,735 \\
\hline Medford, OR & 568,231 & 562,086 & 538,328 & 490,903 & 447,585 & 422,471 & 366,123 & 375,863 & 289,805 \\
\hline Redmond, OR & 558,967 & 503,103 & 488,134 & 445,467 & 417,376 & 371,901 & 328,289 & 328,240 & 261,042 \\
\hline Portland, OR & 471,625 & 349,328 & 325,368 & 324,609 & 286,730 & 311,467 & 251,617 & 295,887 & 211,513 \\
\hline Yakima, WA & 573,644 & 482,147 & 459,087 & 432,529 & 392,577 & 375,957 & 323,271 & 341,412 & 260,682 \\
\hline Burns, OR & 559,294 & 503,382 & 488,411 & 445,723 & 417,630 & 371,982 & 328,368 & 328,303 & 261,097 \\
\hline Olympia, WA & 426,075 & 320,402 & 301,645 & 293,553 & 263,673 & 285,563 & 232,026 & 269,025 & 196,203 \\
\hline Quillayuta, WA & 307,169 & 226,256 & 214,430 & 218,683 & 202,687 & 229,033 & 182,076 & 222,494 & 161,560 \\
\hline Seattle, WA & 404,817 & 293,904 & 274,624 & 278,613 & 249,802 & 274,608 & 221,307 & 263,888 & 189,867 \\
\hline Kalispell, MT & 466,128 & 405,550 & 392,988 & 367,877 & 345,555 & 302,476 & 262,562 & 275,451 & 216,344 \\
\hline Cut Bank, MT & 494,103 & 507,207 & 497,831 & 480,510 & 461,468 & 292,551 & 255,859 & 270,423 & 215,655 \\
\hline
\end{tabular}

Table: C-6 Annual Energy Consumption (Chiller, Fan, and Pump) for the HighPerformance Large Office Building Design for Various HVAC Combinations across 21 Climate Locations (units in kWh) with Ideal Low-Lift Chiller for LLCS Configurations

\begin{tabular}{|l|r|r|r|r|r|r|r|r|r|}
\hline & Case 0 & Case 1 & Case 2 & Case 3 & Case 4 & Case 5 & Case 6 & Case 7 & Case 8 \\
\hline Pendleton, OR & 206,939 & 166,782 & 154,800 & 148,191 & 128,126 & 161,998 & 144,473 & 149,138 & 121,804 \\
\hline Spokane, WA & 165,517 & 136,170 & 128,177 & 119,955 & 106,315 & 138,934 & 125,721 & 128,424 & 108,770 \\
\hline Missoula, MT & 159,408 & 129,500 & 123,130 & 115,003 & 103,134 & 132,178 & 120,929 & 122,772 & 104,123 \\
\hline Boise, ID & 199,594 & 169,346 & 160,305 & 148,273 & 130,629 & 166,805 & 152,738 & 151,761 & 127,763 \\
\hline Pocatello, ID & 189,386 & 163,874 & 158,630 & 137,519 & 123,881 & 150,559 & 141,946 & 132,388 & 116,936 \\
\hline Helena, MT & 175,889 & 146,679 & 141,689 & 126,334 & 116,638 & 139,061 & 130,555 & 124,736 & 110,316 \\
\hline Astoria, OR & 140,856 & 87,756 & 81,816 & 86,061 & 78,318 & 81,348 & 72,619 & 80,686 & 70,185 \\
\hline Salem, OR & 178,058 & 125,258 & 114,402 & 115,255 & 98,382 & 119,878 & 102,284 & 114,554 & 90,323 \\
\hline Eugene, OR & 175,872 & 123,488 & 112,499 & 113,939 & 97,138 & 118,226 & 101,133 & 113,122 & 89,318 \\
\hline North Bend, OR & 133,075 & 87,745 & 82,954 & 86,452 & 79,608 & 79,690 & 71,038 & 79,101 & 68,362 \\
\hline Arcata, CA & 126,258 & 84,147 & 80,865 & 82,964 & 78,476 & 74,245 & 69,019 & 73,941 & 66,829 \\
\hline Medford, OR & 217,231 & 174,726 & 161,994 & 152,116 & 129,793 & 164,861 & 145,436 & 150,606 & 119,991 \\
\hline Redmond, OR & 167,856 & 134,580 & 127,086 & 117,727 & 104,614 & 138,882 & 126,517 & 127,314 & 107,492 \\
\hline Portland, OR & 174,053 & 118,765 & 107,438 & 111,345 & 94,543 & 115,404 & 97,481 & 111,640 & 87,673 \\
\hline Yakima, WA & 191,369 & 146,085 & 133,865 & 132,667 & 113,396 & 143,248 & 124,868 & 134,804 & 107,117 \\
\hline Burns, OR & 167,883 & 134,579 & 127,084 & 117,715 & 104,603 & 138,937 & 126,577 & 127,352 & 107,532 \\
\hline Olympia, WA & 162,886 & 113,095 & 104,508 & 104,799 & 91,565 & 106,006 & 91,537 & 102,143 & 82,934 \\
\hline Quillayuta, WA & 124,592 & 84,523 & 79,537 & 82,479 & 76,148 & 83,315 & 75,224 & 82,355 & 72,132 \\
\hline Seattle, WA & 148,019 & 99,833 & 91,182 & 95,681 & 83,651 & 100,452 & 86,302 & 98,439 & 80,181 \\
\hline Kalispell, MT & 141,589 & 110,363 & 104,345 & 100,912 & 90,709 & 117,002 & 106,330 & 110,953 & 94,214 \\
\hline Cut Bank, MT & 139,664 & 104,572 & 100,435 & 96,152 & 88,580 & 112,077 & 103,069 & 106,527 & 92,570 \\
\hline
\end{tabular}


Table: C-7 Annual Energy Consumption (Chiller, Fan, and Pump) for the StandardPerformance Retail Strip Mall Building Design for Various HVAC Combinations across 21 Climate Locations (units in kWh) with Ideal Low-Lift Chiller for LLCS Configurations

\begin{tabular}{|l|r|r|r|r|r|r|r|r|r|}
\hline & Case 0 & Case 1 & Case 2 & Case 3 & Case 4 & Case 5 & Case 6 & Case 7 & Case 8 \\
\hline Pendleton, OR & 81,844 & 70,149 & 69,171 & 64,944 & 61,052 & 33,276 & 31,740 & 29,776 & 25,100 \\
\hline Spokane, WA & 74,669 & 66,708 & 66,046 & 62,938 & 60,193 & 29,819 & 28,681 & 27,109 & 23,743 \\
\hline Missoula, MT & 75,083 & 66,922 & 66,318 & 62,985 & 60,303 & 28,865 & 27,821 & 26,438 & 22,986 \\
\hline Boise, ID & 82,911 & 71,522 & 70,526 & 66,380 & 62,350 & 33,263 & 31,679 & 29,828 & 24,973 \\
\hline Pocatello, ID & 79,797 & 70,391 & 69,682 & 65,176 & 62,526 & 31,095 & 29,823 & 28,019 & 23,837 \\
\hline Helena, MT & 75,656 & 67,933 & 67,342 & 64,703 & 62,139 & 28,912 & 27,726 & 26,748 & 23,397 \\
\hline Astoria, OR & 49,692 & 47,710 & 47,583 & 47,374 & 46,894 & 21,161 & 20,703 & 21,005 & 20,234 \\
\hline Salem, OR & 68,075 & 59,208 & 58,563 & 56,422 & 53,486 & 26,513 & 25,335 & 25,024 & 21,866 \\
\hline Eugene, OR & 67,989 & 59,077 & 58,430 & 56,438 & 53,331 & 26,594 & 25,407 & 25,151 & 21,788 \\
\hline North Bend, OR & 45,014 & 43,960 & 43,877 & 43,841 & 43,656 & 20,580 & 20,244 & 20,506 & 20,035 \\
\hline Arcata, CA & 43,569 & 43,019 & 42,990 & 42,878 & 42,743 & 20,319 & 20,139 & 20,258 & 19,969 \\
\hline Medford, OR & 83,756 & 70,579 & 69,517 & 63,057 & 59,187 & 33,862 & 32,259 & 29,290 & 24,374 \\
\hline Redmond, OR & 73,489 & 65,033 & 64,388 & 60,894 & 58,112 & 29,730 & 28,523 & 27,049 & 23,068 \\
\hline Portland, OR & 66,850 & 58,342 & 57,618 & 56,462 & 53,781 & 25,761 & 24,421 & 24,808 & 21,892 \\
\hline Yakima, WA & 77,700 & 66,625 & 65,736 & 62,505 & 58,582 & 30,961 & 29,410 & 28,255 & 23,736 \\
\hline Burns, OR & 73,703 & 65,223 & 64,577 & 61,116 & 58,283 & 29,765 & 28,554 & 27,029 & 23,082 \\
\hline Olympia, WA & 63,081 & 56,256 & 55,779 & 53,777 & 51,860 & 25,039 & 24,075 & 23,891 & 21,418 \\
\hline Quillayuta, WA & 51,125 & 49,268 & 49,126 & 48,938 & 48,493 & 21,216 & 20,806 & 21,016 & 20,260 \\
\hline Seattle, WA & 59,775 & 54,527 & 54,084 & 53,413 & 51,945 & 23,622 & 22,643 & 23,022 & 21,103 \\
\hline Kalispell, MT & 70,211 & 63,762 & 63,347 & 61,017 & 58,903 & 26,572 & 25,729 & 24,809 & 22,150 \\
\hline Cut Bank, MT & 68,972 & 64,277 & 63,901 & 62,795 & 61,196 & 25,779 & 24,859 & 24,714 & 22,382 \\
\hline
\end{tabular}

Table: C-8 Annual Energy Consumption (Chiller, Fan, and Pump) for the HighPerformance Retail Strip Mall Building Design for Various HVAC Combinations across 21 Climate Locations (units in kWh) with Ideal Low-Lift Chiller for LLCS Configurations

\begin{tabular}{|l|r|r|r|r|r|r|r|r|r|}
\hline & Case 0 & Case 1 & Case 2 & Case 3 & Case 4 & Case 5 & Case 6 & Case 7 & Case 8 \\
\hline Pendleton, OR & 25,753 & 20,193 & 19,595 & 17,561 & 16,105 & 16,854 & 16,251 & 15,573 & 13,578 \\
\hline Spokane, WA & 21,539 & 18,166 & 17,812 & 16,016 & 15,282 & 15,332 & 14,957 & 14,194 & 12,974 \\
\hline Missoula, MT & 20,208 & 16,829 & 16,488 & 14,514 & 14,064 & 14,711 & 14,378 & 13,840 & 12,569 \\
\hline Boise, ID & 24,097 & 19,170 & 18,635 & 16,023 & 15,013 & 16,958 & 16,433 & 15,464 & 13,524 \\
\hline Pocatello, ID & 21,925 & 18,020 & 17,643 & 15,222 & 14,654 & 15,668 & 15,268 & 14,508 & 12,881 \\
\hline Helena, MT & 20,194 & 17,159 & 16,860 & 15,331 & 14,805 & 14,528 & 14,214 & 13,736 & 12,628 \\
\hline Astoria, OR & 12,842 & 12,410 & 12,391 & 12,283 & 12,219 & 11,949 & 11,911 & 11,930 & 11,847 \\
\hline Salem, OR & 18,956 & 15,564 & 15,200 & 13,791 & 13,253 & 13,822 & 13,492 & 13,250 & 12,291 \\
\hline Eugene, OR & 18,947 & 15,495 & 15,134 & 13,708 & 13,246 & 13,797 & 13,451 & 13,293 & 12,261 \\
\hline North Bend, OR & 11,456 & 11,388 & 11,384 & 11,366 & 11,358 & 11,825 & 11,821 & 11,823 & 11,814 \\
\hline Arcata, CA & 10,897 & 10,823 & 10,821 & 10,790 & 10,781 & 11,822 & 11,817 & 11,820 & 11,809 \\
\hline Medford, OR & 26,486 & 20,635 & 20,000 & 16,121 & 15,233 & 17,564 & 16,944 & 15,529 & 13,441 \\
\hline Redmond, OR & 20,067 & 16,687 & 16,345 & 14,301 & 13,909 & 14,988 & 14,601 & 14,081 & 12,628 \\
\hline Portland, OR & 18,614 & 15,388 & 15,051 & 14,425 & 13,640 & 13,314 & 13,003 & 13,039 & 12,212 \\
\hline Yakima, WA & 22,925 & 18,101 & 17,579 & 15,747 & 14,665 & 15,446 & 14,903 & 14,443 & 12,892 \\
\hline Burns, OR & 20,186 & 16,810 & 16,464 & 14,423 & 14,019 & 15,001 & 14,608 & 14,096 & 12,631 \\
\hline Olympia, WA & 17,156 & 14,569 & 14,356 & 13,101 & 12,805 & 13,309 & 13,074 & 12,894 & 12,179 \\
\hline Quillayuta, WA & 12,689 & 12,306 & 12,271 & 12,162 & 12,107 & 11,959 & 11,932 & 11,932 & 11,840 \\
\hline Seattle, WA & 15,519 & 13,907 & 13,750 & 13,488 & 13,024 & 12,501 & 12,355 & 12,327 & 11,992 \\
\hline Kalispell, MT & 18,742 & 16,183 & 15,931 & 14,648 & 14,286 & 13,612 & 13,359 & 13,048 & 12,257 \\
\hline Cut Bank, MT & 17,561 & 15,969 & 15,817 & 15,168 & 14,920 & 13,060 & 12,893 & 12,785 & 12,208 \\
\hline
\end{tabular}


Table: C-9 Annual Energy Consumption (Chiller, Fan, and Pump) for the Standard-

Performance Retail Stand-Alone Building Design for Various HVAC Combinations across 21 Climate Locations (units in kWh) with Ideal Low-Lift Chiller for LLCS Configurations

\begin{tabular}{|c|c|c|c|c|c|c|c|c|c|}
\hline & Case 0 & Case 1 & Case 2 & Case 3 & Case 4 & Case 5 & Case 6 & Case 7 & Case 8 \\
\hline Pendleton, OR & 118,089 & 103,798 & 102,858 & 98,814 & 93,813 & 35,658 & 33,818 & 32,603 & 27,209 \\
\hline Spokane, WA & 110,142 & 100,221 & 99,587 & 96,264 & 93,098 & 31,878 & 30,570 & 29,407 & 25,546 \\
\hline Missoula, MT & 109,914 & 99,875 & 99,339 & 95,846 & 92,615 & 30,605 & 29,451 & 28,528 & 24,507 \\
\hline Boise, ID & 119,369 & 105,874 & 105,047 & 100,449 & 95,875 & 35,721 & 34,052 & 32,446 & 27,006 \\
\hline Pocatello, ID & 118,467 & 106,806 & 106,120 & 101,437 & 98,012 & 33,638 & 32,170 & 30,623 & 25,716 \\
\hline Helena, MT & 111,572 & 102,112 & 101,541 & 98,781 & 95,654 & 30,769 & 29,399 & 28,745 & 24,873 \\
\hline Astoria, OR & 79,247 & 76,500 & 76,330 & 76,163 & 75,660 & 23,200 & 22,500 & 23,020 & 21,956 \\
\hline Salem, OR & 100,983 & 89,957 & 89,266 & 87,149 & 83,736 & 28,839 & 27,395 & 27,539 & 23,861 \\
\hline Eugene, OR & 101,319 & 90,167 & 89,476 & 87,535 & 83,867 & 28,857 & 27,429 & 27,613 & 23,835 \\
\hline North Bend, OR & 74,433 & 72,655 & 72,517 & 72,499 & 72,212 & 22,748 & 22,102 & 22,635 & 21,773 \\
\hline Arcata, CA & 72,297 & 71,454 & 71,403 & 71,309 & 71,159 & 22,200 & 21,842 & 22,124 & 21,639 \\
\hline Medford, OR & 120,264 & 104,347 & 103,387 & 96,724 & 91,944 & 36,612 & 34,852 & 32,353 & 26,603 \\
\hline Redmond, OR & 108,931 & 98,599 & 97,906 & 94,097 & 90,907 & 32,229 & 30,684 & 29,491 & 24,890 \\
\hline Portland, OR & 99,928 & 89,222 & 88,452 & 87,381 & 84,204 & 28,070 & 26,400 & 27,211 & 23,867 \\
\hline Yakima, WA & 112,325 & 98,849 & 97,960 & 94,403 & 90,012 & 33,342 & 31,470 & 30,796 & 25,677 \\
\hline Burns, OR & 109,217 & 98,853 & 98,159 & 94,337 & 91,139 & 32,266 & 30,718 & 29,527 & 24,906 \\
\hline Olympia, WA & 94,844 & 86,166 & 85,657 & 83,812 & 81,368 & 27,144 & 25,943 & 26,111 & 23,262 \\
\hline Quillayuta, WA & 80,522 & 77,978 & 77,788 & 77,640 & 77,072 & 23,132 & 22,499 & 22,918 & 21,919 \\
\hline Seattle, WA & 91,403 & 84,601 & 84,107 & 83,433 & 81,765 & 25,639 & 24,415 & 25,103 & 22,920 \\
\hline Kalispell, MT & 104,306 & 96,228 & 95,793 & 93,287 & 90,879 & 28,252 & 27,193 & 26,722 & 23,656 \\
\hline Cut Bank, MT & 104,167 & 98,038 & 97,619 & 96,539 & 94,595 & 27,467 & 26,176 & 26,491 & 23,603 \\
\hline
\end{tabular}

Table: C-10 Annual Energy Consumption (Chiller, Fan, and Pump) for the High-

Performance Retail Stand-Alone Building Design for Various HVAC Combinations across 21 Climate Locations (units in kWh) with Ideal Low-Lift Chiller for LLCS Configurations

\begin{tabular}{|c|c|c|c|c|c|c|c|c|c|}
\hline & Case 0 & Case 1 & Case 2 & Case 3 & Case 4 & Case 5 & Case 6 & Case 7 & Case 8 \\
\hline Pendleton, OR & 40,281 & 33,044 & 32,401 & 30,383 & 28,326 & 17,947 & 17,231 & 16,893 & 14,616 \\
\hline Spokane, WA & 35,469 & 30,784 & 30,396 & 28,696 & 27,471 & 16,115 & 15,638 & 15,226 & 13,887 \\
\hline Missoula, MT & 33,689 & 28,982 & 28,640 & 26,384 & 25,751 & 15,592 & 15,162 & 15,018 & 13,480 \\
\hline Boise, ID & 38,519 & 31,887 & 31,341 & 28,763 & 27,186 & 17,789 & 17,133 & 16,749 & 14,462 \\
\hline Pocatello, ID & 36,108 & 30,705 & 30,279 & 27,594 & 26,754 & 16,512 & 15,990 & 15,661 & 13,767 \\
\hline Helena, MT & 33,353 & 29,158 & 28,836 & 27,231 & 26,368 & 15,347 & 14,962 & 14,760 & 13,532 \\
\hline Astoria, OR & 25,472 & 24,772 & 24,739 & 24,634 & 24,517 & 12,946 & 12,886 & 12,920 & 12,805 \\
\hline Salem, OR & 32,839 & 28,062 & 27,644 & 26,114 & 25,297 & 15,153 & 14,686 & 14,696 & 13,380 \\
\hline Eugene, OR & 32,889 & 28,014 & 27,600 & 26,109 & 25,264 & 15,100 & 14,621 & 14,662 & 13,340 \\
\hline North Bend, OR & 23,961 & 23,779 & 23,770 & 23,743 & 23,718 & 12,798 & 12,785 & 12,794 & 12,772 \\
\hline Arcata, CA & 23,581 & 23,465 & 23,460 & 23,415 & 23,396 & 12,796 & 12,787 & 12,791 & 12,771 \\
\hline Medford, OR & 41,322 & 33,572 & 32,937 & 28,765 & 27,426 & 19,051 & 18,380 & 17,146 & 14,626 \\
\hline Redmond, OR & 33,731 & 29,234 & 28,825 & 26,548 & 25,911 & 15,806 & 15,285 & 15,199 & 13,497 \\
\hline Portland, OR & 32,458 & 27,925 & 27,523 & 27,104 & 25,773 & 14,602 & 14,067 & 14,363 & 13,294 \\
\hline Yakima, WA & 37,203 & 30,788 & 30,210 & 28,250 & 26,746 & 16,723 & 16,039 & 15,813 & 13,992 \\
\hline Burns, OR & 33,886 & 29,363 & 28,953 & 26,660 & 26,027 & 15,825 & 15,300 & 15,212 & 13,503 \\
\hline Olympia, WA & 31,714 & 27,901 & 27,660 & 26,297 & 25,803 & 14,508 & 14,172 & 14,159 & 13,215 \\
\hline Quillayuta, WA & 25,778 & 25,119 & 25,071 & 24,945 & 24,845 & 12,946 & 12,893 & 12,918 & 12,799 \\
\hline Seattle, WA & 28,525 & 26,056 & 25,855 & 25,613 & 24,990 & 13,645 & 13,360 & 13,501 & 13,020 \\
\hline Kalispell, MT & 31,289 & 27,717 & 27,444 & 26,035 & 25,450 & 14,629 & 14,292 & 14,242 & 13,218 \\
\hline Cut Bank, MT & 29,294 & 26,997 & 26,800 & 26,154 & 25,694 & 13,884 & 13,642 & 13,715 & 13,069 \\
\hline
\end{tabular}


Table: C-11 Annual Energy Consumption (Chiller, Fan, and Pump) for the StandardPerformance Primary School Building Design for Various HVAC Combinations across 21 Climate Locations (units in kWh) with Ideal Low-Lift Chiller for LLCS Configurations

\begin{tabular}{|l|r|r|r|r|r|r|r|r|r|}
\hline & Case 0 & Case 1 & Case 2 & Case 3 & Case 4 & Case 5 & Case 6 & Case 7 & Case 8 \\
\hline Pendleton, OR & 243,164 & 183,417 & 178,478 & 168,270 & 159,344 & 119,918 & 114,478 & 102,119 & 90,665 \\
\hline Spokane, WA & 207,206 & 168,651 & 164,971 & 157,186 & 150,420 & 105,882 & 101,886 & 92,706 & 83,730 \\
\hline Missoula, MT & 209,978 & 166,707 & 163,950 & 154,975 & 149,619 & 103,521 & 100,023 & 90,085 & 82,318 \\
\hline Boise, ID & 241,603 & 194,085 & 190,416 & 172,703 & 164,458 & 125,007 & 120,582 & 102,143 & 91,418 \\
\hline Pocatello, ID & 222,833 & 180,317 & 177,003 & 166,766 & 159,718 & 108,973 & 105,140 & 93,672 & 84,108 \\
\hline Helena, MT & 211,233 & 173,213 & 170,265 & 159,483 & 153,838 & 106,026 & 102,479 & 91,484 & 83,153 \\
\hline Astoria, OR & 155,433 & 120,879 & 117,860 & 116,778 & 112,484 & 80,200 & 76,558 & 75,343 & 68,630 \\
\hline Salem, OR & 212,800 & 157,616 & 153,187 & 144,444 & 136,636 & 100,851 & 95,461 & 88,123 & 76,942 \\
\hline Eugene, OR & 214,339 & 155,255 & 150,936 & 143,813 & 136,210 & 99,443 & 94,260 & 87,578 & 76,504 \\
\hline North Bend, OR & 148,325 & 115,557 & 113,382 & 111,878 & 108,062 & 80,510 & 77,847 & 74,268 & 68,039 \\
\hline Arcata, CA & 137,608 & 114,091 & 111,560 & 110,702 & 106,430 & 83,989 & 81,016 & 77,989 & 71,745 \\
\hline Medford, OR & 251,753 & 185,511 & 180,714 & 167,488 & 157,926 & 124,348 & 118,874 & 104,249 & 91,464 \\
\hline Redmond, OR & 211,203 & 168,925 & 165,223 & 155,403 & 148,387 & 108,724 & 104,630 & 92,728 & 83,412 \\
\hline Portland, OR & 209,783 & 152,979 & 148,477 & 142,893 & 135,407 & 96,898 & 91,484 & 86,812 & 75,945 \\
\hline Yakima, WA & 227,161 & 173,968 & 169,215 & 161,935 & 152,841 & 112,074 & 107,120 & 98,726 & 87,159 \\
\hline Burns, OR & 211,814 & 169,419 & 165,709 & 155,891 & 148,842 & 108,910 & 104,802 & 92,895 & 83,532 \\
\hline Olympia, WA & 192,964 & 143,838 & 139,993 & 134,551 & 128,348 & 92,608 & 87,801 & 83,043 & 74,143 \\
\hline Quillayuta, WA & 149,228 & 121,682 & 118,780 & 117,413 & 113,526 & 78,808 & 75,216 & 73,763 & 67,505 \\
\hline Seattle, WA & 182,022 & 136,846 & 132,824 & 131,955 & 126,138 & 86,898 & 82,366 & 80,832 & 72,092 \\
\hline Kalispell, MT & 190,514 & 153,614 & 150,984 & 145,157 & 140,293 & 96,192 & 92,957 & 86,404 & 78,985 \\
\hline Cut Bank, MT & 187,744 & 156,703 & 153,860 & 151,440 & 146,693 & 90,524 & 87,185 & 83,769 & 76,804 \\
\hline
\end{tabular}

Table: C-12 Annual Energy Consumption (Chiller, Fan, and Pump) for the HighPerformance Primary School Building Design for Various HVAC Combinations across 21 Climate Locations (units in kWh) with Ideal Low-Lift Chiller for LLCS Configurations

\begin{tabular}{|l|r|r|r|r|r|r|r|r|r|}
\hline & Case 0 & Case 1 & Case 2 & Case 3 & Case 4 & Case 5 & Case 6 & Case 7 & Case 8 \\
\hline Pendleton, OR & 69,733 & 48,771 & 46,887 & 42,105 & 38,590 & 43,914 & 41,786 & 37,214 & 32,555 \\
\hline Spokane, WA & 56,133 & 43,316 & 41,878 & 38,523 & 35,855 & 38,653 & 37,111 & 33,876 & 30,495 \\
\hline Missoula, MT & 56,342 & 41,533 & 40,618 & 36,322 & 34,402 & 37,694 & 36,549 & 32,550 & 29,656 \\
\hline Boise, ID & 68,281 & 51,436 & 50,032 & 42,367 & 39,162 & 45,743 & 44,106 & 37,360 & 32,965 \\
\hline Pocatello, ID & 57,722 & 43,879 & 42,694 & 38,282 & 35,668 & 39,100 & 37,783 & 33,760 & 30,187 \\
\hline Helena, MT & 55,294 & 43,316 & 42,286 & 37,282 & 35,199 & 38,768 & 37,491 & 33,027 & 30,083 \\
\hline Astoria, OR & 46,931 & 34,987 & 34,094 & 32,658 & 31,375 & 29,943 & 28,702 & 28,517 & 26,200 \\
\hline Salem, OR & 60,536 & 42,112 & 40,403 & 36,809 & 34,067 & 36,963 & 34,818 & 32,700 & 28,489 \\
\hline Eugene, OR & 60,572 & 40,932 & 39,302 & 36,413 & 33,776 & 36,060 & 34,043 & 32,348 & 28,164 \\
\hline North Bend, OR & 44,961 & 34,345 & 33,915 & 32,196 & 31,444 & 29,858 & 29,185 & 27,909 & 26,309 \\
\hline Arcata, CA & 41,825 & 34,649 & 34,074 & 32,341 & 31,597 & 31,366 & 30,566 & 29,646 & 28,036 \\
\hline Medford, OR & 74,283 & 50,782 & 48,790 & 43,036 & 39,102 & 45,599 & 43,373 & 38,148 & 32,838 \\
\hline Redmond, OR & 59,106 & 44,074 & 42,707 & 38,603 & 35,909 & 39,383 & 37,819 & 33,879 & 30,294 \\
\hline Portland, OR & 59,119 & 40,140 & 38,389 & 36,379 & 33,582 & 35,103 & 32,933 & 32,194 & 27,982 \\
\hline Yakima, WA & 63,733 & 45,331 & 43,437 & 40,687 & 36,779 & 40,230 & 38,179 & 35,908 & 31,023 \\
\hline Burns, OR & 59,136 & 44,056 & 42,681 & 38,580 & 35,891 & 39,430 & 37,860 & 33,924 & 30,326 \\
\hline Olympia, WA & 56,156 & 39,403 & 38,025 & 35,414 & 33,141 & 34,322 & 32,499 & 31,002 & 27,768 \\
\hline Quillayuta, WA & 42,811 & 34,191 & 33,252 & 31,962 & 30,801 & 29,643 & 28,503 & 27,972 & 25,949 \\
\hline Seattle, WA & 51,064 & 36,019 & 34,573 & 34,126 & 31,938 & 31,452 & 29,689 & 29,939 & 26,744 \\
\hline Kalispell, MT & 50,914 & 38,146 & 37,212 & 34,571 & 32,786 & 34,751 & 33,648 & 31,231 & 28,579 \\
\hline Cut Bank, MT & 45,639 & 36,008 & 35,042 & 33,830 & 32,237 & 31,968 & 30,854 & 29,932 & 27,635 \\
\hline
\end{tabular}


Table: C-13 Annual Energy Consumption (Chiller, Fan, and Pump) for the StandardPerformance Secondary School Building Design for Various HVAC Combinations across 21 Climate Locations (units in kWh) with Ideal Low-Lift Chiller for LLCS Configurations

\begin{tabular}{|c|c|c|c|c|c|c|c|c|c|}
\hline & Case 0 & Case 1 & Case 2 & Case 3 & Case 4 & Case 5 & Case 6 & Case 7 & Case 8 \\
\hline Pendleton, OR & 802,983 & 625,907 & 615,936 & 571,889 & 552,114 & 335,320 & 323,315 & 306,907 & 82,968 \\
\hline Spokane, WA & 702,242 & 573,984 & 567,001 & 541,877 & 527,736 & 298,316 & 289,929 & 282,043 & 65,362 \\
\hline Missoula, MT & 726,628 & 599,930 & 593,768 & 560,348 & 545,636 & 308,195 & 299,983 & 288,322 & 270,527 \\
\hline Boise, ID & 793,361 & 635,932 & 627,997 & 583,625 & 564,530 & 341,849 & 330,839 & 313,153 & 289,666 \\
\hline Pocatello, ID & 728,178 & 600,999 & 594,572 & 558,178 & 543,235 & 318,101 & 309,538 & 295,227 & 276,437 \\
\hline Helena, MT & 732,267 & 603,468 & 596,970 & 566,018 & 551,782 & 307,406 & 298,729 & 287,897 & 269,585 \\
\hline Astoria, OR & 518,700 & 7,647 & 412,305 & 411,354 & 402,264 & 211,671 & 208,103 & ,991 & 204,877 \\
\hline Salem, OR & & & 496,755 & & & & & 639 & 3,919 \\
\hline Eugene, OR & 670,319 & 506,042 & 495,906 & 479,656 & 460,441 & 264,713 & 253,939 & 253,331 & 233,390 \\
\hline North Bend, OR & 484,289 & 400,133 & 396,578 & 395,325 & 387,595 & 200,650 & 197,881 & 199,971 & 196,241 \\
\hline Arcata, CA & 467,536 & 390,046 & 387,301 & 386,292 & 380,793 & 200,996 & 199,566 & 620 & 198,806 \\
\hline Medford, OR & & & 607,926 & 560,996 & 537,293 & 339,227 & 326,134 & 6,555 & 278,308 \\
\hline Redmond, OR & 711,289 & 574,802 & 567,781 & 528,909 & 513,519 & 303,141 & 293,808 & 280,876 & 262,728 \\
\hline Portland, OR & 662,236 & 500,200 & 490,085 & 478,416 & 458,862 & 260,990 & 249,264 & 252,346 & 232,033 \\
\hline Yakima, WA & 744,086 & 575,712 & 565,414 & 541,438 & 520,931 & 309,250 & 295,361 & 291,703 & 264,923 \\
\hline Burns, OR & 712,003 & 575,568 & 568,536 & 529,632 & 514,225 & 303,385 & 294,025 & 281,088 & 262,896 \\
\hline Olympia, WA & 625,336 & 480,949 & 473,036 & 457,545 & 442,267 & 250,416 & 242,186 & 241,256 & 226,879 \\
\hline Quillayuta, WA & 519,483 & 419,933 & 415,431 & 412,643 & 405,619 & 214,224 & 210,885 & 211,447 & 206,457 \\
\hline Seattle, WA & 585,142 & 461,219 & 453,647 & 448,076 & 434,333 & 237,812 & 230,454 & 233,040 & 220,619 \\
\hline Kalispell, MT & 659,825 & 553,735 & 548,667 & 521,960 & 510,367 & 283,389 & 276,877 & 269,110 & 254,914 \\
\hline Cut Bank, MT & 662,458 & 558,709 & 553,387 & 541,288 & 531,066 & 281,167 & 273,689 & 271,821 & 258,033 \\
\hline
\end{tabular}

Table: C-14 Annual Energy Consumption (Chiller, Fan, and Pump) for the High-

Performance Secondary School Building Design for Various HVAC Combinations across 21 Climate Locations (units in kWh) with Ideal Low-Lift Chiller for LLCS Configurations

\begin{tabular}{|c|c|c|c|c|c|c|c|c|c|}
\hline & Case 0 & Case 1 & Case 2 & Case 3 & Case 4 & Case 5 & Case 6 & Case 7 & Case 8 \\
\hline Pendleton, OR & 339,264 & 241,933 & 236,923 & 211,086 & 198,361 & 158,723 & 153,976 & 142,065 & 130,428 \\
\hline Spokane, WA & 280,167 & 13,442 & 209,970 & 191,425 & 183,088 & 139,757 & 136,410 & 128,336 & 120,485 \\
\hline Missoula, MT & 277,278 & 212,041 & 209,299 & 188,472 & 179,925 & 137,193 & 134,524 & 128,003 & 119,901 \\
\hline Boise, ID & 333,867 & & 243,267 & 212,762 & 199,582 & 162,723 & 158,750 & 145,682 & 133,320 \\
\hline Pocatello, ID & 288,739 & 20,852 & 217,683 & 195,636 & 185,423 & 145,212 & 41,995 & 32,633 & 23,512 \\
\hline Helena, MT & 275,933 & 13,147 & 209,900 & 190,706 & 181,969 & 140,801 & 137,811 & 128,466 & 120,691 \\
\hline Astoria, OR & 20,217 & ,393 & 163,585 & 2,433 & 157,894 & 103,520 & 102,434 & 102,548 & 100,938 \\
\hline Salem, OR & 283,981 & 9,590 & 194,540 & 4,225 & 174,274 & 126,370 & 122,451 & 119,997 & 111,981 \\
\hline Eugene, OR & & & 193,054 & & 174,409 & & 946 & 764 & 111,040 \\
\hline North Bend, OR & 208,964 & 165,176 & 163,819 & 162,416 & 158,979 & 100,927 & 100,260 & 100,727 & 99,779 \\
\hline Arcata, CA & 206,736 & 162,059 & 161,335 & 159,058 & 156,589 & 102,301 & 101,626 & 102,056 & 101,135 \\
\hline Medford, OR & 351,444 & 498 & 244,845 & 635 & 198,951 & ,195 & 160 & 145,613 & 994 \\
\hline Redmond, OR & 291,486 & 216,315 & 212,480 & 189,844 & 180,393 & 141,656 & 138,099 & 129,241 & 119,989 \\
\hline Portland, OR & 277,589 & 194,274 & 189,091 & 183,200 & 173,050 & 122,285 & 118,124 & 117,971 & 110,076 \\
\hline Yakima, WA & 307,633 & 218,514 & 213,176 & 199,274 & 187,687 & 139,186 & 133,781 & 131,385 & 120,332 \\
\hline Burns, OR & 291,547 & 216,322 & 212,485 & 189,839 & 180,371 & 141,728 & 138,175 & 129,307 & 120,047 \\
\hline Olympia, WA & 265,439 & & 186,409 & 175,800 & 167,362 & 119,996 & 117,122 & 114,898 & 108,908 \\
\hline Quillayuta, WA & 220,111 & 165,129 & 162,711 & 160,346 & 156,255 & 105,545 & 103,991 & 103,661 & 101,293 \\
\hline Seattle, WA & 238,639 & 176,997 & 172,947 & 170,462 & 163,203 & 111,849 & 109,172 & 109,657 & 105,058 \\
\hline Kalispell, MT & 249,097 & 196,585 & 193,874 & 178,801 & 172,343 & 126,807 & 124,454 & 120,336 & 113,317 \\
\hline Cut Bank, MT & 238,931 & 188,780 & 186,071 & 179,761 & 174,262 & 123,218 & 120,917 & 119,539 & 114,571 \\
\hline
\end{tabular}


Table: C-15 Annual Energy Consumption (Chiller, Fan, and Pump) for the StandardPerformance Hotel Large Building Design for Various HVAC Combinations across 21 Climate Locations (units in kWh) with Ideal Low-Lift Chiller for LLCS Configurations

\begin{tabular}{|c|c|c|c|c|c|c|c|c|c|}
\hline & Case 0 & Case 1 & Case 2 & Case 3 & Case 4 & Case 5 & Case 6 & Case 7 & Case 8 \\
\hline Pendleton, OR & 817,631 & 195,241 & 189,054 & 191,176 & 182,794 & 39,277 & 31,213 & 36,491 & 27,301 \\
\hline Spokane, WA & 750,325 & 190,571 & 185,831 & 186,798 & 180,290 & 32,435 & 26,433 & 29,774 & 22,619 \\
\hline Missoula, MT & 723,289 & 191,673 & 189,485 & 184,492 & 180,741 & 31,663 & 28,744 & 25,813 & 21,463 \\
\hline Boise, ID & 817,242 & 204,283 & 198,892 & 197,683 & 189,248 & 42,513 & 35,459 & 37,751 & 29,302 \\
\hline Pocatello, ID & 760,583 & 194,455 & 190,067 & 190,875 & 183,275 & 32,451 & 26,798 & 29,921 & 22,271 \\
\hline Helena, MT & 752,392 & 190,395 & 186,417 & 186,977 & 180,800 & 29,363 & 23,944 & 27,051 & 20,152 \\
\hline Astoria, OR & 637,206 & 158,017 & 154,122 & 157,196 & 152,293 & 20,557 & 13,850 & 20,010 & 12,759 \\
\hline Salem, OR & 721,969 & 174,694 & 168,785 & 172,435 & 164,656 & 28,944 & & 27,409 & 16,977 \\
\hline Eugene, OR & 722,622 & 173,430 & 167,616 & 171,443 & 163,869 & 28,607 & 19,856 & 27,253 & 16,909 \\
\hline North Bend, OR & 606,181 & 151,257 & 148,022 & 150,376 & 146,154 & 19,355 & 14,124 & 18,849 & 12,830 \\
\hline Arcata, CA & 600,494 & 149,351 & 146,654 & 148,302 & 144,148 & 21,299 & 17,087 & 20,592 & 15,168 \\
\hline Medford, OR & 799,061 & 191,881 & 184,794 & 188,154 & 178,397 & 39,177 & 30,020 & 36,440 & 25,460 \\
\hline Redmond, OR & 751,189 & 184,156 & 179,727 & 181,421 & 174,090 & 28,935 & 23,321 & 27,105 & 19,228 \\
\hline Portland, OR & 727,714 & 175,202 & 168,809 & 173,537 & 165,695 & 29,444 & 19,553 & 28,345 & 17,336 \\
\hline Yakima, WA & 756,522 & 188,420 & 181,543 & 185,834 & 177,099 & 34,870 & 26,241 & 33,135 & 22,751 \\
\hline Burns, OR & 751,228 & 184,171 & 179,743 & 181,428 & 174,104 & 28,940 & 23,325 & 27,109 & 19,231 \\
\hline Olympia, WA & 691,589 & 169,545 & 164,910 & 167,726 & 161,335 & 25,258 & 17,658 & 24,075 & 15,167 \\
\hline Quillayuta, WA & 668,167 & 160,287 & 156,962 & 159,323 & 155,256 & 18,681 & 13,485 & 18,013 & 12,055 \\
\hline Seattle, WA & 683,158 & 169,704 & 164,489 & 168,551 & 162,477 & 24,372 & 16,418 & 23,590 & 14,857 \\
\hline Kalispell, MT & 694,208 & 181,680 & 179,418 & 177,799 & 173,693 & 25,101 & 22,146 & 22,019 & 17,296 \\
\hline Cut Bank, MT & 712,425 & 181,286 & 177,782 & 180,041 & 175,346 & 21,419 & 16,816 & 20,546 & 14,802 \\
\hline
\end{tabular}

Table: C-16 Annual Energy Consumption (Chiller, Fan, and Pump) for the HighPerformance Hotel Large Building Design for Various HVAC Combinations across 21 Climate Locations (units in kWh) with Ideal Low-Lift Chiller for LLCS Configurations

\begin{tabular}{|l|r|r|r|r|r|r|r|r|r|}
\hline & Case 0 & Case 1 & Case 2 & Case 3 & Case 4 & Case 5 & Case 6 & Case 7 & Case 8 \\
\hline Pendleton, OR & 301,508 & 67,681 & 64,316 & 65,916 & 60,428 & 18,069 & 13,735 & 16,852 & 11,171 \\
\hline Spokane, WA & 258,425 & 63,686 & 61,391 & 61,741 & 57,787 & 14,072 & 11,194 & 12,741 & 8,640 \\
\hline Missoula, MT & 254,875 & 60,678 & 58,993 & 59,118 & 55,403 & 11,779 & 9,496 & 10,696 & 6,612 \\
\hline Boise, ID & 293,244 & 69,615 & 66,359 & 67,254 & 61,368 & 18,829 & 14,697 & 17,242 & 11,485 \\
\hline Pocatello, ID & 260,633 & 64,229 & 61,862 & 62,636 & 57,717 & 14,108 & 11,102 & 13,012 & 8,010 \\
\hline Helena, MT & 256,147 & 62,061 & 60,120 & 60,111 & 56,434 & 12,536 & 9,904 & 11,208 & 7,177 \\
\hline Astoria, OR & 228,125 & 54,555 & 53,173 & 52,944 & 51,166 & 7,994 & 5,704 & 7,392 & 4,344 \\
\hline Salem, OR & 266,417 & 61,346 & 59,099 & 58,808 & 54,556 & 13,513 & 10,413 & 11,730 & 6,716 \\
\hline Eugene, OR & 266,489 & 60,804 & 58,645 & 58,608 & 54,410 & 13,255 & 10,243 & 11,807 & 6,675 \\
\hline North Bend, OR & 220,633 & 53,671 & 52,727 & 51,880 & 50,667 & 7,401 & 6,084 & 6,516 & 4,252 \\
\hline Arcata, CA & 229,053 & 52,976 & 51,931 & 51,563 & 50,077 & 6,859 & 5,271 & 6,357 & 3,910 \\
\hline Medford, OR & 303,217 & 68,240 & 65,176 & 65,288 & 59,773 & 18,771 & 14,824 & 16,823 & 10,704 \\
\hline Redmond, OR & 265,025 & 61,965 & 59,827 & 60,379 & 55,829 & 12,734 & 10,050 & 11,649 & 6,890 \\
\hline Portland, OR & 268,494 & 61,225 & 58,726 & 59,260 & 55,003 & 13,594 & 9,974 & 12,392 & 7,335 \\
\hline Yakima, WA & 274,075 & 65,724 & 62,790 & 63,747 & 58,391 & 16,510 & 12,786 & 15,194 & 9,652 \\
\hline Burns, OR & 265,025 & 61,966 & 59,827 & 60,379 & 55,829 & 12,734 & 10,049 & 11,647 & 6,889 \\
\hline Olympia, WA & 250,975 & 58,777 & 57,087 & 56,489 & 53,247 & 11,292 & 8,683 & 9,877 & 5,787 \\
\hline Quillayuta, WA & 240,942 & 53,713 & 52,436 & 52,143 & 50,567 & 6,831 & 5,030 & 6,191 & 3,477 \\
\hline Seattle, WA & 242,664 & 57,577 & 55,570 & 55,886 & 53,279 & 10,400 & 7,652 & 9,529 & 5,793 \\
\hline Kalispell, MT & 233,550 & 57,967 & 56,424 & 56,711 & 53,728 & 9,544 & 7,551 & 8,691 & 5,243 \\
\hline Cut Bank, MT & 228,033 & 57,073 & 55,500 & 56,166 & 53,514 & 8,286 & 6,241 & 7,740 & 4,612 \\
\hline
\end{tabular}


Table: C-17 Annual Energy Consumption (Chiller, Fan, and Pump) for the StandardPerformance Supermarket Building Design for Various HVAC Combinations across 21 Climate Locations (units in kWh) with Ideal Low-Lift Chiller for LLCS Configurations

\begin{tabular}{|c|c|c|c|c|c|c|c|c|c|}
\hline & Case 0 & Case 1 & Case 2 & Case 3 & Case 4 & Case 5 & Case 6 & Case 7 & Case : \\
\hline Pendleton, OR & 202,942 & 186,574 & 184,747 & 183,393 & 179,233 & 65,278 & 62,260 & 63,118 & 57,892 \\
\hline Spokane, WA & 200,614 & 188,304 & 187,108 & 185,559 & 183,074 & 62,181 & 59,991 & 60,320 & 56,956 \\
\hline Missoula, MT & 235,408 & 222,354 & 221,308 & 219,816 & 216,958 & 62,176 & 60,158 & 60,908 & 57,088 \\
\hline Boise, ID & 211,431 & 194,698 & 192,992 & 191,497 & 187,174 & 65,338 & 62,556 & 63,328 & 58,208 \\
\hline Pocatello, ID & 261,675 & 247,016 & 245,739 & 243,711 & 240,121 & 64,189 & 61,867 & 62,379 & 57,629 \\
\hline Helena, MT & 269,236 & 256,411 & 255,429 & 253,982 & 251,508 & 62,643 & 60,551 & 61,266 & 57,621 \\
\hline Astoria, OR & 152,547 & 145,894 & 145,737 & 145,698 & 145,401 & 54,681 & 53,384 & 54,507 & 52,933 \\
\hline Salem, OR & 175,083 & 161,481 & 160,309 & 159,864 & 157,148 & 59,555 & 57,021 & 58,497 & 54,700 \\
\hline Eugene, OR & 173,656 & 160,217 & 159,010 & 158,731 & 156,000 & 59,362 & 56,780 & 58,390 & 54,718 \\
\hline North Bend, & 149,531 & 143,453 & 143,372 & 143,344 & 143,183 & 54,407 & 53,355 & 54,259 & 52,826 \\
\hline Arcata, CA & 148,997 & 143,610 & 143,587 & 143,475 & 143,410 & 54,042 & 53,081 & 53,907 & 52,702 \\
\hline Medford, OR & 194,706 & 175,581 & 173,706 & 169,922 & 165,365 & 66,932 & 63,838 & 63,504 & 57,646 \\
\hline Redmond, OR & 202,653 & 190,154 & 188,942 & 187,847 & 185,020 & 61,701 & 59,401 & 60,267 & 56,318 \\
\hline Portland, OR & 171,717 & 159,383 & 158,247 & 158,302 & 156,056 & 58,758 & 56,136 & 58,053 & 54,486 \\
\hline Yakima, WA & 197,844 & 181,429 & 179,750 & 178,533 & 175,120 & 63,649 & 60,720 & 61,941 & 57,289 \\
\hline Burns, OR & 203,028 & 190,549 & 189,333 & 188,226 & 185,390 & 61,756 & 59,448 & 60,338 & 56,348 \\
\hline Olympia, WA & 174,017 & 162,337 & 161,581 & 160,530 & 158,748 & 58,410 & 56,369 & 57,428 & 54,314 \\
\hline Quillayuta, WA & 156,289 & 149,826 & 149,639 & 149,625 & 149,275 & 54,593 & 53,412 & 54,391 & 52,970 \\
\hline Seattle, WA & 162,047 & 152,615 & 151,971 & 151,853 & 150,827 & 56,543 & 54,659 & 56,004 & 53,636 \\
\hline Kalispell, MT & 232,578 & 221,455 & 220,669 & 219,384 & 217,768 & 60,330 & 58,556 & 59,407 & 56,443 \\
\hline Cut Bank, MT & 266,031 & 256,543 & 255,940 & 255,613 & 254,188 & 59,644 & 57,923 & 59,038 & 56,582 \\
\hline
\end{tabular}

Table: C-18 Annual Energy Consumption (Chiller, Fan, and Pump) for the HighPerformance Supermarket Building Design for Various HVAC Combinations across 21 Climate Locations (units in kWh) with Ideal Low-Lift Chiller for LLCS Configurations

\begin{tabular}{|l|r|r|r|r|r|r|r|r|r|}
\hline & Case 0 & Case 1 & Case 2 & Case 3 & Case 4 & Case 5 & Case 6 & Case 7 & Case 8 \\
\hline Pendleton, OR & 76,131 & 67,888 & 67,315 & 66,190 & 65,458 & 34,553 & 33,913 & 33,955 & 32,426 \\
\hline Spokane, WA & 76,214 & 69,534 & 69,287 & 67,942 & 67,675 & 33,841 & 33,543 & 33,002 & 32,236 \\
\hline Missoula, MT & 78,386 & 71,506 & 71,296 & 70,025 & 69,816 & 33,740 & 33,483 & 32,979 & 32,331 \\
\hline Boise, ID & 79,222 & 71,144 & 70,704 & 69,060 & 68,548 & 34,810 & 34,318 & 33,990 & 32,581 \\
\hline Pocatello, ID & 80,311 & 73,107 & 72,854 & 71,296 & 71,035 & 34,128 & 33,826 & 33,101 & 32,396 \\
\hline Helena, MT & 82,817 & 76,223 & 76,048 & 75,016 & 74,798 & 33,741 & 33,512 & 33,128 & 32,520 \\
\hline Astoria, OR & 60,808 & 55,745 & 55,737 & 55,657 & 55,641 & 31,180 & 31,151 & 31,133 & 31,078 \\
\hline Salem, OR & 67,164 & 60,289 & 59,987 & 59,169 & 58,952 & 32,608 & 32,214 & 32,330 & 31,466 \\
\hline Eugene, OR & 66,817 & 59,924 & 59,616 & 58,846 & 58,593 & 32,579 & 32,186 & 32,293 & 31,416 \\
\hline North Bend, OR & 58,406 & 53,463 & 53,463 & 53,443 & 53,441 & 31,084 & 31,071 & 31,071 & 31,052 \\
\hline Arcata, CA & 58,503 & 53,550 & 53,556 & 53,511 & 53,509 & 31,086 & 31,081 & 31,065 & 31,056 \\
\hline Medford, OR & 73,189 & 64,467 & 63,832 & 61,269 & 60,729 & 35,583 & 34,866 & 34,222 & 32,485 \\
\hline Redmond, OR & 76,628 & 69,857 & 69,614 & 68,449 & 68,254 & 33,328 & 33,037 & 32,597 & 31,960 \\
\hline Portland, OR & 65,922 & 59,341 & 59,081 & 58,666 & 58,341 & 32,294 & 31,935 & 32,122 & 31,389 \\
\hline Yakima, WA & 74,417 & 66,637 & 66,143 & 65,008 & 64,485 & 34,028 & 33,444 & 33,370 & 32,196 \\
\hline Burns, OR & 76,792 & 69,960 & 69,715 & 68,534 & 68,345 & 33,352 & 33,058 & 32,620 & 31,974 \\
\hline Olympia, WA & 67,125 & 60,893 & 60,771 & 59,860 & 59,728 & 32,374 & 32,189 & 31,840 & 31,423 \\
\hline Quillayuta, WA & 62,506 & 57,423 & 57,408 & 57,329 & 57,310 & 31,210 & 31,177 & 31,152 & 31,094 \\
\hline Seattle, WA & 63,847 & 58,263 & 58,170 & 57,809 & 57,697 & 31,740 & 31,605 & 31,524 & 31,216 \\
\hline Kalispell, MT & 77,472 & 71,203 & 71,057 & 70,222 & 70,070 & 33,092 & 32,897 & 32,547 & 32,119 \\
\hline Cut Bank, MT & 82,067 & 76,294 & 76,209 & 75,811 & 75,717 & 32,821 & 32,691 & 32,586 & 32,283 \\
\hline
\end{tabular}


Table: C-19 Annual Energy Consumption (Chiller, Fan, and Pump) for the StandardPerformance Warehouse Building Design for Various HVAC Combinations across 21 Climate Locations (units in kWh) with Ideal Low-Lift Chiller for LLCS Configurations

\begin{tabular}{|l|r|r|r|r|r|r|r|r|r|}
\hline & Case 0 & Case 1 & Case 2 & Case 3 & Case 4 & Case 5 & Case 6 & Case 7 & Case 8 \\
\hline Pendleton, OR & 7,228 & 6,440 & 6,338 & 5,846 & 5,713 & 2,664 & 2,461 & 2,221 & 1,903 \\
\hline Spokane, WA & 6,656 & 6,191 & 6,121 & 5,746 & 5,655 & 2,435 & 2,277 & 2,087 & 1,850 \\
\hline Missoula, MT & 7,256 & 6,737 & 6,677 & 6,345 & 6,266 & 2,231 & 2,098 & 1,956 & 1,743 \\
\hline Boise, ID & 7,269 & 6,649 & 6,544 & 5,949 & 5,828 & 2,708 & 2,524 & 2,210 & 1,921 \\
\hline Pocatello, ID & 7,261 & 6,710 & 6,634 & 6,240 & 6,140 & 2,445 & 2,285 & 2,090 & 1,838 \\
\hline Helena, MT & 7,183 & 6,773 & 6,713 & 6,351 & 6,281 & 2,246 & 2,108 & 1,960 & 1,752 \\
\hline Astoria, OR & 3,794 & 3,714 & 3,701 & 3,675 & 3,662 & 1,955 & 1,862 & 1,883 & 1,783 \\
\hline Salem, OR & 5,922 & 5,432 & 5,358 & 5,008 & 4,937 & 2,278 & 2,127 & 2,033 & 1,843 \\
\hline Eugene, OR & 5,903 & 5,338 & 5,269 & 4,968 & 4,894 & 2,242 & 2,098 & 2,023 & 1,830 \\
\hline North Bend, OR & 3,617 & 3,563 & 3,556 & 3,545 & 3,538 & 1,950 & 1,879 & 1,878 & 1,788 \\
\hline Arcata, CA & 3,583 & 3,567 & 3,564 & 3,545 & 3,540 & 1,755 & 1,658 & 1,669 & 1,548 \\
\hline Medford, OR & 7,797 & 6,803 & 6,698 & 6,007 & 5,860 & 2,855 & 2,647 & 2,285 & 1,938 \\
\hline Redmond, OR & 6,461 & 5,909 & 5,833 & 5,486 & 5,393 & 2,424 & 2,246 & 2,096 & 1,830 \\
\hline Portland, OR & 5,658 & 5,195 & 5,125 & 4,903 & 4,834 & 2,168 & 2,022 & 1,994 & 1,817 \\
\hline Yakima, WA & 6,794 & 6,113 & 6,015 & 5,627 & 5,512 & 2,479 & 2,278 & 2,145 & 1,844 \\
\hline Burns, OR & 6,525 & 5,985 & 5,909 & 5,559 & 5,465 & 2,432 & 2,253 & 2,106 & 1,832 \\
\hline Olympia, WA & 5,264 & 4,835 & 4,788 & 4,550 & 4,494 & 2,136 & 2,016 & 1,965 & 1,815 \\
\hline Quillayuta, WA & 3,989 & 3,880 & 3,862 & 3,830 & 3,815 & 1,953 & 1,863 & 1,878 & 1,782 \\
\hline Seattle, WA & 4,797 & 4,488 & 4,446 & 4,370 & 4,326 & 2,043 & 1,915 & 1,944 & 1,796 \\
\hline Kalispell, MT & 7,008 & 6,609 & 6,560 & 6,388 & 6,325 & 2,061 & 1,929 & 1,889 & 1,700 \\
\hline Cut Bank, MT & 8,444 & 8,164 & 8,123 & 8,010 & 7,964 & 2,004 & 1,871 & 1,869 & 1,693 \\
\hline
\end{tabular}

Table: C-20 Annual Energy Consumption (Chiller, Fan, and Pump) for the HighPerformance Warehouse Building Design for Various HVAC Combinations across 21 Climate Locations (units in kWh) with Ideal Low-Lift Chiller for LLCS Configurations

\begin{tabular}{|c|c|c|c|c|c|c|c|c|c|}
\hline & Case 0 & Case 1 & Case 2 & Case 3 & Case 4 & Case 5 & Case 6 & Case 7 & Case 8 \\
\hline Pendleton, OR & 1,350 & 1,240 & 1,216 & 1,086 & 1,066 & 1,147 & 1,136 & 1,028 & 995 \\
\hline Spokane, WA & 1,267 & 1,199 & 1,167 & 1,079 & 1,065 & 1,105 & 1,098 & 1,012 & 987 \\
\hline Missoula, MT & 1,353 & 1,246 & 1,241 & 1,173 & 1,161 & 1,019 & 1,012 & 978 & 958 \\
\hline Boise, ID & 1,297 & 1,267 & 1,221 & 1,087 & 1,070 & 1,150 & 1,142 & 1,020 & 993 \\
\hline Pocatello, ID & 1,286 & 1,200 & 1,179 & 1,091 & 1,077 & 1,089 & 1,082 & 1,008 & 982 \\
\hline Helena, MT & 1,222 & 1,149 & 1,145 & 1,074 & 1,063 & 1,019 & 1,012 & 979 & 960 \\
\hline Astoria, OR & 975 & 950 & 949 & 940 & 938 & 1,055 & 1,050 & 1,048 & 1,042 \\
\hline Salem, OR & 1,219 & 1,136 & 1,117 & 1,036 & 1,024 & 1,105 & 1,096 & 1,065 & 1,049 \\
\hline Eugene, OR & 1,222 & 1,128 & 1,126 & 1,035 & 1,022 & 1,103 & 1,094 & 1,063 & 1,048 \\
\hline North Bend, OR & 936 & 937 & 936 & 935 & 934 & 1,051 & 1,047 & 1,046 & 1,041 \\
\hline Arcata, CA & 928 & 938 & 937 & 935 & 934 & 869 & 868 & 868 & 866 \\
\hline Medford, OR & 1,461 & 1,397 & 1,275 & 1,104 & 1,084 & 1,234 & 1,222 & 1,036 & 1,002 \\
\hline Redmond, OR & 1,242 & 1,149 & 1,142 & 1,065 & 1,050 & 1,068 & 1,059 & 1,007 & 978 \\
\hline Portland, OR & 1,186 & 1,066 & 1,060 & 1,003 & 993 & 1,081 & 1,072 & 1,061 & 1,046 \\
\hline Yakima, WA & 1,289 & 1,161 & 1,153 & 1,069 & 1,052 & 1,049 & 1,036 & 1,003 & 973 \\
\hline Burns, OR & 1,250 & 1,151 & 1,144 & 1,065 & 1,051 & 1,071 & 1,062 & 1,008 & 979 \\
\hline Olympia, WA & 1,153 & 1,052 & 1,049 & 992 & 983 & 1,076 & 1,069 & 1,057 & 1,045 \\
\hline Quillayuta, WA & 981 & 948 & 947 & 938 & 936 & 1,055 & 1,051 & 1,048 & 1,042 \\
\hline Seattle, WA & 1,078 & 1,012 & 1,008 & 983 & 976 & 1,065 & 1,058 & 1,053 & 1,043 \\
\hline Kalispell, MT & 1,361 & 1,267 & 1,263 & 1,220 & 1,210 & 995 & 989 & 970 & 952 \\
\hline Cut Bank, MT & 1,817 & 1,770 & 1,767 & 1,738 & 1,732 & 984 & 979 & 965 & 952 \\
\hline
\end{tabular}


Table: C-21 Annual Energy Consumption (Chiller, Fan, and Pump) for the StandardPerformance Outpatient Health Care Building Design for Various HVAC Combinations across 21 Climate Locations (units in kWh) with Ideal Low-Lift Chiller for LLCS Configurations

\begin{tabular}{|l|r|r|r|r|r|r|r|r|r|}
\hline & Case 0 & Case 1 & Case 2 & Case 3 & Case 4 & Case 5 & Case 6 & Case 7 & Case 8 \\
\hline Pendleton, OR & 42,047 & 38,444 & 38,157 & 36,549 & 36,067 & 9,138 & 8,351 & 8,204 & 6,706 \\
\hline Spokane, WA & 39,017 & 36,620 & 36,430 & 35,199 & 34,908 & 7,839 & 7,280 & 7,100 & 6,008 \\
\hline Missoula, MT & 38,314 & 35,923 & 35,772 & 34,418 & 34,190 & 7,349 & 6,863 & 6,433 & 5,584 \\
\hline Boise, ID & 42,939 & 39,392 & 39,129 & 37,378 & 36,966 & 9,153 & 8,411 & 8,068 & 6,753 \\
\hline Pocatello, ID & 40,842 & 38,002 & 37,803 & 36,215 & 35,927 & 8,077 & 7,471 & 6,989 & 5,923 \\
\hline Helena, MT & 38,578 & 36,332 & 36,177 & 35,046 & 34,792 & 7,428 & 6,876 & 6,726 & 5,700 \\
\hline Astoria, OR & 27,869 & 27,391 & 27,359 & 27,277 & 27,214 & 5,335 & 5,002 & 5,252 & 4,701 \\
\hline Salem, OR & 37,047 & 34,749 & 34,570 & 33,481 & 33,201 & 7,074 & 6,461 & 6,455 & 5,282 \\
\hline Eugene, OR & 37,042 & 34,683 & 34,501 & 33,393 & 33,124 & 7,093 & 6,478 & 6,520 & 5,302 \\
\hline North Bend, OR & 25,064 & 24,876 & 24,861 & 24,840 & 24,813 & 5,209 & 4,922 & 5,150 & 4,648 \\
\hline Arcata, CA & 24,367 & 24,248 & 24,244 & 24,204 & 24,190 & 4,920 & 4,726 & 4,882 & 4,579 \\
\hline Medford, OR & 42,181 & 38,487 & 38,210 & 35,980 & 35,593 & 9,073 & 8,339 & 7,641 & 6,309 \\
\hline Redmond, OR & 38,661 & 36,369 & 36,192 & 34,775 & 34,544 & 7,728 & 7,167 & 6,697 & 5,614 \\
\hline Portland, OR & 36,592 & 34,271 & 34,073 & 33,311 & 32,961 & 7,015 & 6,328 & 6,695 & 5,343 \\
\hline Yakima, WA & 39,597 & 36,480 & 36,234 & 34,711 & 34,381 & 8,290 & 7,596 & 7,400 & 6,011 \\
\hline Burns, OR & 38,728 & 36,376 & 36,198 & 34,775 & 34,547 & 7,737 & 7,175 & 6,702 & 5,618 \\
\hline Olympia, WA & 34,436 & 32,630 & 32,502 & 31,649 & 31,466 & 6,477 & 5,976 & 5,978 & 5,093 \\
\hline Quillayuta, WA & 29,267 & 28,903 & 28,874 & 28,748 & 28,704 & 5,230 & 4,959 & 5,126 & 4,658 \\
\hline Seattle, WA & 33,314 & 31,983 & 31,868 & 31,497 & 31,259 & 6,232 & 5,710 & 6,034 & 5,033 \\
\hline Kalispell, MT & 36,167 & 34,398 & 34,288 & 33,321 & 33,144 & 6,639 & 6,216 & 6,029 & 5,197 \\
\hline Cut Bank, MT & 35,486 & 34,272 & 34,174 & 33,611 & 33,457 & 6,394 & 5,935 & 6,030 & 5,115 \\
\hline
\end{tabular}


Table: C-22 Annual Energy Consumption (Chiller, Fan, and Pump) for the HighPerformance Outpatient Health Care Building Design for Various HVAC Combinations across 21 Climate Locations (units in kWh) with Ideal Low-Lift Chiller for LLCS Configurations

\begin{tabular}{|l|r|r|r|r|r|r|r|r|r|}
\hline & Case 0 & Case 1 & Case 2 & Case 3 & Case 4 & Case 5 & Case 6 & Case 7 & Case 8 \\
\hline Pendleton, OR & 9,697 & 8,365 & 8,198 & 7,762 & 7,611 & 3,736 & 3,538 & 3,373 & 3,088 \\
\hline Spokane, WA & 8,469 & 7,656 & 7,561 & 7,231 & 7,143 & 3,392 & 3,266 & 3,110 & 2,934 \\
\hline Missoula, MT & 8,322 & 7,548 & 7,454 & 7,153 & 7,089 & 3,184 & 3,079 & 2,945 & 2,807 \\
\hline Boise, ID & 9,828 & 8,485 & 8,339 & 7,858 & 7,716 & 3,763 & 3,589 & 3,371 & 3,108 \\
\hline Pocatello, ID & 8,989 & 8,074 & 7,960 & 7,583 & 7,503 & 3,364 & 3,227 & 3,047 & 2,871 \\
\hline Helena, MT & 8,656 & 7,972 & 7,891 & 7,630 & 7,557 & 3,190 & 3,087 & 2,981 & 2,833 \\
\hline Astoria, OR & 5,231 & 5,191 & 5,186 & 5,177 & 5,172 & 2,700 & 2,692 & 2,694 & 2,685 \\
\hline Salem, OR & 7,897 & 7,243 & 7,154 & 6,926 & 6,862 & 3,046 & 2,940 & 2,876 & 2,755 \\
\hline Eugene, OR & 7,886 & 7,159 & 7,065 & 6,848 & 6,777 & 3,057 & 2,942 & 2,886 & 2,759 \\
\hline North Bend, OR & 4,583 & 4,557 & 4,556 & 4,556 & 4,555 & 2,684 & 2,684 & 2,684 & 2,683 \\
\hline Arcata, CA & 4,433 & 4,384 & 4,384 & 4,381 & 4,381 & 2,685 & 2,684 & 2,684 & 2,683 \\
\hline Medford, OR & 9,969 & 8,462 & 8,295 & 7,661 & 7,538 & 3,735 & 3,547 & 3,241 & 3,010 \\
\hline Redmond, OR & 8,131 & 7,444 & 7,349 & 7,052 & 6,992 & 3,210 & 3,092 & 2,946 & 2,810 \\
\hline Portland, OR & 7,733 & 7,105 & 7,022 & 6,854 & 6,783 & 3,021 & 2,910 & 2,902 & 2,758 \\
\hline Yakima, WA & 8,869 & 7,749 & 7,605 & 7,244 & 7,138 & 3,381 & 3,213 & 3,097 & 2,888 \\
\hline Burns, OR & 8,158 & 7,448 & 7,353 & 7,054 & 6,993 & 3,214 & 3,096 & 2,949 & 2,811 \\
\hline Olympia, WA & 7,128 & 6,585 & 6,533 & 6,348 & 6,306 & 2,947 & 2,879 & 2,821 & 2,743 \\
\hline Quillayuta, WA & 5,631 & 5,551 & 5,543 & 5,530 & 5,524 & 2,707 & 2,698 & 2,695 & 2,685 \\
\hline Seattle, WA & 6,664 & 6,334 & 6,298 & 6,222 & 6,185 & 2,838 & 2,786 & 2,790 & 2,713 \\
\hline Kalispell, MT & 7,719 & 7,278 & 7,214 & 7,043 & 6,998 & 2,962 & 2,890 & 2,824 & 2,735 \\
\hline Cut Bank, MT & 7,742 & 7,486 & 7,447 & 7,355 & 7,325 & 2,865 & 2,813 & 2,784 & 2,720 \\
\hline
\end{tabular}

Table: C-23 Annual Energy Consumption (Chiller, Fan, and Pump) for the StandardPerformance Hospital Building Design for Various HVAC Combinations across 21 Climate Locations (units in kWh) with Ideal Low-Lift Chiller for LLCS Configurations

\begin{tabular}{|c|c|c|c|c|c|c|c|c|c|}
\hline & Case o & Case 1 & Case 2 & Case 3 & Case 4 & Case 5 & Case 6 & Case 7 & Case 8 \\
\hline Pendleton, OR & 324,258 & 117,002 & $1,095,915$ & ,091,836 & \begin{tabular}{|l|}
$1,065,449$ \\
\end{tabular} & 440,702 & 380,735 & & \\
\hline lokane, WA & & & & & & & & & \\
\hline & & & & & & & & & \\
\hline & & & & & & & & & \\
\hline & & & & & & & & & \\
\hline & & & $1,176,173$ & & & & & & \\
\hline & & & 778 & & & & 851 & & 889 \\
\hline & & & & & & 644 & 944 & & 936 \\
\hline & & & & & & 841 & & & 935 \\
\hline & & & & & & & & & 236 \\
\hline & & & 969 & 701 & & 230 & 366 & 123 & 132 \\
\hline & & & 1,07 & 957 & 1,04 & 389 & 235 & & 510 \\
\hline & & & 1,08 & 405 & 1,05 & & 142 & 764 & 907 \\
\hline Portl & & & & & & 426 & 346 & 405 & 034 \\
\hline & & & & & & & & & \\
\hline & & & 1,08 & & & & & 865 & \\
\hline & & & & & & & & 217 & \\
\hline & & & 880,628 & & & 762 & 5,849 & 173 & 9,561 \\
\hline & & & & 942,645 & & & 7,623 & , 398 & 70,608 \\
\hline & & $1,041,423$ & $1,028,530$ & $1,023,513$ & $1,004,513$ & 349,754 & 300,487 & 336,926 & 79,598 \\
\hline & $1,234,131$ & $1,106,299$ & | כנו, דנט, & $1,091,046$ & $1,074,014$ & 364,292 & 322,115 & 348,025 & 300,339 \\
\hline
\end{tabular}


Table: C-24 Annual Energy Consumption (Chiller, Fan, and Pump) for the HighPerformance Hospital Building Design for Various HVAC Combinations across 21 Climate Locations (units in kWh) with Ideal Low-Lift Chiller for LLCS Configurations

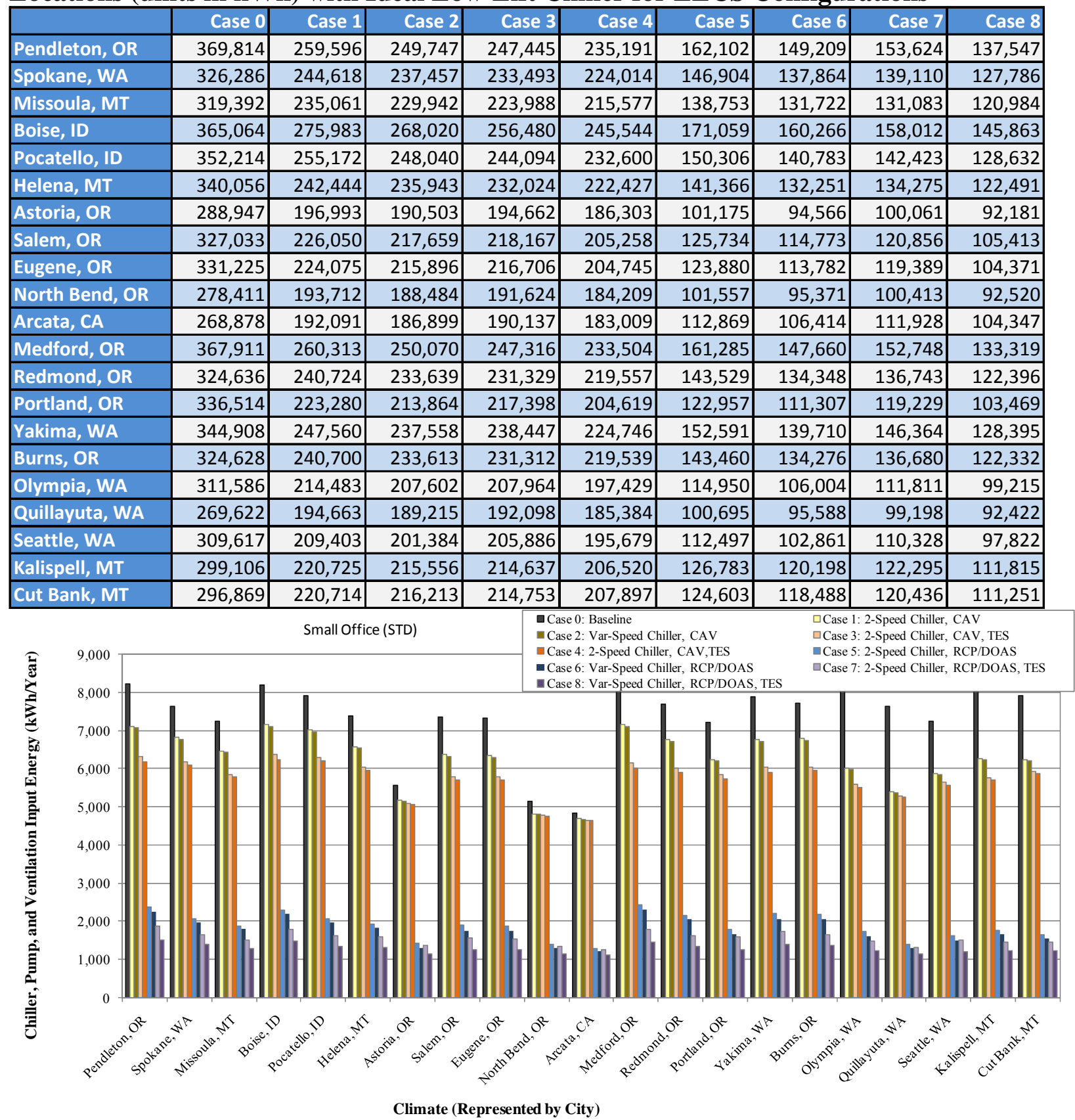

Figure: C-1 Comparison of Annual Chiller and Distribution Energy Consumption for Standard-Performance Small Office Building for Various System Configurations in 21 Locations with Ideal Low-Lift Chiller for the LLCS Configurations 


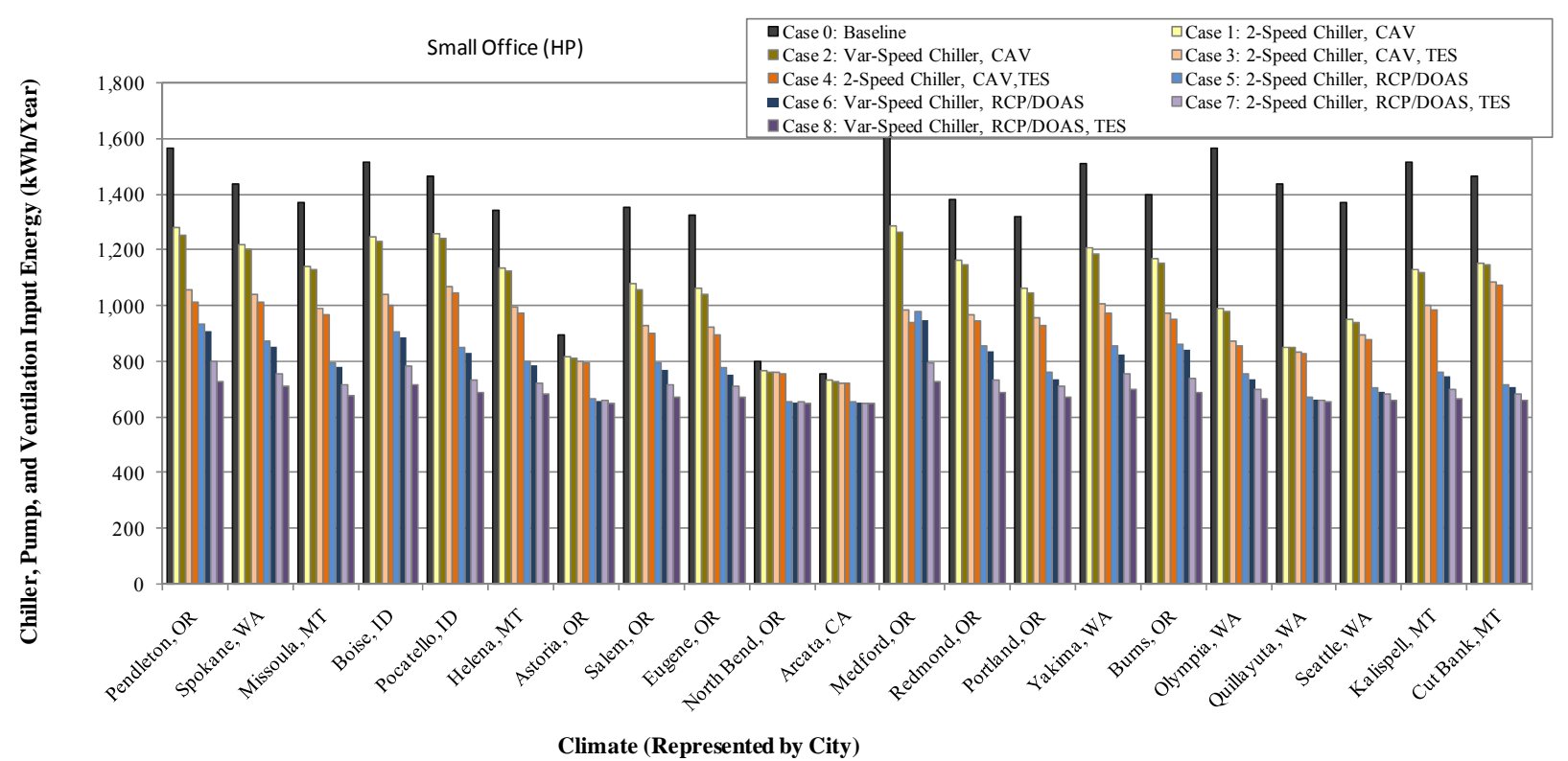

Figure: C-2 Comparison of Annual Chiller and Distribution Energy Consumption for High-Performance Small Office Building for Various System Configurations in 21 Locations with Ideal Low-Lift Chiller for the LLCS Configurations

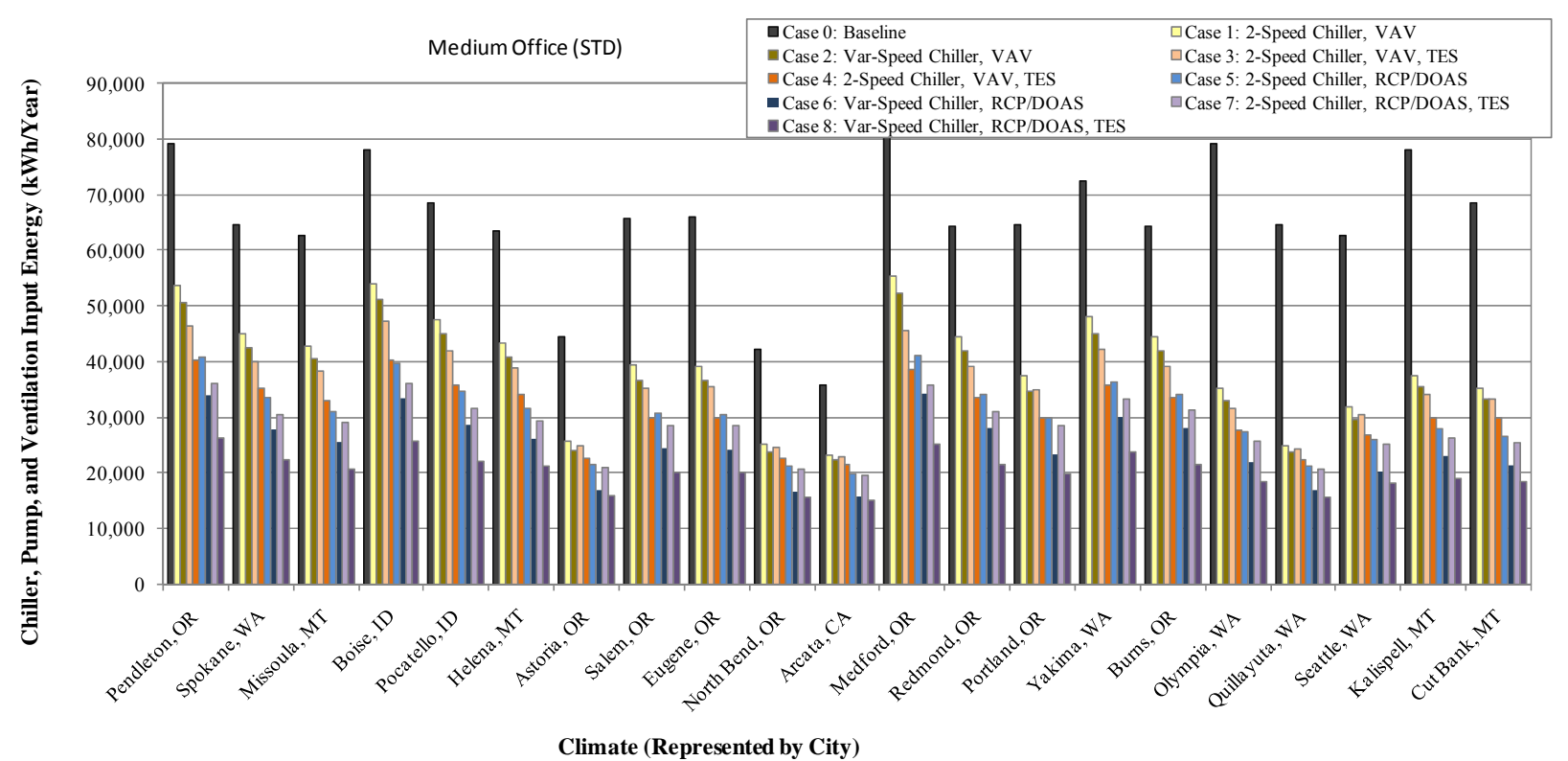

Figure: C-3 Comparison of Annual Chiller and Distribution Energy Consumption for Standard-Performance Medium Office Building for Various System Configurations in 21 Locations with Ideal Low-Lift Chiller for the LLCS Configurations 


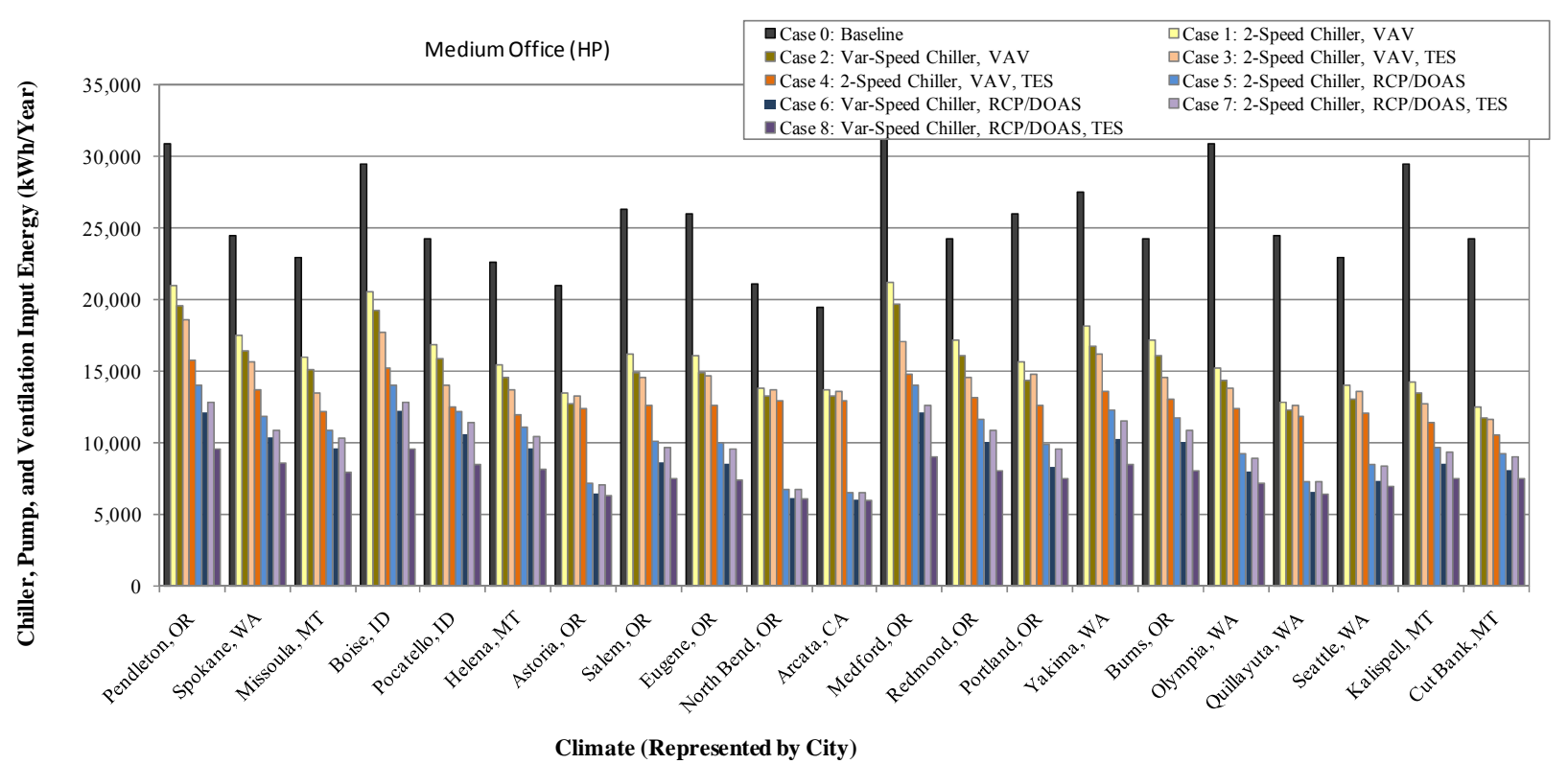

Figure: C-4 Comparison of Annual Chiller and Distribution Energy Consumption for High-Performance Medium Office Building for Various System Configurations in 16 Locations with Ideal Low-Lift Chiller for the LLCS Configurations

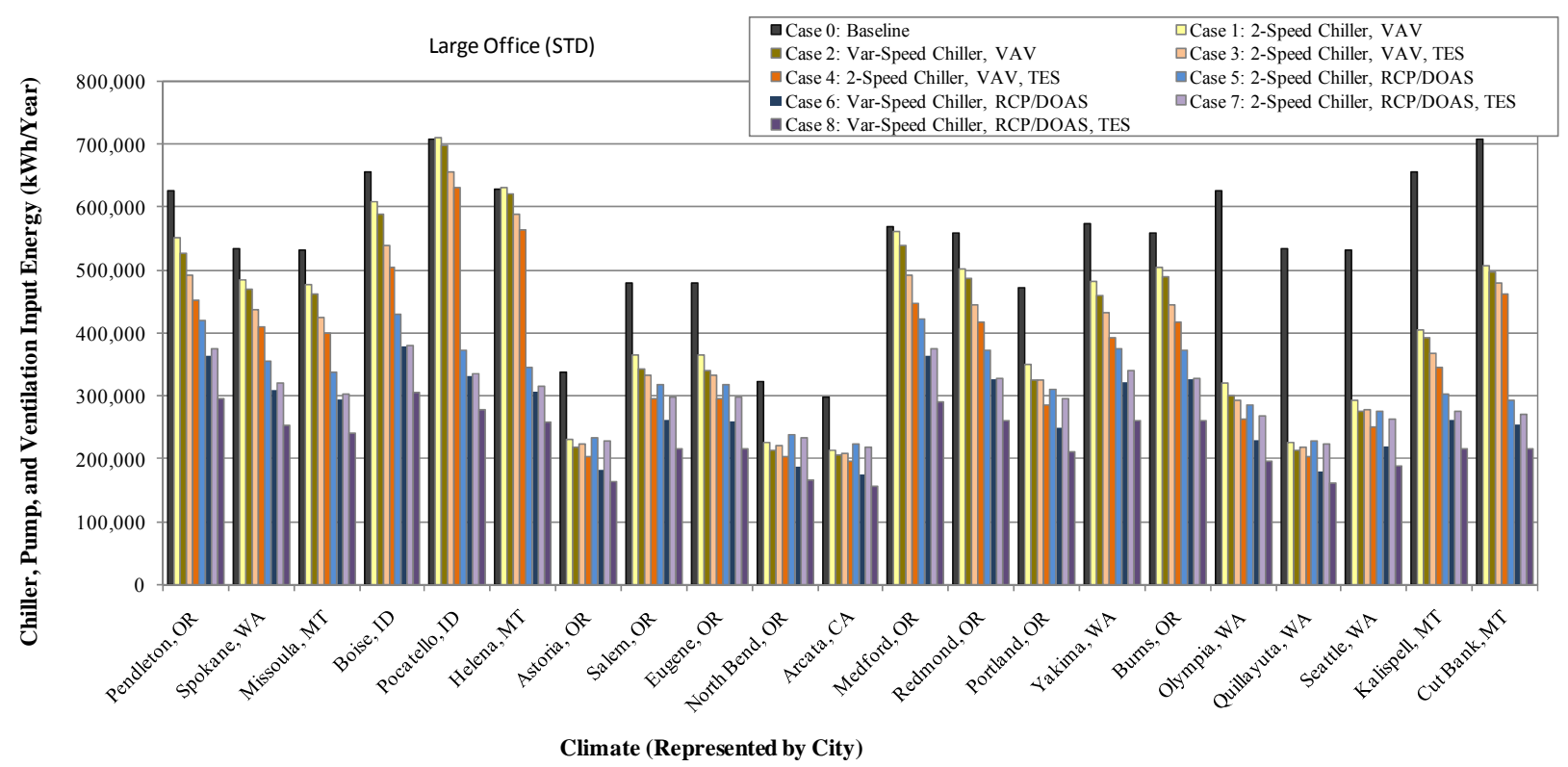

Figure: C-5 Comparison of Annual Chiller and Distribution Energy Consumption for Standard-Performance Large Office Building for Various System Configurations in 21 Locations with Ideal Low-Lift Chiller for the LLCS Configurations 


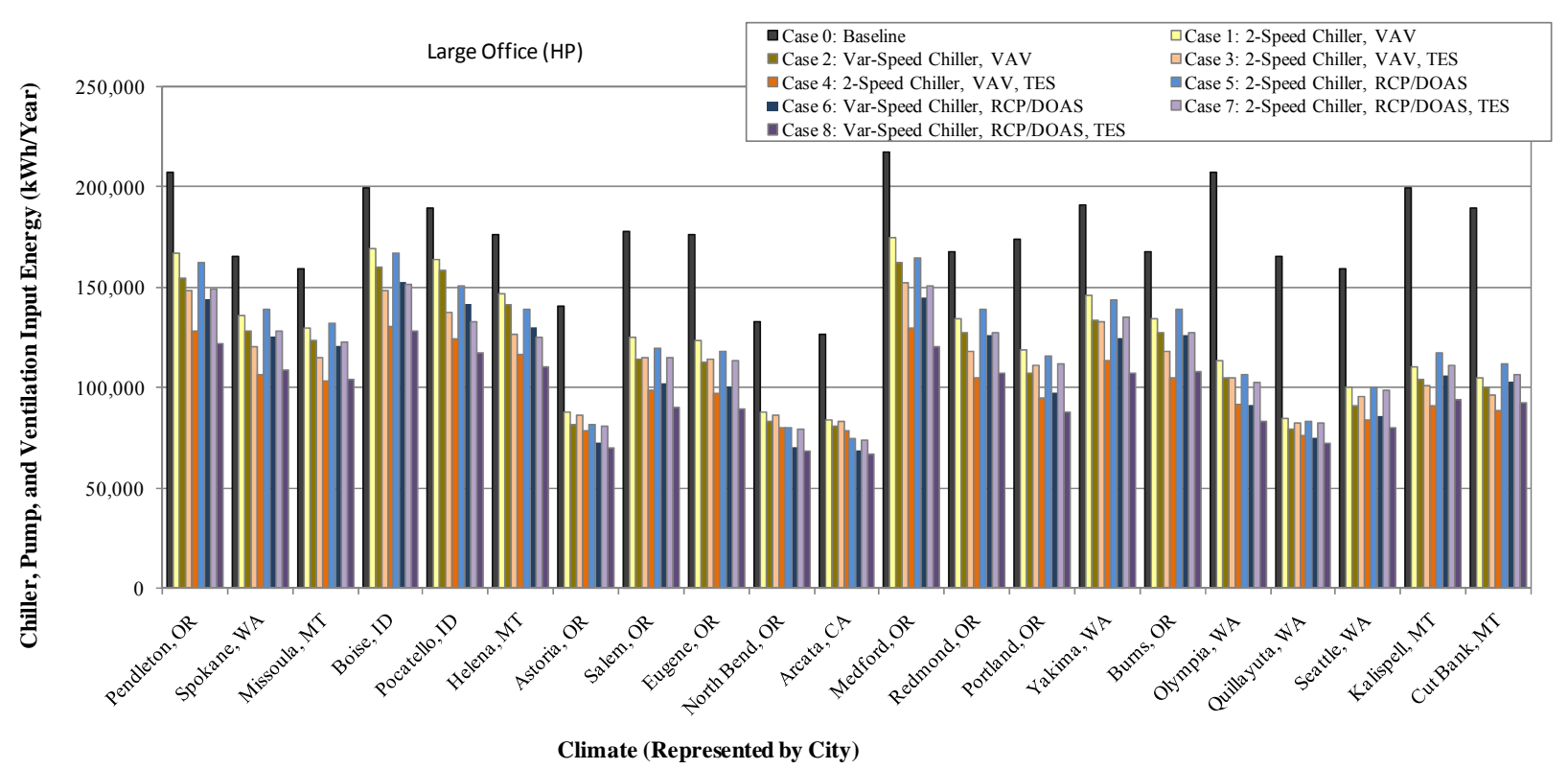

Figure: C-6 Comparison of Annual Chiller and Distribution Energy Consumption for High-Performance Large Office Building for Various System Configurations in 21 Locations with Ideal Low-Lift Chiller for the LLCS Configurations

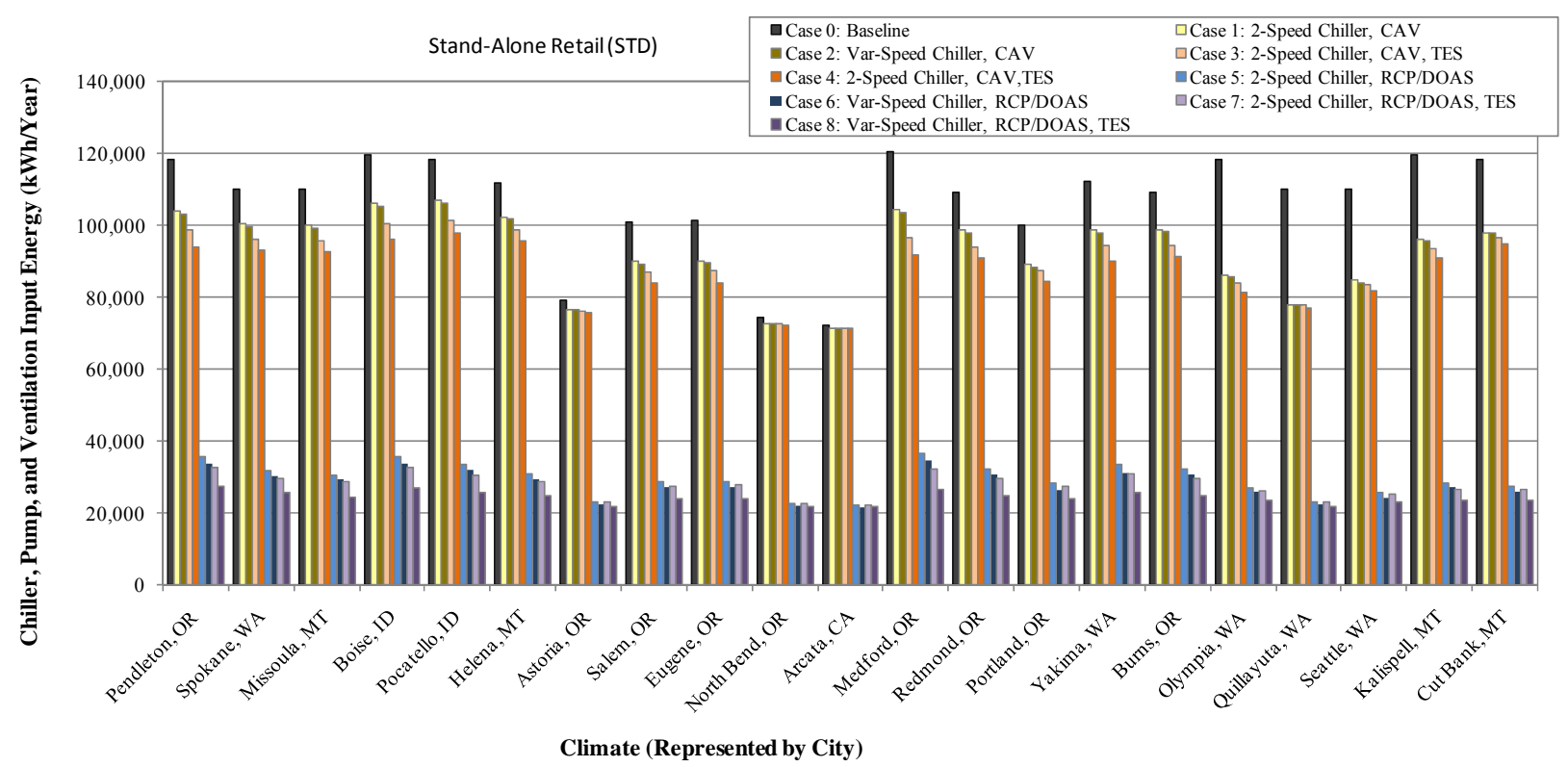

Figure: C-7 Comparison of Annual Chiller and Distribution Energy Consumption for Standard-Performance Stand-Alone Retail Building for Various System Configurations in 21 Locations with Ideal Low-Lift Chiller for the LLCS Configurations 


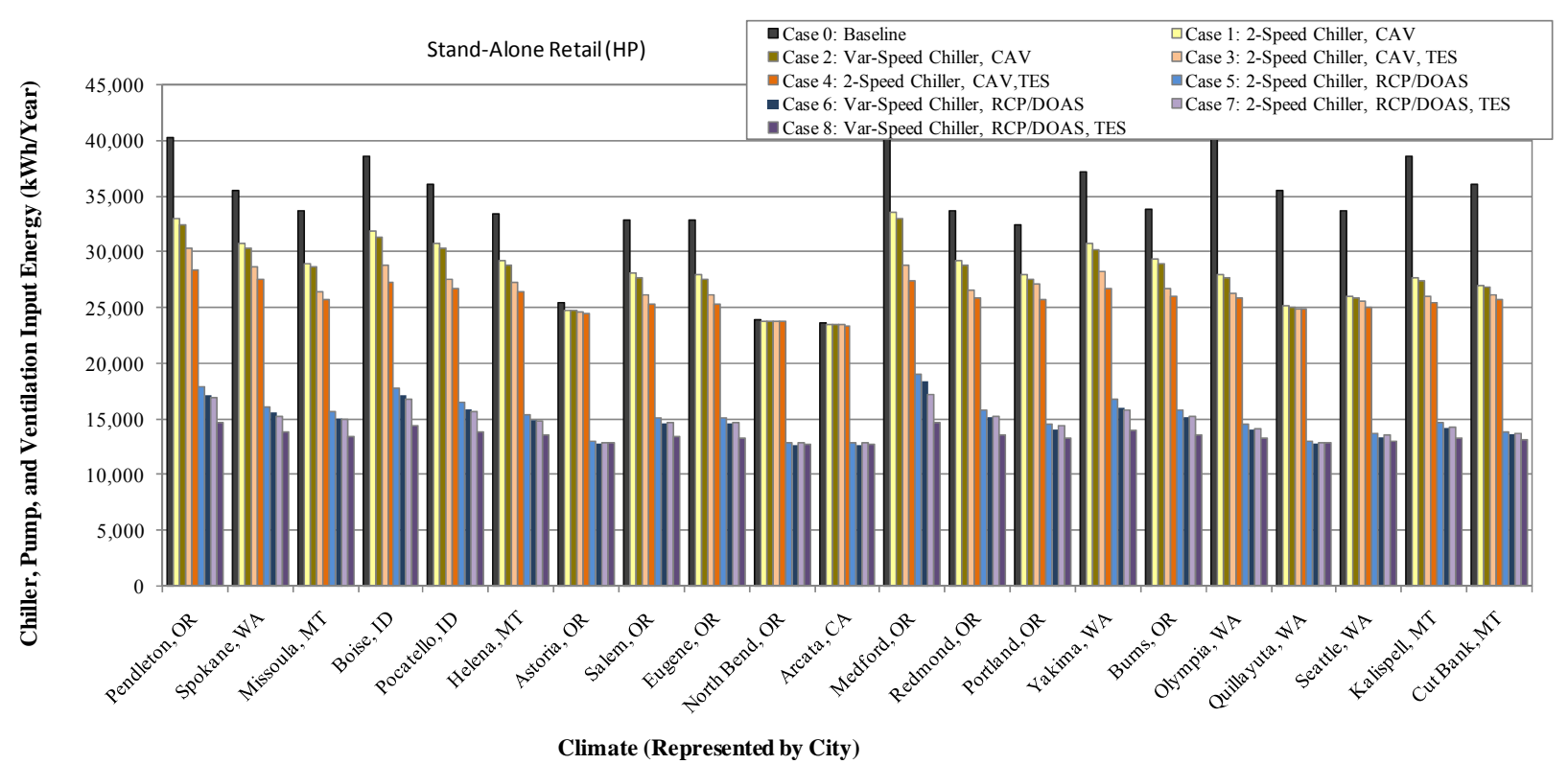

Figure: C-8 Comparison of Annual Chiller and Distribution Energy Consumption for High-Performance Stand-Alone Retail Building for Various System Configurations in 21 Locations with Ideal Low-Lift Chiller for the LLCS Configurations

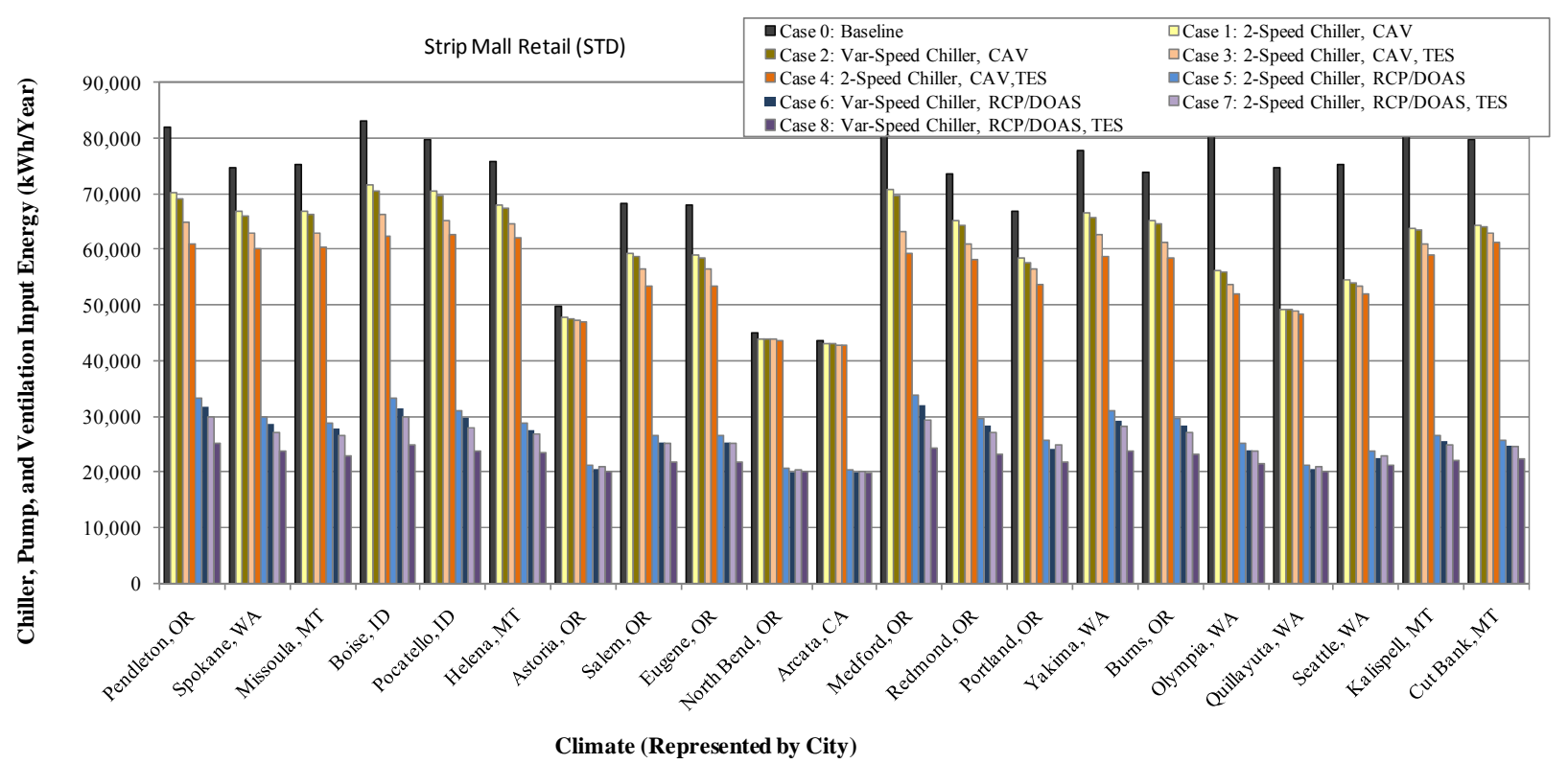

Figure: C-9 Comparison of Annual Chiller and Distribution Energy Consumption for Standard-Performance Strip Mall Retail Building for Various System Configurations in 21 Locations with Ideal Low-Lift Chiller for the LLCS Configurations 


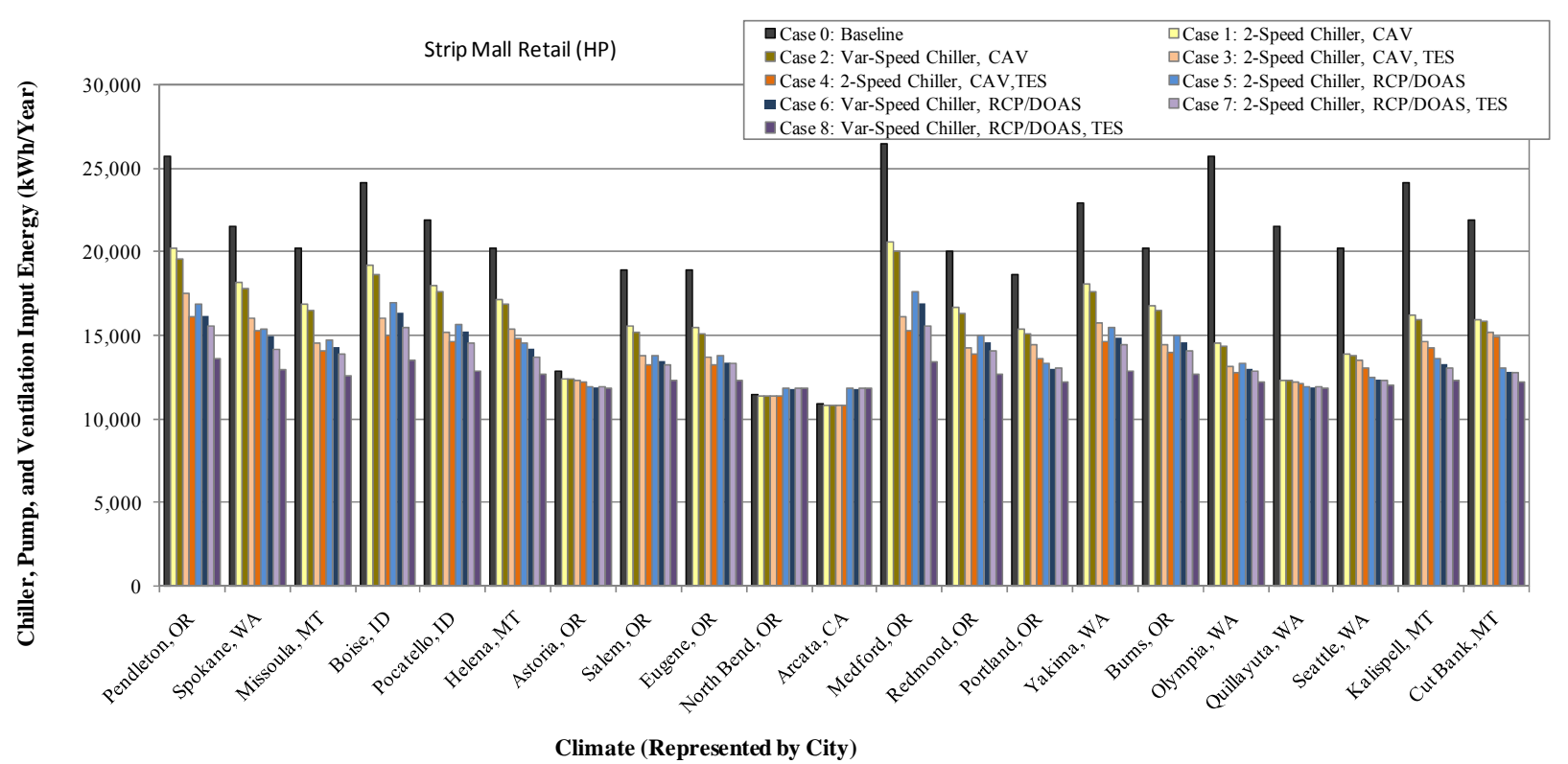

Figure: C-10 Comparison of Annual Chiller and Distribution Energy Consumption for High-Performance Strip Mall Retail Building for Various System Configurations in 21 Locations with Ideal Low-Lift Chiller for the LLCS Configurations

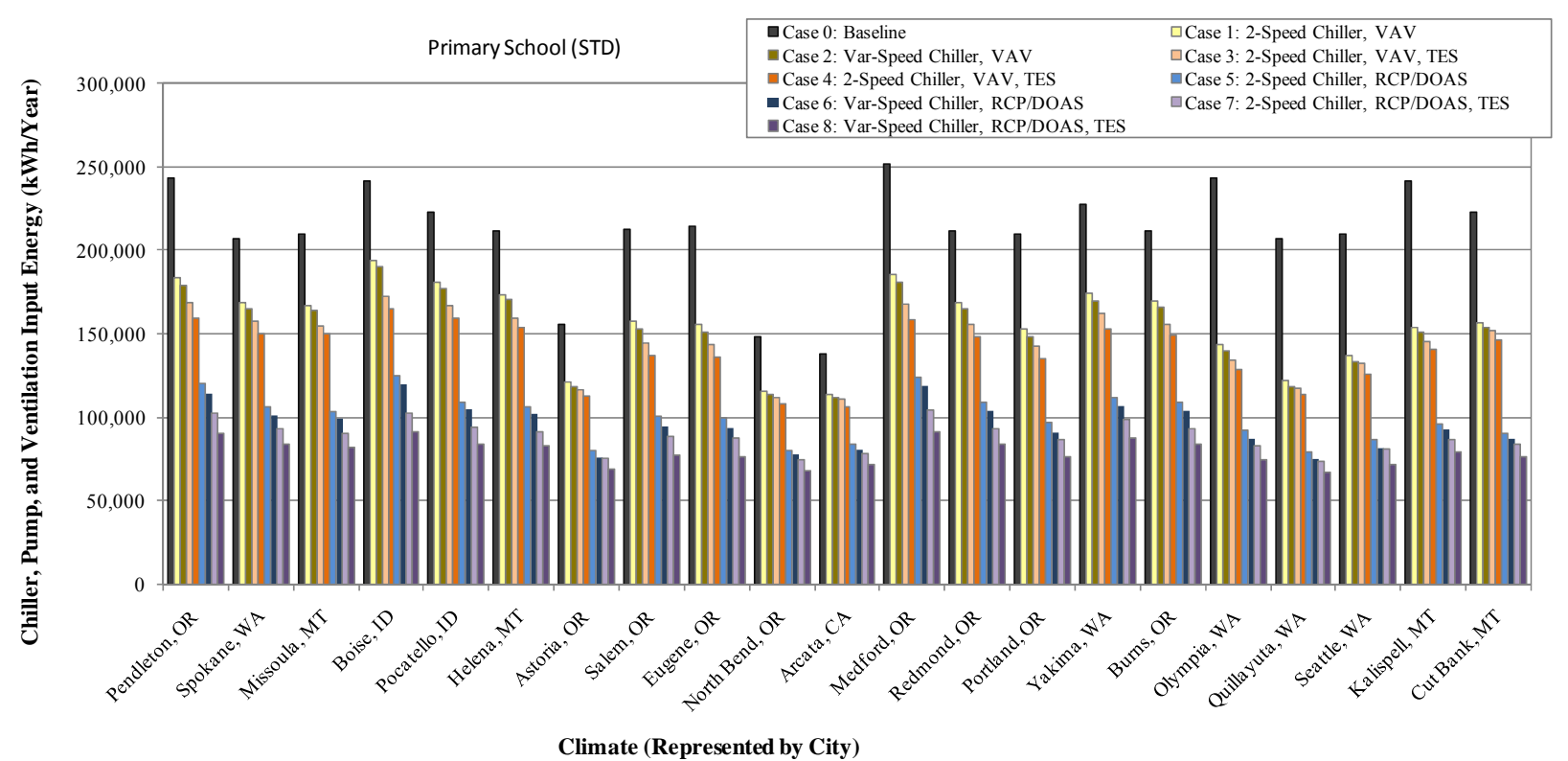

Figure: C-11 Comparison of Annual Chiller and Distribution Energy Consumption for Standard-Performance Primary School Building for Various System Configurations in 21 Locations with Ideal Low-Lift Chiller for the LLCS Configurations 


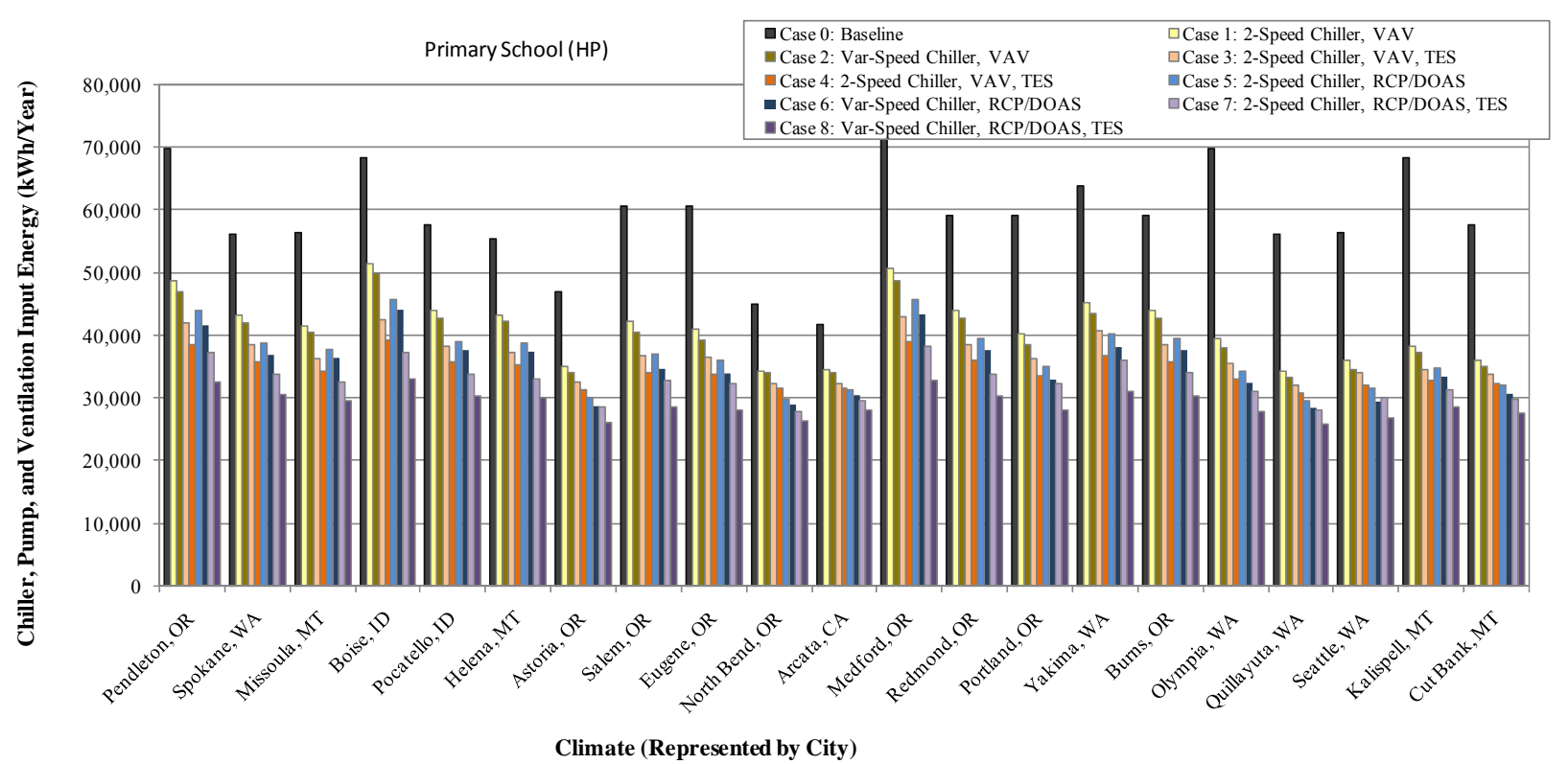

Figure: C-12 Comparison of Annual Chiller and Distribution Energy Consumption for High-Performance Primary School Building for Various System Configurations in 21 Locations with Ideal Low-Lift Chiller for the LLCS Configurations

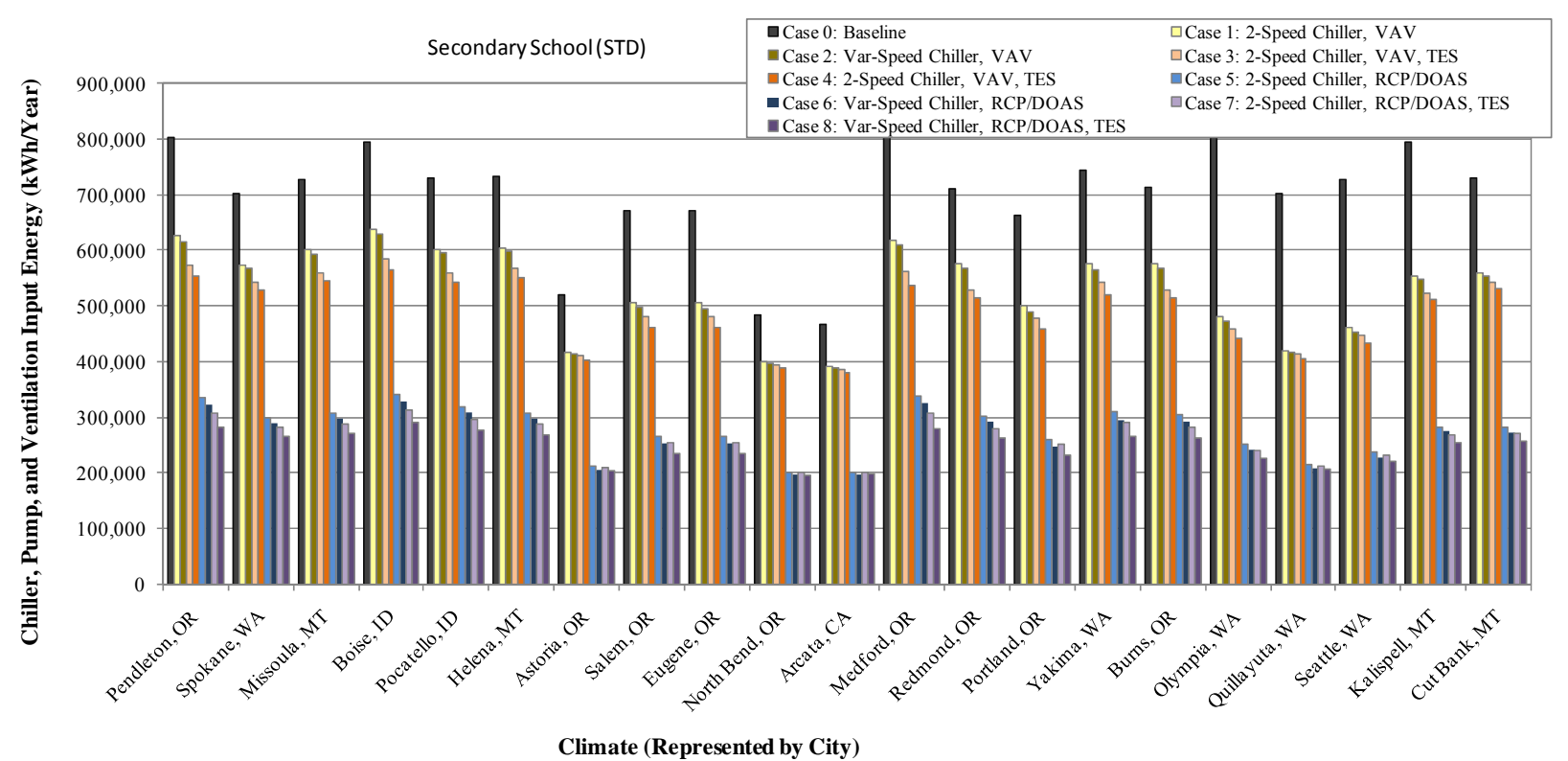

Figure: C-13 Comparison of Annual Chiller and Distribution Energy Consumption for Standard-Performance Secondary School Building for Various System Configurations in 21 Locations with Ideal Low-Lift Chiller for the LLCS Configurations 


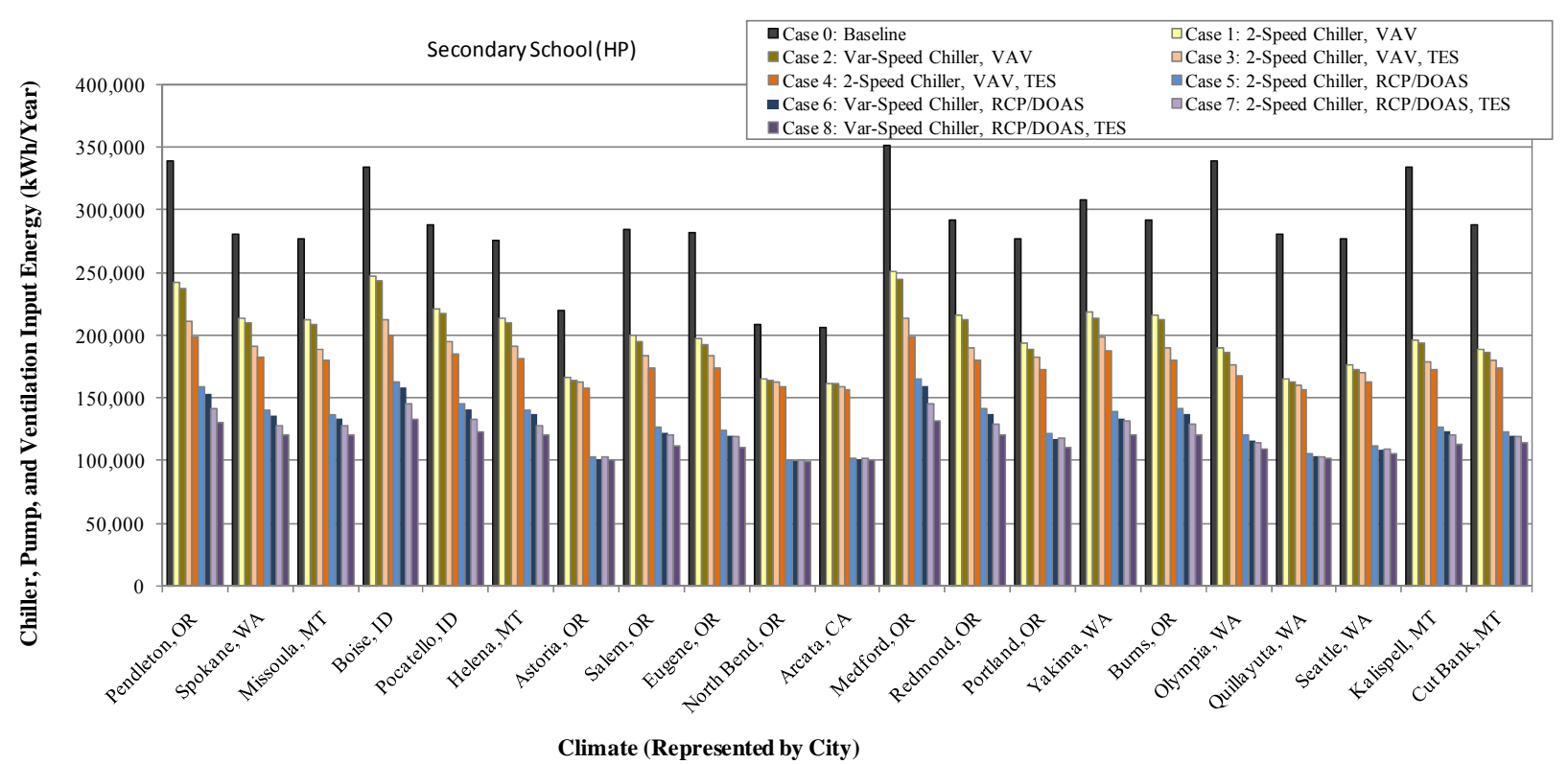

Figure: C-14 Comparison of Annual Chiller and Distribution Energy Consumption for High-Performance Secondary School Building for Various System Configurations in 21 Locations with Ideal Low-Lift Chiller for the LLCS Configurations

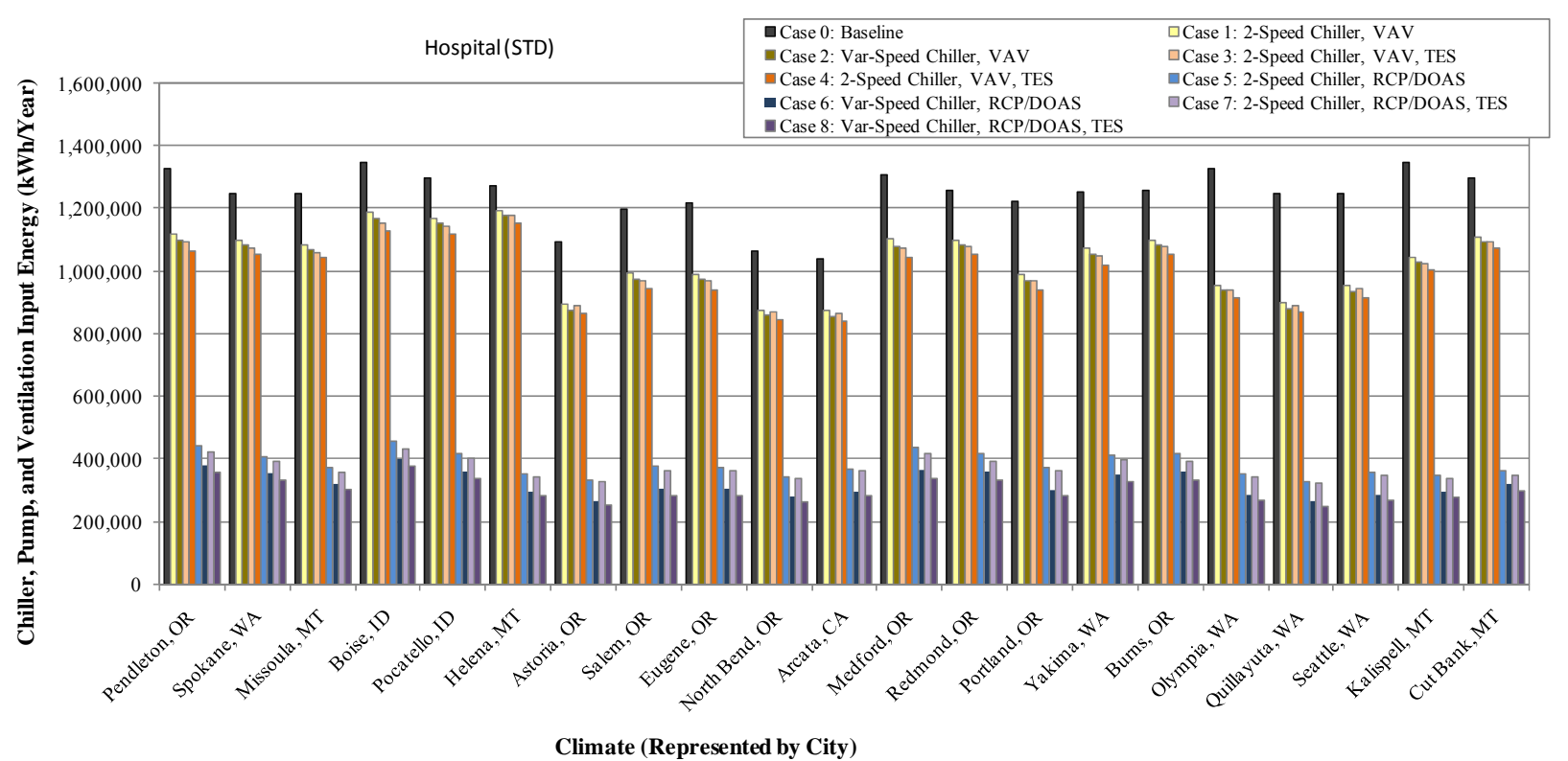

Figure: C-15 Comparison of Annual Chiller and Distribution Energy Consumption for Standard-Performance Hospital Building for Various System Configurations in 21 Locations with Ideal Low-Lift Chiller for the LLCS Configurations 


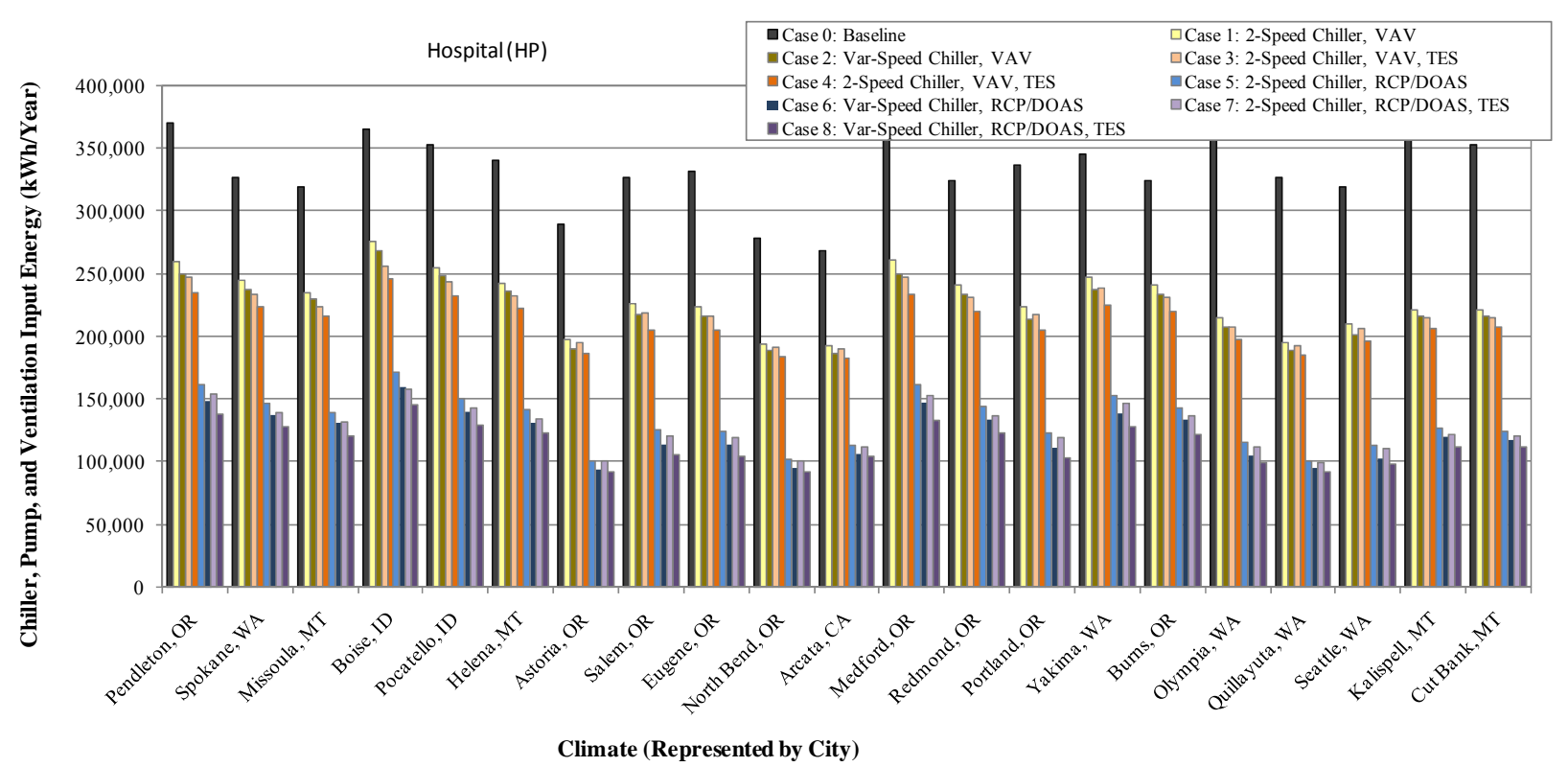

Figure: C-16 Comparison of Annual Chiller and Distribution Energy Consumption for High-Performance Hospital Building for Various System Configurations in 21 Locations with Ideal Low-Lift Chiller for the LLCS Configurations

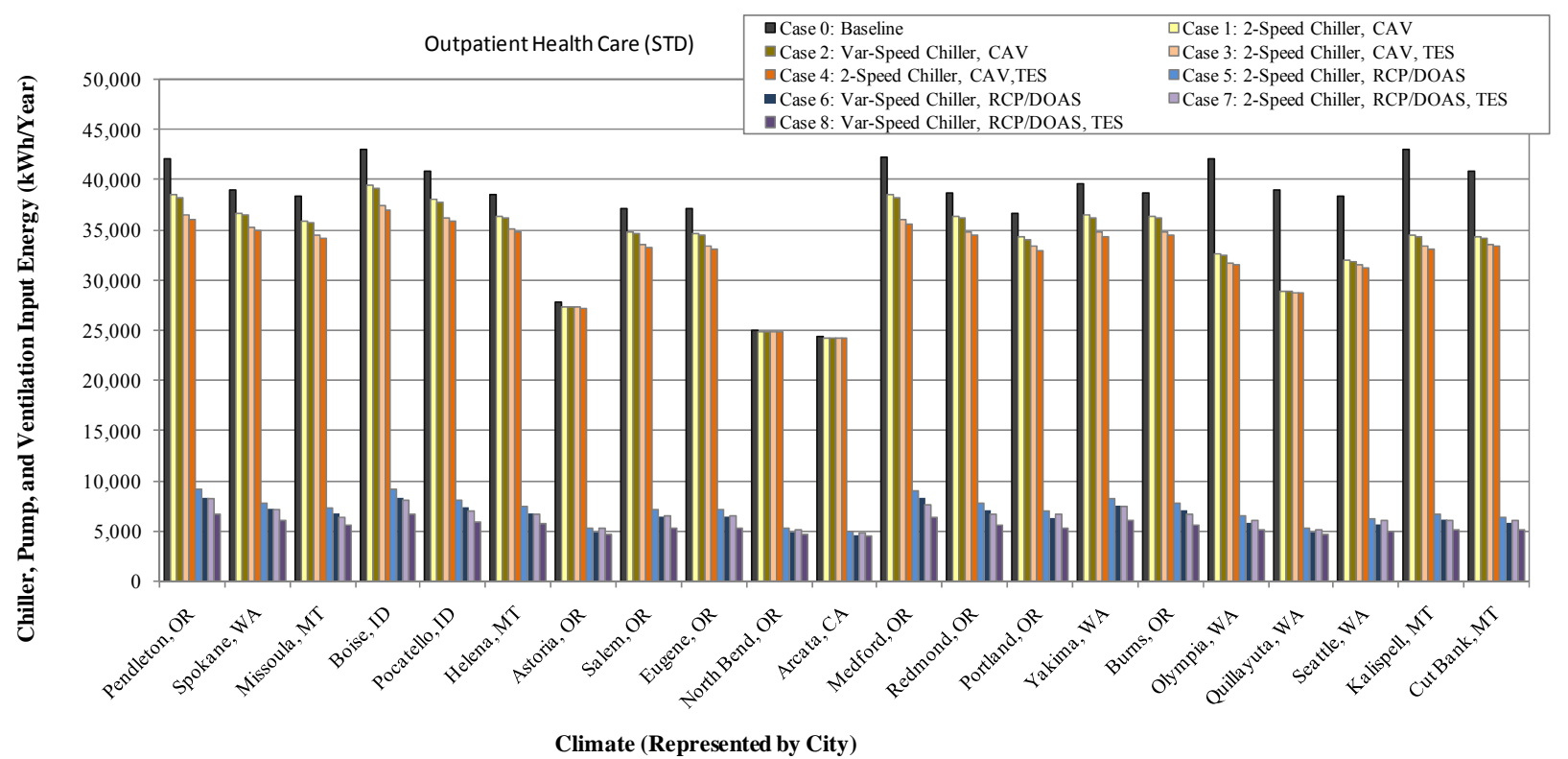

Figure: C-17 Comparison of Annual Chiller and Distribution Energy Consumption for Standard-Performance Outpatient Health Care Building for Various System Configurations in 21 Locations with Ideal Low-Lift Chiller for the LLCS Configurations 


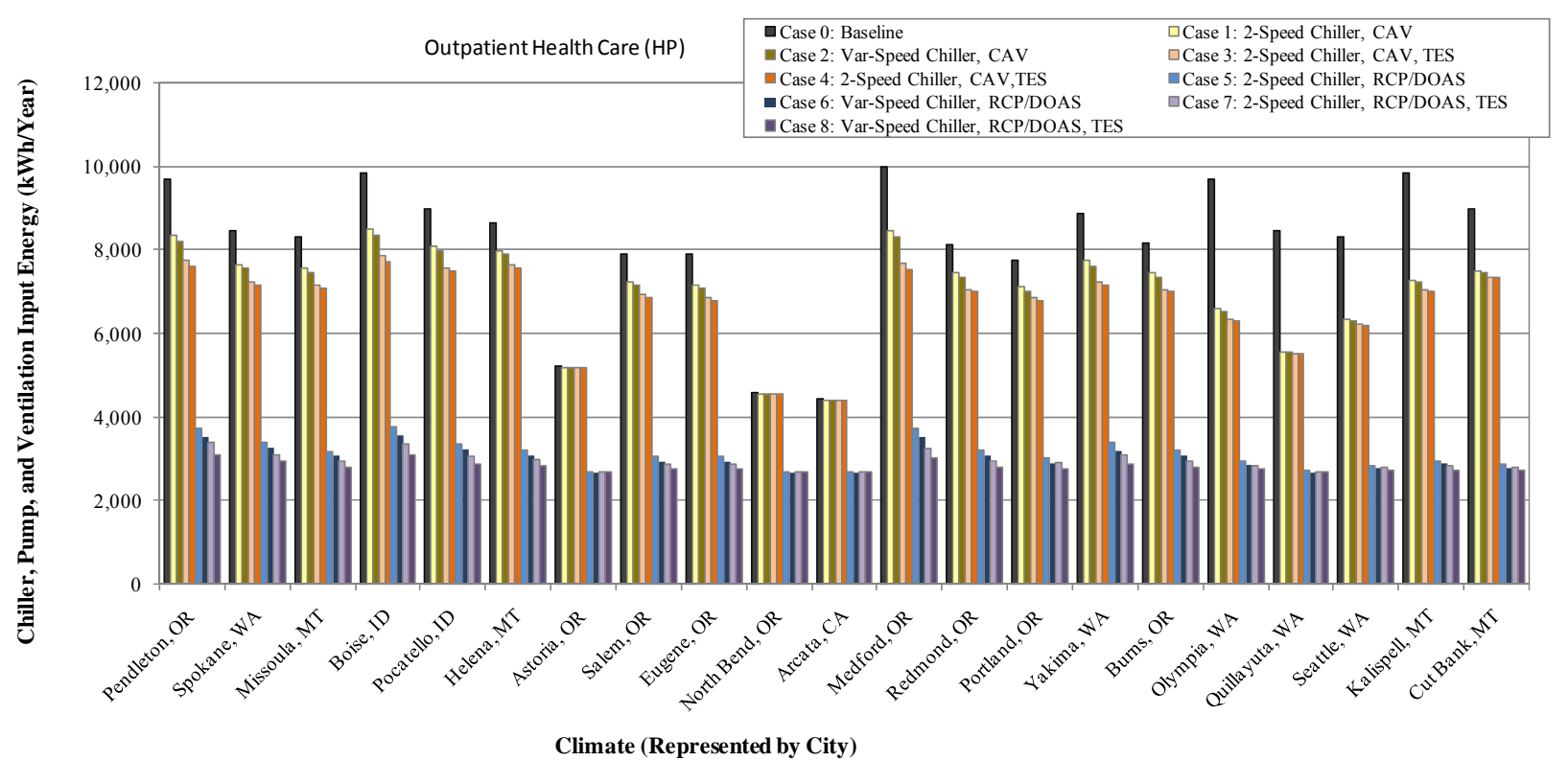

Figure: C-18 Comparison of Annual Chiller and Distribution Energy Consumption for High-Performance Outpatient Health Care Building for Various System Configurations in 21 Locations with Ideal Low-Lift Chiller for the LLCS Configurations

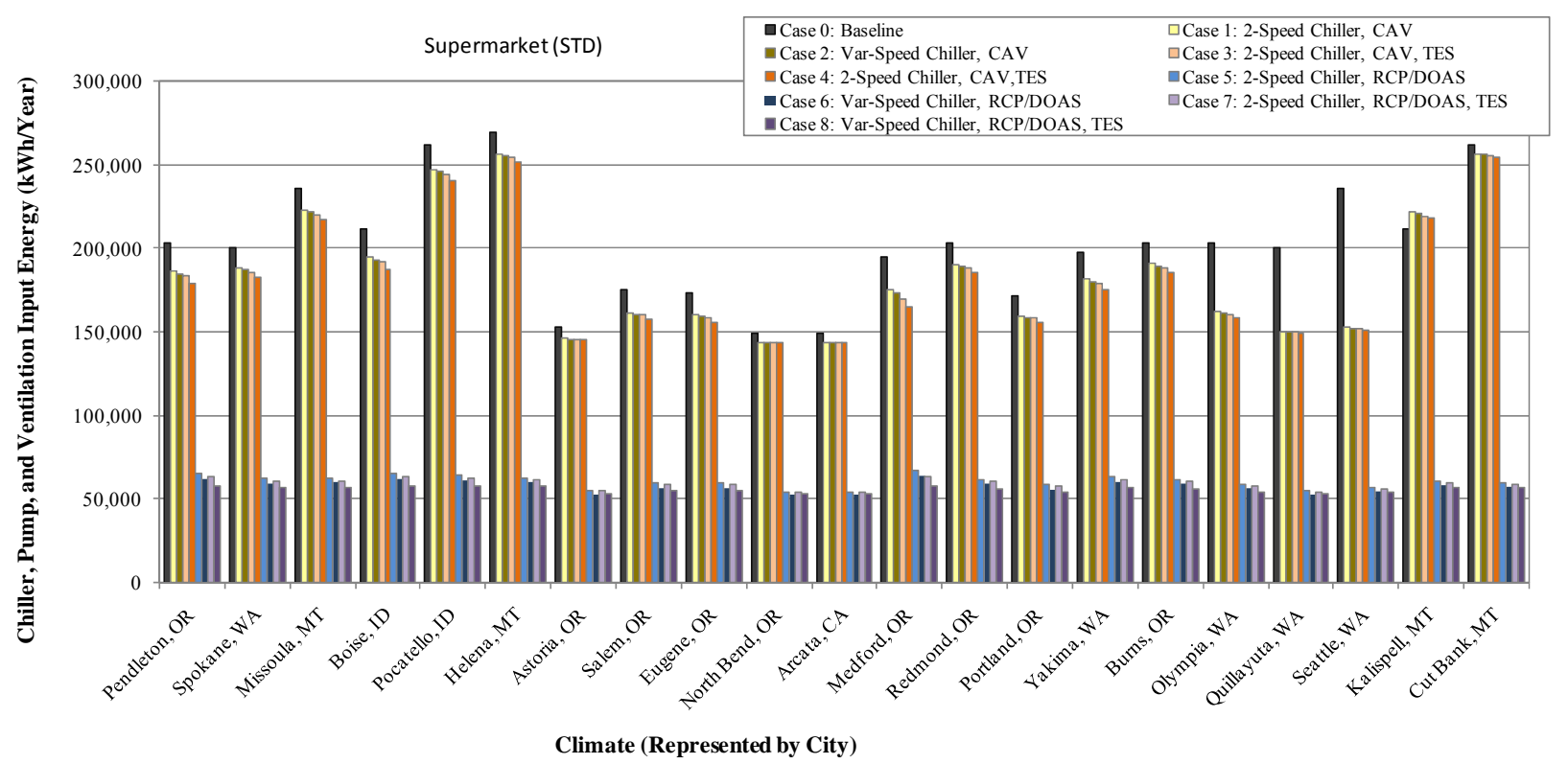

Figure: C-19 Comparison of Annual Chiller and Distribution Energy Consumption for Standard-Performance Supermarket Building for Various System Configurations in 21 Locations with Ideal Low-Lift Chiller for the LLCS Configurations 


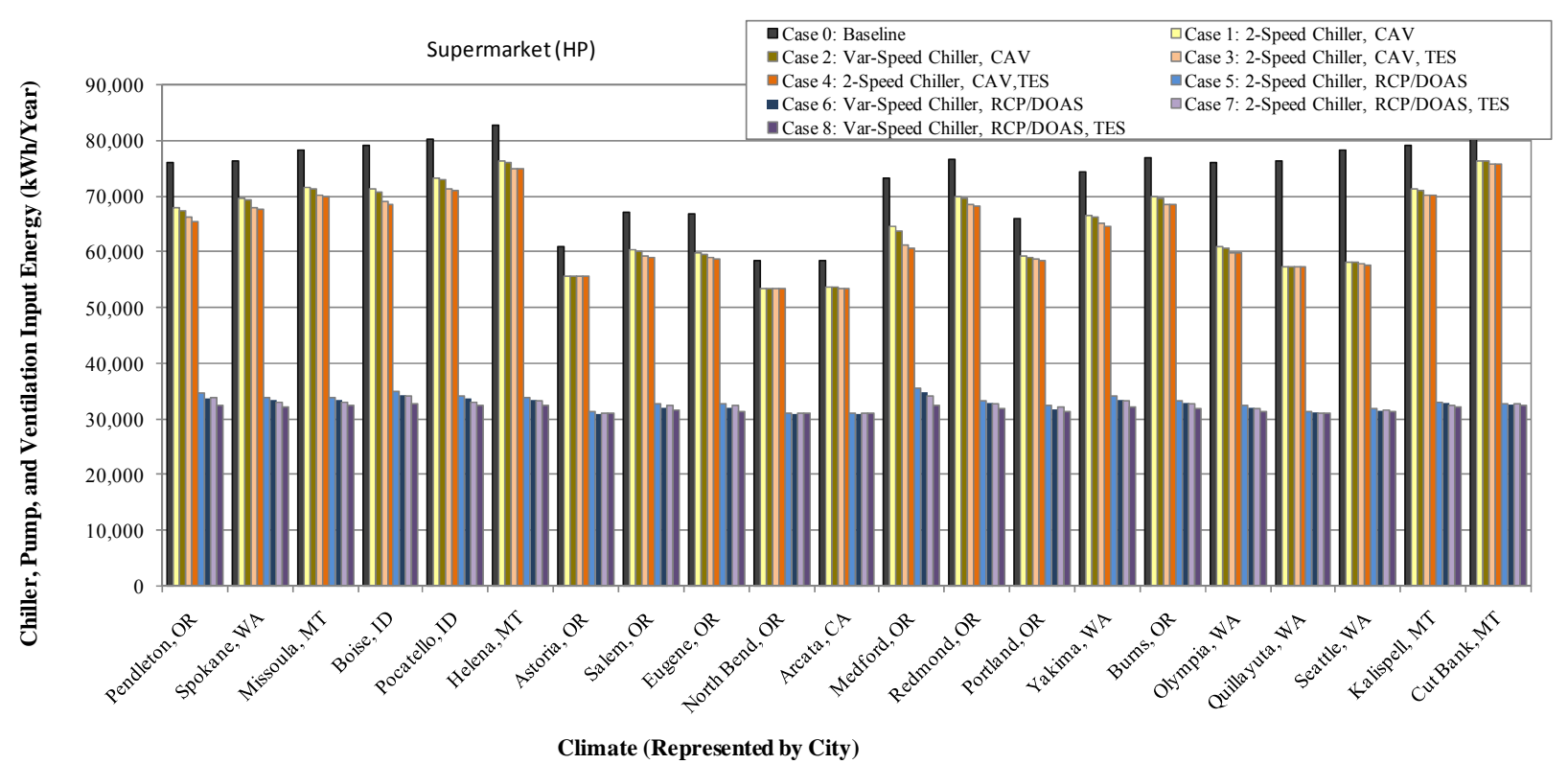

Figure: C-20 Comparison of Annual Chiller and Distribution Energy Consumption for High-Performance Supermarket Building for Various System Configurations in 21 Locations with Ideal Low-Lift Chiller for the LLCS Configurations

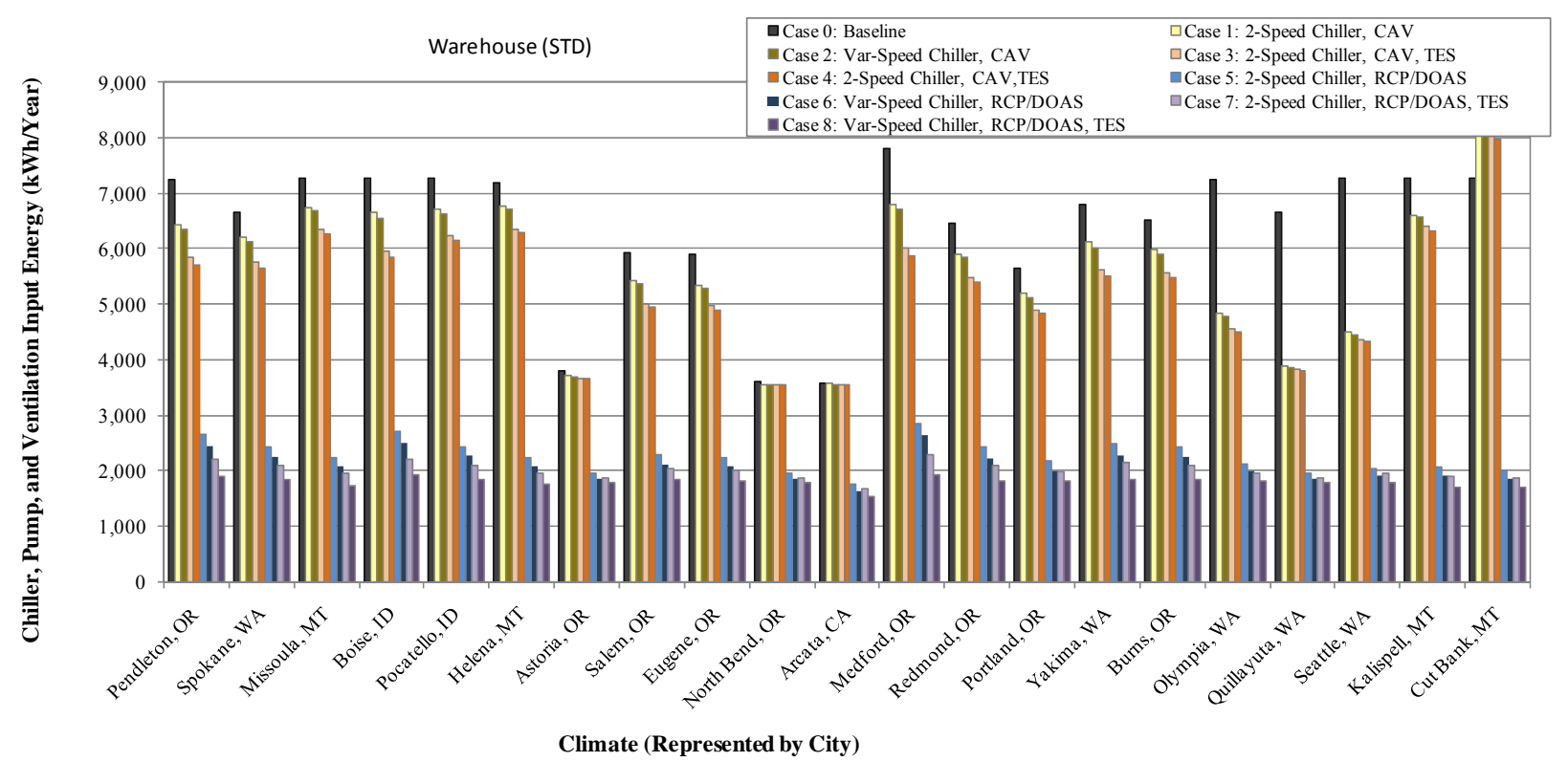

Figure: C-21 Comparison of Annual Chiller and Distribution Energy Consumption for Standard-Performance Warehouse Building for Various System Configurations in 21 Locations with Ideal Low-Lift Chiller for the LLCS Configurations 


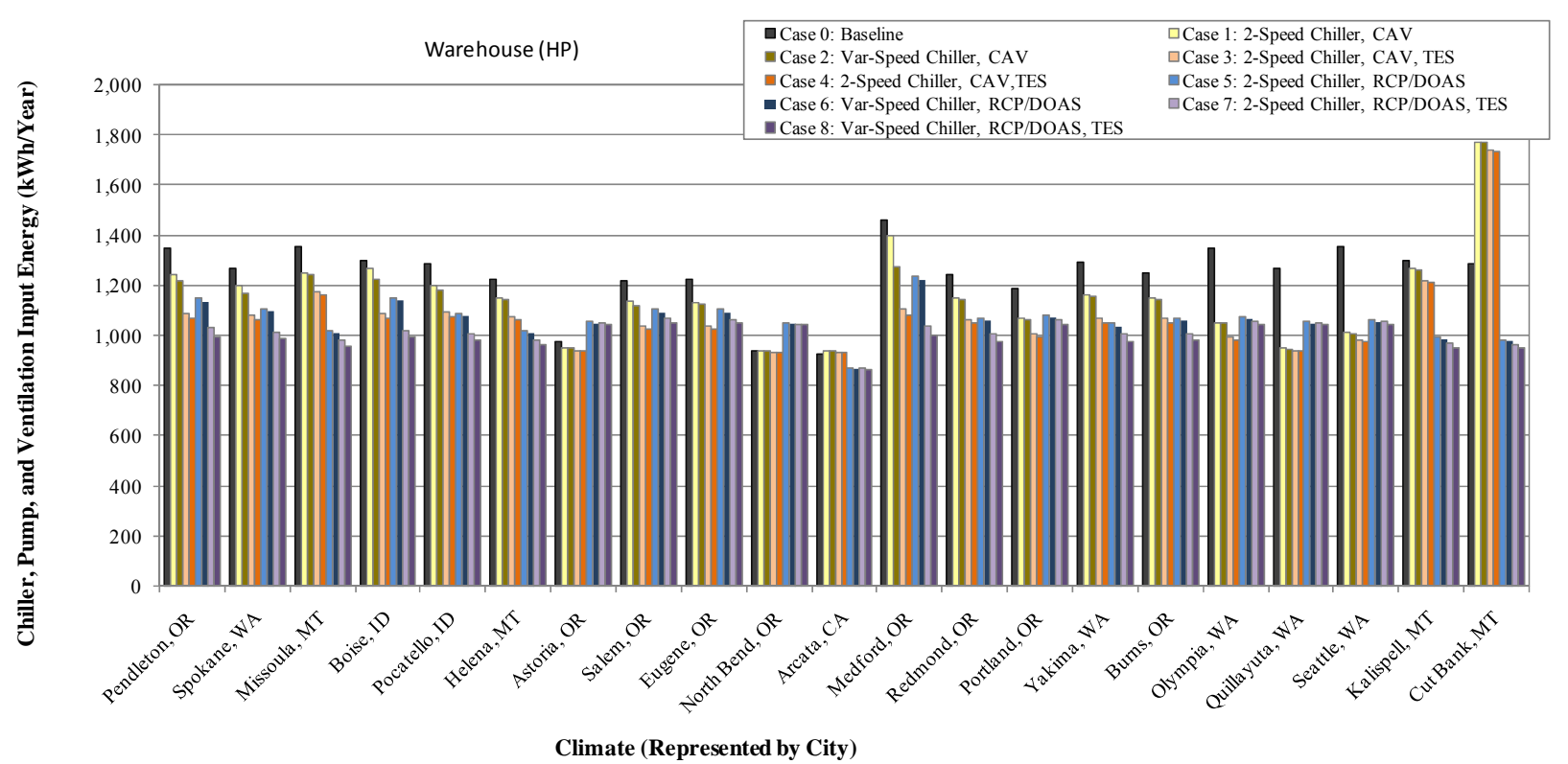

Figure: C-22 Comparison of Annual Chiller and Distribution Energy Consumption for High-Performance Warehouse Building for Various System Configurations in 21 Locations with Ideal Low-Lift Chiller for the LLCS Configurations

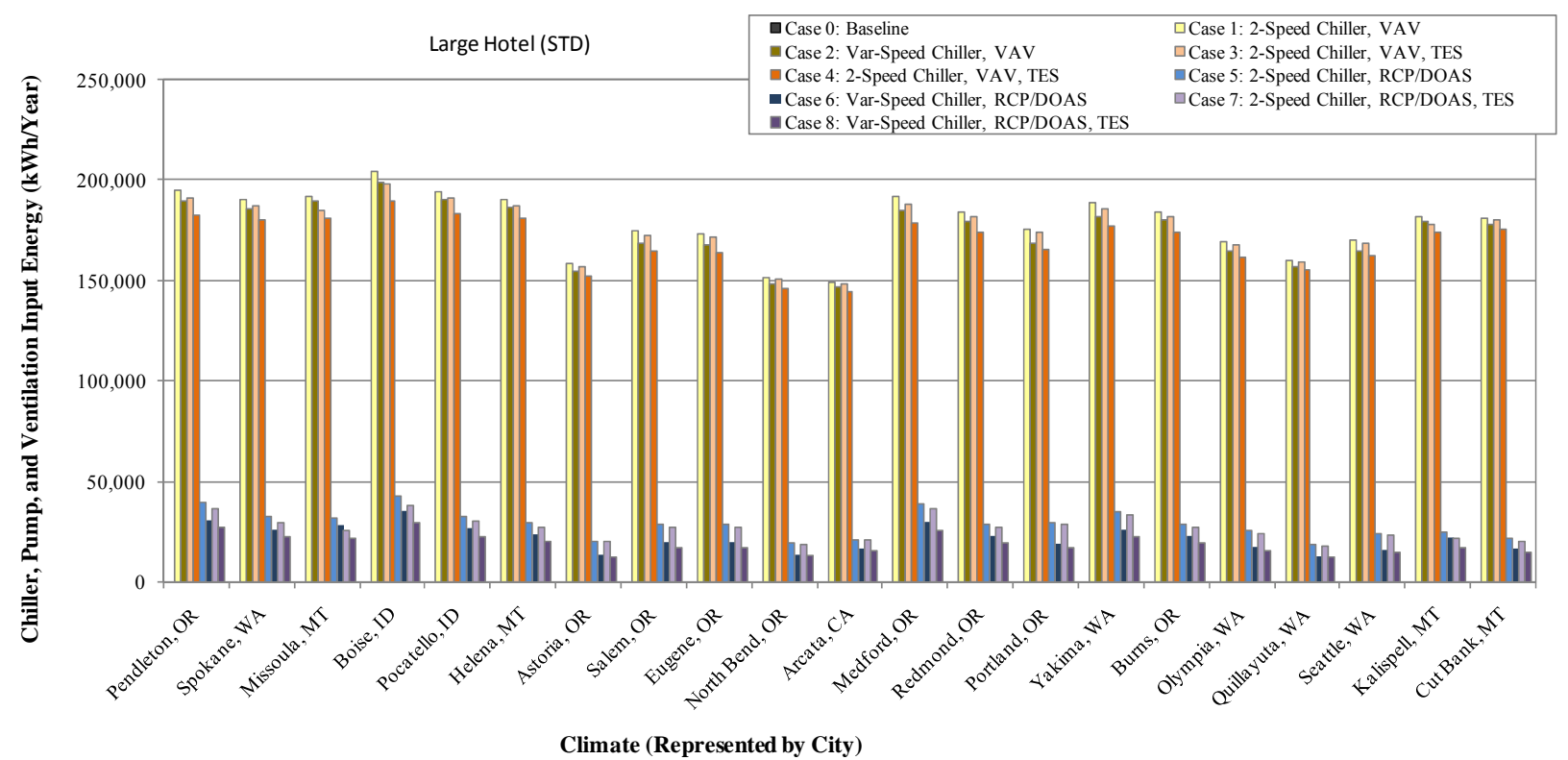

Figure: C-23 Comparison of Annual Chiller and Distribution Energy Consumption for Standard-Performance Large Hotel Building for Various System Configurations in 21 Locations with Ideal Low-Lift Chiller for the LLCS Configurations 


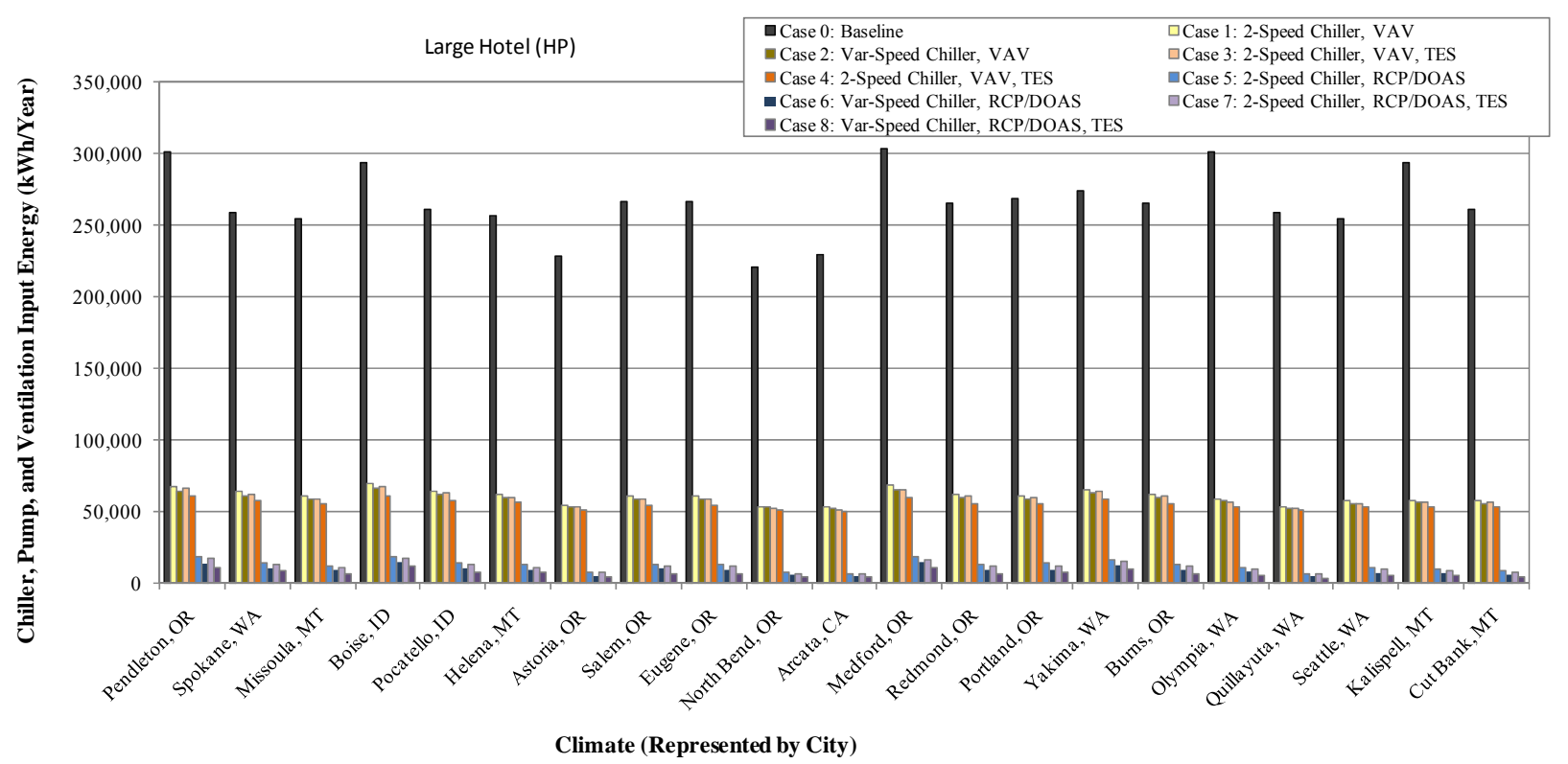

Figure: C-24 Comparison of Annual Chiller and Distribution Energy Consumption for High-Performance Large Hotel Building for Various System Configurations in 21 Locations with Ideal Low-Lift Chiller for the LLCS Configurations

Table: C-25 Annual Energy Consumption (Chiller, Fan, and Pump) for the StandardPerformance Small Office Building Design for Various HVAC Combinations across 21 Climate Locations (units in kWh) with Prototype Low-Lift Chiller for the LLCS Configurations

\begin{tabular}{|c|c|c|c|c|c|c|c|c|c|}
\hline & Case 0 & Case 1 & Case 2 & Case 3 & Case 4 & Case 5 & Case 6 & Case 7 & Case 8 \\
\hline Pendleton, OR & 8,231 & 7,931 & 7,860 & 6,735 & 6,589 & 2,672 & 2,537 & 1,928 & 1,672 \\
\hline Spokane, WA & 7,636 & 7,400 & 7,350 & 6,483 & 6,384 & 2,301 & 2,190 & 1,654 & 1,495 \\
\hline \begin{tabular}{|l} 
Missoula, MT \\
\end{tabular} & 7,250 & 6,950 & 6,910 & 6,077 & 5,995 & 2,049 & 1,951 & 1,476 & 1,343 \\
\hline Boise, ID & 8,181 & 7,943 & 7,879 & 6,758 & 6,625 & 2,572 & 2,445 & 1,848 & 1,634 \\
\hline Pocatello, ID & 7,914 & 7,616 & 7,566 & 6,575 & 6,480 & 2,286 & 2,173 & 1,544 & 1,402 \\
\hline Helena, MT & 7,389 & 7,069 & 7,023 & 6,270 & 6,178 & 2,108 & 1,999 & 1,545 & 1,396 \\
\hline Astoria, OR & 5,564 & 5,254 & 5,226 & 5,138 & 5,096 & 1,507 & 1,390 & 1,330 & 1,148 \\
\hline Salem, OR & 7,356 & 6,857 & 6,800 & 6,034 & 5,921 & 2,072 & 1,937 & 1,482 & 1,290 \\
\hline Eugene, OR & 7,317 & 6,808 & 6,750 & 6,028 & 5,906 & 2,038 & 1,906 & 1,457 & 1,284 \\
\hline North Bend, OR & 5,144 & 4,866 & 4,845 & 4,812 & 4,776 & 1,464 & 1,363 & 1,287 & 1,134 \\
\hline Arcata, CA & 4,844 & 4,717 & 4,709 & 4,665 & 4,650 & 1,347 & 1,255 & 1,198 & 1,117 \\
\hline Medford, OR & 8,383 & 8,063 & 7,990 & 6,548 & 6,411 & 2,760 & 2,616 & 1,770 & 1,569 \\
\hline Redmond, OR & 7,678 & 7,382 & 7,324 & 6,282 & 6,196 & 2,400 & 2,267 & 1,490 & 1,382 \\
\hline Portland, OR & 7,200 & 6,649 & 6,588 & 6,044 & 5,919 & 1,959 & 1,819 & 1,572 & 1,310 \\
\hline Yakima, WA & 7,886 & 7,462 & 7,392 & 6,367 & 6,249 & 2,438 & 2,294 & 1,677 & 1,488 \\
\hline Burns, OR & 7,717 & 7,424 & 7,366 & 6,319 & 6,232 & 2,409 & 2,275 & 1,495 & 1,385 \\
\hline Olympia, WA & 6,817 & 6,379 & 6,334 & 5,768 & 5,678 & 1,866 & 1,747 & 1,388 & 1,239 \\
\hline Quillayuta, WA & 5,708 & 5,484 & 5,461 & 5,334 & 5,299 & 1,472 & 1,372 & 1,233 & 1,138 \\
\hline Seattle, WA & 6,569 & 6,121 & 6,076 & 5,770 & 5,678 & 1,727 & 1,611 & 1,450 & 1,232 \\
\hline Kalispell, MT & 6,975 & 6,654 & 6,618 & 5,949 & 5,874 & 1,893 & 1,798 & 1,334 & 1,241 \\
\hline Cut Bank, MT & 6,811 & 6,503 & 6,465 & 6,058 & 5,993 & 1,762 & 1,664 & 1,349 & 1,239 \\
\hline
\end{tabular}


Table: C-26 Annual Energy Consumption (Chiller, Fan, and Pump) for the HighPerformance Small Office Building Design for Various HVAC Combinations across 21 Climate Locations (units in kWh) with Prototype Low-Lift Chiller for the LLCS Configurations

\begin{tabular}{|l|r|r|r|r|r|r|r|r|r|}
\hline & Case 0 & Case 1 & Case 2 & Case 3 & Case 4 & Case 5 & Case 6 & Case 7 & Case 8 \\
\hline Pendleton, OR & 1,567 & 1,515 & 1,485 & 1,167 & 1,124 & 1,000 & 975 & 826 & 769 \\
\hline Spokane, WA & 1,436 & 1,394 & 1,374 & 1,121 & 1,092 & 924 & 908 & 773 & 734 \\
\hline Missoula, MT & 1,369 & 1,276 & 1,259 & 1,047 & 1,020 & 827 & 812 & 708 & 679 \\
\hline Boise, ID & 1,514 & 1,469 & 1,444 & 1,137 & 1,099 & 965 & 945 & 806 & 752 \\
\hline Pocatello, ID & 1,464 & 1,418 & 1,399 & 1,141 & 1,112 & 892 & 876 & 728 & 697 \\
\hline Helena, MT & 1,339 & 1,266 & 1,251 & 1,054 & 1,029 & 835 & 822 & 727 & 694 \\
\hline Astoria, OR & 892 & 834 & 830 & 808 & 801 & 669 & 665 & 658 & 651 \\
\hline Salem, OR & 1,353 & 1,210 & 1,187 & 987 & 954 & 822 & 802 & 709 & 676 \\
\hline Eugene, OR & 1,322 & 1,184 & 1,163 & 981 & 948 & 806 & 787 & 706 & 673 \\
\hline North Bend, OR & 797 & 773 & 770 & 765 & 761 & 655 & 653 & 652 & 650 \\
\hline Arcata, CA & 753 & 735 & 734 & 726 & 725 & 654 & 653 & 650 & 650 \\
\hline Medford, OR & 1,656 & 1,563 & 1,533 & 1,096 & 1,054 & 1,059 & 1,033 & 806 & 754 \\
\hline Redmond, OR & 1,381 & 1,328 & 1,307 & 1,039 & 1,015 & 902 & 884 & 722 & 697 \\
\hline Portland, OR & 1,317 & 1,166 & 1,145 & 1,007 & 974 & 782 & 763 & 716 & 677 \\
\hline Yakima, WA & 1,511 & 1,400 & 1,371 & 1,097 & 1,061 & 900 & 877 & 759 & 716 \\
\hline Burns, OR & 1,397 & 1,334 & 1,313 & 1,041 & 1,017 & 906 & 887 & 723 & 697 \\
\hline Olympia, WA & 1,217 & 1,090 & 1,076 & 918 & 895 & 778 & 764 & 694 & 671 \\
\hline Quillayuta, WA & 906 & 872 & 867 & 841 & 835 & 673 & 669 & 656 & 651 \\
\hline Seattle, WA & 1,117 & 1,007 & 994 & 925 & 903 & 718 & 707 & 686 & 661 \\
\hline Kalispell, MT & 1,311 & 1,232 & 1,217 & 1,049 & 1,027 & 787 & 774 & 682 & 664 \\
\hline Cut Bank, MT & 1,272 & 1,213 & 1,203 & 1,114 & 1,099 & 731 & 723 & 676 & 662 \\
\hline
\end{tabular}


Table: C-27 Annual Energy Consumption (Chiller, Fan, and Pump) for the StandardPerformance Retail Standalone Building Design for Various HVAC Combinations across 21 Climate Locations (units in kWh) with Prototype Low-Lift Chiller for the LLCS Configurations

\begin{tabular}{|c|c|c|c|c|c|c|c|c|c|}
\hline & Case 0 & Case 1 & Case 2 & Case 3 & Case 4 & Case 5 & Case 6 & Case 7 & Case 8 \\
\hline Pendleton, OR & 118,089 & 114,142 & 112,917 & 102,043 & 99,065 & 38,757 & 36,932 & 34,725 & 29,447 \\
\hline Spokane, WA & 110,142 & 107,187 & 106,353 & 98,578 & 96,543 & 34,113 & 32,794 & 30,754 & 26,864 \\
\hline Missoula, MT & 109,914 & 106,285 & 105,569 & 97,082 & 95,413 & 32,462 & 31,279 & 28,965 & 25,294 \\
\hline Boise, ID & 119,369 & 116,013 & 114,919 & 103,599 & 100,941 & 38,806 & 37,113 & 34,322 & 29,187 \\
\hline Pocatello, ID & 118,467 & 114,833 & 113,921 & 103,639 & 101,592 & 36,171 & 34,638 & 31,123 & 26,851 \\
\hline Helena, MT & 111,572 & 108,050 & 107,295 & 100,351 & 98,499 & 32,662 & 31,269 & 29,736 & 25,877 \\
\hline Astoria, OR & 79,247 & 77,234 & 77,020 & 76,563 & 76,001 & 23,584 & 22,852 & 23,247 & 22,038 \\
\hline Salem, OR & 100,983 & 95,537 & 94,656 & 88,097 & 86,223 & 30,393 & 29,078 & 28,451 & 24,319 \\
\hline Eugene, OR & 101,319 & 95,776 & 94,897 & 88,284 & 86,424 & 30,400 & 29,097 & 28,624 & 24,294 \\
\hline North Bend, OR & 74,433 & 73,025 & 72,854 & 72,824 & 72,463 & 23,051 & 22,359 & 22,833 & 21,887 \\
\hline Arcata, CA & 72,297 & 71,671 & 71,609 & 71,451 & 71,272 & 22,359 & 21,947 & 22,144 & 21,683 \\
\hline Medford, OR & 120,264 & 115,903 & 114,637 & 99,467 & 96,992 & 40,130 & 38,359 & 33,649 & 28,360 \\
\hline Redmond, OR & 108,931 & 105,408 & 104,500 & 95,641 & 93,947 & 34,477 & 32,872 & 29,156 & 25,632 \\
\hline Portland, OR & 99,928 & 94,086 & 93,124 & 89,059 & 86,496 & 29,449 & 27,978 & 28,347 & 24,736 \\
\hline Yakima, WA & 112,325 & 107,408 & 106,265 & 96,519 & 94,115 & 35,870 & 34,056 & 31,929 & 27,162 \\
\hline Burns, OR & 109,217 & 105,680 & 104,771 & 95,882 & 94,190 & 34,522 & 32,913 & 29,184 & 25,634 \\
\hline Olympia, WA & 94,844 & 90,341 & 89,682 & 84,775 & 83,200 & 28,341 & 27,231 & 26,677 & 23,812 \\
\hline Quillayuta, WA & 80,522 & 78,762 & 78,526 & 78,013 & 77,504 & 23,499 & 22,862 & 23,017 & 22,080 \\
\hline Seattle, WA & 91,403 & 87,310 & 86,692 & 85,079 & 83,140 & 26,530 & 25,420 & 25,791 & 23,403 \\
\hline Kalispell, MT & 104,306 & 100,761 & 100,188 & 94,256 & 92,848 & 29,606 & 28,563 & 26,461 & 23,916 \\
\hline Cut Bank, MT & 104,167 & 101,101 & 100,564 & 97,260 & 96,077 & 28,576 & 27,312 & 26,920 & 24,089 \\
\hline
\end{tabular}


Table: C-28 Annual Energy Consumption (Chiller, Fan, and Pump) for the HighPerformance Retail Standalone Building Design for Various HVAC Combinations across 21 Climate Locations (units in kWh) with Prototype Low-Lift Chiller for the LLCS Configurations

\begin{tabular}{|l|r|r|r|r|r|r|r|r|r|}
\hline & Case 0 & Case 1 & Case 2 & Case 3 & Case 4 & Case 5 & Case 6 & Case 7 & Case 8 \\
\hline Pendleton, OR & 40,281 & 37,902 & 37,125 & 31,646 & 30,676 & 19,114 & 18,470 & 17,683 & 15,433 \\
\hline Spokane, WA & 35,469 & 33,946 & 33,468 & 29,576 & 28,934 & 16,881 & 16,456 & 15,551 & 14,307 \\
\hline Missoula, MT & 33,689 & 31,800 & 31,380 & 27,389 & 26,873 & 16,187 & 15,814 & 14,550 & 13,667 \\
\hline Boise, ID & 38,519 & 36,627 & 35,961 & 30,317 & 29,404 & 18,930 & 18,335 & 17,375 & 15,242 \\
\hline Pocatello, ID & 36,108 & 34,256 & 33,733 & 28,822 & 28,206 & 17,326 & 16,856 & 15,085 & 14,062 \\
\hline Helena, MT & 33,353 & 31,686 & 31,287 & 27,996 & 27,470 & 15,896 & 15,553 & 14,842 & 13,763 \\
\hline Astoria, OR & 25,472 & 24,967 & 24,926 & 24,701 & 24,604 & 12,982 & 12,934 & 12,912 & 12,797 \\
\hline Salem, OR & 32,839 & 30,464 & 29,959 & 26,850 & 26,270 & 15,660 & 15,267 & 14,492 & 13,479 \\
\hline Eugene, OR & 32,889 & 30,403 & 29,907 & 26,865 & 26,242 & 15,588 & 15,191 & 14,614 & 13,444 \\
\hline North Bend, OR & 23,961 & 23,822 & 23,812 & 23,761 & 23,738 & 12,805 & 12,794 & 12,789 & 12,771 \\
\hline Arcata, CA & 23,581 & 23,507 & 23,502 & 23,432 & 23,413 & 12,801 & 12,794 & 12,782 & 12,773 \\
\hline Medford, OR & 41,322 & 39,231 & 38,454 & 30,537 & 29,700 & 20,582 & 19,947 & 16,977 & 15,321 \\
\hline Redmond, OR & 33,731 & 32,133 & 31,635 & 27,590 & 27,103 & 16,448 & 15,994 & 14,312 & 13,672 \\
\hline Portland, OR & 32,458 & 29,910 & 29,428 & 27,289 & 26,578 & 14,977 & 14,555 & 14,671 & 13,485 \\
\hline Yakima, WA & 37,203 & 34,642 & 33,948 & 29,198 & 28,434 & 17,593 & 17,004 & 15,899 & 14,396 \\
\hline Burns, OR & 33,886 & 32,276 & 31,777 & 27,723 & 27,222 & 16,471 & 16,014 & 14,338 & 13,682 \\
\hline Olympia, WA & 31,714 & 29,665 & 29,365 & 26,884 & 26,495 & 14,873 & 14,590 & 13,903 & 13,319 \\
\hline Quillayuta, WA & 25,778 & 25,336 & 25,276 & 25,017 & 24,945 & 12,983 & 12,939 & 12,872 & 12,797 \\
\hline Seattle, WA & 28,525 & 27,022 & 26,780 & 25,864 & 25,406 & 13,830 & 13,605 & 13,656 & 13,109 \\
\hline Kalispell, MT & 31,289 & 29,601 & 29,266 & 26,636 & 26,203 & 15,015 & 14,728 & 13,659 & 13,230 \\
\hline Cut Bank, MT & 29,294 & 28,125 & 27,886 & 26,519 & 26,200 & 14,098 & 13,896 & 13,566 & 13,129 \\
\hline
\end{tabular}


Table: C-29 Annual Energy Consumption (Chiller, Fan, and Pump) for the StandardPerformance Retail Strip Mall Building Design for Various HVAC Combinations across 21 Climate Locations (units in kWh) with Prototype Low-Lift Chiller for the LLCS

\section{Configurations}

\begin{tabular}{|c|c|c|c|c|c|c|c|c|c|}
\hline & Case 0 & Case 1 & Case 2 & Case 3 & Case 4 & Case 5 & Case 6 & Case 7 & Case 8 \\
\hline Pendleton, OR & 81,844 & 79,354 & 78,109 & 68,188 & 65,628 & 36,269 & 34,669 & 31,601 & 27,045 \\
\hline Spokane, WA & 74,669 & 72,906 & 72,058 & 64,909 & 63,203 & 31,994 & 30,798 & 28,407 & 24,949 \\
\hline Missoula, MT & 75,083 & 72,642 & 71,863 & 64,071 & 62,782 & 30,682 & 29,569 & 26,474 & 23,711 \\
\hline Boise, ID & 82,911 & 80,614 & 79,358 & 69,065 & 66,770 & 36,244 & 34,576 & 31,613 & 26,930 \\
\hline Pocatello, ID & 79,797 & 77,410 & 76,490 & 67,115 & 65,534 & 33,443 & 32,065 & 28,150 & 24,770 \\
\hline Helena, MT & 75,656 & 73,182 & 72,418 & 66,069 & 64,542 & 30,718 & 29,461 & 27,547 & 24,251 \\
\hline Astoria, OR & 49,692 & 48,337 & 48,177 & 47,654 & 47,224 & 21,440 & 20,967 & 21,153 & 20,292 \\
\hline Salem, OR & 68,075 & 64,169 & 63,351 & 57,136 & 55,665 & 27,924 & 26,825 & 25,566 & 22,259 \\
\hline Eugene, OR & 67,989 & 64,050 & 63,233 & 57,068 & 55,520 & 28,011 & 26,890 & 25,767 & 22,267 \\
\hline North Bend, OR & 45,014 & 44,210 & 44,107 & 44,008 & 43,808 & 20,751 & 20,391 & 20,616 & 20,068 \\
\hline Arcata, CA & 43,569 & 43,206 & 43,170 & 42,971 & 42,846 & 20,420 & 20,217 & 20,233 & 19,992 \\
\hline Medford, OR & 83,756 & 80,919 & 79,574 & 65,574 & 63,566 & 37,184 & 35,550 & 30,288 & 25,905 \\
\hline Redmond, OR & 73,489 & 71,034 & 70,196 & 62,002 & 60,714 & 31,808 & 30,499 & 26,334 & 23,632 \\
\hline Portland, OR & 66,850 & 62,605 & 61,705 & 57,666 & 55,757 & 26,997 & 25,791 & 25,773 & 22,520 \\
\hline Yakima, WA & 77,700 & 74,183 & 73,059 & 64,182 & 62,145 & 33,359 & 31,805 & 29,321 & 24,978 \\
\hline Burns, OR & 73,703 & 71,242 & 70,402 & 62,180 & 60,882 & 31,851 & 30,536 & 26,357 & 23,652 \\
\hline Olympia, WA & 63,081 & 59,976 & 59,365 & 54,690 & 53,451 & 26,128 & 25,212 & 24,197 & 21,891 \\
\hline Quillayuta, WA & 51,125 & 49,927 & 49,749 & 49,219 & 48,791 & 21,504 & 21,087 & 21,047 & 20,295 \\
\hline Seattle, WA & 59,775 & 56,902 & 56,351 & 54,599 & 53,113 & 24,424 & 23,519 & 23,637 & 21,502 \\
\hline Kalispell, MT & 70,211 & 67,782 & 67,243 & 61,817 & 60,624 & 27,892 & 26,995 & 24,337 & 22,317 \\
\hline Cut Bank, MT & 68,972 & 66,935 & 66,455 & 63,457 & 62,492 & 26,813 & 25,836 & 24,999 & 22,661 \\
\hline
\end{tabular}


Table: C-30 Annual Energy Consumption (Chiller, Fan, and Pump) for the HighPerformance Retail Strip Mall Building Design for Various HVAC Combinations across 21 Climate Locations (units in kWh) with Prototype Low-Lift Chiller for the LLCS Configurations

\begin{tabular}{|l|r|r|r|r|r|r|r|r|r|}
\hline & Case 0 & Case 1 & Case 2 & Case 3 & Case 4 & Case 5 & Case 6 & Case 7 & Case 8 \\
\hline Pendleton, OR & 25,753 & 24,304 & 23,588 & 18,785 & 18,049 & 18,004 & 17,431 & 16,249 & 14,341 \\
\hline Spokane, WA & 21,539 & 20,831 & 20,402 & 16,973 & 16,503 & 16,140 & 15,787 & 14,500 & 13,418 \\
\hline Missoula, MT & 20,208 & 19,173 & 18,761 & 15,385 & 14,984 & 15,322 & 15,005 & 13,404 & 12,737 \\
\hline Boise, ID & 24,097 & 23,217 & 22,576 & 17,544 & 16,870 & 18,142 & 17,625 & 15,996 & 14,300 \\
\hline Pocatello, ID & 21,925 & 20,952 & 20,491 & 16,283 & 15,807 & 16,512 & 16,116 & 13,987 & 13,170 \\
\hline Helena, MT & 20,194 & 19,250 & 18,884 & 16,103 & 15,683 & 15,102 & 14,802 & 13,763 & 12,889 \\
\hline Astoria, OR & 12,842 & 12,550 & 12,526 & 12,338 & 12,280 & 11,974 & 11,943 & 11,904 & 11,840 \\
\hline Salem, OR & 18,956 & 17,507 & 17,071 & 14,455 & 14,017 & 14,255 & 13,964 & 12,977 & 12,373 \\
\hline Eugene, OR & 18,947 & 17,416 & 16,987 & 14,449 & 14,000 & 14,218 & 13,921 & 13,029 & 12,362 \\
\hline North Bend, OR & 11,456 & 11,409 & 11,404 & 11,377 & 11,367 & 11,828 & 11,824 & 11,819 & 11,814 \\
\hline Arcata, CA & 10,897 & 10,850 & 10,846 & 10,802 & 10,792 & 11,825 & 11,821 & 11,816 & 11,809 \\
\hline Medford, OR & 26,486 & 25,461 & 24,702 & 17,804 & 17,119 & 18,985 & 18,392 & 15,280 & 14,025 \\
\hline Redmond, OR & 20,067 & 19,063 & 18,648 & 15,213 & 14,841 & 15,662 & 15,297 & 13,356 & 12,794 \\
\hline Portland, OR & 18,614 & 16,955 & 16,552 & 14,736 & 14,269 & 13,627 & 13,365 & 13,238 & 12,347 \\
\hline Yakima, WA & 22,925 & 21,290 & 20,671 & 16,609 & 16,031 & 16,251 & 15,772 & 14,473 & 13,268 \\
\hline Burns, OR & 20,186 & 19,198 & 18,778 & 15,334 & 14,961 & 15,677 & 15,308 & 13,352 & 12,799 \\
\hline Olympia, WA & 17,156 & 15,998 & 15,738 & 13,636 & 13,353 & 13,628 & 13,418 & 12,635 & 12,259 \\
\hline Quillayuta, WA & 12,689 & 12,460 & 12,416 & 12,223 & 12,176 & 11,987 & 11,963 & 11,877 & 11,838 \\
\hline Seattle, WA & 15,519 & 14,651 & 14,466 & 13,622 & 13,340 & 12,647 & 12,533 & 12,433 & 12,043 \\
\hline Kalispell, MT & 18,742 & 17,718 & 17,413 & 15,201 & 14,894 & 13,982 & 13,752 & 12,625 & 12,259 \\
\hline Cut Bank, MT & 17,561 & 16,861 & 16,676 & 15,524 & 15,304 & 13,282 & 13,133 & 12,596 & 12,275 \\
\hline
\end{tabular}


Table: C-31 Annual Energy Consumption (Chiller, Fan, and Pump) for the StandardPerformance Primary School Building Design for Various HVAC Combinations across 21 Climate Locations (units in kWh) with Prototype Low-Lift Chiller for the LLCS

\section{Configurations}

\begin{tabular}{|c|c|c|c|c|c|c|c|c|c|}
\hline & Case 0 & Case 1 & Case 2 & Case 3 & Case 4 & Case 5 & Case 6 & Case 7 & Case 8 \\
\hline Pendleton, OR & 243,164 & 214,781 & 208,853 & 188,616 & 178,150 & 130,238 & 126,058 & 105,157 & 96,872 \\
\hline Spokane, WA & 207,206 & 191,977 & 187,557 & 171,660 & 163,939 & 114,419 & 111,084 & 96,540 & 88,767 \\
\hline Missoula, MT & 209,978 & 186,149 & 182,712 & 167,159 & 160,770 & 109,997 & 106,935 & 91,917 & 85,473 \\
\hline Boise, ID & 241,603 & 228,325 & 223,562 & 193,821 & 184,087 & 138,322 & 133,781 & 107,607 & 98,965 \\
\hline Pocatello, ID & 222,833 & 205,268 & 201,199 & 181,448 & 174,273 & 117,578 & 114,165 & 96,740 & 89,384 \\
\hline Helena, MT & 211,233 & 193,876 & 190,146 & 172,104 & 165,660 & 114,142 & 110,702 & 93,539 & 86,775 \\
\hline Astoria, OR & 155,433 & 130,619 & 127,022 & 122,802 & 118,078 & 83,472 & 80,446 & 76,179 & 69,676 \\
\hline Salem, OR & 212,800 & 179,660 & 174,127 & 158,221 & 149,490 & 108,986 & 103,104 & 90,203 & 80,441 \\
\hline Eugene, OR & 214,339 & 176,280 & 170,971 & 157,364 & 148,824 & 106,298 & 101,378 & 88,768 & 79,700 \\
\hline North Bend, OR & 148,325 & 124,041 & 121,484 & 116,881 & 113,559 & 83,044 & 81,207 & 73,345 & 68,533 \\
\hline Arcata, CA & 137,608 & 122,781 & 119,997 & 113,994 & 111,335 & 86,904 & 85,364 & 79,175 & 74,699 \\
\hline Medford, OR & 251,753 & 219,853 & 214,034 & 189,205 & 178,465 & 135,664 & 131,364 & 108,138 & 99,266 \\
\hline Redmond, OR & 211,203 & 193,020 & 188,600 & 169,982 & 163,111 & 116,151 & 113,290 & 95,272 & 88,877 \\
\hline Portland, OR & 209,783 & 173,053 & 167,567 & 155,745 & 147,132 & 103,359 & 98,123 & 88,632 & 79,331 \\
\hline Yakima, WA & 227,161 & 202,224 & 196,476 & 180,363 & 168,753 & 121,389 & 116,674 & 102,731 & 93,639 \\
\hline Burns, OR & 211,814 & 193,572 & 189,140 & 170,519 & 163,598 & 116,357 & 113,488 & 95,427 & 89,019 \\
\hline Olympia, WA & 192,964 & 161,036 & 156,352 & 145,778 & 138,791 & 98,555 & 94,113 & 85,015 & 77,182 \\
\hline Quillayuta, WA & 149,228 & 130,513 & 127,078 & 122,571 & 118,203 & 81,978 & 78,838 & 74,585 & 68,696 \\
\hline Seattle, WA & 182,022 & 150,545 & 145,740 & 140,583 & 133,836 & 91,478 & 87,188 & 82,066 & 73,954 \\
\hline Kalispell, MT & 190,514 & 168,840 & 165,644 & 154,100 & 149,002 & 101,246 & 98,413 & 87,022 & 81,091 \\
\hline Cut Bank, MT & 187,744 & 168,906 & 165,521 & 158,751 & 153,429 & 94,371 & 91,444 & 84,578 & 78,797 \\
\hline
\end{tabular}


Table: C-32 Annual Energy Consumption (Chiller, Fan, and Pump) for the HighPerformance Primary School Building Design for Various HVAC Combinations across 21 Climate Locations (units in kWh) with Prototype Low-Lift Chiller for the LLCS Configurations

\begin{tabular}{|l|r|r|r|r|r|r|r|r|r|}
\hline & Case 0 & Case 1 & Case 2 & Case 3 & Case 4 & Case 5 & Case 6 & Case 7 & Case 8 \\
\hline Pendleton, OR & 69,733 & 60,235 & 58,001 & 48,298 & 45,175 & 47,741 & 46,041 & 38,627 & 34,664 \\
\hline Spokane, WA & 56,133 & 51,626 & 49,966 & 42,510 & 40,455 & 41,678 & 40,519 & 35,322 & 32,098 \\
\hline Missoula, MT & 56,342 & 48,470 & 47,321 & 40,127 & 38,416 & 40,030 & 38,936 & 33,003 & 30,572 \\
\hline Boise, ID & 68,281 & 64,220 & 62,402 & 49,386 & 46,238 & 50,653 & 48,810 & 39,603 & 35,570 \\
\hline Pocatello, ID & 57,722 & 52,584 & 51,142 & 42,590 & 40,561 & 42,104 & 40,905 & 34,730 & 31,881 \\
\hline Helena, MT & 55,294 & 50,755 & 49,513 & 41,541 & 39,415 & 41,816 & 40,737 & 33,929 & 31,293 \\
\hline Astoria, OR & 46,931 & 38,397 & 37,381 & 34,667 & 33,306 & 31,023 & 30,112 & 28,227 & 26,251 \\
\hline Salem, OR & 60,536 & 49,651 & 47,526 & 41,084 & 38,239 & 39,720 & 37,355 & 33,357 & 29,334 \\
\hline Eugene, OR & 60,572 & 47,942 & 45,936 & 40,376 & 37,692 & 38,379 & 36,270 & 32,481 & 28,839 \\
\hline North Bend, OR & 44,961 & 37,280 & 36,798 & 34,122 & 33,337 & 30,687 & 30,431 & 27,403 & 26,547 \\
\hline Arcata, CA & 41,825 & 37,598 & 37,104 & 34,011 & 33,317 & 32,224 & 32,449 & 29,830 & 28,706 \\
\hline Medford, OR & 74,283 & 63,433 & 61,057 & 49,666 & 46,186 & 49,883 & 47,950 & 39,647 & 35,225 \\
\hline Redmond, OR & 59,106 & 52,724 & 51,100 & 42,949 & 40,850 & 41,983 & 40,744 & 34,812 & 31,981 \\
\hline Portland, OR & 59,119 & 46,737 & 44,604 & 39,937 & 37,340 & 37,235 & 34,998 & 32,811 & 28,653 \\
\hline Yakima, WA & 63,733 & 55,162 & 52,899 & 45,325 & 42,292 & 43,460 & 41,440 & 37,469 & 33,216 \\
\hline Burns, OR & 59,136 & 52,719 & 51,085 & 42,918 & 40,839 & 42,035 & 40,789 & 34,862 & 32,016 \\
\hline Olympia, WA & 56,156 & 45,375 & 43,714 & 38,649 & 36,542 & 36,336 & 34,663 & 31,688 & 28,451 \\
\hline Quillayuta, WA & 42,811 & 37,204 & 36,146 & 33,574 & 32,414 & 30,667 & 29,800 & 27,687 & 26,066 \\
\hline Seattle, WA & 51,064 & 40,331 & 38,605 & 36,313 & 34,463 & 32,813 & 31,096 & 30,168 & 26,955 \\
\hline Kalispell, MT & 50,914 & 43,449 & 42,321 & 37,193 & 35,782 & 36,513 & 35,500 & 31,432 & 29,174 \\
\hline Cut Bank, MT & 45,639 & 39,888 & 38,737 & 35,736 & 34,411 & 33,173 & 32,122 & 29,962 & 27,909 \\
\hline
\end{tabular}


Table: C-33 Annual Energy Consumption (Chiller, Fan, and Pump) for the StandardPerformance Large Hotel Building Design for Various HVAC Combinations across 21 Climate Locations (units in kWh) with Prototype Low-Lift Chiller for the LLCS Configurations

\begin{tabular}{|c|c|c|c|c|c|c|c|c|c|}
\hline & Case 0 & Case 1 & Case 2 & Case 3 & Case 4 & Case 5 & Case 6 & Case 7 & Case 8 \\
\hline Pendleton, OR & 817,631 & 217,275 & 209,992 & 207,120 & 198,098 & 44,572 & 37,498 & 40,160 & 32,557 \\
\hline Spokane, WA & 750,325 & 207,686 & 202,071 & 197,733 & 191,501 & 37,138 & 31,527 & 33,288 & 26,819 \\
\hline Missoula, MT & 723,289 & 205,872 & 203,160 & 194,349 & 190,633 & 35,780 & 32,736 & 27,736 & 23,914 \\
\hline Boise, ID & 817,242 & 228,388 & 221,772 & 214,993 & 205,341 & 50,079 & 42,768 & 43,261 & 35,343 \\
\hline Pocatello, ID & 760,583 & 211,913 & 206,727 & 201,403 & 194,515 & 36,731 & 31,745 & 33,149 & 26,234 \\
\hline Helena, MT & 752,392 & 204,647 & 199,747 & 197,362 & 190,161 & 33,855 & 28,007 & 30,272 & 23,662 \\
\hline Astoria, OR & 637,206 & 165,601 & 161,011 & 162,230 & 157,534 & 22,573 & 16,277 & 21,596 & 14,897 \\
\hline Salem, OR & 721,969 & 188,506 & 181,421 & 182,918 & 173,071 & 33,376 & 24,159 & 30,721 & 20,430 \\
\hline Eugene, OR & 722,622 & 186,932 & 180,051 & 181,747 & 172,743 & 32,187 & 23,876 & 29,793 & 20,394 \\
\hline North Bend, OR & 606,181 & 158,251 & 154,473 & 154,526 & 150,740 & 20,615 & 16,139 & 19,548 & 14,090 \\
\hline Arcata, CA & 600,494 & 156,172 & 153,139 & 150,956 & 148,149 & 23,134 & 20,018 & 22,185 & 17,975 \\
\hline Medford, OR & 799,061 & 214,030 & 205,765 & 205,430 & 192,314 & 44,722 & 36,608 & 40,690 & 31,541 \\
\hline Redmond, OR & 751,189 & 199,297 & 194,155 & 189,989 & 183,390 & 32,401 & 27,631 & 29,727 & 23,369 \\
\hline Portland, OR & 727,714 & 189,210 & 181,656 & 184,835 & 175,059 & 33,008 & 23,614 & 31,059 & 20,989 \\
\hline Yakima, WA & 756,522 & 207,708 & 199,697 & 200,336 & 188,783 & 39,736 & 32,042 & 37,041 & 28,066 \\
\hline Burns, OR & 751,228 & 199,316 & 194,174 & 190,023 & 183,410 & 32,407 & 27,637 & 29,726 & 23,373 \\
\hline Olympia, WA & 691,589 & 180,710 & 175,195 & 175,996 & 168,225 & 28,411 & 21,097 & 26,392 & 18,067 \\
\hline Quillayuta, WA & 668,167 & 166,679 & 162,770 & 163,090 & 159,022 & 20,624 & 15,645 & 19,469 & 13,674 \\
\hline Seattle, WA & 683,158 & 180,234 & 174,098 & 176,545 & 169,906 & 26,836 & 19,447 & 25,389 & 17,560 \\
\hline Kalispell, MT & 694,208 & 192,209 & 189,474 & 183,886 & 180,484 & 28,042 & 25,130 & 23,469 & 18,652 \\
\hline Cut Bank, MT & 712,425 & 190,316 & 186,208 & 185,934 & 181,016 & 23,571 & 19,431 & 22,134 & 17,165 \\
\hline
\end{tabular}


Table: C-34 Annual Energy Consumption (Chiller, Fan, and Pump) for the HighPerformance Large Hotel Building Design for Various HVAC Combinations across 21 Climate Locations (units in kWh) with Prototype Low-Lift Chiller for the LLCS Configurations

\begin{tabular}{|l|r|r|r|r|r|r|r|r|r|}
\hline & Case 0 & Case 1 & Case 2 & Case 3 & Case 4 & Case 5 & Case 6 & Case 7 & Case 8 \\
\hline Pendleton, OR & 301,508 & 79,605 & 75,645 & 72,253 & 68,509 & 21,002 & 17,154 & 19,047 & 13,774 \\
\hline Spokane, WA & 258,425 & 72,702 & 69,969 & 66,120 & 63,717 & 16,560 & 13,837 & 14,643 & 10,452 \\
\hline Missoula, MT & 254,875 & 67,660 & 65,617 & 62,377 & 59,978 & 13,620 & 11,358 & 11,894 & 7,786 \\
\hline Boise, ID & 293,244 & 82,244 & 78,324 & 73,423 & 69,568 & 22,632 & 18,532 & 20,311 & 14,519 \\
\hline Pocatello, ID & 260,633 & 73,441 & 70,659 & 66,364 & 63,667 & 16,384 & 13,744 & 14,817 & 9,922 \\
\hline Helena, MT & 256,147 & 69,554 & 67,157 & 64,039 & 61,369 & 14,942 & 12,080 & 12,729 & 8,688 \\
\hline Astoria, OR & 228,125 & 58,562 & 56,895 & 55,425 & 53,674 & 9,183 & 6,916 & 7,184 & 4,559 \\
\hline Salem, OR & 266,417 & 69,209 & 66,434 & 62,647 & 59,522 & 16,162 & 12,697 & 13,062 & 7,666 \\
\hline Eugene, OR & 266,489 & 68,476 & 65,846 & 62,587 & 59,431 & 15,502 & 12,398 & 12,734 & 7,538 \\
\hline North Bend, OR & 220,633 & 57,323 & 56,191 & 54,472 & 53,214 & 8,234 & 7,013 & 5,753 & 4,565 \\
\hline Arcata, CA & 229,053 & 56,239 & 55,061 & 53,109 & 51,954 & 7,622 & 6,441 & 6,700 & 4,779 \\
\hline Medford, OR & 303,217 & 80,552 & 76,906 & 71,723 & 67,801 & 22,006 & 18,348 & 19,017 & 13,150 \\
\hline Redmond, OR & 265,025 & 70,140 & 67,642 & 63,419 & 60,885 & 14,686 & 12,344 & 13,074 & 8,571 \\
\hline Portland, OR & 268,494 & 69,186 & 66,155 & 63,491 & 60,386 & 15,804 & 12,133 & 13,529 & 8,176 \\
\hline Yakima, WA & 274,075 & 76,526 & 73,057 & 68,901 & 65,448 & 19,354 & 15,936 & 17,398 & 11,879 \\
\hline Burns, OR & 265,025 & 70,140 & 67,641 & 63,409 & 60,888 & 14,686 & 12,343 & 13,070 & 8,568 \\
\hline Olympia, WA & 250,975 & 65,118 & 63,048 & 59,763 & 57,132 & 13,183 & 10,512 & 10,675 & 6,350 \\
\hline Quillayuta, WA & 240,942 & 57,013 & 55,495 & 53,867 & 52,462 & 7,842 & 6,083 & 5,852 & 3,604 \\
\hline Seattle, WA & 242,664 & 63,305 & 60,906 & 59,389 & 57,053 & 11,867 & 9,207 & 9,811 & 6,137 \\
\hline Kalispell, MT & 233,550 & 63,331 & 61,497 & 58,953 & 56,923 & 10,997 & 9,098 & 9,451 & 5,826 \\
\hline Cut Bank, MT & 228,033 & 61,686 & 59,832 & 58,294 & 56,347 & 9,454 & 7,577 & 8,260 & 5,196 \\
\hline
\end{tabular}


Table: C-35 Annual Energy Consumption (Chiller, Fan, and Pump) for the Standard Performance Warehouse Building Design for Various HVAC Combinations across 21 Climate Locations (units in kWh) with Prototype Low-Lift Chiller for the LLCS Configurations

\begin{tabular}{|c|c|c|c|c|c|c|c|c|c|}
\hline & Case 0 & Case 1 & Case 2 & Case 3 & Case 4 & Case 5 & Case 6 & Case 7 & Case 8 \\
\hline Pendleton, OR & 7,228 & 7,042 & 6,921 & 6,138 & 6,005 & 2,878 & 2,689 & 2,218 & 2,009 \\
\hline Spokane, WA & 6,656 & 6,635 & 6,553 & 5,959 & 5,866 & 2,608 & 2,463 & 2,094 & 1,935 \\
\hline Missoula, MT & 7,256 & 7,082 & 7,013 & 6,508 & 6,418 & 2,352 & 2,229 & 1,915 & 1,781 \\
\hline Boise, ID & 7,269 & 7,326 & 7,203 & 6,249 & 6,125 & 2,958 & 2,781 & 2,246 & 2,047 \\
\hline Pocatello, ID & 7,261 & 7,176 & 7,086 & 6,462 & 6,355 & 2,614 & 2,468 & 2,087 & 1,921 \\
\hline Helena, MT & 7,183 & 7,135 & 7,064 & 6,507 & 6,431 & 2,385 & 2,249 & 1,922 & 1,796 \\
\hline Astoria, OR & 3,794 & 3,752 & 3,738 & 3,694 & 3,679 & 1,997 & 1,910 & 1,846 & 1,782 \\
\hline Salem, OR & 5,922 & 5,789 & 5,701 & 5,164 & 5,079 & 2,395 & 2,248 & 1,971 & 1,854 \\
\hline Eugene, OR & 5,903 & 5,661 & 5,579 & 5,121 & 5,032 & 2,341 & 2,207 & 1,951 & 1,833 \\
\hline North Bend, OR & 3,617 & 3,581 & 3,573 & 3,556 & 3,547 & 1,984 & 1,921 & 1,845 & 1,790 \\
\hline Arcata, CA & 3,583 & 3,584 & 3,583 & 3,552 & 3,547 & 1,805 & 1,727 & 1,682 & 1,592 \\
\hline Medford, OR & 7,797 & 7,546 & 7,423 & 6,354 & 6,203 & 3,108 & 2,920 & 2,279 & 2,056 \\
\hline Redmond, OR & 6,461 & 6,334 & 6,245 & 5,689 & 5,589 & 2,578 & 2,417 & 2,087 & 1,914 \\
\hline Portland, OR & 5,658 & 5,461 & 5,379 & 5,029 & 4,947 & 2,250 & 2,114 & 1,930 & 1,820 \\
\hline Yakima, WA & 6,794 & 6,624 & 6,509 & 5,867 & 5,746 & 2,653 & 2,466 & 2,137 & 1,937 \\
\hline Burns, OR & 6,525 & 6,415 & 6,325 & 5,761 & 5,662 & 2,588 & 2,425 & 2,090 & 1,918 \\
\hline Olympia, WA & 5,264 & 5,074 & 5,019 & 4,661 & 4,597 & 2,215 & 2,099 & 1,916 & 1,815 \\
\hline Quillayuta, WA & 3,989 & 3,928 & 3,907 & 3,854 & 3,837 & 1,993 & 1,911 & 1,843 & 1,781 \\
\hline Seattle, WA & 4,797 & 4,613 & 4,564 & 4,442 & 4,389 & 2,101 & 1,981 & 1,893 & 1,795 \\
\hline Kalispell, MT & 7,008 & 6,824 & 6,766 & 6,498 & 6,425 & 2,144 & 2,022 & 1,833 & 1,714 \\
\hline Cut Bank, MT & 8,444 & 8,321 & 8,273 & 8,095 & 8,038 & 2,077 & 1,955 & 1,821 & 1,708 \\
\hline
\end{tabular}


Table: C-36 Annual Energy Consumption (Chiller, Fan, and Pump) for the High Performance Warehouse Building Design for Various HVAC Combinations across 21 Climate Locations (units in kWh) with Prototype Low-Lift Chiller for the LLCS Configurations

\begin{tabular}{|l|r|r|r|r|r|r|r|r|r|}
\hline & Case 0 & Case 1 & Case 2 & Case 3 & Case 4 & Case 5 & Case 6 & Case 7 & Case 8 \\
\hline Pendleton, OR & 1,350 & 1,358 & 1,372 & 1,141 & 1,121 & 1,193 & 1,239 & 1,035 & 1,010 \\
\hline Spokane, WA & 1,267 & 1,291 & 1,303 & 1,121 & 1,107 & 1,143 & 1,180 & 1,020 & 1,000 \\
\hline Missoula, MT & 1,353 & 1,308 & 1,303 & 1,202 & 1,188 & 1,034 & 1,028 & 977 & 962 \\
\hline Boise, ID & 1,297 & 1,389 & 1,410 & 1,139 & 1,122 & 1,205 & 1,265 & 1,032 & 1,011 \\
\hline Pocatello, ID & 1,286 & 1,287 & 1,291 & 1,130 & 1,116 & 1,122 & 1,142 & 1,014 & 995 \\
\hline Helena, MT & 1,222 & 1,213 & 1,207 & 1,101 & 1,089 & 1,036 & 1,029 & 981 & 965 \\
\hline Astoria, OR & 975 & 959 & 957 & 944 & 941 & 1,058 & 1,054 & 1,046 & 1,042 \\
\hline Salem, OR & 1,219 & 1,207 & 1,209 & 1,066 & 1,052 & 1,120 & 1,123 & 1,063 & 1,051 \\
\hline Eugene, OR & 1,222 & 1,196 & 1,203 & 1,065 & 1,050 & 1,116 & 1,132 & 1,060 & 1,048 \\
\hline North Bend, OR & 936 & 939 & 939 & 936 & 935 & 1,053 & 1,050 & 1,045 & 1,041 \\
\hline Arcata, CA & 928 & 940 & 940 & 935 & 935 & 870 & 869 & 868 & 866 \\
\hline Medford, OR & 1,461 & 1,567 & 1,649 & 1,175 & 1,154 & 1,304 & 1,450 & 1,044 & 1,019 \\
\hline Redmond, OR & 1,242 & 1,226 & 1,220 & 1,100 & 1,086 & 1,095 & 1,087 & 1,013 & 991 \\
\hline Portland, OR & 1,186 & 1,119 & 1,111 & 1,028 & 1,014 & 1,090 & 1,082 & 1,058 & 1,046 \\
\hline Yakima, WA & 1,289 & 1,252 & 1,243 & 1,112 & 1,094 & 1,071 & 1,059 & 1,008 & 985 \\
\hline Burns, OR & 1,250 & 1,230 & 1,223 & 1,102 & 1,087 & 1,098 & 1,090 & 1,014 & 992 \\
\hline Olympia, WA & 1,153 & 1,099 & 1,095 & 1,014 & 1,003 & 1,084 & 1,077 & 1,055 & 1,046 \\
\hline Quillayuta, WA & 981 & 957 & 955 & 943 & 940 & 1,058 & 1,055 & 1,047 & 1,042 \\
\hline Seattle, WA & 1,078 & 1,039 & 1,034 & 997 & 988 & 1,070 & 1,064 & 1,051 & 1,043 \\
\hline Kalispell, MT & 1,361 & 1,309 & 1,304 & 1,241 & 1,230 & 1,006 & 999 & 966 & 953 \\
\hline Cut Bank, MT & 1,817 & 1,800 & 1,796 & 1,754 & 1,745 & 992 & 987 & 964 & 953 \\
\hline
\end{tabular}


Table: C-37 Annual Energy Consumption (Chiller, Fan, and Pump) for the StandardPerformance Outpatient Healthcare Building Design for Various HVAC Combinations across 21 Climate Locations (units in kWh) with Prototype Low-Lift Chiller for the LLCS Configurations

\begin{tabular}{|c|c|c|c|c|c|c|c|c|c|}
\hline & Case 0 & Case 1 & Case 2 & Case 3 & Case 4 & Case 5 & Case 6 & Case 7 & Case 8 \\
\hline Pendleton, OR & 42,047 & 41,089 & 40,728 & 37,976 & 37,539 & 10,165 & 9,346 & 8,404 & 7,392 \\
\hline Spokane, WA & 39,017 & 38,366 & 38,124 & 36,122 & 35,842 & 8,583 & 7,978 & 7,027 & 6,442 \\
\hline Missoula, MT & 38,314 & 37,481 & 37,289 & 35,146 & 34,916 & 7,960 & 7,431 & 6,237 & 5,809 \\
\hline Boise, ID & 42,939 & 42,086 & 41,751 & 38,842 & 38,465 & 10,183 & 9,399 & 8,145 & 7,430 \\
\hline Pocatello, ID & 40,842 & 39,932 & 39,680 & 37,134 & 36,857 & 8,849 & 8,202 & 6,739 & 6,215 \\
\hline Helena, MT & 38,578 & 37,797 & 37,598 & 35,794 & 35,539 & 8,062 & 7,463 & 6,545 & 6,016 \\
\hline Astoria, OR & 27,869 & 27,527 & 27,489 & 27,348 & 27,283 & 5,543 & 5,158 & 5,193 & 4,683 \\
\hline Salem, OR & 37,047 & 36,074 & 35,852 & 34,097 & 33,803 & 7,639 & 7,018 & 6,080 & 5,407 \\
\hline Eugene, OR & 37,042 & 36,025 & 35,801 & 34,024 & 33,738 & 7,657 & 7,040 & 6,061 & 5,436 \\
\hline North Bend, OR & 25,064 & 24,923 & 24,906 & 24,872 & 24,841 & 5,387 & 5,047 & 5,047 & 4,626 \\
\hline Arcata, CA & 24,367 & 24,284 & 24,279 & 24,221 & 24,207 & 5,016 & 4,773 & 4,761 & 4,575 \\
\hline Medford, OR & 42,181 & 41,295 & 40,946 & 37,316 & 36,932 & 10,122 & 9,353 & 7,495 & 6,771 \\
\hline Redmond, OR & 38,661 & 37,976 & 37,751 & 35,534 & 35,311 & 8,425 & 7,816 & 6,095 & 5,749 \\
\hline Portland, OR & 36,592 & 35,460 & 35,218 & 33,852 & 33,525 & 7,569 & 6,886 & 6,637 & 5,571 \\
\hline Yakima, WA & 39,597 & 38,554 & 38,249 & 35,771 & 35,444 & 9,117 & 8,402 & 7,127 & 6,415 \\
\hline Burns, OR & 38,728 & 37,986 & 37,761 & 35,546 & 35,316 & 8,435 & 7,825 & 6,094 & 5,754 \\
\hline Olympia, WA & 34,436 & 33,604 & 33,443 & 32,096 & 31,907 & 6,914 & 6,402 & 5,645 & 5,175 \\
\hline Quillayuta, WA & 29,267 & 29,054 & 29,018 & 28,829 & 28,781 & 5,402 & 5,096 & 4,899 & 4,651 \\
\hline Seattle, WA & 33,314 & 32,613 & 32,469 & 31,791 & 31,567 & 6,626 & 6,078 & 6,078 & 5,155 \\
\hline Kalispell, MT & 36,167 & 35,442 & 35,300 & 33,813 & 33,627 & 7,099 & 6,638 & 5,564 & 5,240 \\
\hline Cut Bank, MT & 35,486 & 34,966 & 34,842 & 33,960 & 33,799 & 6,794 & 6,297 & 5,601 & 5,196 \\
\hline
\end{tabular}


Table: C-38 Annual Energy Consumption (Chiller, Fan, and Pump) for the HighPerformance Outpatient Health Care Building Design for Various HVAC Combinations across 21 Climate Locations (units in kWh) with Prototype Low-Lift Chiller for the LLCS Configurations

\begin{tabular}{|l|r|r|r|r|r|r|r|r|r|}
\hline & Case 0 & Case 1 & Case 2 & Case 3 & Case 4 & Case 5 & Case 6 & Case 7 & Case 8 \\
\hline Pendleton, OR & 9,697 & 9,188 & 8,996 & 8,184 & 8,035 & 3,970 & 3,799 & 3,493 & 3,263 \\
\hline Spokane, WA & 8,469 & 8,174 & 8,062 & 7,488 & 7,399 & 3,552 & 3,442 & 3,177 & 3,034 \\
\hline Missoula, MT & 8,322 & 7,956 & 7,850 & 7,333 & 7,258 & 3,289 & 3,202 & 2,945 & 2,842 \\
\hline Boise, ID & 9,828 & 9,335 & 9,167 & 8,284 & 8,151 & 4,003 & 3,852 & 3,499 & 3,293 \\
\hline Pocatello, ID & 8,989 & 8,599 & 8,469 & 7,819 & 7,728 & 3,510 & 3,394 & 3,046 & 2,924 \\
\hline Helena, MT & 8,656 & 8,363 & 8,268 & 7,815 & 7,737 & 3,299 & 3,211 & 3,017 & 2,894 \\
\hline Astoria, OR & 5,231 & 5,205 & 5,199 & 5,185 & 5,178 & 2,703 & 2,697 & 2,692 & 2,685 \\
\hline Salem, OR & 7,897 & 7,565 & 7,463 & 7,073 & 6,992 & 3,122 & 3,038 & 2,865 & 2,771 \\
\hline Eugene, OR & 7,886 & 7,484 & 7,376 & 6,997 & 6,911 & 3,135 & 3,043 & 2,878 & 2,775 \\
\hline North Bend, OR & 4,583 & 4,559 & 4,558 & 4,557 & 4,556 & 2,684 & 2,684 & 2,684 & 2,683 \\
\hline Arcata, CA & 4,433 & 4,387 & 4,386 & 4,383 & 4,382 & 2,686 & 2,685 & 2,684 & 2,683 \\
\hline Medford, OR & 9,969 & 9,360 & 9,169 & 8,050 & 7,924 & 3,983 & 3,821 & 3,300 & 3,128 \\
\hline Redmond, OR & 8,131 & 7,840 & 7,731 & 7,229 & 7,160 & 3,320 & 3,223 & 2,916 & 2,837 \\
\hline Portland, OR & 7,733 & 7,392 & 7,296 & 6,991 & 6,904 & 3,090 & 3,002 & 2,928 & 2,790 \\
\hline Yakima, WA & 8,869 & 8,341 & 8,176 & 7,527 & 7,416 & 3,531 & 3,393 & 3,126 & 2,970 \\
\hline Burns, OR & 8,158 & 7,847 & 7,738 & 7,232 & 7,163 & 3,326 & 3,227 & 2,920 & 2,839 \\
\hline Olympia, WA & 7,128 & 6,817 & 6,757 & 6,450 & 6,399 & 3,002 & 2,947 & 2,816 & 2,754 \\
\hline Quillayuta, WA & 5,631 & 5,571 & 5,562 & 5,540 & 5,533 & 2,711 & 2,704 & 2,691 & 2,685 \\
\hline Seattle, WA & 6,664 & 6,461 & 6,418 & 6,285 & 6,240 & 2,870 & 2,829 & 2,797 & 2,724 \\
\hline Kalispell, MT & 7,719 & 7,510 & 7,437 & 7,148 & 7,094 & 3,020 & 2,962 & 2,797 & 2,738 \\
\hline Cut Bank, MT & 7,742 & 7,624 & 7,580 & 7,422 & 7,385 & 2,902 & 2,859 & 2,777 & 2,727 \\
\hline
\end{tabular}


Table: C-39 Annual Energy Consumption (Chiller, Fan, and Pump) for the StandardPerformance Hospital Building Design for Various HVAC Combinations across 21 Climate Locations (units in kWh) with Prototype Low-Lift Chiller for the LLCS Configurations

\begin{tabular}{|c|c|c|c|c|c|c|c|c|c|}
\hline & Case 0 & Case 1 & Case 2 & Case 3 & Case 4 & Case 5 & Case 6 & Case 7 & Case 8 \\
\hline Pendleton, OR & $1,324,258$ & $1,245,818$ & $1,220,033$ & $1,204,512$ & $1,178,354$ & 452,531 & 432,418 & 427,642 & 409,741 \\
\hline Spokane, WA & $, 245,511$ & $1,200,253$ & $1,180,545$ & $1,159,713$ & $1,135,149$ & 424,103 & 401,359 & 400,960 & 379,491 \\
\hline Missoula, MT & $1,244,822$ & $1,164,680$ & $1,148,947$ & $1,125,308$ & $1,105,620$ & 379,103 & 363,082 & 357,007 & 341,909 \\
\hline Boise, ID & $1,345,011$ & $1,322,603$ & $1,300,570$ & $1,254,561$ & $1,241,311$ & 475,146 & 454,901 & 443,342 & 428,029 \\
\hline Pocatello, ID & $1,295,903$ & $1,276,165$ & $1,255,517$ & $1,236,876$ & $1,209,284$ & 429,907 & 408,647 & 405,302 & 385,358 \\
\hline Helena, MT & $1,272,125$ & $1,268,814$ & $1,247,470$ & $1,244,483$ & $1,218,863$ & 353,446 & 334,769 & 339,700 & 319,747 \\
\hline Astoria, OR & $1,093,803$ & 942,853 & 919,255 & 932,872 & 903,404 & 324,686 & 291,594 & 314,785 & 277,245 \\
\hline Salem, OR & $1,198,803$ & $1,078,720$ & $1,054,835$ & $1,046,236$ & $1,011,105$ & 376,390 & 335,393 & 356,323 & 312,082 \\
\hline Eugene, OR & $1,215,700$ & $1,074,925$ & $1,051,799$ & $1,045,294$ & & 370,544 & & 351,321 & 311,794 \\
\hline North Bend, OR & $1,062,919$ & 919,922 & 900,225 & 910,267 & 882,005 & 327,403 & 301,679 & 315,629 & 284,922 \\
\hline Arcata, CA & $1,038,178$ & 915,419 & 894,955 & 905,267 & 877,062 & 373,955 & 341,245 & 365,012 & 327,808 \\
\hline Medford, OR & $1,308,969$ & $1,230,304$ & $1,203,242$ & $1,189,916$ & $1,155,066$ & 445,609 & 421,937 & 420,335 & 396,777 \\
\hline Redmond, OR & $1,254,928$ & $1,196,202$ & $1,175,517$ & $1,155,709$ & $1,130,594$ & 426,141 & 407,862 & 397,612 & 381,018 \\
\hline Portland, OR & $1,223,742$ & $1,074,298$ & $1,048,260$ & $1,050,407$ & $1,014,316$ & 368,405 & 332,988 & 351,947 & 312,318 \\
\hline Yakima, WA & $1,252,564$ & $1,189,910$ & $1,164,070$ & $1,155,104$ & $1,121,377$ & 426,029 & 400,104 & 404,394 & 377,651 \\
\hline Burns, OR & $1,255,433$ & $1,196,646$ & $1,175,953$ & $1,156,147$ & $1,131,019$ & 426,225 & 407,942 & 397,702 & 381,106 \\
\hline Olympia, WA & $1,154,597$ & $1,025,181$ & $1,004,251$ & 999,289 & 968,303 & 351,051 & 313,296 & 335,365 & 293,015 \\
\hline Quillayuta, WA & $1,055,489$ & 936,966 & 917,414 & 925,532 & 901,427 & 322,058 & 289,348 & 310,448 & 272,991 \\
\hline Seattle, WA & $1,165,511$ & $1,019,063$ & 994,243 & $1,003,544$ & 971,252 & 348,629 & 315,777 & 335,768 & 298,284 \\
\hline Kalispell, MT & $1,192,106$ & $1,106,922$ & $1,091,128$ & $1,081,607$ & $1,060,017$ & 352,940 & 335,649 & 334,901 & 316,701 \\
\hline Cut Bank, MT & $1,234,131$ & $1,166,394$ & $1,151,542$ & $1,140,831$ & $1,122,580$ & 368,121 & 356,486 & 346,707 & 337,186 \\
\hline
\end{tabular}

Table: C-40 Annual Energy Consumption (Chiller, Fan, and Pump) for the HighPerformance Hospital Building Design for Various HVAC Combinations across 21 Climate Locations (units in kWh) with Prototype Low-Lift Chiller for the LLCS Configurations

\begin{tabular}{|l|r|r|r|r|r|r|r|r|r|}
\hline & Case 0 & Case 1 & Case 2 & Case 3 & Case 4 & Case 5 & Case 6 & Case 7 & Case 8 \\
\hline Pendleton, OR & 369,814 & 307,544 & 295,671 & 284,989 & 267,199 & 174,763 & 162,638 & 161,959 & 149,352 \\
\hline Spokane, WA & 326,286 & 281,292 & 272,619 & 263,772 & 247,254 & 157,674 & 148,722 & 146,208 & 136,062 \\
\hline Missoula, MT & 319,392 & 264,192 & 257,768 & 243,800 & 232,720 & 146,859 & 139,356 & 135,363 & 126,846 \\
\hline Boise, ID & 365,064 & 328,553 & 318,306 & 295,221 & 278,947 & 188,428 & 176,040 & 168,829 & 157,428 \\
\hline Pocatello, ID & 352,214 & 294,250 & 285,575 & 274,017 & 255,144 & 160,775 & 151,775 & 149,008 & 138,297 \\
\hline Helena, MT & 340,056 & 273,758 & 265,550 & 255,767 & 241,581 & 151,499 & 141,176 & 140,783 & 129,786 \\
\hline Astoria, OR & 288,947 & 211,214 & 203,519 & 207,919 & 196,752 & 103,627 & 97,524 & 101,816 & 94,701 \\
\hline Salem, OR & 327,033 & 255,988 & 245,629 & 241,437 & 223,409 & 133,948 & 122,539 & 126,454 & 111,765 \\
\hline Eugene, OR & 331,225 & 253,176 & 243,217 & 241,161 & 224,090 & 130,865 & 121,019 & 123,991 & 110,442 \\
\hline North Bend, OR & 278,411 & 206,524 & 200,381 & 202,326 & 193,224 & 103,381 & 98,227 & 101,495 & 94,993 \\
\hline Arcata, CA & 268,878 & 203,542 & 197,777 & 200,343 & 192,080 & 114,518 & 110,019 & 113,286 & 108,035 \\
\hline Medford, OR & 367,911 & 309,528 & 297,160 & 284,775 & 263,569 & 174,091 & 161,243 & 161,452 & 145,860 \\
\hline Redmond, OR & 324,636 & 274,941 & 266,483 & 256,773 & 239,875 & 152,262 & 143,841 & 142,619 & 131,172 \\
\hline Portland, OR & 336,514 & 252,755 & 241,364 & 243,651 & 224,973 & 129,472 & 118,373 & 123,683 & 109,636 \\
\hline Yakima, WA & 344,908 & 290,134 & 278,180 & 274,406 & 252,003 & 163,923 & 151,822 & 154,806 & 139,450 \\
\hline Burns, OR & 324,628 & 274,904 & 266,444 & 256,715 & 239,847 & 152,188 & 143,766 & 142,553 & 131,105 \\
\hline Olympia, WA & 311,586 & 238,107 & 229,741 & 227,540 & 212,210 & 120,254 & 111,659 & 115,393 & 103,842 \\
\hline Quillayuta, WA & 269,622 & 206,567 & 200,157 & 202,121 & 193,829 & 103,187 & 98,449 & 100,867 & 94,764 \\
\hline Seattle, WA & 309,617 & 230,280 & 220,753 & 225,038 & 211,028 & 116,796 & 107,859 & 113,248 & 102,169 \\
\hline Kalispell, MT & 299,106 & 242,664 & 236,430 & 231,785 & 219,546 & 132,540 & 126,113 & 125,944 & 116,890 \\
\hline Cut Bank, MT & 296,869 & 239,843 & 234,409 & 230,456 & 220,260 & 129,757 & 123,776 & 123,361 & 115,911 \\
\hline
\end{tabular}




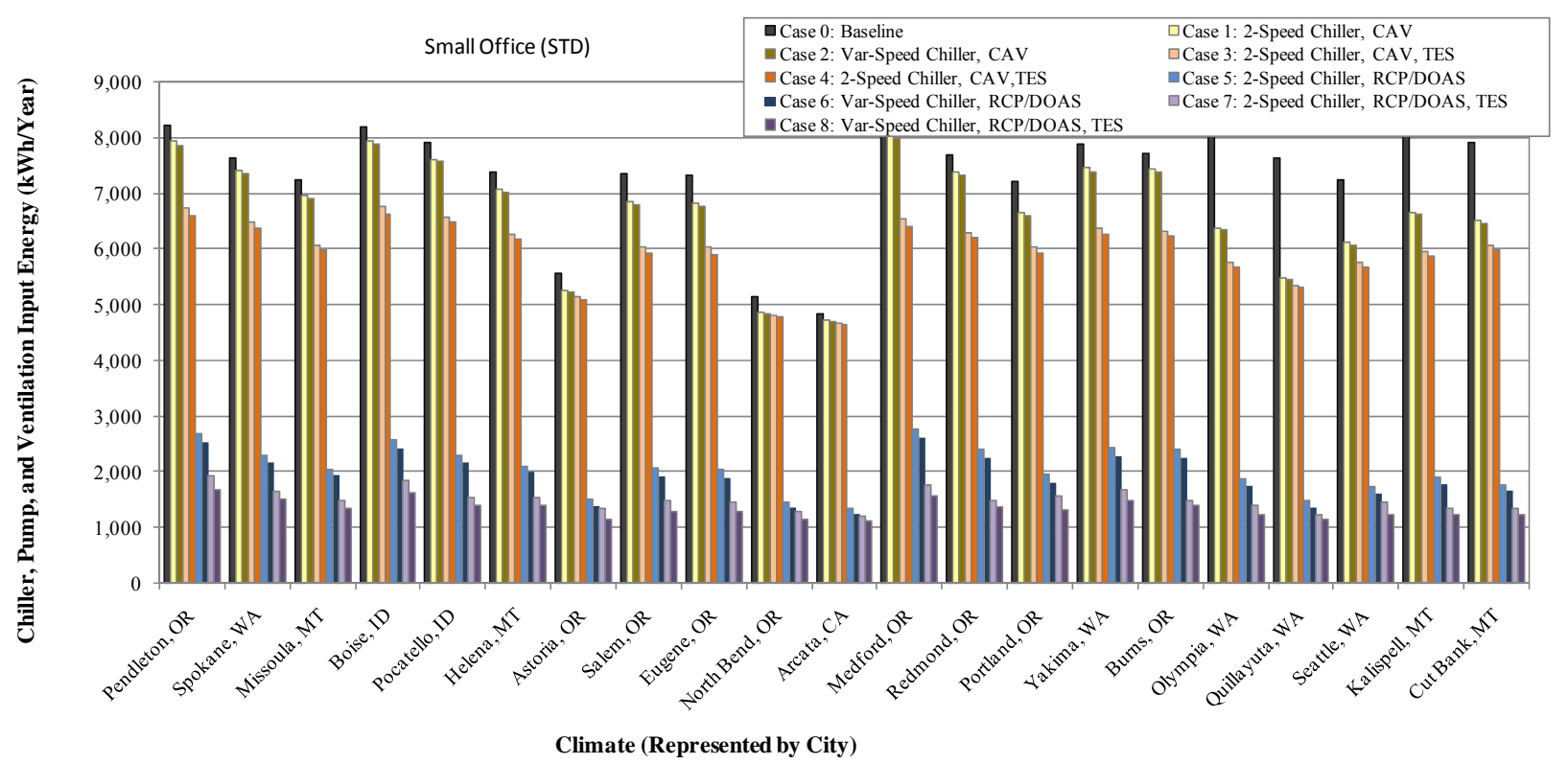

Figure: C-25 Comparison of Annual Chiller and Distribution Energy Consumption for Standard-Performance Small Office Building for Various System Configurations in 21 Locations with Prototype Low-Lift Chiller for the LLCS Configurations

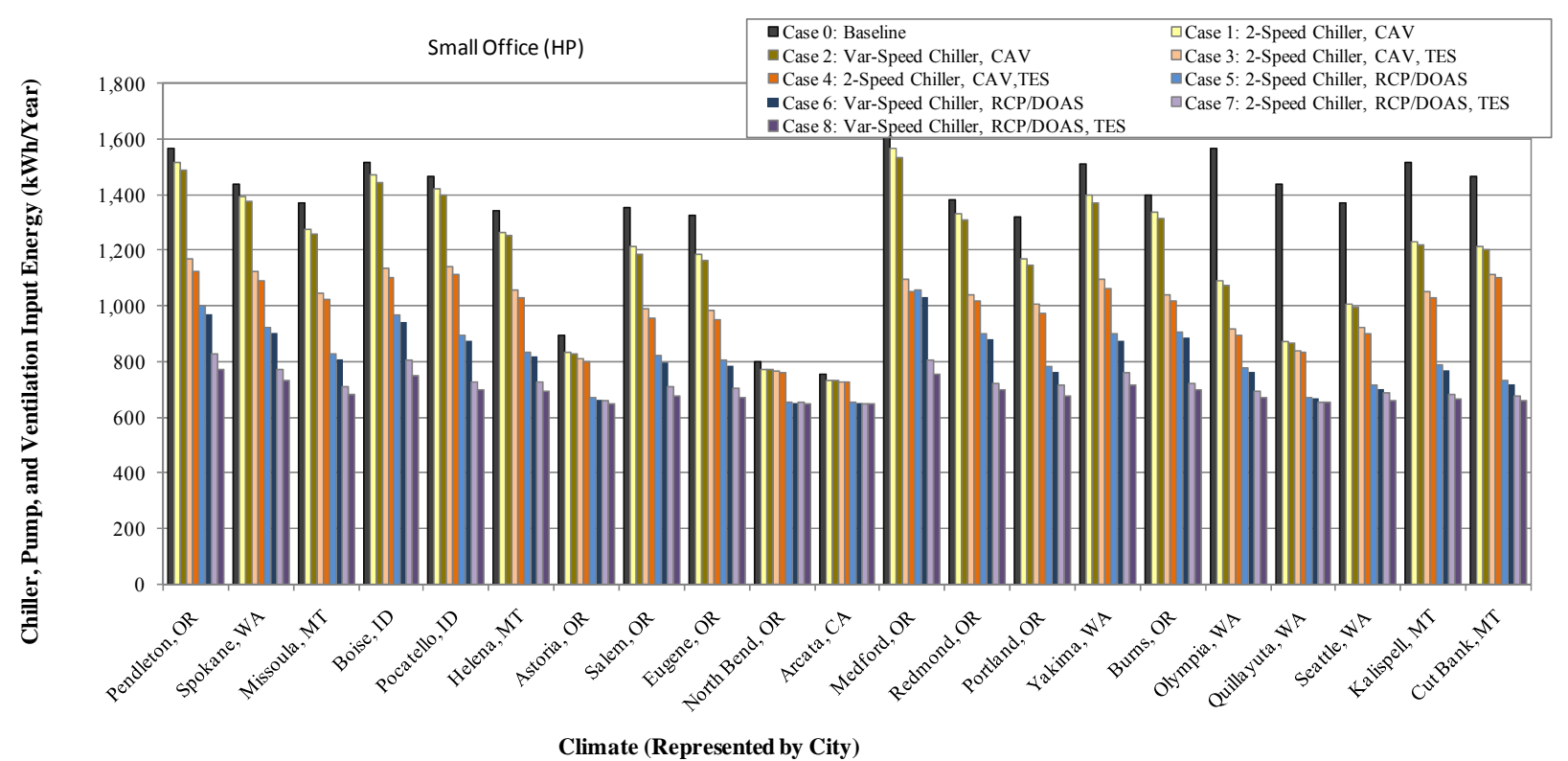

Figure: C-26 Comparison of Annual Chiller and Distribution Energy Consumption for High-Performance Small Office Building for Various System Configurations in 21 Locations with Prototype Low-Lift Chiller for the LLCS Configurations 


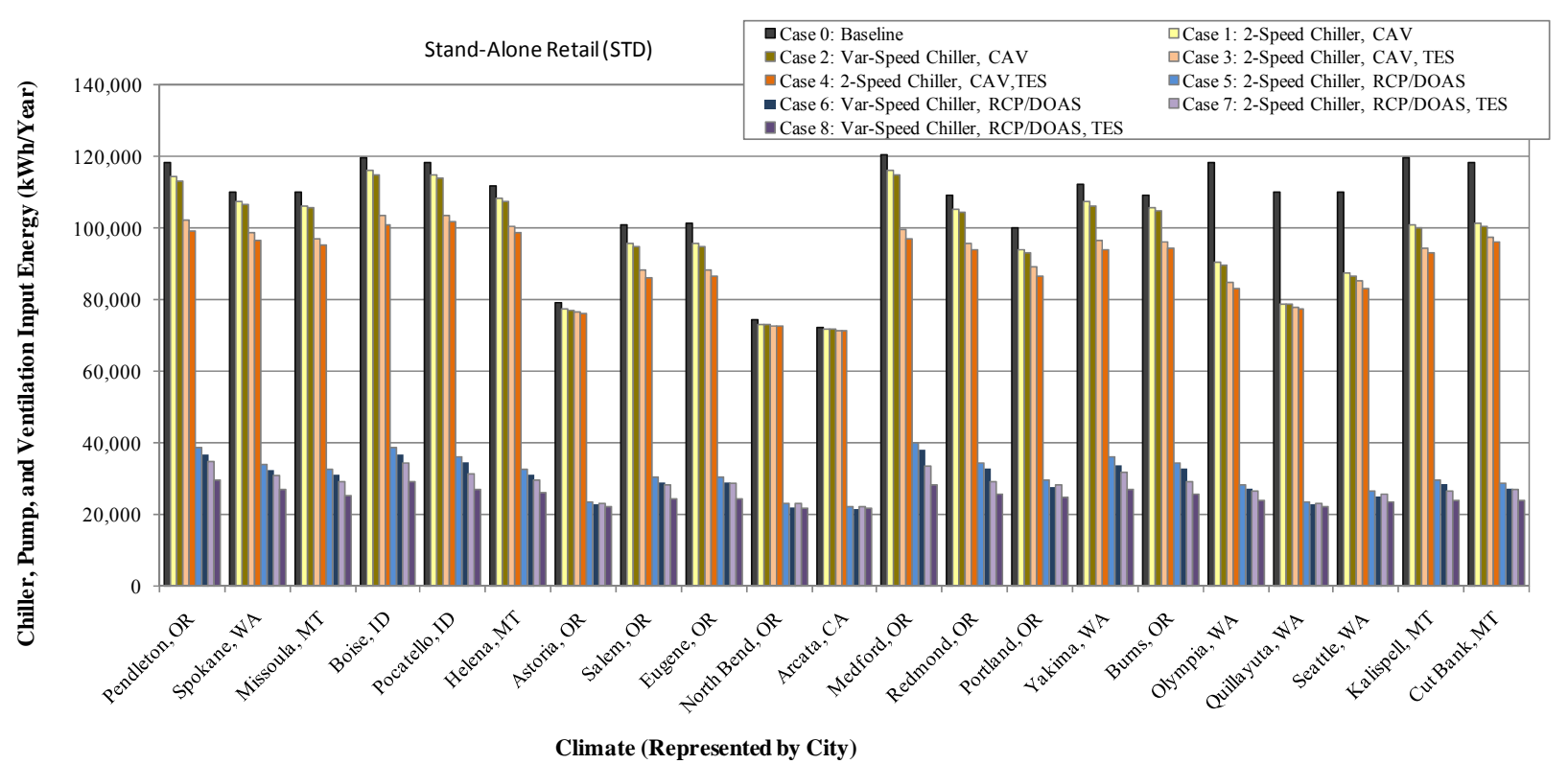

Figure: C-27 Comparison of Annual Chiller and Distribution Energy Consumption for Standard-Performance Standalone Retail Building for Various System Configurations in 21 Locations with Prototype Low-Lift Chiller for the LLCS Configurations

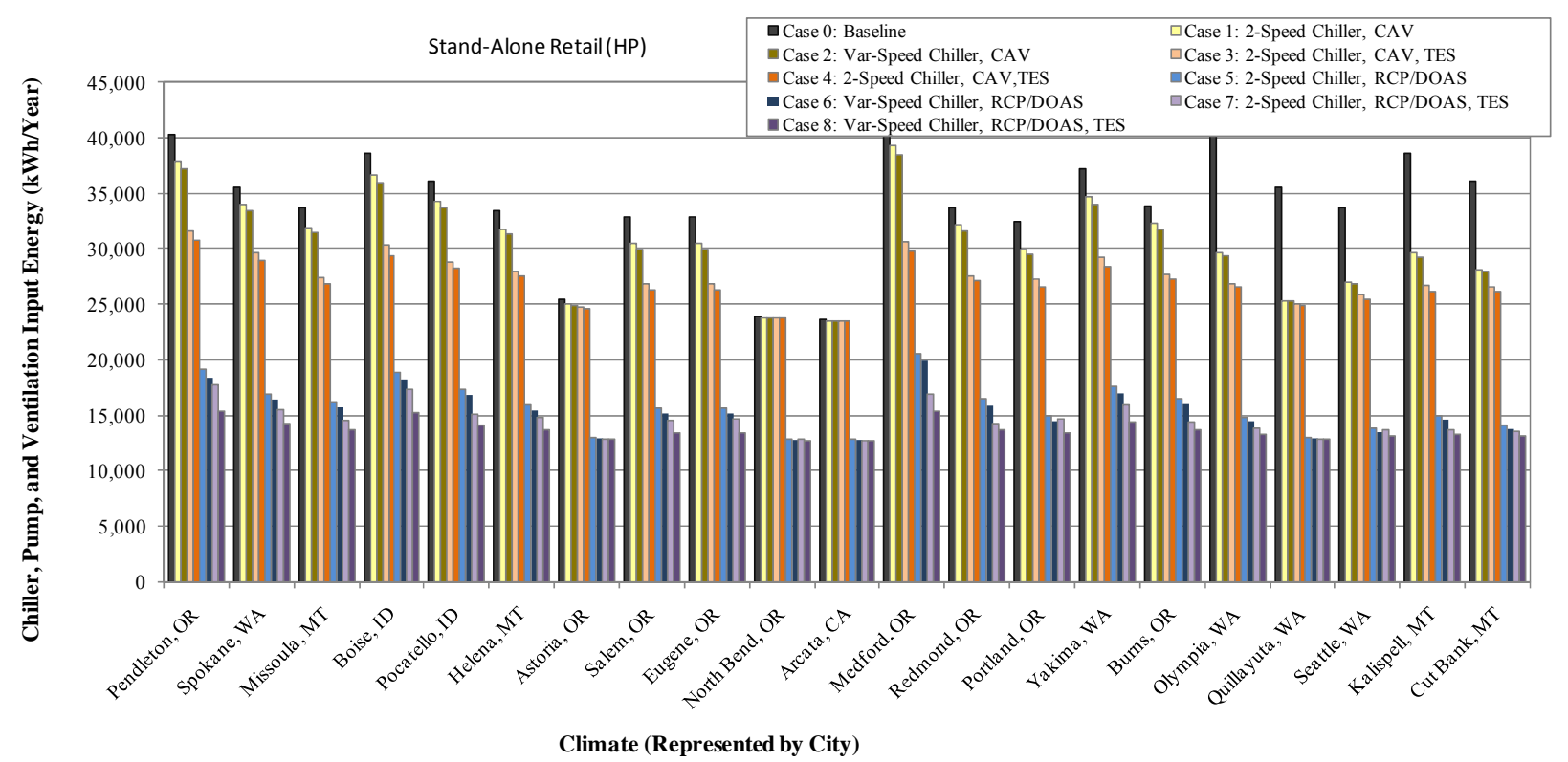

Figure: C-28 Comparison of Annual Chiller and Distribution Energy Consumption for High-Performance Standalone Retail Building for Various System Configurations in 21 Locations with Prototype Low-Lift Chiller for the LLCS Configurations 


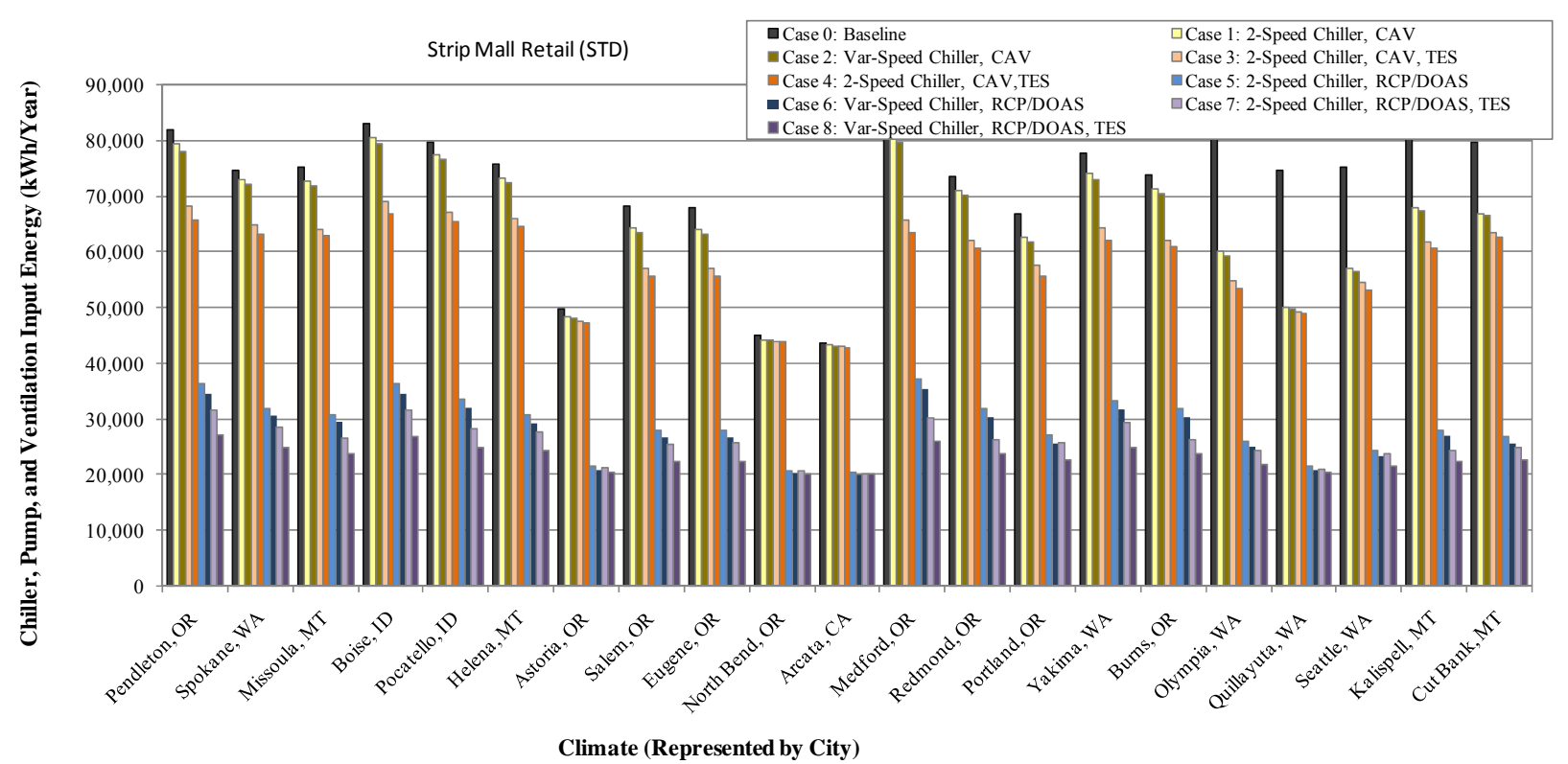

Figure: C-29 Comparison of Annual Chiller and Distribution Energy Consumption for Standard-Performance Strip Mall Retail Building for Various System Configurations in 21 Locations with Prototype Low-Lift Chiller for the LLCS Configurations

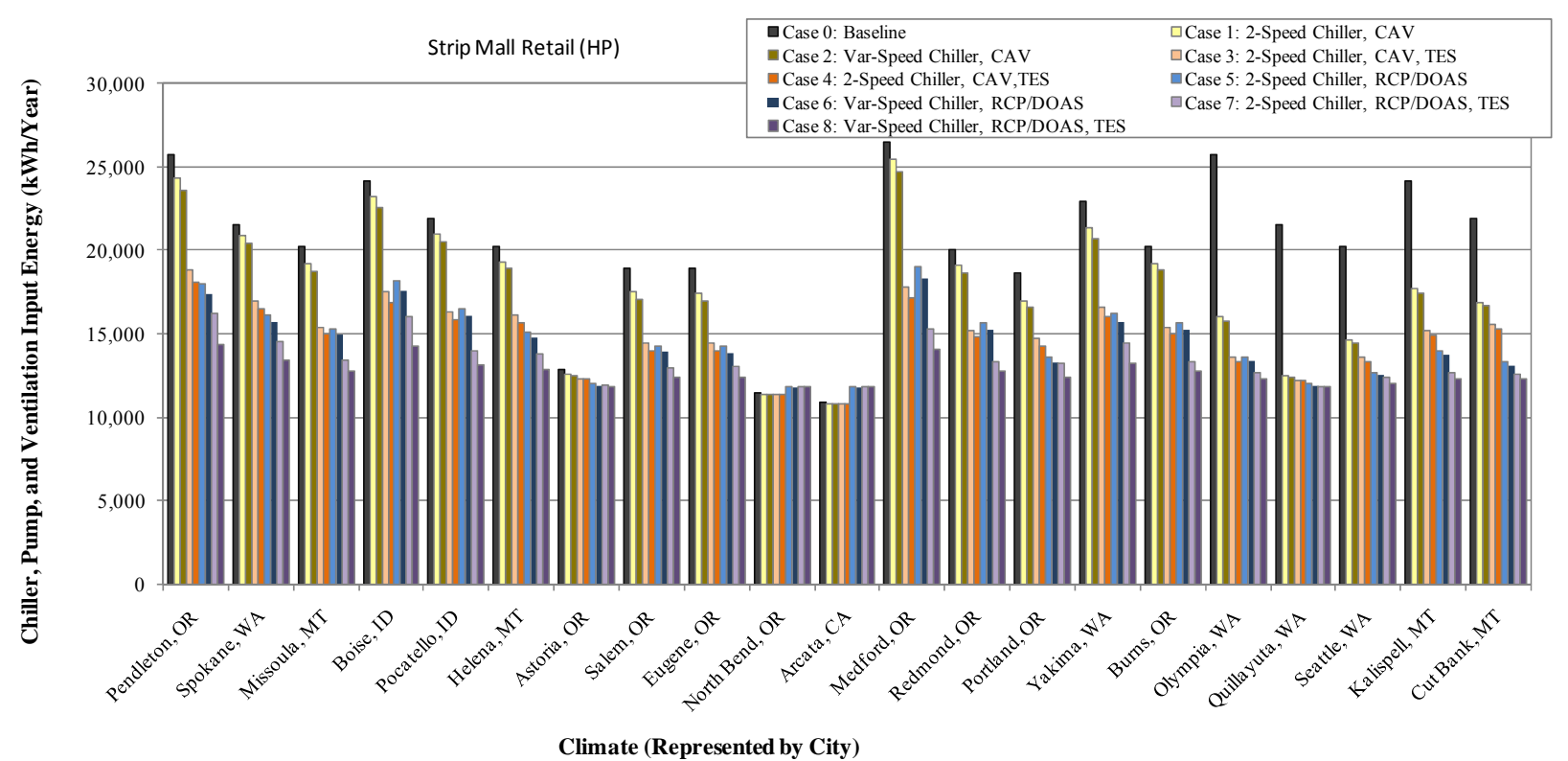

Figure: C-30 Comparison of Annual Chiller and Distribution Energy Consumption for High-Performance Strip Mall Retail Building for Various System Configurations in 21 Locations with Prototype Low-Lift Chiller for the LLCS Configurations 


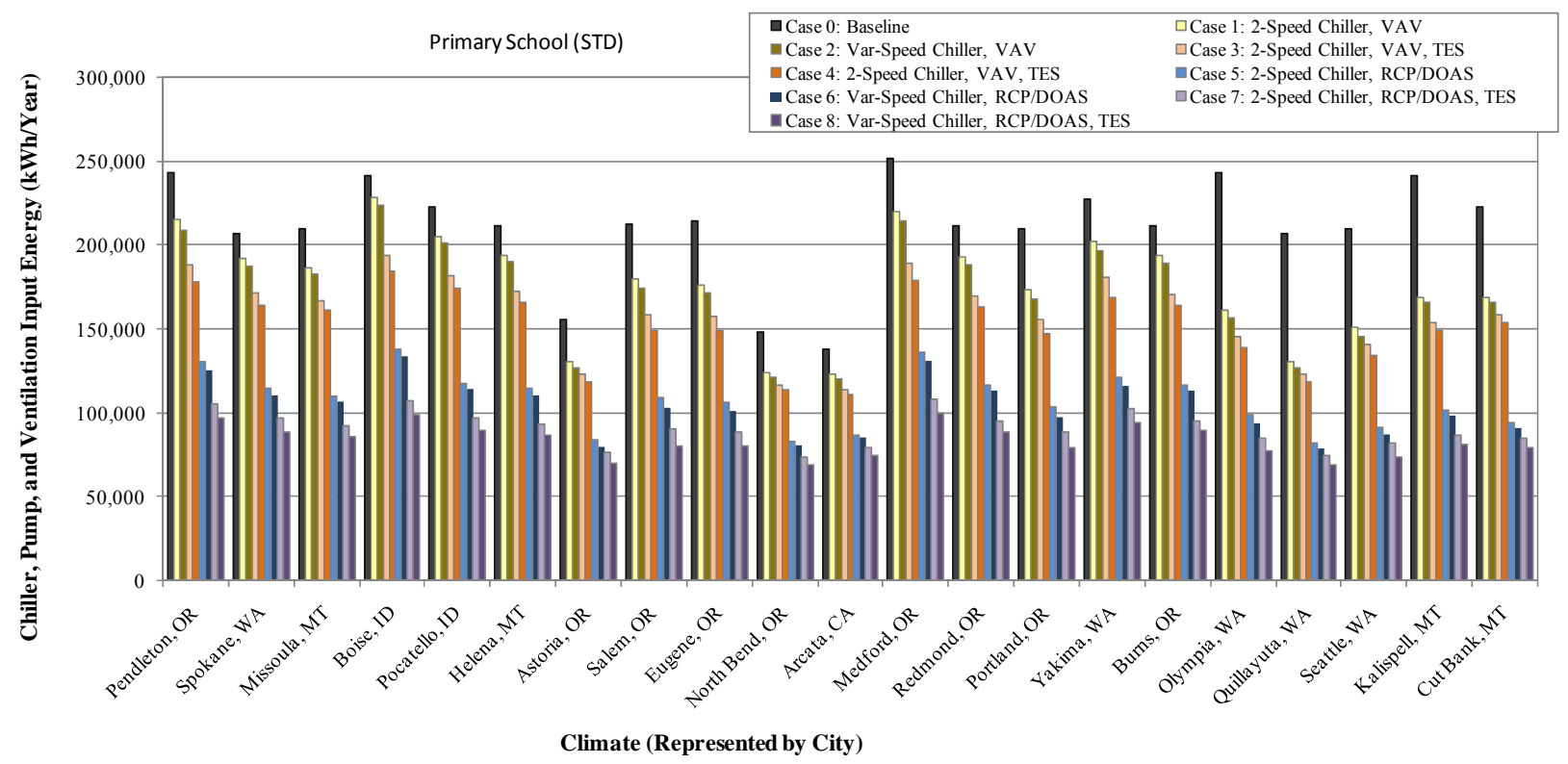

Figure: C-31 Comparison of Annual Chiller and Distribution Energy Consumption for Standard-Performance Primary School Building for Various System Configurations in 21 Locations with Prototype Low-Lift Chiller for the LLCS Configurations

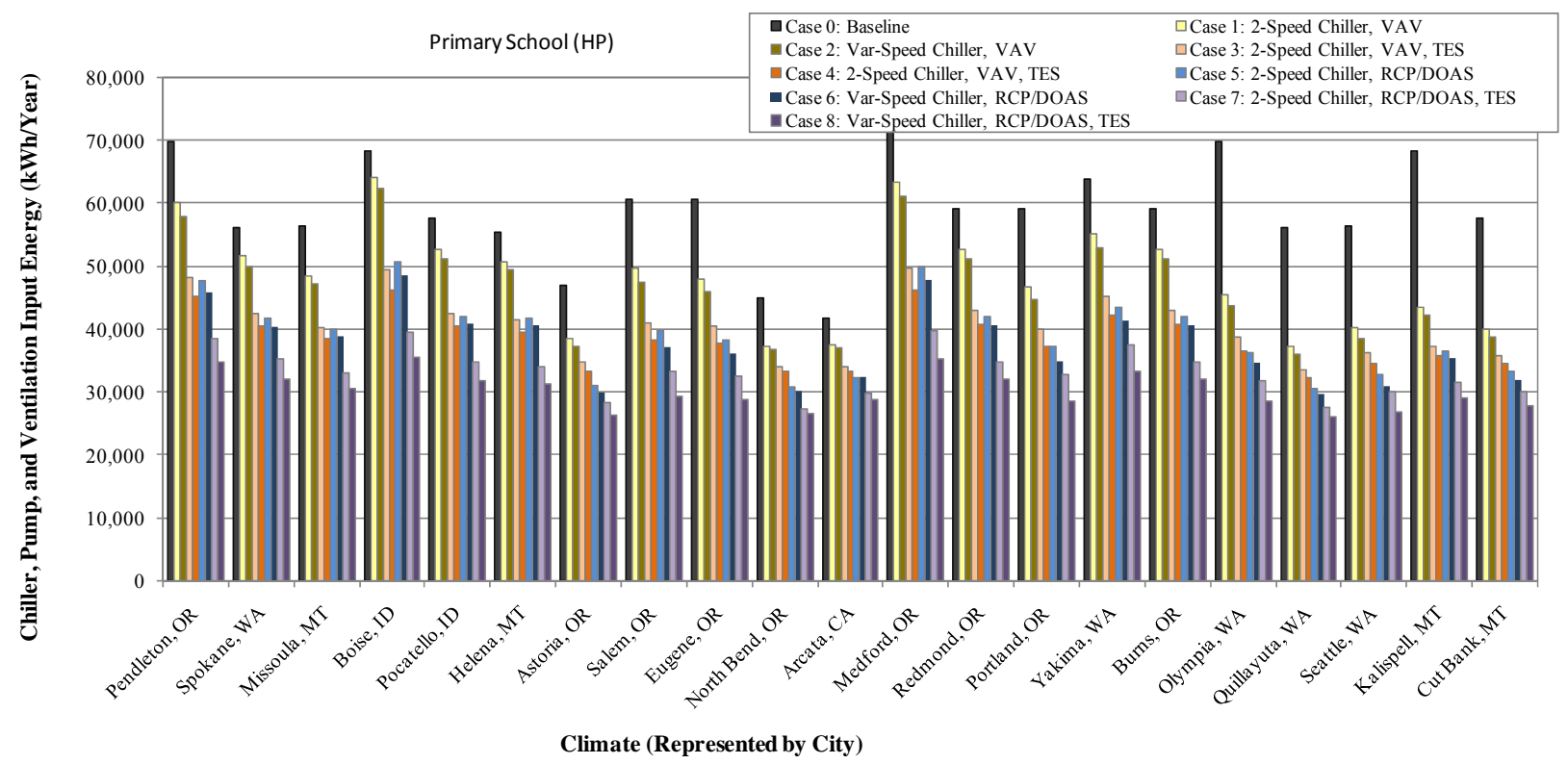

Figure: C-32 Comparison of Annual Chiller and Distribution Energy Consumption for High-Performance Primary School Building for Various System Configurations in 21 Locations with Prototype Low-Lift Chiller for the LLCS Configurations 


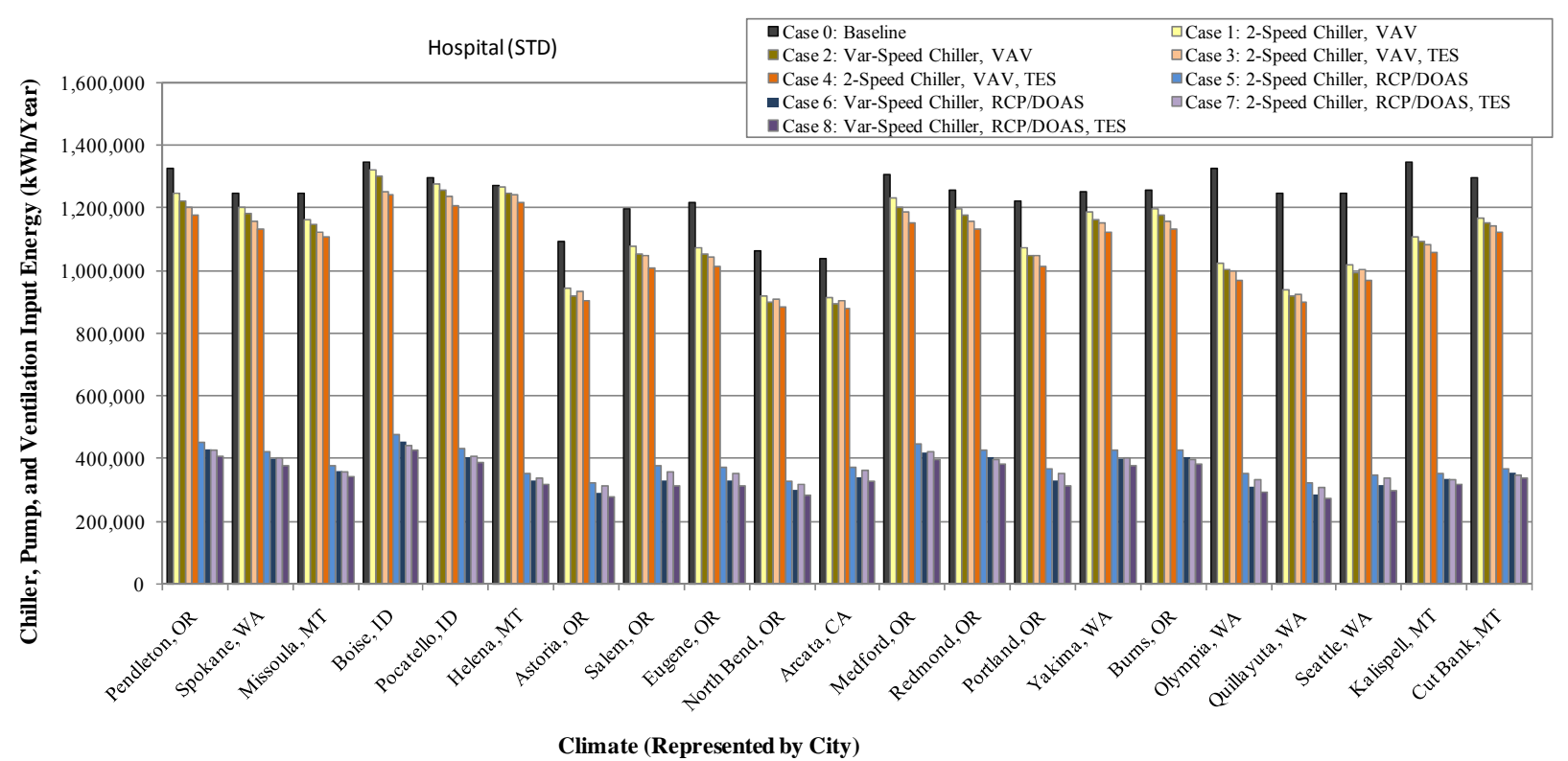

Figure: C-33 Comparison of Annual Chiller and Distribution Energy Consumption for Standard-Performance Hospital Building for Various System Configurations in 21 Locations with Prototype Low-Lift Chiller for the LLCS Configurations

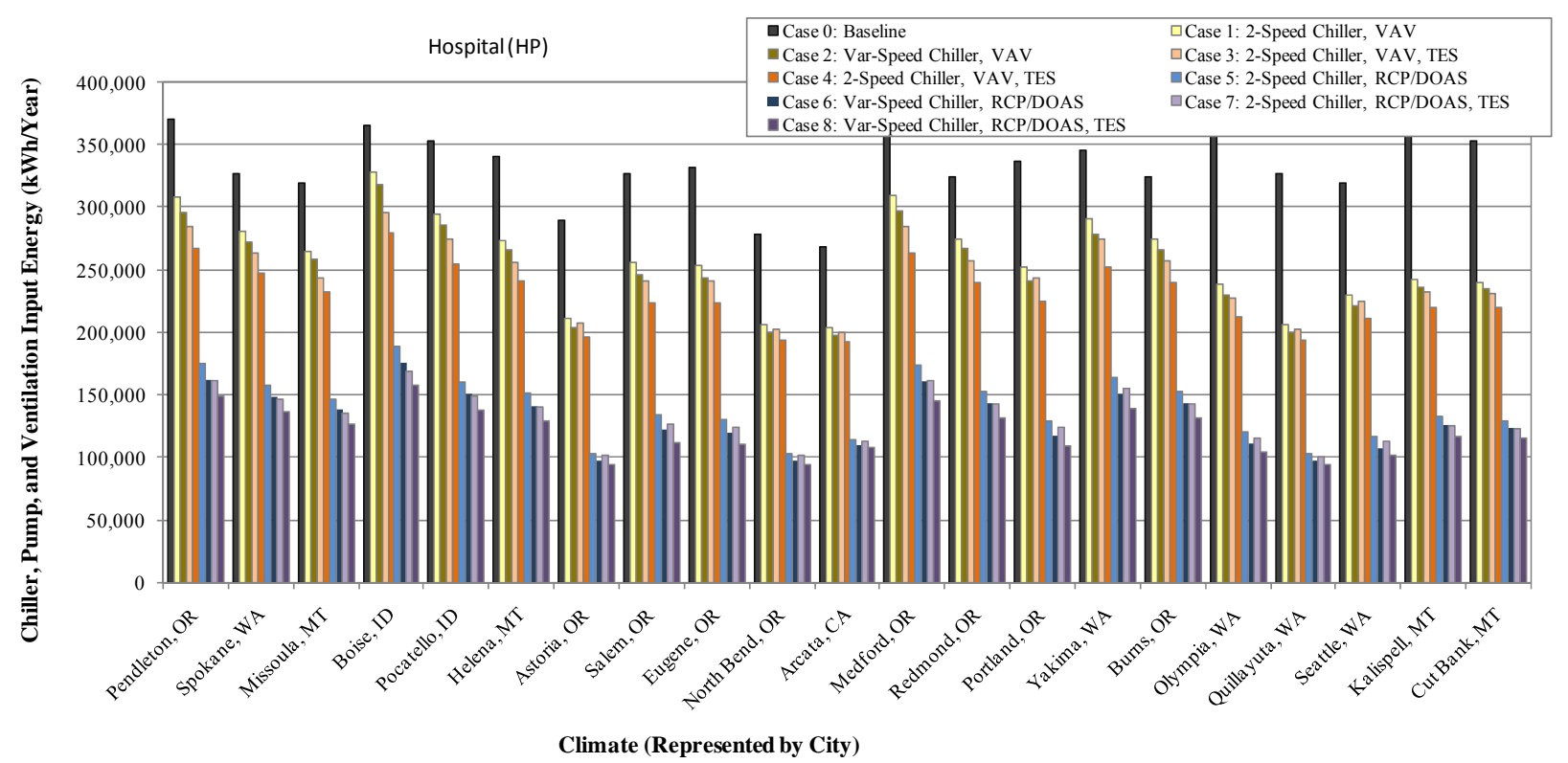

Figure: C-34 Comparison of Annual Chiller and Distribution Energy Consumption for High-Performance Hospital Building for Various System Configurations in 21 Locations with Prototype Low-Lift Chiller for the LLCS Configurations 


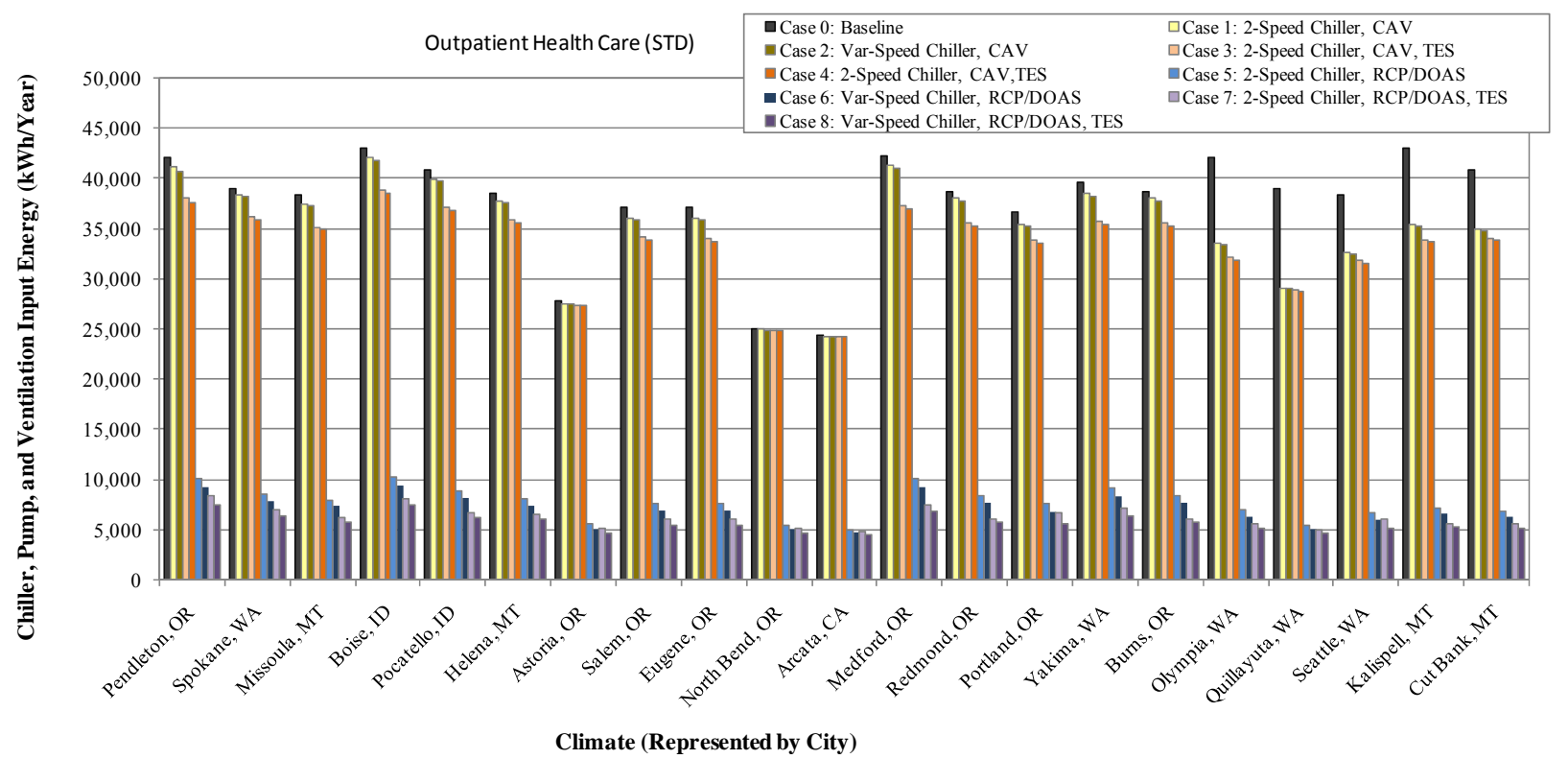

Figure: C-35 Comparison of Annual Chiller and Distribution Energy Consumption for Standard-Performance Outpatient Health Care Building for Various System Configurations in 21 Locations with Prototype Low-Lift Chiller for the LLCS Configurations

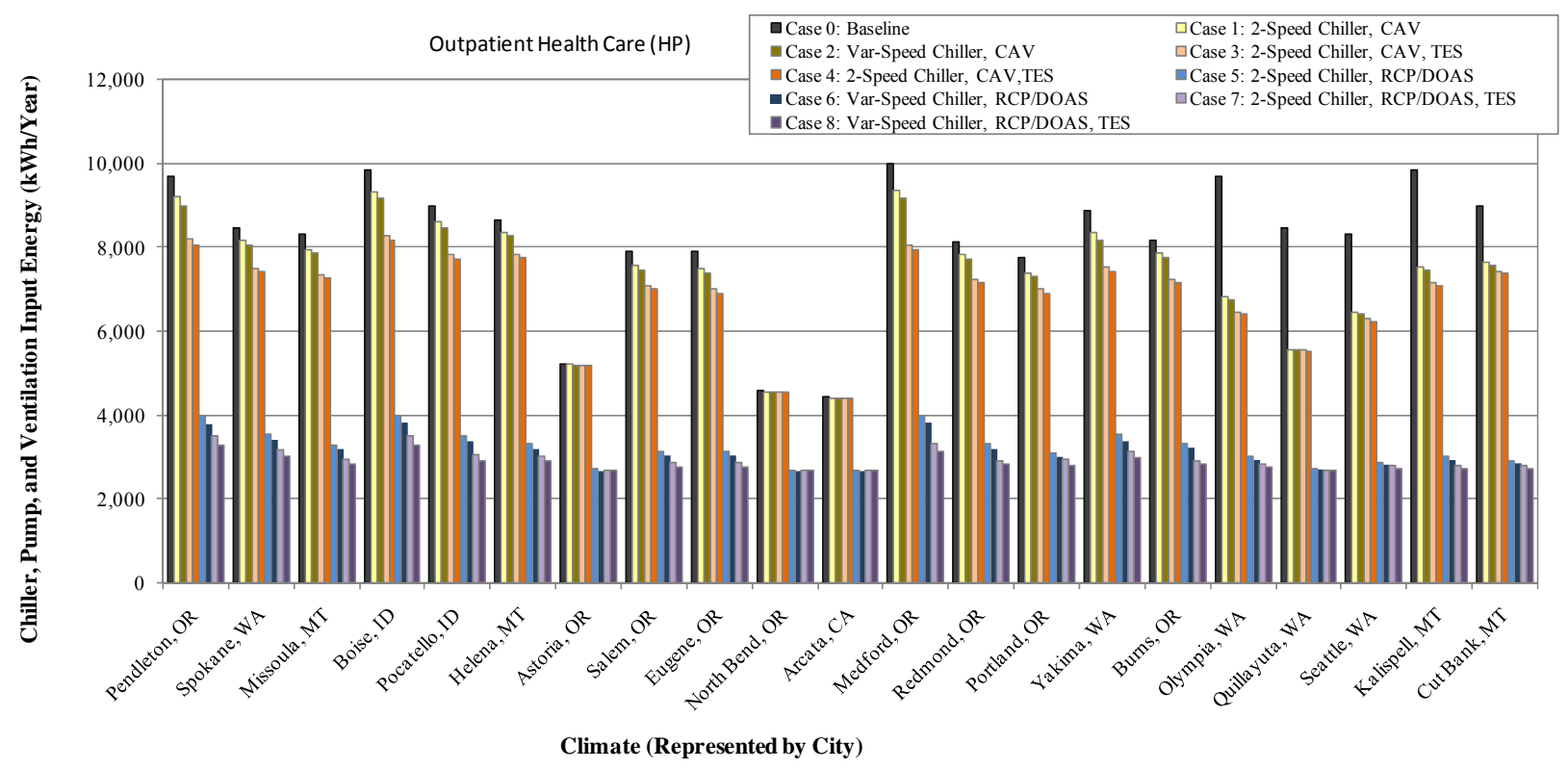

Figure: C-36 Comparison of Annual Chiller and Distribution Energy Consumption for High-Performance Outpatient Health Care Building for Various System Configurations in 21 Locations with Prototype Low-Lift Chiller for the LLCS Configurations 


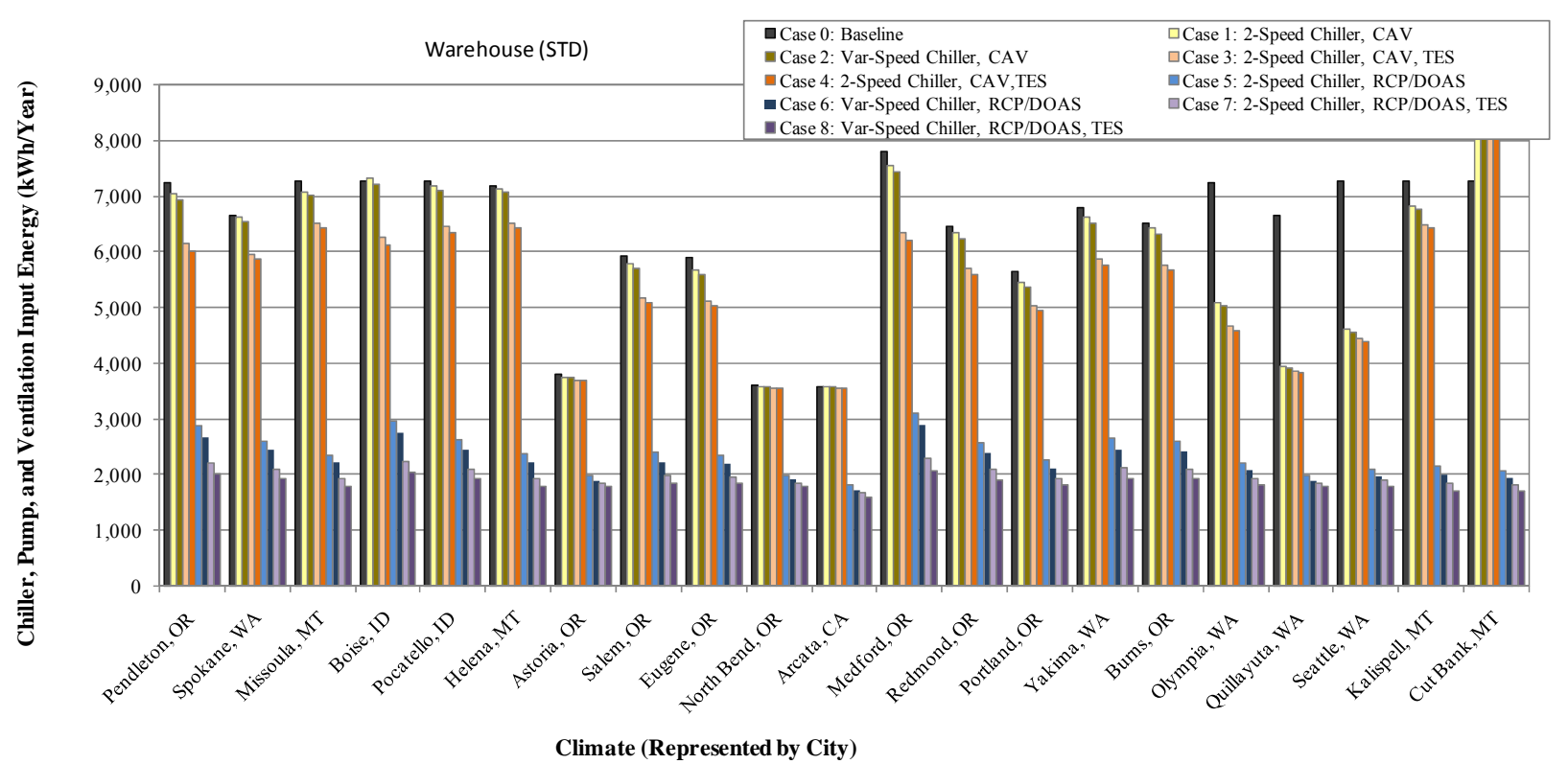

Figure: C-37 Comparison of Annual Chiller and Distribution Energy Consumption for Standard-Performance Warehouse Building for Various System Configurations in 21 Locations with Prototype Low-Lift Chiller for the LLCS Configurations

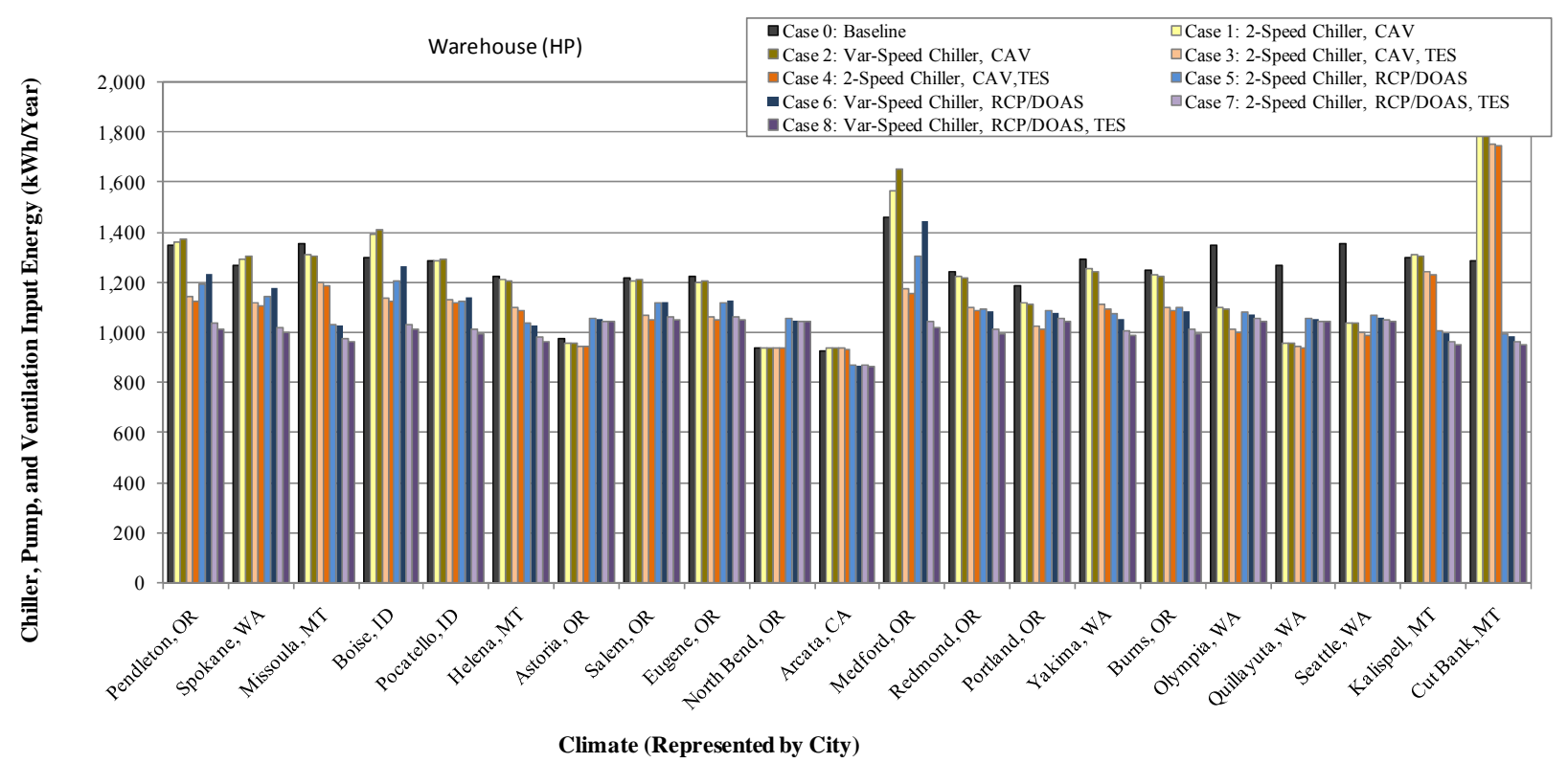

Figure: C-38 Comparison of Annual Chiller and Distribution Energy Consumption for High-Performance Warehouse Building for Various System Configurations in 21 Locations with Prototype Low-Lift Chiller for the LLCS Configurations 


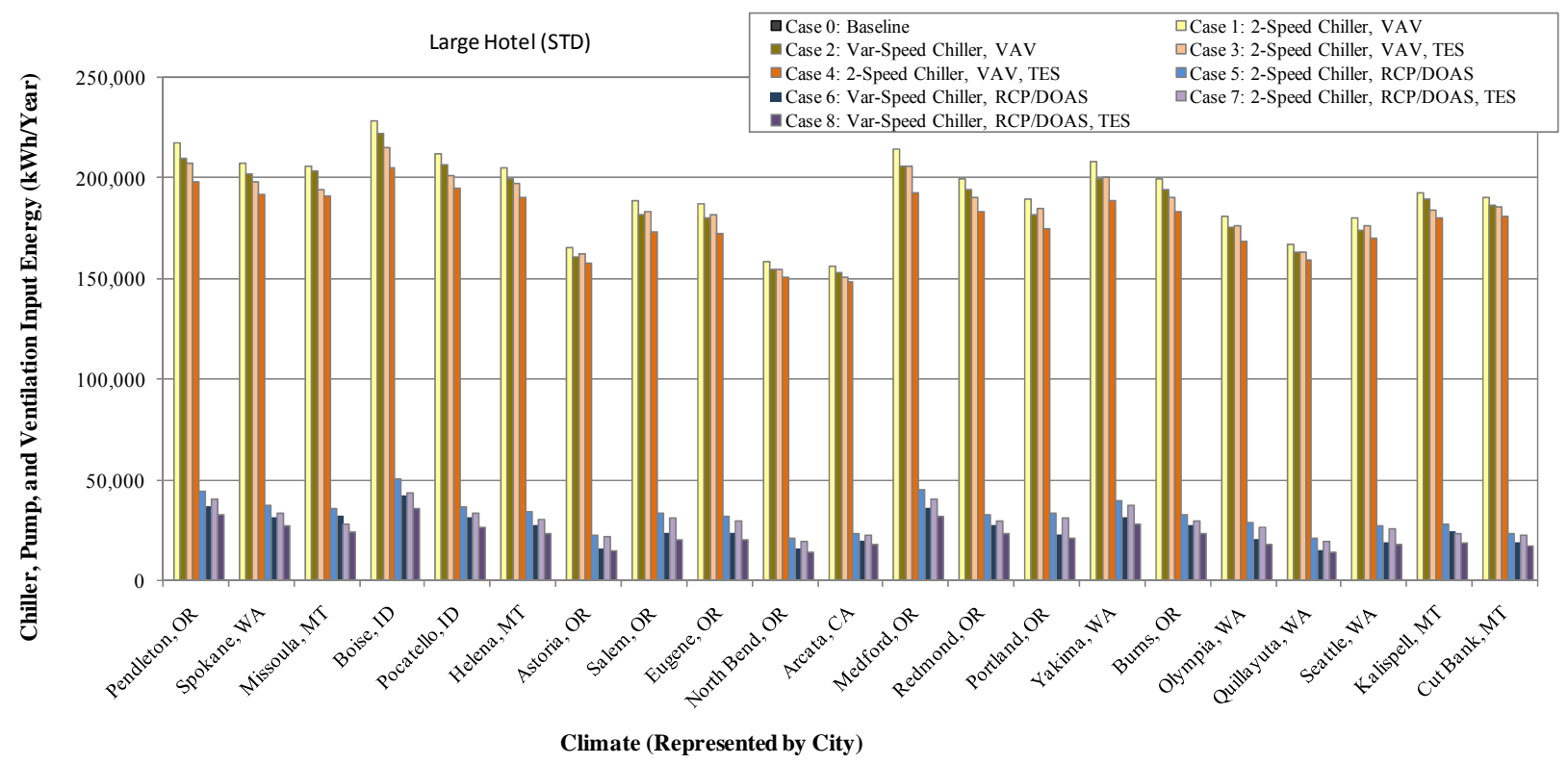

Figure: C-39 Comparison of Annual Chiller and Distribution Energy Consumption for Standard-Performance Large Hotel Building for Various System Configurations in 21 Locations with Prototype Low-Lift Chiller for the LLCS Configurations

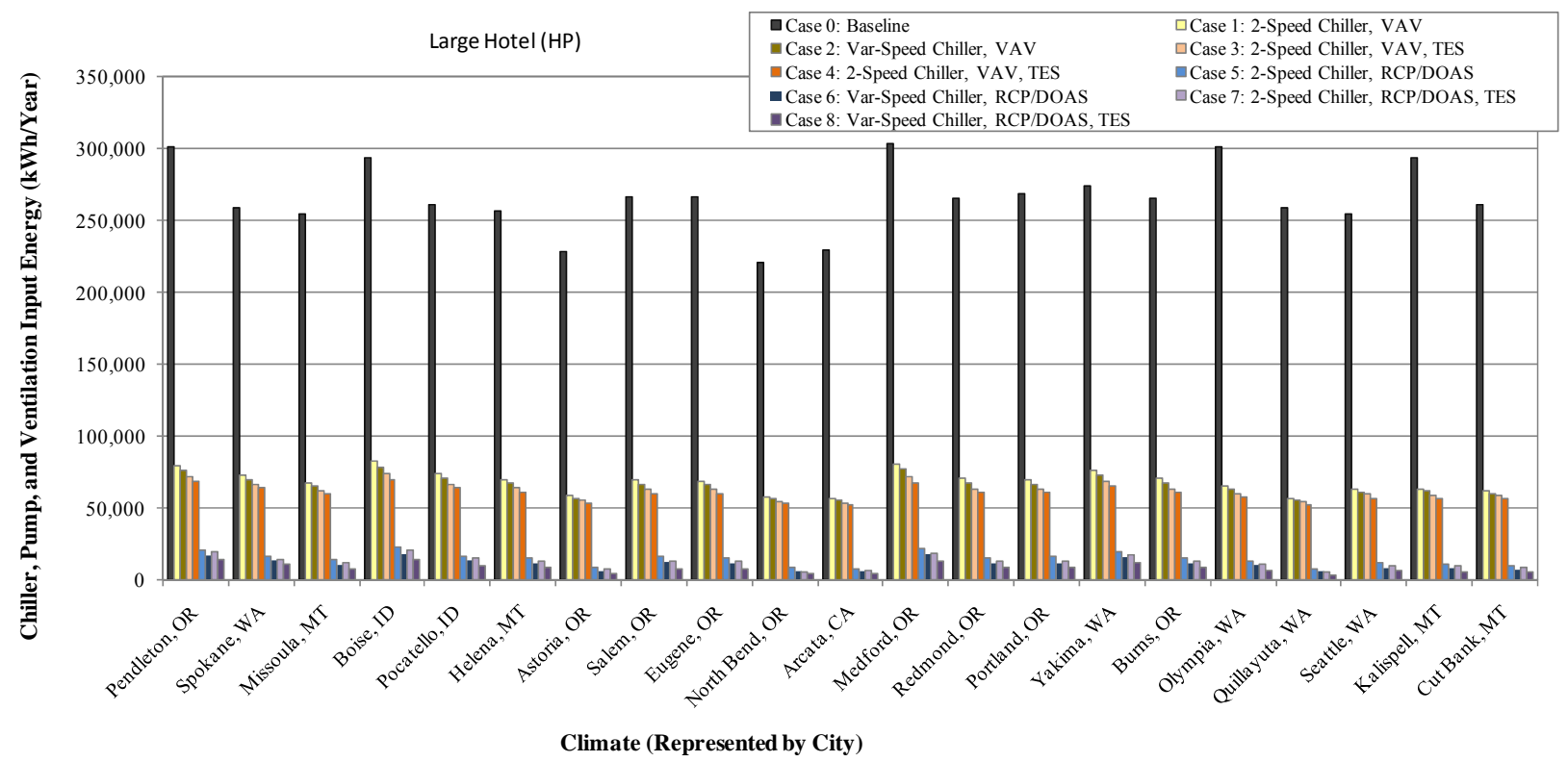

Figure: C-40 Comparison of Annual Chiller and Distribution Energy Consumption for High-Performance Large Hotel Building for Various System Configurations in 21 Locations with Prototype Low-Lift Chiller for the LLCS Configurations 


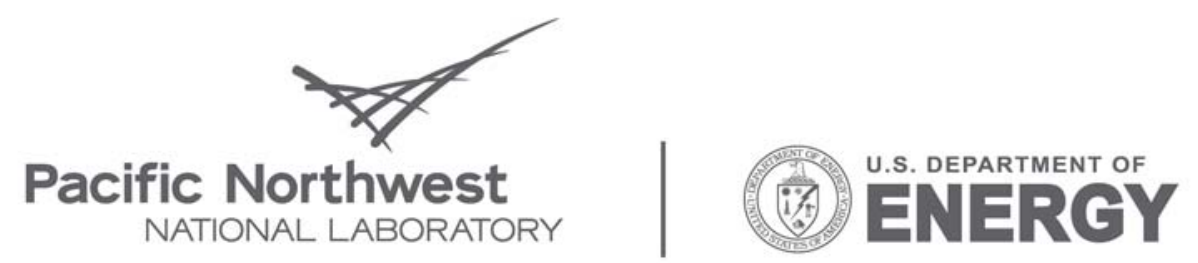

Proudly Operated by Battelle Since 1965

902 Battelle Boulevard

P.O. Box 999

Richland, WA 99352

1-888-375-PNNL (7665)

www.pnl.gov 